\title{
Investigating the Role of ROMO1 in Mitochondrial Protein Import and Inner Membrane Morphology
}

\author{
Dissertation \\ for the award of the degree \\ "Doctor rerum naturalium" \\ of the Georg-August-Universität Göttingen \\ within the doctoral program \\ "International Max Planck Research School - Molecular Biology" \\ of the Georg-August University School of Science (GAUSS)
}

submitted by

Frank Richter

from Ludwigshafen, Germany

Göttingen 2018 


\section{Members of the Thesis Committee and Examination Board:}
Prof. Dr. Peter Rehling
Department of Cellular Biochemistry
(Supervisor and first referee)
University Medical Center Göttingen
Göttingen, Germany
Prof. Dr. Stefan Jakobs
Department of NanoBiophotonics
(second referee)
Max Planck Institute for Biophysical Chemistry
Göttingen, Germany
Prof. Dr. Nils Brose
Department of Molecular Neurobiology
Max Planck Institute of Experimental Medicine
Göttingen, Germany

\section{Further members of the Examination Board:}

Prof. Dr. Blanche Schwappach

Prof. Dr. Henning Urlaub

Prof. Dr. Detlef Doenecke

\section{Date of oral examination:}

September 25, 2018
Department of Molecular Biology

University Medical Center Göttingen

Göttingen, Germany

Bioanalytical Mass Spectrometry Group

Max Planck Institute for Biophysical Chemistry

Göttingen, Germany

Department of Molecular Biology

University Medical Center Göttingen

Göttingen, Germany 


\section{Affidavit}

I hereby declare, that my dissertation "Investigating the Role of ROMO1 in Mitochondrial Protein Import and Inner Membrane Morphology" has been written independently and with no other sources and aids than quoted.

Frank Richter

Göttingen, August 2018

Parts of this thesis will be communicated in the following publication:

Richter F., Dennerlein S., Nikolov M., Jans D.C., Naumenko N., Aich A., MacVicar T., Linden A., Jakobs S., Urlaub H., Langer T. and Rehling P. ROMO1 is a constituent of the human presequence translocase required for YME1L import. (in Revision) 


\section{Table of contents}

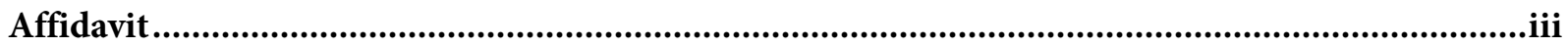

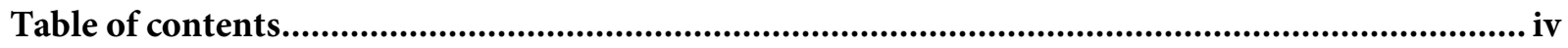

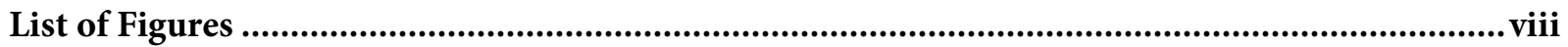

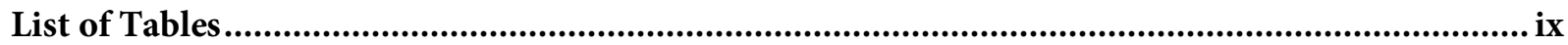

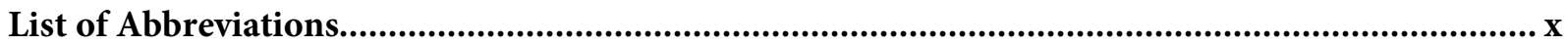

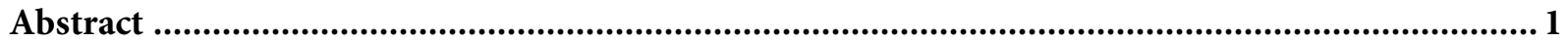

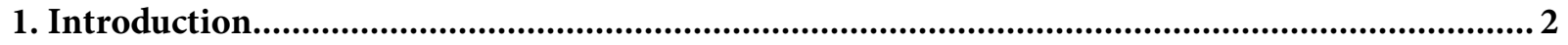

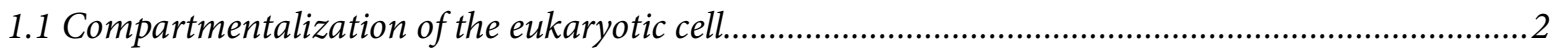

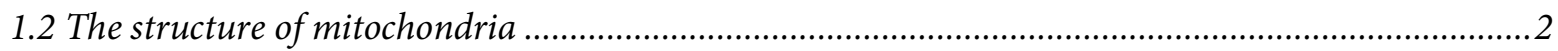

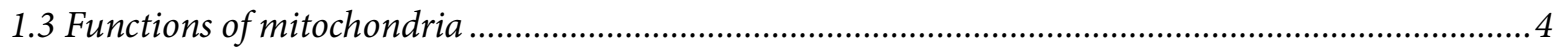

1.3.1 The respiratory chain and oxidative phosphorylation ..............................................................

1.3.2 Assembly of cytochrome $c$ oxidase ................................................................................................

1.4 Mitochondrial dynamics and inner membrane maintenance.......................................................6

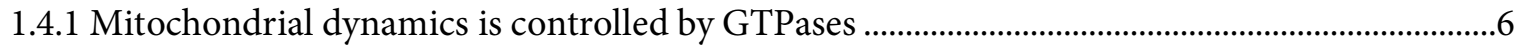

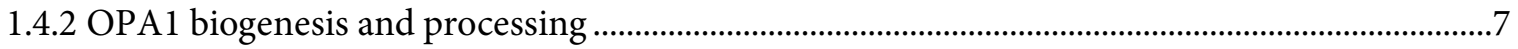

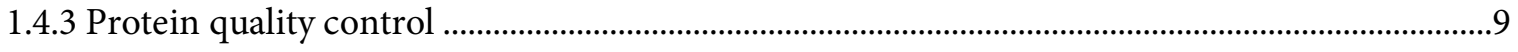

1.4.4 Mitochondrial reactive oxygen-species signaling....................................................................... 11

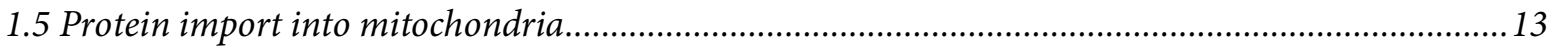

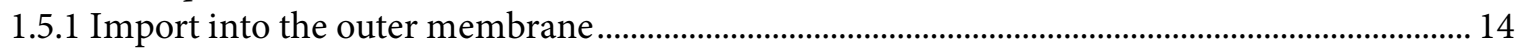

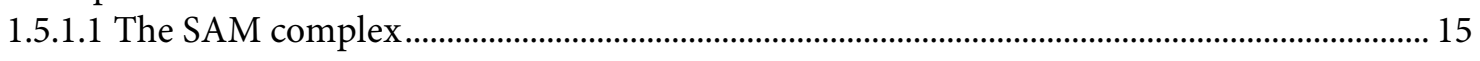

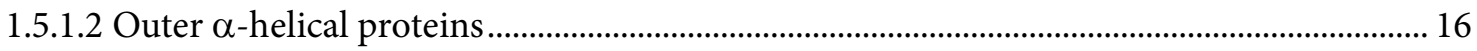

1.5.2 Transport into the intermembrane space via the MIA pathway.................................................... 16

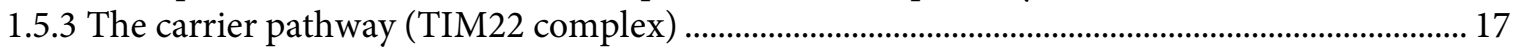

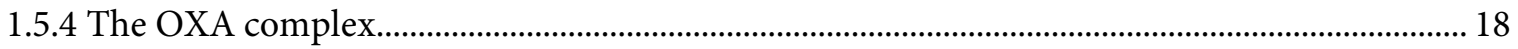

1.5.5 Protein translocation by the TIM23 complex ………................................................................. 19

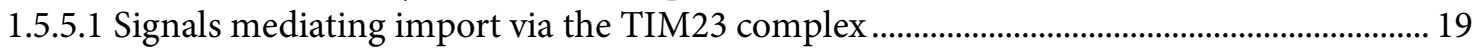

1.5.5.2 Processing of presequence-containing proteins ................................................................... 21

1.5.5.3 Transport of presequence-containing proteins through the TOM complex....................... 21

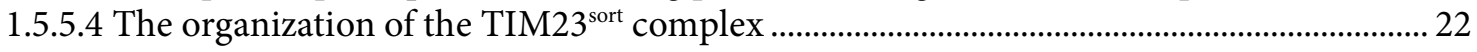

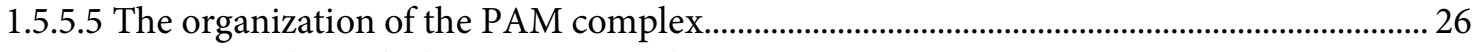

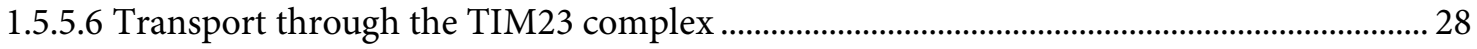

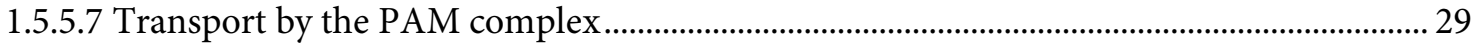

1.5.5.8 Transport of inner membrane proteins along the sorting pathway ...................................... 30

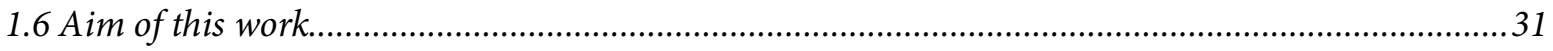

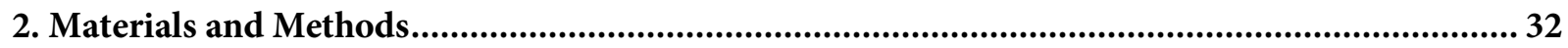




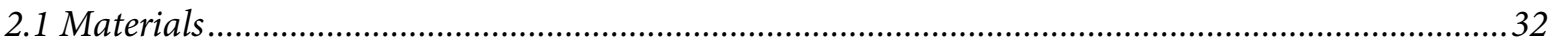

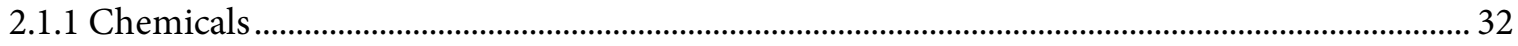

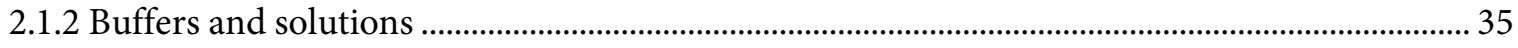

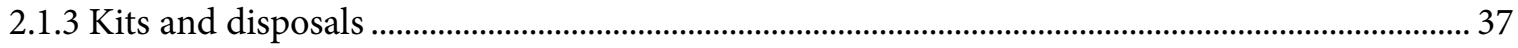

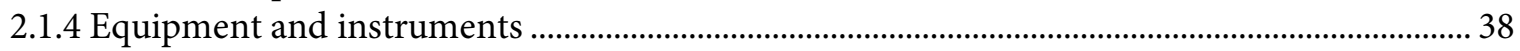

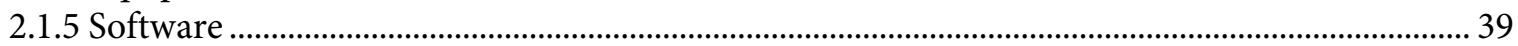

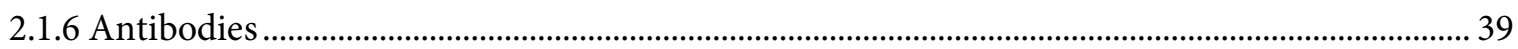

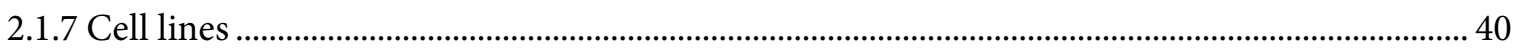

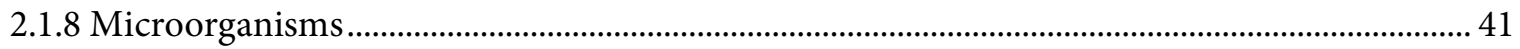

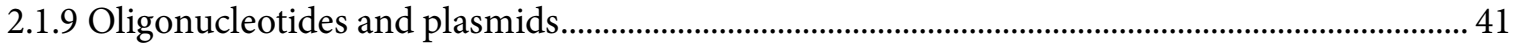

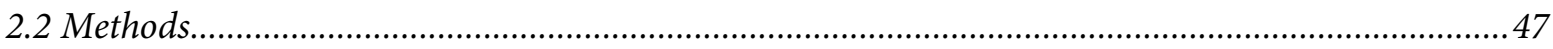

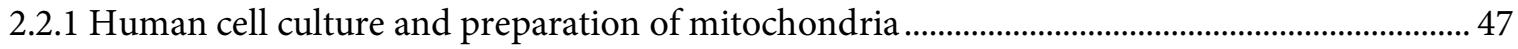

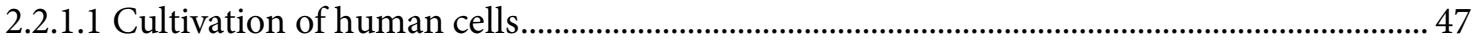

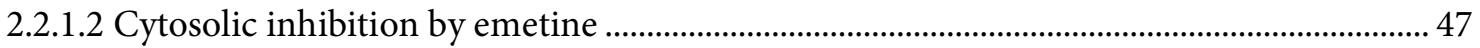

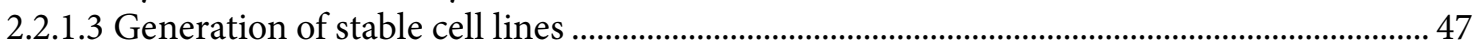

2.2.1.4 Generation of knockout cell lines ....................................................................................... 48

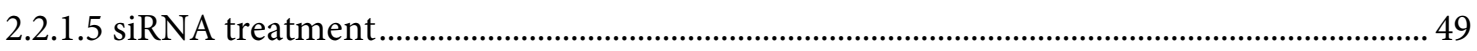

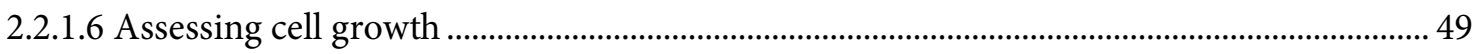

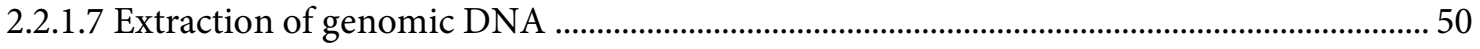

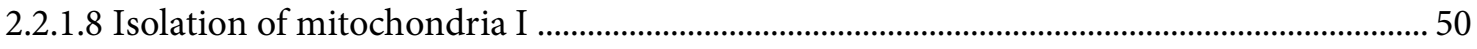

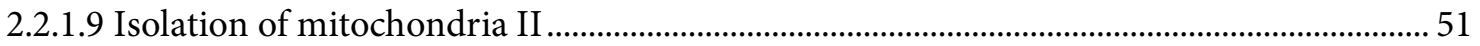

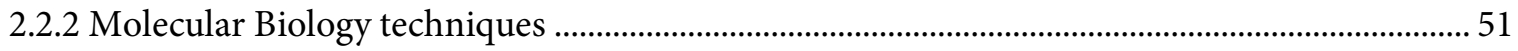

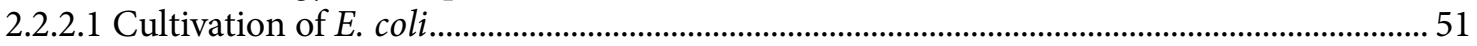

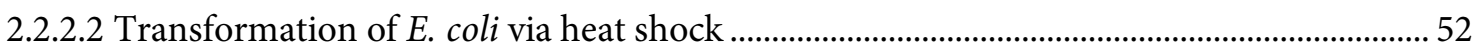

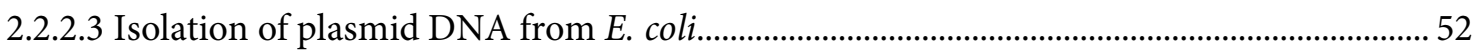

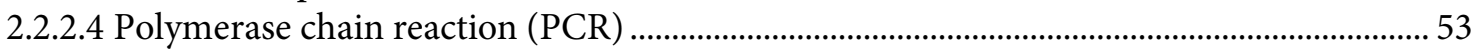

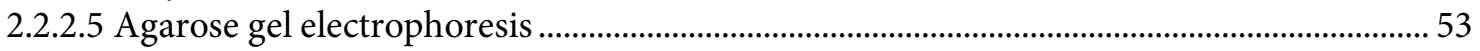

2.2.2.6 Purification of PCR products................................................................................................ 53

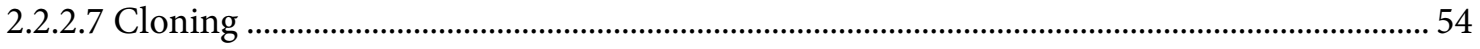

2.2.2.8 In vitro mutagenesis ............................................................................................................ 54

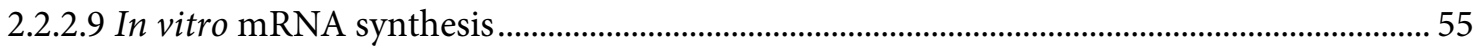

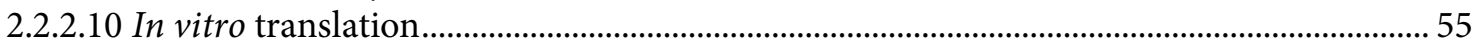

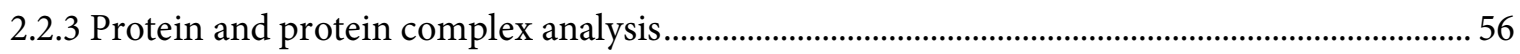

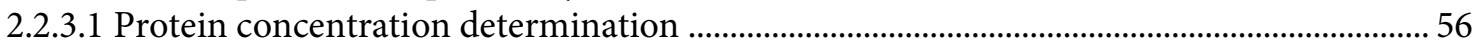

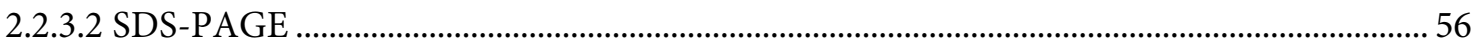

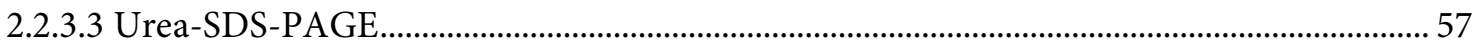

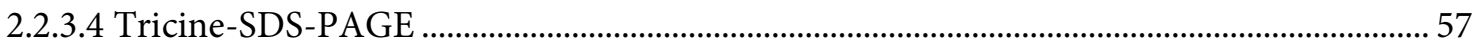

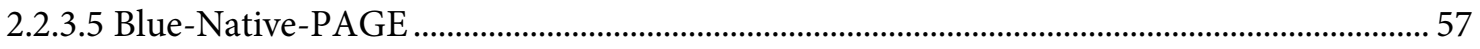

2.2.3.6 Coomassie Brilliant Blue staining ………........................................................................... 58

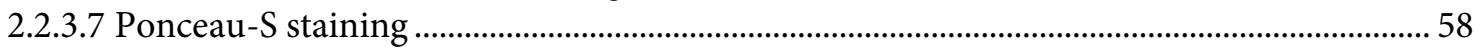

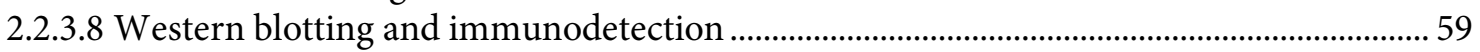

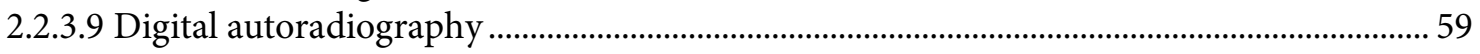

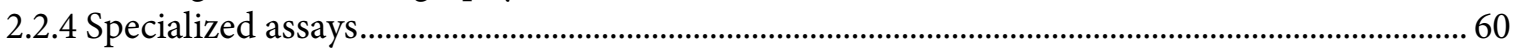

2.2.4.1 Radiolabeled precursor protein import and assembly into mitochondria.......................... 60

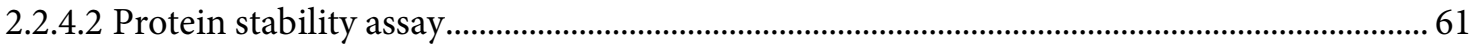

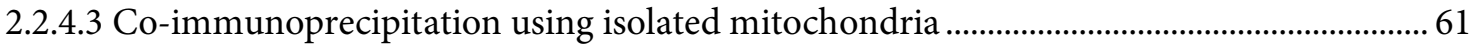

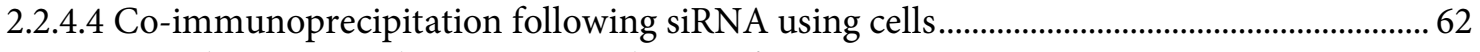

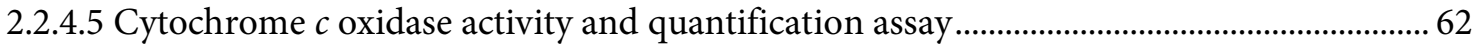




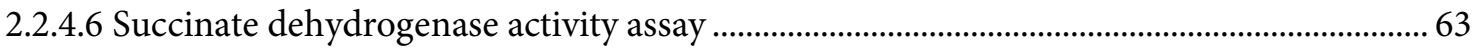

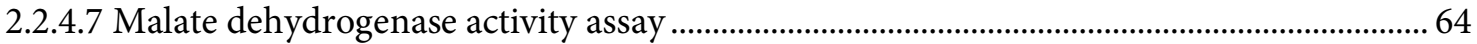

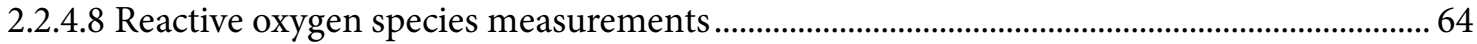

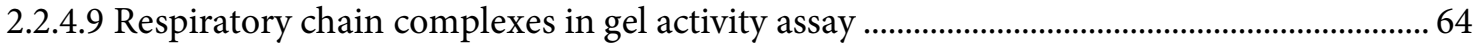

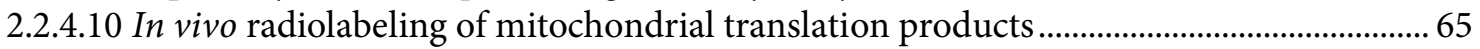

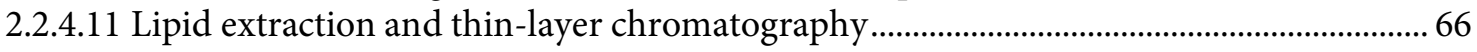

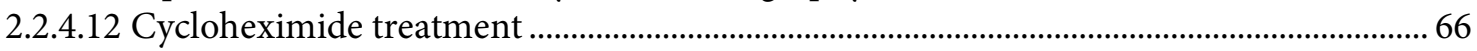

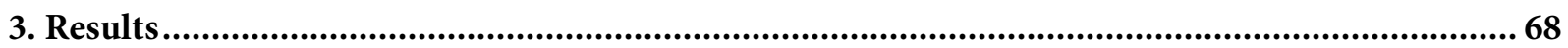

3.1 ROMO1 is a constituent of the TIM23 complex.............................................................................6

$3.2 \mathrm{~A} \mathrm{ROMO1}^{-1-}$ cell line can be used to study its molecular function.....................................................69

3.2.1 Steady state analysis of the ROMO1 ${ }^{-1}$ cell line shows differences in mitochondrial protein

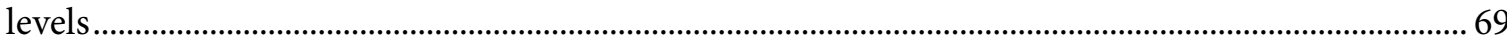

3.2.2 $\mathrm{ROMO}^{-1-}$ cells exhibit changes in cell proliferation, mitochondrial inner membrane

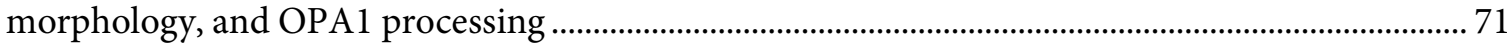

3.2.3 ROMO1 ${ }^{-1}$ cells show changes in respiratory chain quantity and activity .................................... 74

3.2.4 Analysis of reactive oxygen species production hints at secondary effects.................................. 79

3.3 Transient depletion of ROMO1 mimics the knockout phenotype but does not produce ROS...........81

3.3.1 ROMO1 has a rapid turnover and is required for cell proliferation ............................................ 81

3.3.2 Transient depletion of ROMO1 does not lead to increased ROS production but mimics

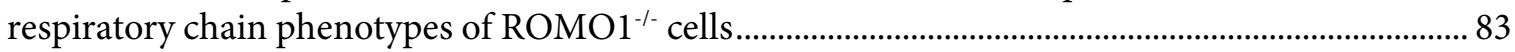

3.4 ROMO1 couples TIM21 onto the translocase while it does not affect protein import in general .....87

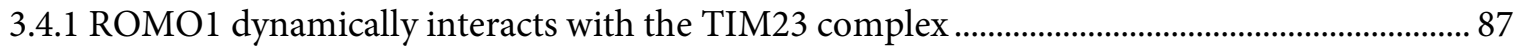

3.4.2 ROMO1 plays a minor role in general protein import ................................................................... 89

3.5 ROMO1 is required for the import of the $i-A A A$ protease YME1L.................................................94

3.5.1 ROMO1 is rapidly degraded by the $i$-AAA protease YME1L ....................................................... 94

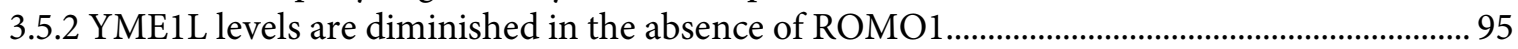

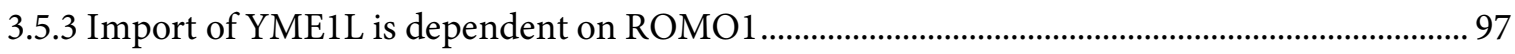

3.6 ROMO1 plays a role in the import of precursors with long presequences........................................99

3.6.1 The long C-terminus of YME1L does not impact its import efficiency ....................................... 99

3.6.2 Exchanging the transmembrane domain does not alleviate the import phenotype of YME1L

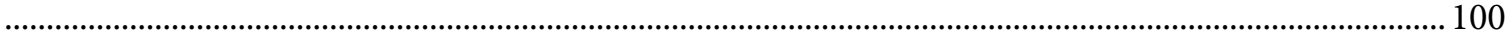

3.6.3 YME1L is dependent on ROMO1 for its import due to its long presequence.......................... 101

3.6.4 ROMO1 plays a role for the import of precursors with long presequences ............................. 103

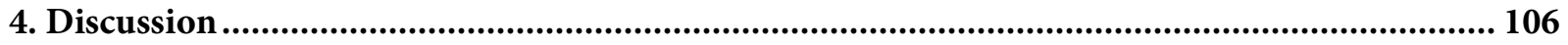

4.1 Functions of ROMO1 as a TIM23 complex component ................................................................. 106

4.1.1 Human ROMO1, the potential orthologue of Mgr2, is a component of the TIM23 complex

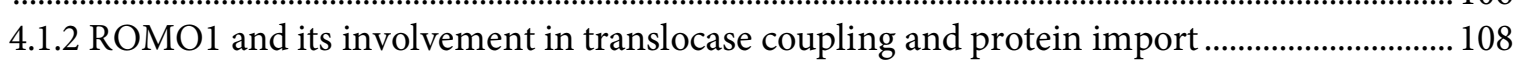

4.1.3 ROMO1 - part of a specific translocase? ........................................................................................ 109

4.2 ROMO1 and its effects on inner membrane morphology and respiratory chain activity................112

4.2.1 Observed phenotypes in OPA1 processing and cristae structure are related to YME1L....... 112

4.2.2 ROMO1 and respiratory chain activity .................................................................................... 115

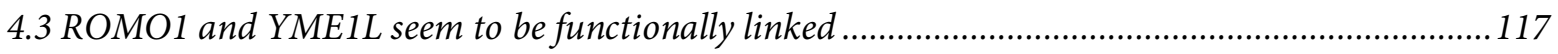


4.3.1 ROMO1 as a new YME1L substrate

4.3.2 Microdomains might connect different processes within the inner mitochondrial membrane

5. Conclusions and Perspectives .................................................................................................. 120

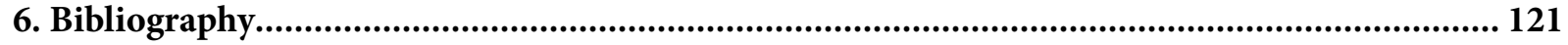

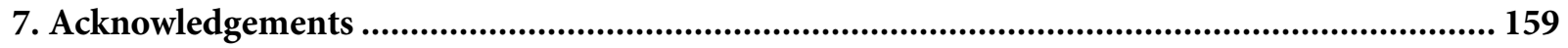

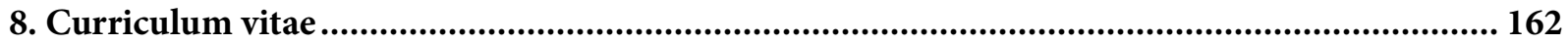




\section{List of Figures}

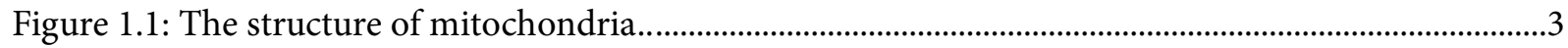

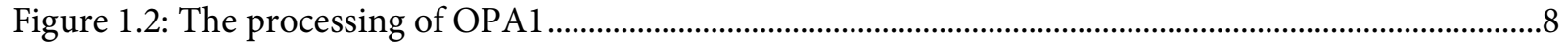

Figure 1.3: The hexameric structure of YME1L .......................................................................................... 10

Figure 1.4: Schematic overview of major import pathways into mitochondria........................................... 14

Figure 1.5: Schematic depiction of the yeast TIM23 $3^{\text {sort }}$ complex................................................................... 24

Figure 1.6: Schematic depiction of the human TIM23 $3^{\text {sort }}$ complex............................................................... 26

Figure 1.7: Schematic depiction of the TIM23 motor complex......................................................................2 27

Figure 3.1: ROMO1 interacts with TIM23 and TIM21 of the human TIM23 complex. ........................... 69

Figure 3.2: CRISPR/Cas9 mediated deletion of ROMO1 disrupts its open reading frame......................... 70

Figure 3.3: $\mathrm{ROMO}^{-1-}$ mitochondria show different protein levels. ............................................................... 71

Figure 3.4: $\mathrm{ROMO}^{-1-}$ cells grow more slowly compared to WT cells............................................................ 72

Figure 3.5: Inner membrane morphology and OPA1 processing are changed in $\mathrm{ROMO}^{-/-}$

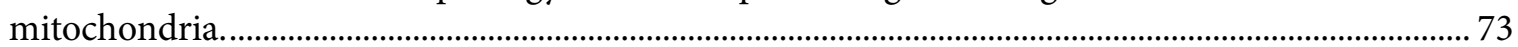

Figure 3.6: Lipid composition does not change in $\mathrm{ROMO}^{-1-}$ mitochondria.............................................. 74

Figure 3.7: Amounts of complex II and IV are reduced in ROMO1 $1^{-1-}$ mitochondria on BN-PAGE....... 76

Figure 3.8: Mitochondrial translation efficiency is not changed in ROMO1 ${ }^{-/}$cells.................................. 76

Figure 3.9: In-gel activity staining reveals reduced complex II and IV activity in ROMO1 ${ }^{-1-}$

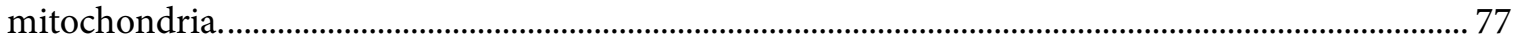

Figure 3.10: Quantitative respiratory chain analysis of WT and $\mathrm{ROMO}^{-/}$cells or mitochondria

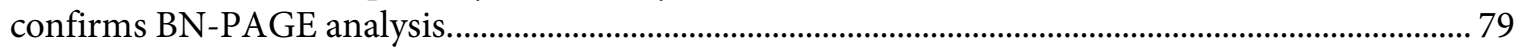

Figure 3.11: ROS levels are drastically increased in $\mathrm{ROMO}^{-/-}$cells. ........................................................... 80

Figure 3.12: Stability assay of mitochondrial proteins using emetine reveals that ROMO1 is quickly

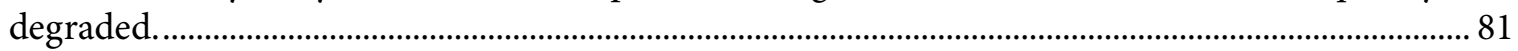

Figure 3.13: siRomo1 cells mimic phenotypes of ROMO1 ${ }^{-1}$ cell line........................................................... 82

Figure 3.14: ROS levels are slightly reduced in siRomol cells....................................................................... 84

Figure 3.15: OXPHOS complex analysis of siRomol mitochondria mimics ROMO1 ${ }^{-1-}$ phenotypes...... 86

Figure 3.16: ROMO1 couples TIM21 onto TIM23 ....................................................................................... 88

Figure 3.17: Import of matrix targeted proteins is not dependent on ROMO1....................................... 90

Figure 3.18: Import of selected inner membrane targeted proteins is not dependent on ROMO1......... 91

Figure 3.19: Inner membrane sorting efficiency of COX4I-1 is dependent on ROMO1........................ 93

Figure 3.20: Yeast Mgr2 is a stable protein. .................................................................................................. 94

Figure 3.21: ROMO1 accumulates in siYme1l cells....................................................................................... 95

Figure 3.22: YME1L levels are reduced in $\mathrm{ROMO}^{-1-}$ mitochondria................................................................ 96

Figure 3.23: Import of YME1L protein is dependent on ROMO1................................................................ 97

Figure 3.24: YME1L is stable upon import in siRomol mitochondria........................................................ 98

Figure 3.25: C-terminal shortening of YME1L does not abolish its import dependence on ROMO1 .. 100

Figure 3.26: The COX6A1 transmembrane domain in YME1L does not abolish its import dependence on ROMO1.

101

Figure 3.27: The presequence of COX6A1 on YME1L abolishes its import dependence on ROMO1. 102 Figure 3.28: Other proteins with long presequences show a mild import dependence on ROMO1..... 104

Figure 4.1: ROMO1, a novel subunit of the TIM23 complex.

Figure 4.2: ROMO1 dependent YME1L import defects have pleiotropic effects...................................... 116 


\section{List of Tables}

Table 1.1 Subunits of the TIM23 and PAM complexes in yeast and human ..............................................25

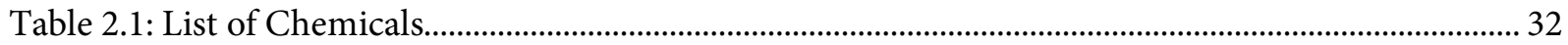

Table 2.2: Buffers and solutions ............................................................................................................. 35

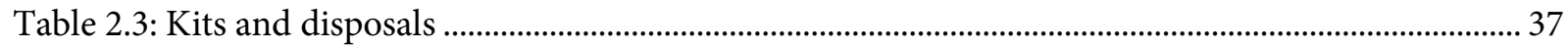

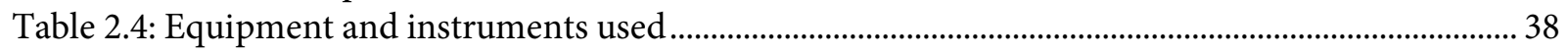

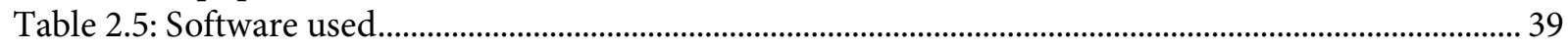

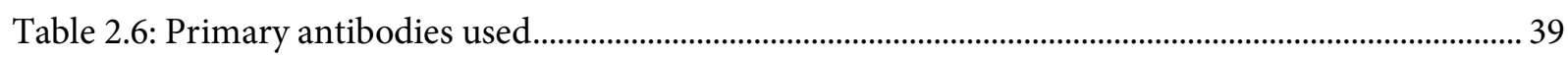

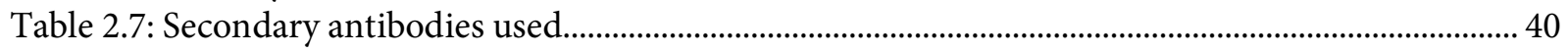

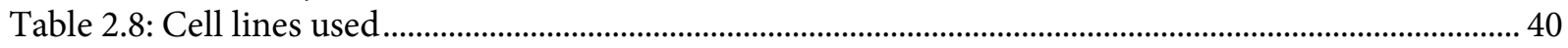

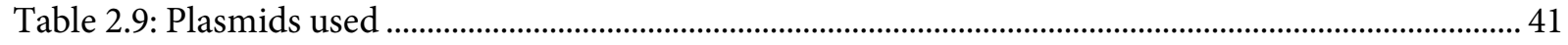

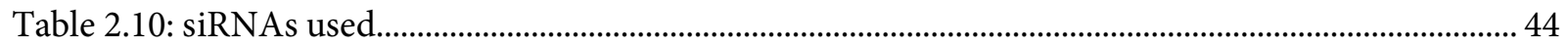

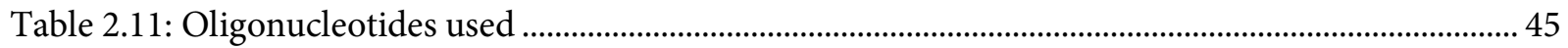




\section{List of Abbreviations}

\begin{tabular}{|c|c|}
\hline AAA & ATPases Associated with various cellular Activities \\
\hline $\mathrm{ADP}$ & Adenosine diphosphate \\
\hline APS & Ammonium persulfate \\
\hline ATP & Adenosine triphosphate \\
\hline AVO & Antimycin A, valinomycin, oligomycin mixture \\
\hline $\mathrm{BN}$ & Blue native \\
\hline bp & Base pair(s) \\
\hline BSA & Bovine serum albumin \\
\hline${ }^{\circ} \mathrm{C}$ & Degree Celsius \\
\hline CIII & Complex III \\
\hline Cas9 & CRISPR associated protein 9 \\
\hline CL & Cardiolipin \\
\hline $\mathrm{COA}$ & Cytochrome $c$ oxidase assembly intermediate \\
\hline CoQ & Ubiquinone \\
\hline $\mathrm{COX} / \mathrm{CIV}$ & Cytochrome $c$ oxidase/ complex IV \\
\hline CRISPR & Clustered regularly interspaced short palindromic repeats \\
\hline Cys & Cysteine \\
\hline $\mathrm{dd}_{2} \mathrm{O}$ & Double-deionized water \\
\hline del & Deletion \\
\hline DHFR & Mouse dihydrofolate reductase \\
\hline DMSO & Dimethyl sulfoxide \\
\hline DNA & Deoxyribonucleic acid \\
\hline ECL & Enhanced chemiluminescence \\
\hline EDTA & Ethylenediaminetetraacetic acid \\
\hline EGTA & Ethyleneglycoltetraacetic acid \\
\hline FCS & Fetal calf serum \\
\hline g & gram \\
\hline
\end{tabular}




\begin{tabular}{ll} 
GFP & Green fluorescent protein \\
GTP & Guanosine triphosphate \\
h & Hour(s) \\
HCl & Hydrochloric acid \\
HEK & Human embryonic kidney \\
HEPES & 4-(2-hydroxyethyl)-1-piperazineethanesulfonic acid \\
HRP & Horseradish peroxidase \\
HSP & Heat shock protein \\
IgG & Immunoglobulin G \\
IMM & Inner mitochondrial membrane \\
IMP & Intermediate processing peptidase \\
IMS & Intermembrane space \\
kDa & Kilodalton \\
KD & Knockdown \\
KO & Knockout \\
L & Liter \\
LB & Lysogeny broth \\
m & Mature protein \\
M & Moles per liter \\
mA & Milliampere \\
MDa & Megadalton \\
mg & Milligram \\
MDH & Malate dehydrogenase \\
MIA & Mitochondrial IMS assembly machinery \\
MICOS & Mitochondrial contact site and cristae organizing system \\
MIM & Mitochondrial import complex \\
min & Minute(s) \\
mito & Mitochondria \\
MITRAC & Mitochondrial translation regulation assembly intermediate \\
& of cytochrome c oxidase \\
\hline
\end{tabular}




$\begin{array}{ll}\text { mM } & \text { Millimoles per liter } \\ \text { MOPS } & \text { 3-(N-morpholino)propanesulfonic acid } \\ \text { MPP } & \text { Mitochondrial processing peptidase } \\ \text { mRNA } & \text { Messenger RNA } \\ \text { MS } & \text { Mass spectrometry } \\ \text { mt } & \text { mitochondrial } \\ \text { MTS } & \text { Mitochondrial targeting sequence/presequence } \\ \text { NADH } & \text { Nicotinamide adenine dinucleotide } \\ \text { nm } & \text { Nanometer } \\ \text { NT } & \text { Non-targeting } \\ \text { OD } & \text { Optical density } \\ \text { OMM } & \text { Outer mitochondrial membrane } \\ \text { ORF } & \text { Open reading frame } \\ \text { OXA } & \text { Oxidase assembly translocase } \\ \text { OXPHOS } & \text { Oxidative phosphorylation } \\ \text { p } & \text { precursor } \\ \text { PAGE } & \text { Polyacrylamide gel electrophoresis } \\ \text { PAM } & \text { Presequence translocase-associated motor } \\ \text { PBD } & \text { Presequence binding domain } \\ \text { PBS } & \text { Phosphate buffered saline } \\ \text { PC } & \text { Phosphatidylcholine } \\ \text { PCR } & \text { Polymerase chain reaction } \\ \text { PE } & \text { Phosphatidylethanolamine } \\ \text { PG } & \text { Phosphatidylglycerol } \\ \text { PK } & \text { Proteinase K } \\ \text { PMSF } & \text { Phenylmethylsulfonyl fluoride } \\ \text { PVDF } & \text { Polyvinylidene fluoride } \\ \text { RCS } & \text { Respiratory chain supercomplex(es) } \\ \text { RNA } & \text { Ribonucleic acid } \\ \text { ROS } & \text { Reactive oxygen species } \\ & \end{array}$




\begin{tabular}{|c|c|}
\hline rpm & Revolutions per minute \\
\hline SAM & Sorting and assembly machinery \\
\hline sc & Scramble \\
\hline $\mathrm{SDH}$ & Succinate dehydrogenase \\
\hline SEM & Standard error of the mean \\
\hline SDS & Sodium dodecyl sulfate \\
\hline SILAC & Stable isotope labeling of amino acids in cell culture \\
\hline siRNA & Small interfering RNA \\
\hline TBS & Tris buffered saline \\
\hline TCA & Trichloroacetic acid \\
\hline TEMED & $\mathrm{N}, \mathrm{N}, \mathrm{N}^{\prime}, \mathrm{N}^{\prime}$-Tetramethylethane-1,2-diamine \\
\hline Tet & Tetracycline \\
\hline TIM22 & Carrier translocase of the inner membrane \\
\hline TIM23 & Presequence translocase of the inner membrane \\
\hline TLC & Thin-layer chromatography \\
\hline $\mathrm{TM}$ & Transmembrane domain/span \\
\hline TOM & Translocase of the outer membrane \\
\hline Tris & Tris(hydroxymethyl)aminomethane \\
\hline tRNA & Transfer RNA \\
\hline UV & Ultraviolet \\
\hline $\mathrm{V}$ & Volt(s) \\
\hline WT & Wild-type \\
\hline YPD & Yeast extract, peptone, glucose \\
\hline$\Delta \psi$ & Membrane potential across the mitochondria inner membrane \\
\hline$\mu \mathrm{L}$ & Microliter(s) \\
\hline$\mu g$ & Microgram(s) \\
\hline$\%$ & Percent \\
\hline
\end{tabular}




\section{Abstract}

Mitochondria are vital organelles that perform fundamental functions such as ATP synthesis and iron-sulfur cluster formation. More than $99 \%$ of the mitochondrial proteome is imported by dedicated translocation machineries. Proteins destined for the mitochondrial matrix, or the inner membrane, are imported by the presequence translocase of the inner membrane (TIM23 complex). The molecular architecture of the mitochondrial translocation machinery is conserved between yeast and human, but most of the functional characterization to date has been carried out in S.cerevisiae.

Quantitative mass spectrometry was used to analyze the interactome of the isolated human TIM23 complex. A high enrichment of a protein named ROMO1 was found. The upregulation of ROMO1 had previously been correlated with high levels of reactive oxygen species (ROS). It also plays a role in the regulation of mitochondrial morphology. However, the molecular function of ROMO1 is unknown. ROMO1 displays sequence similarity to yeast Mgr2, which is a subunit of the TIM23 complex and acts in quality control during import.

Using HEK293T cells as a model system, this study showed, by immunoprecipitation, that ROMO1 interacts with TIM21 and TIM23 and is therefore a constituent of the human TIM23 complex. To study the function of ROMO1, a CRISPR/Cas9-mediated knockout cell line was generated, which displays aberrant cristae structure. Biochemical analysis showed that the processing of OPA1, a protein involved in mitochondrial morphology, is disturbed. Furthermore, steady-state levels of the OPA1 processing protease, YME1L, are reduced. Even though ROMO1 couples TIM21 onto TIM23 and affects respiratory chain assembly, general protein import is not dependent on ROMO1. However, in vitro import assays showed that the import of YME1L is drastically affected in the absence of ROMO1. The molecular reason for this import defect seems to be the unusually long targeting sequence of YME1L. Therefore, an interesting link between protein import and inner membrane morphology could be established. 


\section{Introduction}

\subsection{Compartmentalization of the eukaryotic cell}

Eukaryotic cells, in contrast to prokaryotic cells, have the capacity to form complex organisms, in part due to differentiation and compartmentalization (Palade, 1964). Organelles equip the eukaryotic cell with the ability to spatially and temporally segregate numerous processes, which gives them an evolutionary advantage. The presence of membrane-enclosed organelles, in particular, enables the division of opposing pathways, making these processes more efficient. Moreover, it lets the cell store certain compounds until needed, as well as sequester deleterious substances (Lane \& Martin, 2010). Additionally, by separating molecules, membranes provide a platform for the generation of gradients, which can be used for biochemical processes, such as ATP synthesis using a proton gradient in mitochondria.

It is believed that mitochondria could be one of the reasons why eukaryotes were able to increase their genome size and thereby their complexity (Friedman \& Nunnari, 2014; Lane \& Martin, 2010). Mitochondria developed after engulfment of an $\alpha$-proteobacterium by a eukaryotic progenitor cell (de Duve, 2007). The mitochondrial genome has almost been completely transferred to the nucleus (Gray et al., 1999; Taanman, 1999) so that mitochondria depend on cytosolic translation and elaborate transport machineries for their biogenesis (Kang et al., 2018; Wiedemann \& Pfanner, 2017). This study focuses on the human translocation machinery, its components, mechanisms and possible interactions with other mitochondrial processes.

\subsection{The structure of mitochondria}

Mitochondria form a dynamic network that undergoes constant fission and fusion. Due to their endosymbiotic origin, mitochondria possess a characteristic morphology as they are doublemembrane bound organelles (Figure 1.1). The outer mitochondrial membrane (OMM) harbors 
multiple channels and allows the passage of small molecules (Benz, 1994; Krüger et al., 2017). It also holds protein import complexes that function in the biogenesis of the mitochondrial proteome (Mokranjac \& Neupert, 2015). The intermembrane space (IMS), between the outer and inner membranes, forms a soluble environment and houses chaperones crucial for protein import (Ellenrieder et al., 2015; Rehling et al., 2004). The protein-rich inner mitochondrial membrane (IMM) is highly folded and separates the matrix from the IMS. This is a prerequisite to establish a proton gradient, which enables ATP synthesis by multi-subunit protein complexes of the oxidative phosphorylation (OXPHOS) machinery (Winge, 2012). This proton gradient also drives protein import (Dudek et al., 2013). The mitochondrial matrix contains chaperones assisting in protein folding but most prominently, it houses the mitochondrial gene expression machinery and the mitochondrial genome (Gustafsson et al., 2016; Ott et al., 2016).

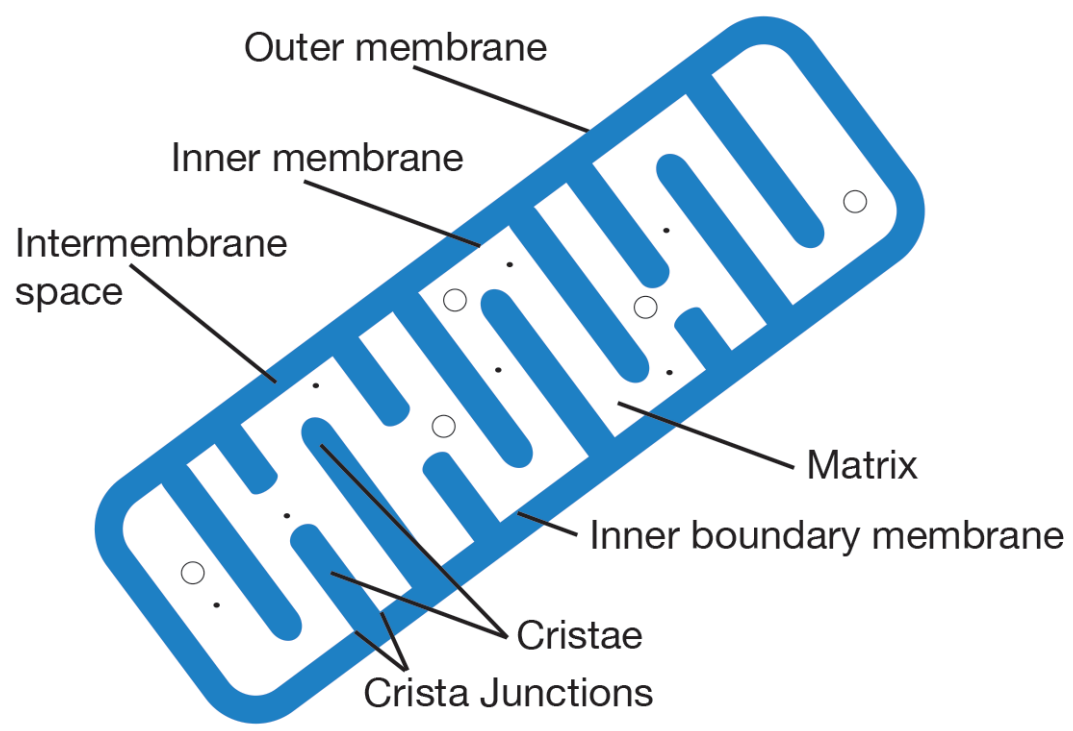

Fig. 1.1 The structure of mitochondria. The four main compartments of mitochondria are outer membrane, inner membrane, intermembrane space and matrix. The inner membrane can be subdivided further into inner boundary membrane, cristae and crista junctions.

The inner membrane consists of three domains; the inner boundary membrane that lies parallel to the outer membrane; cristae, the invaginations that reach inside mitochondria and crista junctions, which connect the other two domains (Figure 1.1). Using quantitative immunoelectron microscopy, it has been shown that respiratory chain complexes are primarily found in cristae, while complexes of the protein import machinery mainly localize to the inner 
boundary membrane (Vogel et al., 2006). The architecture of the cristae is maintained by the MICOS complex at crista junctions and by the $\mathrm{F}_{\mathrm{O}} \mathrm{F}_{1}$ ATP synthase dimers at regions of high crista curvature (Strauss et al., 2008; van der Laan et al., 2012).

\subsection{Functions of mitochondria}

Mitochondria are best known for their role in energetics and metabolism, including ATP production, biosynthesis of amino acids, fatty acids and heme. Furthermore, mitochondria accommodate the citric acid cycle and urea cycle and are crucial in calcium signaling, apoptosis and iron-sulfur cluster formation (Friedman \& Nunnari, 2014; Lill \& Mühlenhoff, 2008; Lill et al., 2012). Being termed the powerhouses of the cell, the mechanisms of ATP generation by oxidative phosphorylation (OXPHOS) have been studied in detail.

\subsubsection{The respiratory chain and oxidative phosphorylation}

The OXPHOS machinery in the inner mitochondrial membrane consists of five complexes (Complexes I-V). Complexes I to IV of the respiratory chain undergo redox reactions which establishes a flow of electrons via electron carriers. This flow of electrons leads to a proton gradient across the inner membrane, due to the translocation of protons into the IMS by the complexes of the respiratory chain. ATP synthase (Complex V) uses this proton gradient to produce ATP by rotational catalysis (von Ballmoos et al., 2008; Winge, 2012).

Complex I (NADH:ubiquinone oxidoreductase) passes two electrons from NADH to ubiquinone and translocates four protons across the membrane into the IMS. Complex II (succinate dehydrogenase) converts succinate to fumarate, transferring two electrons but no protons. Complex III (ubiquinol-cytochrome $c$ oxidoreductase) houses the intricate Q cycle, facilitating electron transfers between electron carriers that concomitantly pump two protons

per electron across the membrane. Complex IV (cytochrome $c$ oxidase) marks the final step of respiration. Here, molecular oxygen is reduced by four electrons to produce two molecules of 
water while transferring four protons from the matrix to the IMS (Fernández-Vizarra et al., 2009; Guo et al., 2018). It has been known for some time that supercomplexes are formed by OXPHOS complexes. The most prominent supercomplex consists of complex I, a complex III dimer and complex IV. This oligomerization is considered to assist in substrate channeling and therefore makes respiration more efficient (Guo et al., 2018; Schägger \& Pfeiffer, 2000; Winge, 2012).

Mitochondria have retained their own genome, as well as gene expression machinery. 13 mostly hydrophobic core subunits of the OXPHOS machinery are encoded by the mitochondrial genome (complexes I, III, IV and V). These complexes with subunits of dual genetic origin have to be assembled in a coordinated manner (Lazarou et al., 2009; Mick et al., 2012; Mick et al., 2011). The next section will focus on the assembly of the terminal enzyme of the respiratory chain, cytochrome $c$ oxidase.

\subsubsection{Assembly of cytochrome $c$ oxidase}

Human complex IV consists of 14 subunits and has three mitochondrial-encoded subunits that form the catalytic core (COX1, 2 and 3). More than 30 vital assembly factors have been identified that mediate complex IV biogenesis (Timón-Gómez et al., 2018). It is thought that the complex assembles in a modular way, in which certain subcomplexes form before they assemble into the holoenzyme. In this model, three modules containing one mitochondrial-encoded subunit each assemble independently before a sequential assembly of the intermediates (Vidoni et al., 2017).

Significant research has focused on the biogenesis of COX1 and its role as a seed for further complex IV assembly. COX1 associates with a number of maturation and stabilization factors, such as SURF1, C12ORF62 (COX14), MITRAC12 (COA3) or MITRAC7, before it associates with COX4I-1 and COX5A (Dennerlein et al., 2015; Mick et al., 2012; Richter-Dennerlein et al., 2016; Stiburek et al., 2005; Szklarczyk et al., 2012). The expression, assembly and metalation of COX2 is regulated by factors such as COX16, COX18, COX20, TMEM177, COA6 or SCO1/2, 
before it forms a subcomplex with COX6C, COX7B, COX7C and COX8A (Aich et al., 2018; Lazarou et al., 2009; Lorenzi et al., 2018; Pacheu-Grau et al., 2015; Williams et al., 2004). The biogenesis of the COX3 module is the least studied. It is thought to interact with COX6A, COX6B and COX7A before it associates with the assembling enzyme (Timón-Gómez et al., 2018).

\subsection{Mitochondrial dynamics and inner membrane maintenance}

\subsubsection{Mitochondrial dynamics is controlled by GTPases}

Proper function of mitochondrial enzymes in the inner membrane, especially the respiratory chain, is tightly linked to mitochondrial dynamics. Controlled mitochondrial fusion and fission ensures quality control, as well as enables the organelle to adapt to metabolic changes (MacVicar \& Langer, 2016; Youle \& van der Bliek, 2012). Fusion is thought to be necessary for proper distribution of mitochondrial DNA and efficient respiration (Hoppins, 2014). Fission, on the other hand, separates and segregates dysfunctional mitochondria to assist in their degradation (Elgass, et al., 2013).

Fission of the outer membrane is mediated by the GTPase DRP1 (dynamin-related protein 1), which is recruited to the outer membrane to initiate division (Otera et al., 2013). The adapter proteins MID49 and MID51 aid in its targeting (Losón et al.. 2013; Palmer et al., 2013). The antagonists of DRP1 are also GTPases, namely Mitofusins MFN1 and MFN2, which regulate outer membrane fusion (Santel \& Fuller, 2001).

While the exact molecular machinery mediating inner membrane fission is not known, research has focused on the dynamin-like GTPase OPA1, which induces inner membrane fusion. Its name is derived from autosomal dominant optic atrophy after it was shown that its mutation was the main cause of the disease. It contains a GTP-effector domain and a conserved GTPbinding domain (Alexander et al., 2000; Delettre et al., 2000). OPA1 is not only connected to 
mitochondrial morphology, but also to cristae structure as well as to respiration and apoptosis (Olichon et al., 2006). Reports show that OPA1 mainly localizes to cristae of the inner membrane, most likely involved in curvature formation (Griparic et al., 2004).

It is believed in the field that processing of OPA1 into multiple long and short forms is key to its function and to understanding its mechanism regarding mitochondrial cristae organization and fusion. At least five forms are present - two long and three short (Anand et al., 2014; Figure 1.2). Short and long forms of OPA1 are thought to assemble into oligomeric complexes that maintain proper cristae morphology (Frezza et al., 2006; Yamaguchi et al., 2008). Their biogenesis and regulation will be discussed in the section below.

\subsubsection{OPA1 biogenesis and processing}

Alternative splicing leads to at least eight different mRNA OPA1 isoforms, which are expressed tissue dependently (Delettre et al., 2001). At the protein level, two forms of long (L)-OPA1 exist, both of which are membrane-bound. The two forms differ in the presence of one or two proteolytic cleavage sites, named S1 and S2, where one half of L-OPA1 only contains S1 and one half contains both (Ishihara et al., 2006; Song et al., 2007; Figure 1.2). S1 and S2 allow proteolysis by OMA1 and YME1L respectively (Käser et al., 2003; Song et al., 2007). It has been postulated that long and short forms of OPA1 have to be present at almost equimolar amounts to ensure proper mitochondrial morphology and dynamics (Wai \& Langer, 2016). Different physiological conditions lead to a lower or higher expression of both proteases, allowing the mitochondria to adapt to these changes.

Both proteases have their active site facing the IMS. OMA1 (zinc metalloprotease overlapping with $m$-AAA protease) contains a catalytic M48 metallopeptidase domain (López-Pelegrín et al., 2013). Under normal conditions, OMA1 is barely expressed but is activated by oxidative stress or loss of membrane potential (Baker et al., 2014; Quiros et al., 2012; Rainbolt et al., 2016; Rainbolt et al. 2015; Zhang et al., 2014). This means that only under stress all L-OPA1 forms are 
converted to S-OPA1 (Anand et al., 2014; Ishihara et al., 2006). In contrast, the ATP-dependent protease YME1L (yeast mitochondrial DNA escape 1-like) is active under basal conditions (Song et al., 2007). In general, it is thought that a higher expression of S-OPA1 is linked to mitochondrial fission and L-OPA1 to fusion (Anand et al., 2014; MacVicar \& Langer, 2016). This has been demonstrated by the fact that processing of OPA1 is not necessary for fusion, since cells lacking OMA1 and YME1L, and therefore only containing membrane-bound LOPA1, are able to fuse (Anand et al., 2014; Ishihara et al., 2006; Quiros et al., 2012; Tondera et al., 2009). Regarding proper inner membrane morphology, OMA1 is dispensable, while a lack of YME1L severely disturbs cristae morphology (Anand et al., 2014; Stiburek et al., 2012).
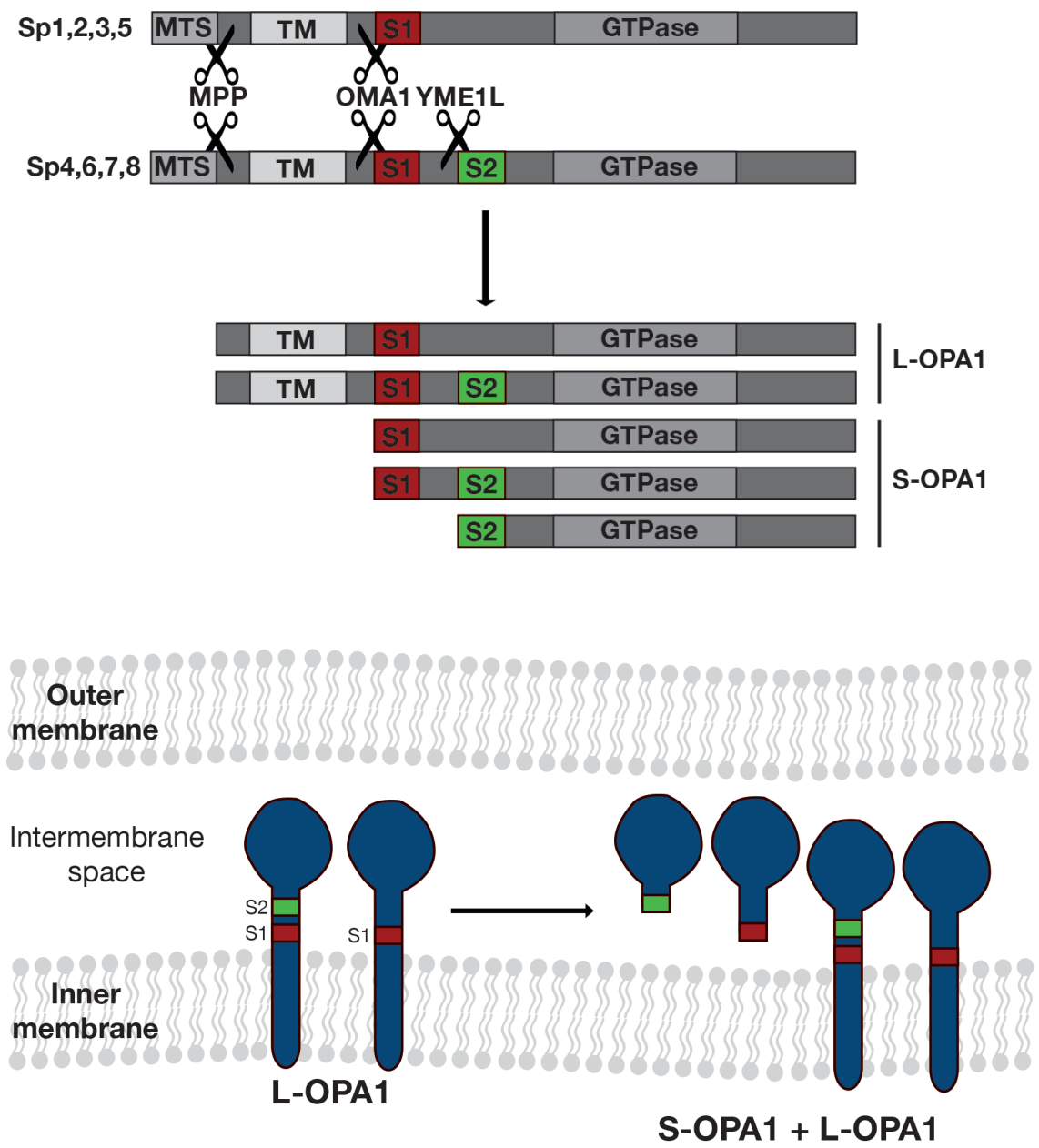

Fig. 1.2: The processing of OPA1. 8 splice variants form two different membrane bound L-OPA1 forms, which can be processed further by OMA1 and YME1L to three soluble S-OPA1 forms. MTS - mitochondrial targeting sequence; TM - transmembrane domain. 
The activity of YME1L has been shown to be modulated by oxidative stress (Rainbolt et al., 2015), as well as OXPHOS activity (Mishra et al., 2014). Along with a few other proteins, YME1L also plays a role in general protein homeostasis and quality control (Rainbolt et al., 2013; Stiburek et al., 2012).

\subsubsection{Protein quality control}

Due to the high abundance of proteins in the inner membrane, tight quality control and maintenance is necessary to ensure proper mitochondrial function (Levytskyy et al., 2017). The maturation or clearance of damaged or misfolded proteins is performed by proteases, which can be subdivided into ATP-independent and ATP-dependent proteases (Wasilewski et al., 2017). ATP-independent examples include MPP in the matrix and OMA1 and PARL in the IMS.

ATP-dependent proteases in mitochondria belong to the $\mathrm{AAA}^{+}$superfamily (AAA stands for ATPases Associated with various cellular Activities). Examples include LONP1 or $m$-AAA (Paraplegin and AFG3L2) and $i$-AAA (YME1L) proteases, which expose their active sites to the matrix or the IMS respectively. They also ensure protein homeostasis of inner membrane proteins exposed to their respective leaflet (Levytskyy et al., 2017).

AAA metalloproteases are conserved and share common features, most notably an $\mathrm{AAA}^{+}$ ATPase domain, with so-called Walker A and B motifs that bind the nucleotide. Moreover, a Cterminal $\mathrm{Zn}^{2+}$ metalloprotease domain with an $\mathrm{HExxH}$ or variant HxxEH motif (Ammelburg et al., 2006; Scharfenberg et al., 2015). The catalytic site is formed by the HExxH domain and a mutation from $E$ to $Q$ can abolish its activity in YME1L (Graef et al., 2007). The $m$-AAA protease forms a heteromeric, hexameric complex comprised of Paraplegin and AFG3L2, even though AFG3L2 can also form a homohexameric complex. Its best described substrate in yeast is the ribosomal protein MrpL32 (Nolden et al., 2005). In mammals, the $m$-AAA protease has been shown to degrade the EMRE protein, linked to calcium signaling (König et al., 2016), as well as selected respiratory chain proteins (Levytskyy et al., 2017). 

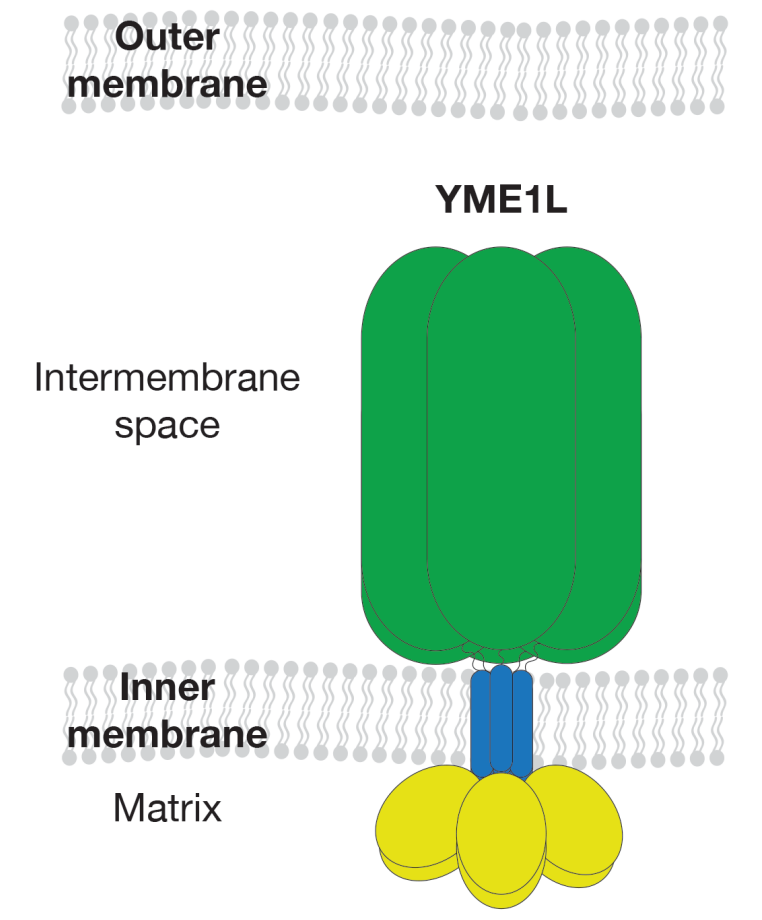

Fig. 1.3: The hexameric structure of YME1L. The $i$-AAA protease YME1L forms a homohexameric complex in the inner membrane. It has a short soluble $\mathrm{N}$-terminus in the matrix, one transmembrane domain and a large $\mathrm{C}$ terminus in the IMS. This part holds its catalytic domain.

The $i$-AAA protease forms a homohexameric complex of YME1L in the inner membrane (Figure 1.3). Mature YME1L exposes a short N-terminal domain into the matrix and has only a single transmembrane span. Its C-terminus, exposed to the IMS, holds the catalytic $\mathrm{AAA}^{+}$ ATPase domain, followed by a zinc metalloprotease domain (Coppola et al., 2000; Shah et al., 2000; Shi et al., 2016). Recently, it has been shown that this complex further associates with the rhomboid protease PARL and SPL2 to form the SPY complex. This $2 \mathrm{MDa}$ complex spatially organizes proteolysis and seems to be crucial to ensure YME1L activity during high substrate load (Wai et al., 2016). Besides its best described substrate L-OPA1 (see section 1.4.2), known YME1L substrates include TIM17A (Rainbolt et al., 2013), TIM23 (Wai et al., 2016) and respiratory chain components such as NDUFB6, COX4I-1 and COX2 (Stiburek et al., 2012). Furthermore, during stress, such as depolarization or low ATP levels, YME1L and OMA1 reciprocally control their expression by degradation (Rainbolt et al., 2016). Interestingly, small Tims, which are its substrates in yeast, are not degraded by YME1L in human (Baker et al., 2012). 
It has been hypothesized that YME1L recognizes its substrates by specific motifs, so called degrons. A possible recognition signal could be F-h-h-F (h being a hydrophobic amino acid) (Shi et al., 2016). Substrates are most likely destabilized as initial unfolding is necessary for recognition (Rampello \& Glynn, 2017). However, Shi et al. showed that YME1L is also able to unfold stable proteins. A recent structural study of yeast Yme1 gave more insights regarding its mechanism (Puchades et al., 2017). They showed that Yme1 forms two stacked rings. While the protease ring is planar, ATPase domains on top of this planar ring form an asymmetric spiral staircase. Coordinated cycles of ATP hydrolysis drive stepwise, processive translocation of the unfolded substrate into the proteolytic chamber, where it is progressively degraded.

\subsubsection{Mitochondrial reactive oxygen-species signaling}

Aberrations in mitochondrial inner membrane morphology have been linked to deleterious reactive oxygen species signaling (Ježek et al., 2018). While mitochondrial fragmentation and inner membrane aberrations can lead to higher ROS levels, ROS has also been shown to induce morphological changes (Brand, 2016; Ježek et al., 2018). ROS is mainly produced in the electron transport chain where electrons are passed on from one complex to the other. However, oxygen can undergo side reactions with leaked electrons to produce reactive oxygen species (a superoxide anion $\mathrm{O}_{2}^{-}$radical) instead of water. This charged radical can be interconverted to $\mathrm{H}_{2} \mathrm{O}_{2}$, which can diffuse freely (Murphy, 2009). Besides complex I and III of the respiratory chain that produce ROS on both the matrix as well as IMS side, a number of other metabolic enzymes in both the matrix and IMS have been found to be sites of ROS generation (Holmström \& Finkel, 2014).

ROS is involved in multiple signaling pathways. During cellular response to insults, ROS activates signaling cascades to protect the cell, especially in conditions of hypoxia or ER stress (Chandel et al., 1998; Ježek et al., 2018). Moreover, low levels of ROS are beneficial and necessary for intracellular signaling as it mediates (de)phosphorylation and oxidation and reduction of signaling components. These processes regulate cell growth, cellular metabolism, immune 
response, stem cell biology and aging (Holmström \& Finkel, 2014; Nemoto et al., 2000; Sena \& Chandel, 2012). However, ROS production has also been linked to damaged DNA, proteins and lipids, as well as cell death and ultimately to the progression of multiple diseases, especially cancer (Bae et al., 2011; Sena \& Chandel, 2012).

One recently identified protein that is associated with high ROS levels and has been shown to be upregulated in various cancers is ROMO1 (Reactive Oxygen Species Modular 1) (Swarnabala et al., 2014). ROMO1 was identified in a study using differential-display PCR to monitor upand downregulated genes in tumor tissue. It is a mitochondrial protein found in the inner membrane (Chung et al., 2006; Zhao et al., 2009). Its upregulation correlates with increased tumor invasiveness and size and decreased patient survival (Chung et al., 2012; Kim et al., 2017; Lee et al., 2015; Yu et al., 2014). ROS produced by ROMO1 originates in the electron transport chain and leads to DNA damage, as well as aging and replicative senescence of cells. However, the generation of ROS signaling by ROMO1 is necessary for proliferation of both cancer and normal cells ( $\mathrm{Na}$ et al., 2008). Knockdown of ROMO1 by siRNA leads to decreased ROS production (Chung et al., 2010; Chung et al., 2008; Kim et al., 2014; Lee et al., 2011; Lee et al., 2009; Shin et al., 2013; Shyamsunder et al., 2015). ROMO1 has been termed an oncomarker and is not just related to cancer but also involved in bone-marrow failure, diabetes, heart failure and obstructive sleep apnea syndrome (Chen et al., 2017; John et al., 2017; Petrovic et al., 2015; Shyamsunder et al., 2015; Ye et al., 2018).

Besides these physiological studies, only a few publications have tried to address the molecular function of ROMO1 and surprisingly have revealed strikingly different outcomes. Most recently, one study described ROMO1 as forming a virus-related viroporin-like non-selective cation channel. This biophysical study showed that ROMO1 can form homooligomers and its amphipathic helices can form a pore for cations. Furthermore, bioinformatic modeling revealed a hexameric structure of this channel (Lee et al., 2018). Another study looked at a possible molecular connection between ROMO1 and mitochondrial morphology (Norton et al., 2014). This study found that oxidative stress leads to the formation of ROMO1 complexes at high molecular weight. Furthermore, the absence of ROMO1 leads to processing defects of OPA1 
and concomitantly disturbed cristae structure and impaired respiration. Interestingly, the knockdown approach in this study led to increased levels of ROS, which is the opposite of what had been published before (i.e. Chung et al., 2008). Nevertheless, ROMO1 seems to be another player linking ROS production to mitochondrial morphology. Its exact molecular function remains to be elucidated.

\subsection{Protein import into mitochondria}

The mitochondrial proteome consists of about 1,500 proteins in human (Nunnari \& Suomalainen, 2012). Only 13 proteins are encoded by mitochondrial DNA and translated within mitochondria (Gustafsson et al., 2016; Hällberg \& Larsson, 2014; Ott et al., 2016). More than 99\% of the mitochondrial proteome is encoded in the nucleus und translated on cytosolic ribosomes. It is thought that protein import into mitochondria occurs post-translationally in general (Dudek et al., 2013). However, for a few proteins, evidence exists that their import occurs co-translationally (Lesnik et al., 2014; Luk et al., 2005; Yogev et al., 2007). Furthermore, it has been shown that signals found both in the 3' untranslated and coding regions of mRNAs can guide cytosolic translating ribosomes close to the outer mitochondrial membrane (CorralDebrinski et al., 2000; Garcia et al., 2010; Margeot et al., 2002; 2005). In fact, ribosome have been visualized on the surface of mitochondria directly interacting with the protein import machinery (Gold et al., 2017).

Mitochondrial proteins are equipped with targeting signals that guide them to mitochondria (Chacinska et al., 2009; Wiedemann \& Pfanner, 2017). Targeting of precursors to mitochondria is assisted by chaperones to prevent aggregation and misfolding and guide them to the mitochondrial outer membrane (Bhangoo et al., 2007; Young et al., 2003; Zara et al., 2009). Once in the vicinity of the mitochondrial outer membrane, receptors recognize the targeting signals on the precursors and initiate their transport into mitochondria (Abe et al., 2000). 
The majority of current understanding regarding protein import into mitochondria stems from studies using the model organism Saccharomyces cerevisiae. It is strongly believed that the general principles regarding protein import, as well as the core translocation machineries are conserved from yeast to human (Bauer et al., 1999; Kang et al., 2018). However, recent studies have revealed new factors and features, which are unique to metazoan (Kang et al., 2018; Sokol et al., 2014). These differences will be highlighted in the following sections.

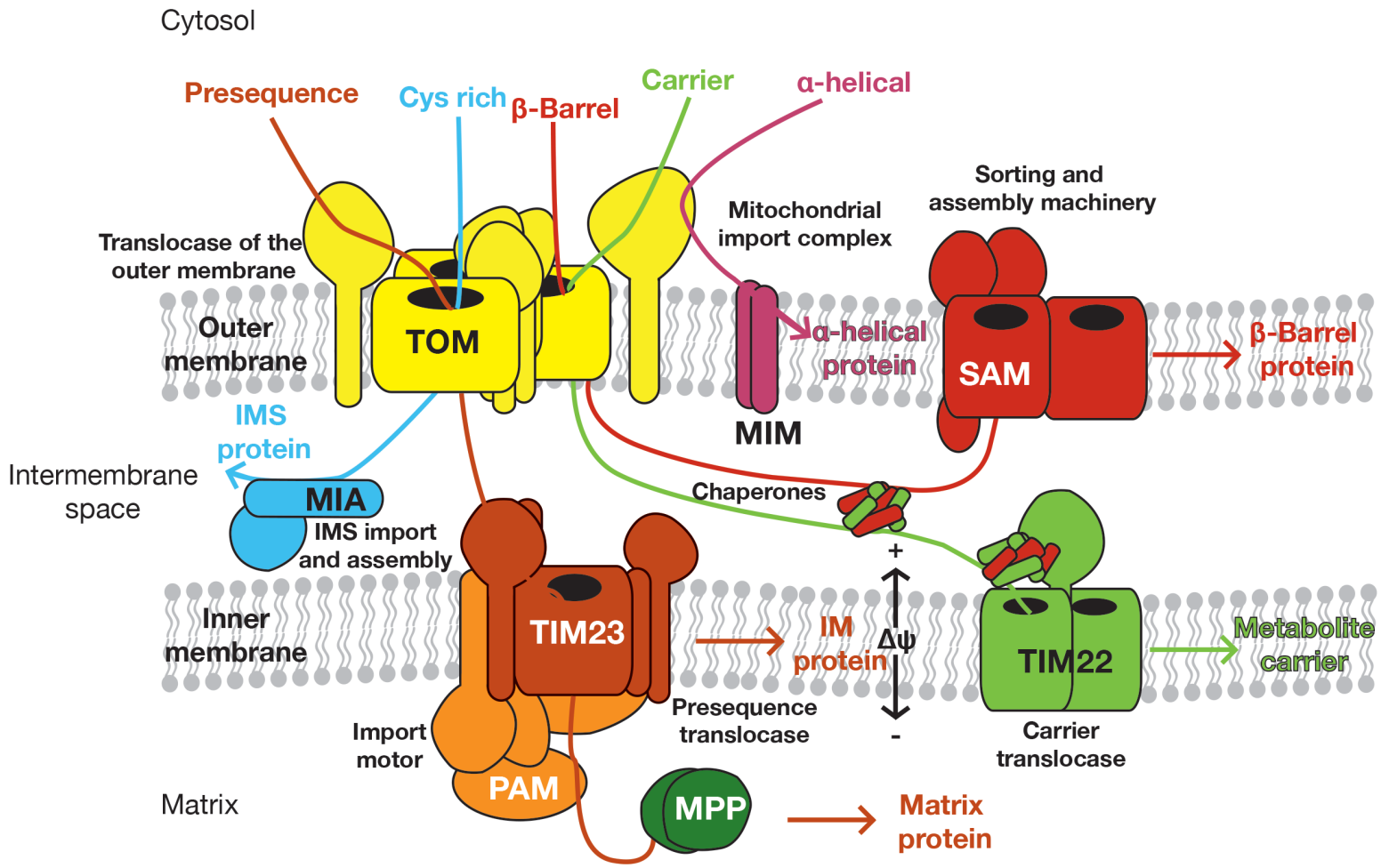

Fig. 1.4: Schematic overview of major import pathways into mitochondria. Proteins targeted to the inner membrane or matrix carry a presequence and are imported via the TOM and the TIM23 complex. Full matrix translocation is driven by the PAM complex. Cysteine-rich IMS proteins are imported via TOM and the MIA pathway. $\beta$-barrel proteins of the outer membrane are inserted using the TOM and the SAM complex. Carrier proteins of the inner membrane use the TOM complex to enter mitochondria, then bind chaperones in the IMS and are inserted by the TIM22 complex. $\alpha$-helical proteins of the outer membrane are imported via the MIM complex.

\subsubsection{Import into the outer membrane}

The translocase of the outer membrane (TOM complex) forms the general entry gate into mitochondria for almost all mitochondrial proteins (Figure 1.4; Kiebler et al., 1990; Mokranjac 
\& Neupert, 2015). It consists of the receptor proteins Tom 20 , Tom 22 and Tom70, while Tom 40 forms a channel which allows entry into mitochondria (Hill et al., 1998; Hines \& Schatz, 1993; Hines et al., 1990; Krimmer et al., 2001; Lithgow et al., 1994; Moczko et al., 1992; Schneider et al., 1991b; Shiota et al., 2015). The TOM complex can serve as the general import translocase since it contains hydrophobic, as well as hydrophilic, regions to accommodate both soluble and transmembrane proteins (Esaki et al., 2003; Melin et al., 2014; Shiota et al., 2015). Tom 5, 6 and 7, the so called small TOMs, mainly act in the stability and assembly of the TOM complex while Tom5 also acts as a receptor (Alconada et al., 1995; Dietmeier et al., 1997; Hönlinger et al., 1996). Import through the TOM complex is driven by the increasing affinities of the precursors towards the IMS, before they are handed over to further machineries to reach their final destination (Dudek et al., 2013).

\subsubsection{The SAM complex}

Due to the fact that mitochondria originated from Gram-negative bacteria, they contain mainly $\beta$-barrel proteins in their outer membrane. Examples include the channel protein VDAC, the import channel Tom40, as well as Sam50 which itself is involved in the import of $\beta$-barrel proteins. The targeting sequence of $\beta$-barrel proteins is a $\beta$-hairpin consisting of two adjacent $\beta$-strands, connected by a loop present at the very C-terminus (Jores et al., 2016). Together with the two peripheral membrane proteins Sam 35 and Sam37, the $\beta$-barrel channel Sam50 forms the sorting and assembly machinery (SAM complex, Figure 1.4; Wiedemann \& Pfanner, 2017).

Once a $\beta$-barrel precursor protein emerges from the TOM complex, small soluble TIM chaperones, found in the IMS, bind to its hydrophobic patches to prevent aggregation (Curran et al., 2002a; Hoppins \& Nargang, 2004; Wiedemann et al., 2004). The insertion of multispanning transmembrane proteins is mediated by Sam50. First, a transmembrane precursor is inserted into the lumen of the channel, before the $\mathrm{C}$-terminal $\beta$-signal induces the opening of the lateral gate for its release. Membrane insertion is then facilitated by membrane thinning to aid the translocation of the whole protein (Höhr et al., 2018). 
In contrast, the mechanism of $\beta$-barrel protein biogenesis in human is not as well understood (Kang et al., 2018). While Sam50 itself is highly conserved in human (Paschen et al., 2003), functional homologs of Sam35 and Sam 37 have not been clearly identified. There is evidence that Metaxins have taken over their role (Kozjak-Pavlovic et al., 2007). While Metaxin-1 forms a complex with Sam50 in human, it has also been shown to play a role in cristae structure maintenance and respiratory chain complex assembly (Huynen et al., 2016).

\subsubsection{Outer $\alpha$-helical proteins}

Besides $\beta$-barrel proteins, the proteome of the outer membrane also consists of $\alpha$-helical proteins, i.e. Tom 20 and Tom70. These can be divided into three classes: multi-spanning, tailanchored with a C-terminal $\alpha$-helix, and signal-anchored proteins with an N-terminal $\alpha$-helix (Wiedemann \& Pfanner, 2017). The insertion of signal-anchored and multispanning proteins is mediated by the mitochondrial import (MIM) complex (Figure 1.4; Becker et al., 2008; Dimmer et al., 2012), with the help of Tom70 as receptor (Becker et al., 2011). In contrast, no translocation machinery for tail-anchored proteins has been identified, but the lipid composition is thought to play a crucial role in their targeting (Kemper et al., 2008).

\subsubsection{Transport into the intermembrane space via the MIA pathway}

Proteins in the intermembrane space, such as the small TIM chaperones often contain characteristic cysteine motifs (i.e. $\mathrm{Cx}_{3} \mathrm{C}$ or $\mathrm{Cx}_{9} \mathrm{C}$ ) that form disulfide bonds (Dudek et al., 2013). The import of such proteins is facilitated by the mitochondrial intermembrane space import and assembly (MIA) machinery (Figure 1.4), with the key players Mia40 and sulfhydryl oxidase Erv1 (known as ALR in human) (Chacinska et al., 2004; Daithankar et al., 2009; Kang et al., 2018; Rissler et al., 2005). While Mia40 in both yeast and human functions in a similar way, human MIA40 is imported via the MIA pathway as it is a soluble intermembrane space protein itself. Mia40 in yeast is anchored in the inner membrane with a soluble domain in the IMS and is imported via the TIM23 complex (Chacinska et al., 2004; 2008; Hofmann et al., 2005). 
The sorting signal of MIA substrates comprises of two cysteine residues flanking hydrophobic residues and the substrates are kept in reduced form during translocation through the outer membrane (Gornicka et al., 2014; Milenkovic et al., 2009; Sideris et al., 2009). Mia40 acts as receptor in the intermembrane space and uses a disulfide relay system to stabilize the conformation and aid in assembly of the intermembrane space protein (Fischer \& Riemer, 2013). Mia40 displays oxidoreductase activity and oxidizes its substrate and thereby assists in the correct formation of its disulfide bonds and folding. After it releases its substrate, Mia40 is reoxidized by Erv1/ALR and the electrons flow to molecular oxygen or cytochrome $c$ (Bien et al., 2010; Dabir et al., 2007).

\subsubsection{The carrier pathway (TIM22 complex)}

Metabolite carriers, such as the ADP/ATP carrier or the phosphate carrier, contain six transmembrane domains and are part of a large class of multi-spanning inner membrane proteins. Their import is carried out by the TIM22 complex (Figure 1.4). In yeast, it consists of Tim22, Tim54, Tim18 and Sdh3, while its subunits in human are TIM22, TIM29, TIM10B and AGK, showing a large divergence in regard to evolutionary conservation (Kang et al., 2018; Wiedemann \& Pfanner, 2017). Further TIM22 complex substrates include Tim17, Tim22 and Tim23, which contain only four transmembrane domains (Curran et al., 2002b). Carrier substrates are targeted to mitochondria by internal, hydrophobic stretches, which interact with Hsp70 and Hsp90 in the cytosol (Brix et al., 1999; Chacinska et al., 2009; Young et al., 2003). On the mitochondrial surface, the transmembrane proteins interact with several molecules of the receptor Tom70, before they are threaded through Tom40 in a loop formation (Wiedemann et al., 2001). Tom40 possibly recruits small TIM chaperones in the IMS which deliver the precursor protein through the IMS to the TIM22 complex in the inner membrane, protecting them from aggregation (Webb et al., 2006). The soluble Tim9-Tim10 complex interacts with carrier proteins and binds to inner membrane bound Tim12 to form the Tim9-Tim10-Tim12 chaperone complex that delivers the precursor protein to the Tim22 complex (Davis et al., 2007; Gebert et al., 2008). 
Tim22 forms a channel that resembles the presequence translocase component, Tim23, as well as Tim17, hinting at a common ancestor (Žárský \& Dolezal, 2016). The other complex constituent, Tim54, recruits the Tim9-Tim10-Tim12 chaperone complex (Wagner et al., 2008). Tim 18 and Sdh3 form a module that is involved in TIM22 complex assembly. Interestingly, Sdh3 displays dual localization in both the TIM22 complex, as well as complex II of the respiratory chain (Gebert et al., 2011). The insertion of the precursor proteins is mediated by Tim 22 forming a twin-pore in a membrane potential-dependent manner (Rehling et al., 2003). However, the exact mechanism of the lateral release into the inner membrane is unknown.

As implied above, the human TIM22 complex shows the most striking differences to its yeast counterpart (Kang et al., 2018). The small TIM chaperone complex TIM9-TIM10A-TIM10B exists in human, where TIM10B is the human Tim12. However, TIM10B is a constitutive subunit of the TIM22 complex and does not only associate with the translocase as a chaperone complex (Kang et al., 2016). Furthermore, no sequence homologs of Tim54 and Tim18 have been found (Mühlenbein et al., 2004). However, recently, the human-specific subunit TIM29 was identified and shown to function in the assembly of the TIM22 complex (Callegari et al., 2016; Kang et al., 2016). Furthermore, TIM29 is involved in the membrane insertion of TIM22 substrates and couples TIM22 to the TOM complex (Callegari et al., 2016; Kang et al., 2016). The fourth human subunit, AGK, is a lipid kinase that has been implicated in Sengers syndrome. However, it also has a kinase-independent function as it stabilizes the TIM22 complex and mediates import of a number of carrier proteins (Kang et al., 2017; Vukotic et al., 2017).

\subsubsection{The OXA complex}

Another pathway into the mitochondrial inner membrane is via the oxidase assembly (OXA) translocase, with its main component being Oxal. This insertion machinery is related to the bacterial YidC insertase and mediates protein export from the matrix into the inner membrane (Hell et al., 2001). The roles of Oxal can be broken down into two major categories. As mitochondria have retained their own translation machinery to produce a number of highly 
hydrophobic proteins, Oxa1, as well as Mba1, directly bind to the mitochondrial ribosome to assist the co-translational export of these proteins into the inner membrane (Pfeffer et al., 2015). Secondly, Oxa1 is involved in the biogenesis of nuclear-encoded proteins by the so-called conservative sorting pathway. This nomenclature stems from the resemblance of this pathway to the bacterial export route (Hartl et al., 1986; Rojo et al., 1995). Here, proteins are first imported into the matrix via the presequence pathway (see section 1.5.5), before they are again exported into the inner membrane by the OXA machinery (Stiller et al., 2016). Furthermore, another example is the multispanning inner membrane protein Mdll. Its hydrophobic Nterminal domain is first laterally released into the inner membrane by the stop-transfer mechanism (1.5.5.8). Then, the rest of the protein is imported into the matrix before it is exported again into the inner membrane by the OXA translocase (Bohnert et al., 2010).

\subsubsection{Protein translocation by the TIM23 complex}

\subsubsection{Signals mediating import via the TIM23 complex}

Up to $70 \%$ of mitochondrial proteins carry an $\mathrm{N}$-terminal presequence as a signal (Vögtle et al., 2009), which targets them to the inner mitochondrial membrane or the matrix. This makes the presequence pathway, mediated by the TIM23 complex, by far the most prominent mitochondrial import pathway (Figure 1.4). Presequences are usually 15-55 amino acids long, even though they significantly vary in length. Shorter presequences and considerably longer ones (100-150 amino acids) have also been reported (i.e. Hartmann et al., 2016). Their specific characteristic is an amphipathic $\alpha$-helix with a hydrophobic and a positively charged side, usually 12 to 15 amino acids long, which is found at the N-terminal region (von Heijne, 1986; Roise et al., 1986). Long presequences have also been predicted to form multiple $\alpha$-helices and even $\beta$-sheets (Huang et al., 2009).

Originally, only a small number of presequences had been analyzed. However, global proteomic studies of the $\mathrm{N}$-termini of mature mitochondrial proteins in the last decade, have broadened 
our understanding of presequences throughout species (Calvo et al., 2017; Huang et al., 2009; Vaca Jacome et al., 2015; Vögtle et al., 2009). These studies provided a systematic resource and revealed the limitations of frequently used prediction programs (i.e. MitoProtII, Claros \& Vincens, 1996). They could show that the primary amino acid sequence of presequences is not conserved. However, they confirmed the general notion of charge distribution (net charge of +3 to +6 ) and length (mostly 20-60 amino acids) of both yeast and mammalian presequences (Calvo et al., 2017; Vögtle et al., 2009). Furthermore, mature mitochondrial proteins have stable amino acids at their processed N-terminus, adhering to the N-end rule from bacteria (Tasaki et al., 2012).

The information conveyed by the presequence is threefold: its hydrophobic and polar faces are recognized by the receptors Tom 20 and Tom 22 respectively (Saitoh et al., 2007; Yamano et al., 2008). When cleaved, structural studies have shown that the cleavage site is recognized by the processing peptidase MPP in an extended conformation (Taylor et al., 2001). Thirdly, the overall positive charge drives the precursor's translocation into the matrix due to electrophoretic effects (Krayl et al., 2007; Martin et al., 1991; Shariff et al., 2004; van der Laan et al., 2007).

Most presequence-containing precursors are soluble proteins and are directed to the matrix. However, numerous proteins also contain a hydrophobic sorting signal, either located directly C-terminal to the presequence, or in the case of a soluble $\mathrm{N}$-terminal domain, separated by a spacer (Chacinska et al., 2009). This anchor of 16-18 amino acids stops the transfer across the inner membrane and leads to the lateral release into the membrane (Glick et al., 1992; Rojo et al., 1998). Recent studies have found that the adjacent regions of the transmembrane domain play an important role, whereby positively charged amino acids on both sides favor sorting (Botelho et al., 2011).

A number of unusual targeting signals for TIM23 substrates exist. First of all, some proteins contain non-cleavable presequences that target them to the inner membrane or matrix (Chacinska et al., 2009). Furthermore, even internal hydrophobic signals, usually following the carrier import pathway, have been shown to target proteins along the presequence pathway (i.e. 
Sym1; Reinhold et al., 2012). Finally, cleavable C-terminal targeting sequences, such as for Mgr2 (Ieva et al., 2013) and Hmil (Lee et al., 1999), have also been detected.

\section{5.5.2 Processing of presequence-containing proteins}

Upon translocation, presequence processing by the mitochondrial processing peptidase (MPP) occurs at a defined cleavage site, with an arginine present at the -2 position (von Heijne et al., 1989; Schneider et al., 1998). MPP processes most presequences in an extended conformation (Taylor et al., 2001). In both yeast and human, this protease is a soluble matrix protein and consists of two subunits, Mas1/PMPCB and Mas2/PMPCA (Poveda-Huertes et al., 2017).

A few proteins targeted to the intermembrane space are cleaved a second time by the Imp1 protease upon their translocation into the inner membrane. This cleavage step releases these soluble proteins into the IMS, but a specific cleavage motif has not been identified (Luo et al., 2006; Schneider et al., 1991a). While the mammalian homologues IMMP1L and IMMP2L have been identified, their substrates are not known (Mossmann et al., 2012).

An additional protease which processes proteins after MPP cleavage is Icp55 (Intermediate cleaving peptidase 55), which converts destabilizing N-termini from MPP cleavage, into stable $\mathrm{N}$-termini by usually removing one amino acid (Vögtle et al., 2009). In human, the protein APP3m is thought to be its potential homologue, even though ClpP might also be a candidate (Erşahin et al., 2005; Vögtle et al., 2009). Oct 1, with only 12 substrates in yeast, cleaves 8 amino acids, most likely also to contribute to their stability (Vögtle et al., 2011).

\subsubsection{Transport of presequence-containing proteins through the TOM complex}

Initial binding of the amphipathic mitochondrial targeting sequence occurs with Tom 20 via its hydrophobic face. The presequence is then handed over to the cytosolic portion of Tom22, which interacts with the positively charged, hydrophilic face (Abe et al., 2000; Brix et al., 1997; Yamano et al., 2008). While Tom70 had been described to only interact with substrates of the 
carrier pathway (1.5.3), recent evidence has shown that a dedicated groove of Tom70 can also bind presequences. It could be possible that a subset of presequence-containing proteins also uses Tom70 as a receptor (Melin et al., 2015). Both Tom20 and Tom70 function in quality control as they allow only proteins destined for mitochondria to enter (Dudek et al., 2013).

Upon recognition of the precursor protein, it is handed over from the Tom20-Tom 22 clamp to Tom5 (Dietmeier et al., 1997), prior to entry into mitochondria through the protein-conducting channel formed by the $\beta$-barrel protein Tom40 (Hill et al., 1998; Krimmer et al., 2001). Tom40 specifically interacts with the precursor protein and therefore actively facilitates its translocation through the outer membrane (Melin et al., 2014). The translocation is driven by both hydrophilic and hydrophobic interactions along the channel, most likely involving a hand-over mechanism with increasing affinity towards the IMS (Komiya et al., 1998). Once the presequence reaches the intermembrane space, it interacts again with the IMS domain of Tom 22 to further guide its import (Bolliger et al., 1995; Moczko et al., 1997).

All subunits described above are also present in human and the general principles are conserved (Kang et al., 2018). The subunits of the TOM complex are involved in signaling pathways, as well as disease, i.e. Parkinson's disease (Wiedemann \& Pfanner, 2017). This illustrates that mitochondrial import machineries can act as a sensor of mitochondrial fitness and, being on the outer membrane, the TOM complex is highly accessible to regulation by cytosolic factors (Harbauer et al., 2014).

\subsubsection{The organization of the TIM23 ${ }^{\text {sort }}$ complex}

Once presequence-carrying precursors emerge from the TOM complex, they are handed over to the translocase of the inner membrane, the TIM23 complex. This complex is present in dynamic stages, transporting proteins into the matrix or the inner membrane (Schulz et al., 2015; Wiedemann \& Pfanner, 2017). The core complex (TIM23 ${ }^{\text {core }}$ ) consists of the three essential inner membrane proteins; Tim23, its homolog Tim17, as well as Tim50 (Figure 1.5; Dekker et al., 1993; Geissler et al., 2002; Maarse et al., 1994; Mokranjac et al., 2003a; Yamamoto 
et al., 2002). The C-terminus of Tim 23 consists of four transmembrane domains within the inner membrane, which form a hydrophilic channel, allowing the precursor protein to pass (Truscott et al., 2001). When inactive, this pore is closed, which is mediated by the IMS domain of Tim50. In the presence of membrane potential, as well as a propeptide, the channel opens (Meinecke et al., 2006). Furthermore, Tim23 consists of a hydrophilic N-terminus, which is highly flexible and unstructured (de la Cruz et al., 2010). It not only binds incoming presequences, but also interacts with Tim50 ${ }^{\mathrm{IMS}}$ (Bauer et al., 1996; Geissler et al., 2002; Tamura et al., 2009). It has been pointed out that this interaction is essential for proper presequence binding (Tamura et al., 2009).

Tim50 has been termed the initial presequence receptor, as it exhibits a large hydrophilic domain in the IMS (Figure 1.5; Geissler et al., 2002; Mokranjac et al., 2003a; Yamamoto et al., 2002). Tim $50^{\mathrm{IMS}}$ interacts with Tom 22 and is therefore thought to be the first point of contact of the TIM23 complex with the presequence (Schulz et al., 2011; Shiota et al., 2011). Furthermore, it has two different binding sites for the precursor, a protein-binding domain Tim50 ${ }^{\mathrm{PBD}}$ and a core domain Tim50 core (Rahman et al., 2014).

Tim17 is analogous to Tim 23 and has been hypothesized to also constitute the channel (Figure 1.5; Kübrich et al., 1994; Maarse et al., 1994), where its C-terminus is essential in the formation of a twin-pore and its N-terminus regulates voltage gating (Martinez-Caballero et al., 2007). The exact composition of the pore has been disputed in the field. It has been shown that Tim 23 alone can form a channel in vitro as well as in vivo (Truscott et al., 2001). However, Tim17 contributes to the gating of the channel and has been shown to facilitate inner membrane sorting (Chacinska et al., 2005; Meier et al., 2005). Most likely, the channel is composed of a combination of 2 to 3 subunits of Tim23 and/or Tim17. Interestingly, it has also been hypothesized that the recently discovered small subunit, Mgr2, is a constituent of the channel (Schulz et al., 2015).

The small membrane protein Mgr2, possessing two transmembrane domains, couples Tim21 to the TIM23 complex and is required for efficient import at elevated temperatures (Figure 1.5; Gebert et al., 2012). Mgr2 has a C-terminal targeting sequence whose cleavage is necessary for 
proper assembly of TIM23 (Ieva et al., 2013). Mgr2 has been shown to act in quality control of the lateral release of inner membrane proteins by binding to the stop-transfer signal before release (Ieva et al., 2014). While its overexpression delays the inner membrane sorting of these proteins, its deletion leads to accelerated and erroneous sorting.

The dynamic subunit Tim 21 couples the TIM23 complex to Tom 22 of the TOM complex via its hydrophilic C-terminus (Albrecht et al., 2006; Chacinska et al., 2005; Shiota et al., 2011). Tim50 also binds to Tim21 in the absence of a precursor protein (Lytovchenko et al., 2013). Furthermore, Tim21 interacts with components of the respiratory chain (Qcr6 of complex III and with complex IV; Figure 1.5), placing TIM23 complex in proximity to regions of enhanced membrane potential to facilitate translocation. Moreover, this makes the translocase less vulnerable to membrane potential changes (van der Laan et al., 2006; Wiedemann et al., 2007).

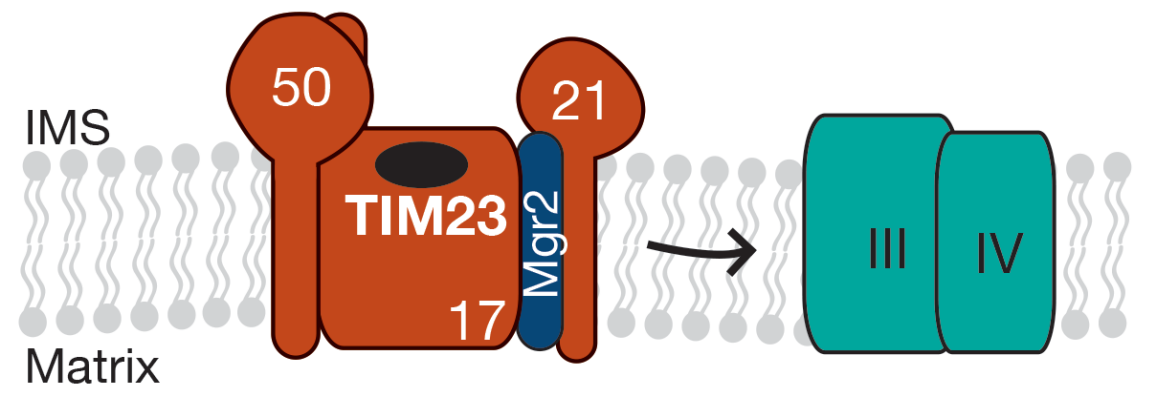

Fig. 1.5: Schematic depiction of the yeast TIM23 ${ }^{\text {sort }}$ complex. Tim 23 and Tim 17 form the channel, while Mgr2 couples Tim 21 and indirectly the respiratory chain to the translocase.

The human TIM23 complex has not been studied in comparable molecular detail to its yeast counterpart, even though, in recent years, it has also attracted more attention. However, many studies have focused on the components involved in disease (Demishtein-Zohary \& Azem, 2017; Kang et al., 2018; Sokol et al., 2014). In general, it is believed that core features of the yeast TIM23 complex are preserved in human while molecular details might differ substantially.

Human TIM50, for example, has been claimed to have catalytic phosphatase activity with a so far undetermined role (Guo et al., 2004). TIM23 has an ortholog termed TIM23B, which has two isoforms TIM23B1 and TIM23B2 (Table 1.1). Their sequence is fairly similar to TIM23, but 
their function is unknown (Prieto-Ruiz et al., 2018). Furthermore, Tim17 exists as two paralogs, TIM17A and TIM17B, where TIM17B has a further two isoforms, TIM17B1 and TIM17B2 (Figure 1.6; Table 1.1; Bauer et al., 1999). These are also described to be part of three distinct translocases, where TIM17B plays a more active role in import (Sinha et al., 2014). TIM17B is indispensable, constitutively expressed and has an essential role to maintain mitochondrial function, whereas TIM17A is thought to be dispensable, is variably expressed and is related to stress (Rainbolt et al., 2013; Sinha et al., 2014).

Table 1.1 Subunits of the TIM23 and PAM complexes in yeast and human

\begin{tabular}{|l|l|}
\hline Fungal components & Human components \\
\hline Tim23 & TIM23/TIM23B \\
\hline Tim17 & TIM17A, TIM17B \\
\hline Tim50 & TIM50 \\
\hline Tim44 & TIM44 \\
\hline Pam18 & DNAJC15/DNAJC19 \\
\hline Pam16 & Magmas \\
\hline mtHsp70 & Mortalin \\
\hline Mge1 & GrpE \\
\hline Pam17 & \\
\hline Tim21 & TIM21 \\
\hline Mgr2 & \\
\hline
\end{tabular}

TIM21 has been shown to be highly dynamically associated with the TIM23 complex, where it is dispensable for protein import (Mick et al., 2012). On the other hand, it is part of the inner membrane complex MITRAC (mitochondrial translation regulation assembly intermediate of cytochrome $c$ oxidase), which contains both mitochondrial- as well as nuclear-encoded subunits of the respiratory chain complex cytochrome $c$ oxidase. TIM21 shuttles between the translocase and MITRAC interacting with both nuclear- and mitochondrial-encoded subunits (Figure 1.6). It therefore links protein import to respiratory chain assembly as well as mitochondrial 
translation regulation (Mick et al., 2012). However, in contrast to yeast, there is no evidence so far for direct coupling between the TIM23 complex and the respiratory chain.

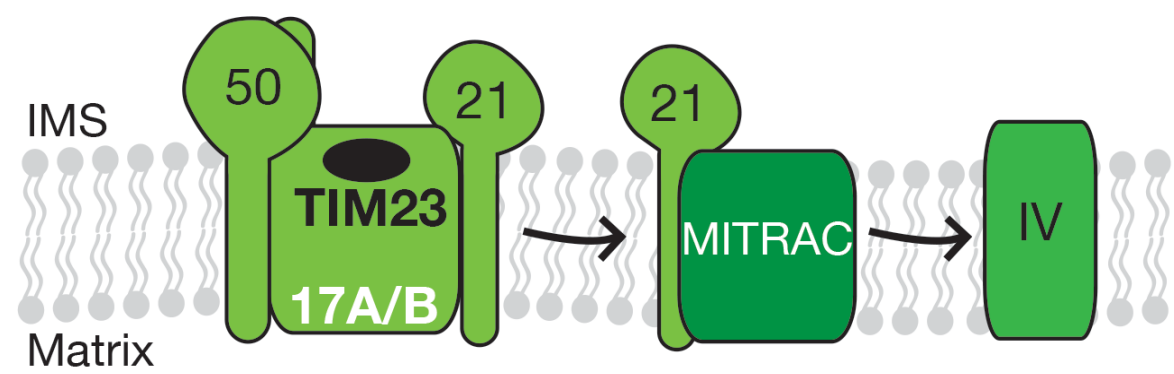

Fig. 1.6: Schematic depiction of the human TIM23 ${ }^{\text {sort }}$ complex. TIM17 exists as two paralogs TIM17A/B and TIM21 is highly dynamic. Besides the translocase, it also associates with the MITRAC complex, which links protein import to complex IV assembly.

\subsubsection{The organization of the PAM complex}

Precursor proteins destined for the mitochondrial matrix rely not only on the membrane potential but additionally on the activity of the presequence-associated motor (PAM complex), which uses energy derived from ATP hydrolysis for translocation (Schulz et al., 2015). The PAM complex consists of mtHsp70 (70-kDa mitochondrial heat shock protein), which is both the motor core and a chaperone that drives ATP-dependent translocation into the matrix (Horst et al., 1997; Kang et al., 1990; Schneider et al., 1994). The scaffolding protein, Tim44, is peripherally associated with the membrane and tethers and recruits Hsp70 to the translocase (Figure 1.7; Horst et al., 1993; Kronidou et al., 1994; Maarse et al., 1992).

The J-protein complex of Pam18 and Pam16 supports the function of mtHsp70 (Frazier et al., 2004; Kozany et al., 2004; Li et al., 2004; Mokranjac et al., 2003b; Truscott et al., 2003). Pam18 activates mtHsp70 and stimulates its ATP hydrolysis activity, which leads to closure of its protein binding pocket (Mokranjac et al., 2003b; Truscott et al., 2003). Pam16 on the other hand recruits and strongly interacts with Pam18 (Figure 1.7). It is able to regulate and also inhibit the function of Pam18 to stimulate ATP hydrolysis by mtHsp70 (Li et al., 2004). 
To recycle mtHsp70, ADP is replaced by the nucleotide exchange factor Mge1, which leads to the release of the bound preprotein (Laloraya et al., 1994; Miao et al., 1997; Voos et al., 1994). Finally, Pam17, another regulatory protein, acts in recruiting Pam18 and Pam16 to the complex and facilitates precursor transport (Schiller, 2009; van der Laan et al., 2005). Recently, another function of Pam17 has become apparent as it is recruited by Tim50 for a subclass of matrix proteins that are hypersensitive to the reduction of membrane potential (Schendzielorz et al., 2017).

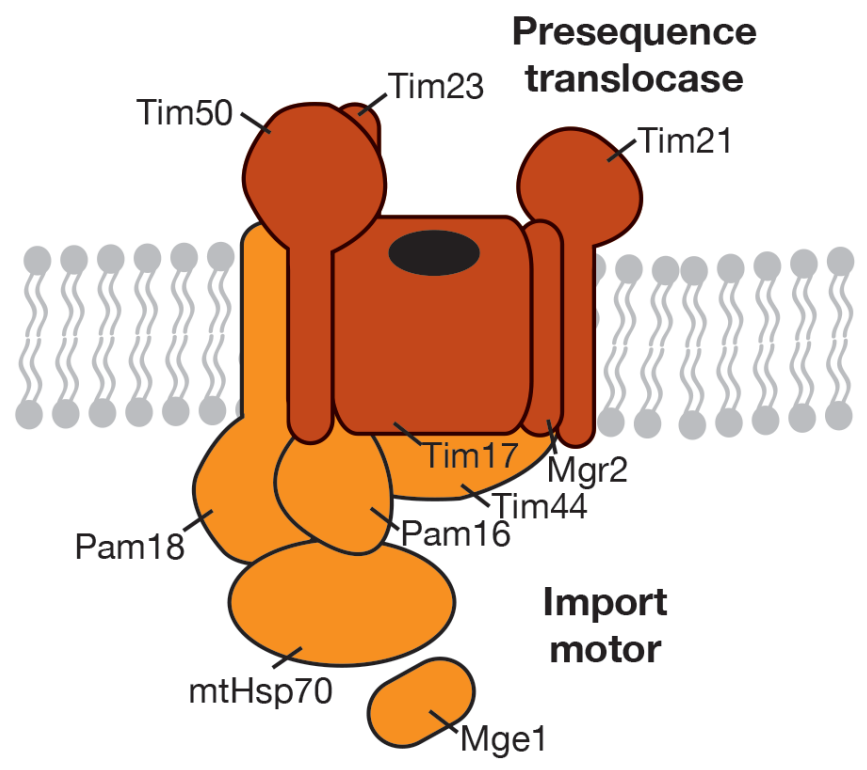

Fig. 1.7: Schematic depiction of the TIM23 motor complex. The Tim23 complex consists of Tim23, Tim17, Tim50, Tim21 and Mgr2. For the translocation of matrix targeted proteins, it associates with the PAM complex consisting of Pam18, Pam16, Tim44, mtHsp70 and Mge1.

It is believed that the components of the import motor are conserved in human even though not all players have been identified (Table 1.1; Sokol et al., 2014). Mortalin (human mtHsp70) is an ATPase that drives precursor import in the matrix, but is also present in the cytosol and the nucleus (Table 1.1; De Mena et al., 2009; Lu et al., 2011; Yaguchi et al., 2007). GrpE and Magmas have been described as the human orthologues of Mge1 and Pam16 respectively (Table 1.1; Kang et al., 2018), as Magmas also recruits J-proteins to the motor (Sinha et al., 2010). The J-proteins DNAJC15 and DNAJC19 have been proposed as Pam18 orthologues, however, only DNAJC15 can complement Pam18 in yeast and stimulate the activity of mortalin (Schusdziarra et al., 2013; 
Sinha et al., 2016). DNAJC19 has also been shown to interact with prohibitins and is involved in cardiolipin remodeling, linking the import motor in human to these extensive fields (RichterDennerlein et al., 2014).

\subsubsection{Transport through the TIM23 complex}

Since detailed mechanistic studies of the human TIM23 complex are still missing, the subsequent sections focus on advances made in S. cerevisiae. The membrane potential present across the inner membrane leads to a negative charge on the matrix side which drives initial translocation through the TIM23 complex, since its electrophoretic force acts on the positively charged presequence (Martin et al., 1991). As the presequence emerges from the TOM complex bound to Tom 22 ${ }^{\mathrm{IMS}}$, it interacts with high affinity with TIM50 ${ }^{\mathrm{IMS}}$ (Geissler et al., 2002; Mokranjac et al., 2009; Schulz et al., 2011; Yamamoto et al., 2002). In the current model, the amphipathic presequence is handed over from the Tim $50^{\mathrm{PBD}}$ and Tim $50^{\text {core }}$ to the IMS domain of Tim23, with which it interacts with low affinity. It is speculated that this reduced affinity allows the presequence to enter the channel (Rahman et al., 2014; Waegemann et al., 2015). Here, Tim50 is able to regulate the channel as its interaction with the presequence and Tim23 are separate and exclude each other (Schulz et al., 2011). The highly flexible N-terminal domain of Tim23 in the IMS serves multiple functions. By not only interacting with Tim50, but also with Tom22 and Tim21 (Bajaj et al., 2014; Tamura et al., 2009), it binds necessary components to keep TOM and TIM in tight connection and also allows for flexibility, given the variable nature of presequences. The cooperation of all these components facilitates the precursor's handover from the TOM complex into the import channel.

The channel of the TIM23 complex allows the passage of one $\alpha$-helix, since it is only approximately $13 \AA$ wide (Schwartz \& Matouschek, 1999; Truscott et al., 2001). Once the precursor enters the channel, its translocation is not only driven by the membrane potential, but also by the presence of matrix-located components, especially Tim44, to which it has a higher affinity as compared to Tim 23 or Tim50 (Figure 1.7; Marom et al., 2011). The precursor is bound by channel-forming Tim23, most likely by interactions with transmembrane domains 1 and 2 
(Alder et al., 2008; Pareek et al., 2013). Although Tim17 can also form a channel with Tim23, it does not bind the precursor, but is crucial in forming the proper channel structure (MartinezCaballero et al., 2007). The precursor then emerges on the matrix side, where its translocation is further driven by ATP hydrolysis.

\section{5.5.7 Transport by the PAM complex}

The PAM complex assists in the translocation of matrix-targeted proteins, as well as inner membrane proteins where the stop-transfer signal is not directly adjacent to the presequence (Bohnert et al., 2010; Gärtner et al., 1995). Once the presequence binds to Tim50, its interaction with Tim21 weakens leading to its dissociation. In turn, Pam17 is recruited which facilitates the PAM-dependent translocation into the matrix (Lytovchenko et al., 2013). The precursor emerging from the import channel immediately interacts with components of the PAM complex. First, Tim44 interacts with Tim23 and Tim17 to allow tight coupling (Figure 1.7; Banerjee et al., 2015; Ting et al., 2014). Tim44 then recruits mtHsp70 to the channel, which binds the precursor and undergoes multiple cycles of ATP hydrolysis, leading to release and rebinding (Kronidou et al., 1994; Liu et al., 2003). For this purpose, mtHsp70 contains a substrate binding domain on its C-terminus and a nucleotide binding domain on its $\mathrm{N}$-terminus, which is stimulated by J-proteins (Mayer \& Bukau, 2005). The exact mechanism of how this vectorial movement drives the precursor's transport into the matrix is not known, however, two models exist.

One model is called the Brownian ratchet, or trapping model in which the binding of mtHsp70 keeps the precursor simply from sliding back through the import channel. Subsequently, by Brownian motion, the precursor moves into the matrix until another mtHsp70 binds. Numerous mtHsp70 molecules undergoing constant cycles of ATP hydrolysis and ATP binding leads to the diffusion of the precursor into the matrix until it is fully translocated (De Los Rios et al., 2006). 
In contrast to the rather passive trapping model, mtHsp70 and its ATP cycle play a much more active role in the pulling model. Here, conformational changes of mtHsp70 upon ATP hydrolysis exert a pulling force that actively pulls the precursor into the matrix and allows another mtHsp70 molecule to bind, which carries on the inward directed force (Voisine et al., 1999). It is conceivable that a combination of both mechanisms exists, or that the exact mechanism depends on the substrate and its characteristics, i.e. how tightly it is folded (Geissler et al., 2001; Wiedemann \& Pfanner, 2017).

It should be noted that throughout precursor transport into the matrix, the constituents of the PAM complex are continuously remodeled. Co-chaperones and other regulatory proteins are recruited from a free pool to ensure continuous translocation (Schulz \& Rehling, 2014).

\subsubsection{Transport of inner membrane proteins along the sorting pathway}

The translocation of inner membrane proteins containing a hydrophobic stretch after the presequence is arrested upon recognition of the sorting signal (Botelho et al., 2011). Currently, it is thought that Mgr2 interacts with the sorting signal and acts in quality control for the lateral release (Ieva et al., 2014). While it is known that membrane potential is necessary for translocation across the inner membrane (van der Laan et al., 2007), it is not entirely clear if it is also necessary for sorting (Schulz et al., 2015). Tim21 is thought to position the TIM23 complex in the vicinity of high membrane potential, however, it dissociates upon the presequence entering into the channel and it is not required for lateral sorting (Lytovchenko et al., 2013; van der Laan et al., 2006). The current model states that just Tim23 and Tim17 are required for sorting, while the newly identified subunit Mgr2 assists in quality control (Chacinska et al., 2005; Ieva et al., 2014). However, the exact mechanism of release into the lipid bilayer remains to be elucidated. The idea of a putative lateral gate was proposed due to the $\alpha$ helices found in the channel components. Mgr2 functions in quality control while Tim17 facilitates the sorting process (Ieva et al., 2014; Schulz et al., 2015). 


\subsection{Aim of this work}

Protein import is crucial for mitochondrial biogenesis and function. While great mechanistic advances have been made in yeast it has also become obvious that mechanistic details might vary significantly between yeast and metazoan. It is conceivable that further proteins interact with the TIM23 complex to facilitate the lateral release or link the translocase to additional processes within the inner membrane (Schulz et al., 2015). ROMO1 (Reactive oxygen species modulator 1) has been described as the putative orthologue of Mgr2 (Kang et al., 2018). However, recent publications put ROMO1 in the center of ROS production, changes in inner membrane morphology and OPA1 processing (i.e. Chung et al., 2012; Chung et al., 2006; Norton et al., 2014). A bioinformatic analysis based on sequence analysis of the Tim 17 protein family grouped ROMO1 and its yeast orthologue Mgr2 with the Tim17 family, indicating involvement in protein import into mitochondria for both proteins. Their orthologues are found throughout eukaryotes, which gives further evidence of a conserved role (Žárský \& Dolezal, 2016). However, the role of ROMO1 in protein import has not been addressed experimentally, but could potentially provide a link to its observed phenotypes related to cristae structure and ROS production.

Mass spectrometric analyses showed that ROMO1 is part of the interactome of TIM21, TIM23 and TIM50 in HEK293T cells. This study focused on confirming ROMO1 as a TIM23 complex constituent and elucidating its mechanistic role on the translocase. Of special interest was whether ROMO1 acted in the lateral release similar to Mgr2 or if it had obtained a different function. For this purpose, a ROMO1 ${ }^{-}$cell line was generated, characterized biochemically and used for functional studies. Concomitantly, a transient knockdown approach was used to study dynamics at the translocase as well as import and assembly of nuclear-encoded proteins.

Furthermore, this work aimed to put the published results of OPA1 processing and inner membrane morphology into context and find their relationship to the TIM23 complex. This was done by mechanistic studies focusing on the relation between ROMO1 and OPA1-processing protease YME1L. 


\section{Materials and Methods}

\subsection{Materials}

\subsubsection{Chemicals}

Standard reagents were used at analytical grade purity and purchased from AppliChem (Darmstadt, Germany), Life Technologies (Grand Island, USA), Merck, Novagen and Calbiochem (Darmstadt, Germany), Roche (Mannheim, Germany), Roth (Karlsruhe, Germany), Serva (Heidelberg, Germany), Sigma-Aldrich (Taufkirchen, Germany), Thermo Scientific (Schwerte, Germany). Enzymes were purchased from Roche (Mannheim, Germany) and Invitrogen (Darmstadt, Germany). Standard lipids were purchased from Avanti Polar Lipids, Inc. (Alabaster, USA). A list of all chemicals used can be found in Table 2.1.

Table 2.1: List of Chemicals

\begin{tabular}{|l|l|}
\hline Chemical & Supplier \\
\hline${ }^{35}$ S]-L-methionine & $\begin{array}{l}\text { Hartmann Analytic (Braunschweig, } \\
\text { Germany) }\end{array}$ \\
\hline 2-Mercaptoethanol & Sigma-Aldrich \\
\hline 4- Nitro blue tetrazolium chloride & Roth \\
\hline 6-Aminocaproic acid & Sigma-Aldrich \\
\hline Acetic acid & Roth \\
\hline Acetone & Roth \\
\hline Acrylamide/bisacrylamide (37.5:1) solution & Roth \\
\hline Acrylamide, 2x crystallized & Roth \\
\hline Agarose NEEO ultra-quality & Roth \\
\hline Ampicillin & AppliChem \\
\hline Anti-FLAG M2 Affinity Gel & Sigma-Aldrich \\
\hline Antimycin A & Sigma-Aldrich \\
\hline ATP (Adenosine-5'-triphosphate) & Roche \\
\hline Bis-Tris Buffer grade & AppliChem \\
\hline Bovine serum albumin (BSA) & Sigma-Aldrich \\
\hline Bromophenol Blue & Merck \\
\hline Cardiolipin & Avanti \\
\hline
\end{tabular}




\begin{tabular}{|l|l|}
\hline Chloroform & Roth \\
\hline $\begin{array}{l}\text { COmplete, EDTA-free protease inhibitor } \\
\text { Tablet }\end{array}$ & Roche \\
\hline Coomassie Brilliant Blue G-250 & Serva \\
\hline Coomassie Brilliant Blue R-250 & Serva \\
\hline Copper(II)sulfate pentahydrate & Merck \\
\hline Creatine kinase & Roche \\
\hline Creatine phosphate & Roche \\
\hline Coomassie Brilliant Blue R-250 & Serva \\
\hline Cycloheximide & Applichem \\
\hline Cytochrome c & Calbiochem \\
\hline Diaminobenzidine & Sigma-Aldrich \\
\hline Digitonin & Calbiochem \\
\hline Dipotassium phosphate & Roth \\
\hline Disodium phosphate & Roth \\
\hline DMSO (dimethylsulfoxide) & Applichem \\
\hline EDTA & Roth \\
\hline EGTA & Roth \\
\hline Emetine dihydrochloride hydrate & Sigma-Aldrich \\
\hline Ethanol & Roth \\
\hline Ethidium Bromide (0.025\%) & Roth \\
\hline Fetal Bovine Serum & Biochrom \\
\hline GeneJuice & Merck \\
\hline Glucose & Roth \\
\hline Glutamine & Life Technologies \\
\hline Glycerol & Sigma-Aldrich \\
\hline Glycine & Roth \\
\hline HEPES & Roth \\
\hline Hydrochloric acid, 37\% & Roth \\
\hline Hydrogen peroxide & Sigma-Aldrich \\
\hline IgG from human serum & Sigma-Aldrich \\
\hline IgG protein standard & BioRad \\
\hline Imidazole & Roth \\
\hline Lipofectamine RNAiMAX & Invitrogen \\
\hline Magnesium acetate & Merck \\
\hline Magnesium chloride & Merck \\
\hline Magnesium sulfate & Applichem \\
\hline Malate & Sigma-Aldrich \\
\hline Mannitol & Roth \\
\hline Methanol & Roth \\
\hline Methionine & Roth \\
\hline MOPS & Roth \\
\hline NADH & Roche \\
\hline & \\
\hline
\end{tabular}




\begin{tabular}{|l|l|}
\hline $\begin{array}{l}\text { N,N-Methylenebisacrylamide, } \\
\text { 2x crystallized }\end{array}$ & Serva \\
\hline Oligomycin & Sigma \\
\hline o-phosphoric acid & Merck \\
\hline Opti-Mem & Life Technologies \\
\hline OrangeG & Sigma-Aldrich \\
\hline Oxaloacetic acid & Sigma-Aldrich \\
\hline Penicillin Streptomycin & Life Technologies \\
\hline Peptone & Roth \\
\hline Phenazine methosulfate & Sigma \\
\hline Phenol & Roth \\
\hline Phenol-Chloroform & Roth \\
\hline Phosphatidylcholine & Avanti \\
\hline Phosphatidylethanolamine & Avanti \\
\hline Phosphatidylglycerol & Avanti \\
\hline PMSF & Roth \\
\hline Potassium chloride & Roth \\
\hline Potassium cyanide & Sigma-Aldrich \\
\hline Potassium hydrogen phosphate & Merck \\
\hline Potassium dihydrogen phosphate & Roth \\
\hline Protein-A sepharose & GE Healthcare \\
\hline Proteinase K & Roche \\
\hline PVDF membrane (Immobilon-P) & Merck \\
\hline Roti-Quant reagent & Roth \\
\hline SDS (sodium dodecyl sulfate) & Serva \\
\hline SDS marker broad range & Biorad \\
\hline SDS-PAGE protein standard & Serva \\
\hline Sodium chloride & Roth \\
\hline Sodium hydroxide & Roth \\
\hline Sodium pyruvate & Sigma-Aldrich \\
\hline Sodium succinate & Sigma-Aldrich \\
\hline Sucrose & Roth \\
\hline Tetramethylethylenediamine (TEMED) & Roth \\
\hline Tetracycline hydrochloride & Sigma-Aldrich \\
\hline Trehalose & Roth \\
\hline Tricine & Roth \\
\hline Trichloroacetic acid & Roth \\
\hline Triethylamine & Roth \\
\hline Tris (tris(hydroxymethyl)aminomethane) & Roth \\
\hline Triton-X-100 & Roth \\
\hline Tween-20 & Roth \\
\hline Urea & Roth \\
\hline Uridine & Sigma-Aldrich \\
\hline & \\
\hline
\end{tabular}




\begin{tabular}{|l|l|}
\hline Valinomycin & Sigma-Aldrich \\
\hline Yeast extract & Roth \\
\hline
\end{tabular}

\subsubsection{Buffers and solutions}

Autoclaved deionized water was used unless otherwise stated to prepare buffers and solutions, which are given in Table 2.2 in $1 \mathrm{x}$ concentration. Where noted, solutions were filtered or autoclaved.

Table 2.2: Buffers and solutions

\begin{tabular}{|c|c|}
\hline Buffer & Components \\
\hline${ }^{35}$ S-labeling medium & $\begin{array}{l}\text { DMEM (Dulbecco's Modified Eagle Medium) } \\
\text { with or without fetal calf serum, without } \\
\text { sodium pyruvate, L-Glutamine, L-Methionine } \\
\text { and L-Cysteine (filtered) }\end{array}$ \\
\hline AVO mix & $\begin{array}{l}0.8 \mathrm{mM} \text { antimycin, } 0.1 \mathrm{mM} \text { valinomycin, } 2 \mathrm{mM} \\
\text { oligomycin in ethanol }\end{array}$ \\
\hline Blotting buffer & $\begin{array}{l}20 \mathrm{mM} \text { Tris, } 150 \mathrm{mM} \text { glycine, } 0.02 \% \text { SDS, } 20 \% \\
\text { methanol }\end{array}$ \\
\hline BN anode buffer & 50mM Bis-Tris/HCl pH 7.0 \\
\hline BN cathode buffer & $\begin{array}{l}50 \mathrm{mM} \text { Tricine, pH 7.0, } 15 \mathrm{mM} \text { Bis-Tris, with or } \\
\text { without } 0.02 \% \text { Coomassie Brilliant Blue G-250 }\end{array}$ \\
\hline BN gel buffer & $\begin{array}{l}\text { 66.67mM } 6 \text {-aminocaproic acid, 50mM Bis- } \\
\text { Tris/HCl pH } 7.0\end{array}$ \\
\hline BN sample loading buffer & $\begin{array}{l}\text { 0.5\% Coomassie Brilliant Blue G-250, 50mM 6- } \\
\text { aminocaproic acid, 10mM Bis-Tris, pH 7.0 }\end{array}$ \\
\hline BN solubilization buffer & $\begin{array}{l}1 \% \text { Digitonin, } 20 \mathrm{mM} \text { Tris/HCl } \mathrm{pH} 7.4,0.1 \mathrm{mM} \\
\text { EDTA, pH } 8,50 \mathrm{mM} \mathrm{NaCl}, 10 \% \text { Glycerol, } 1 \mathrm{mM} \\
\text { PMSF }\end{array}$ \\
\hline Cell culture medium & $\begin{array}{l}\text { DMEM (Dulbecco's Modified Eagle Medium) } \\
\text { supplemented with } 10 \%(\mathrm{v} / \mathrm{v}) \text { fetal calf serum } \\
\text { (FCS), } 1 \mathrm{mM} \text { sodium pyruvate, } 2 \mathrm{mM} \mathrm{L} \text { - } \\
\text { Glutamine, } 50 \mu \mathrm{g} / \mathrm{ml} \text { uridine and with or } \\
\text { without penicillin streptomycin (filtered) }\end{array}$ \\
\hline Coomassie staining solution & $\begin{array}{l}\text { 2.5g/L Coomassie Brilliant Blue R-250, 40\% } \\
\text { ethanol, } 10 \% \text { acetic acid }\end{array}$ \\
\hline Coomassie destaining solution & $40 \%$ ethanol, $10 \%$ acetic acid \\
\hline Hypertonic buffer & $\begin{array}{l}1.25 \mathrm{mM} \text { Sucrose, } 10 \mathrm{mM} \text { MOPS, } \mathrm{pH} 7.2 \\
\text { (filtered) }\end{array}$ \\
\hline Hypotonic buffer & $100 \mathrm{mM}$ Sucrose, $10 \mathrm{mM}$ MOPS, $\mathrm{pH} 7.2,1 \mathrm{mM}$ \\
\hline
\end{tabular}




\begin{tabular}{|c|c|}
\hline & EGTA (filtered) \\
\hline Lysogeny broth (LB medium) & $1 \% \mathrm{NaCl}, 0,5 \%$ yeast extract, $1 \%$ tryptone \\
\hline Import buffer & $\begin{array}{l}250 \mathrm{mM} \text { Sucrose, } 5 \mathrm{mM} \text { magnesium acetate, } \\
80 \mathrm{mM} \text { potassium acetate, } 5 \mathrm{mM} \text { methionine, } \\
10 \mathrm{mM} \text { sodium succinate, } 5 \mathrm{mM} \text { ATP, } 20 \mathrm{mM} \\
\text { Hepes, pH } 7.4\end{array}$ \\
\hline Isolation buffer & $\begin{array}{l}75 \mathrm{mM} \text { Mannitol, } 225 \mathrm{mM} \text { Sucrose, } 10 \mathrm{mM} \\
\text { MOPS, pH 7.2, 1mM EGTA (filtered) }\end{array}$ \\
\hline Potassium phosphate buffer, $\mathrm{pH} 7.4$ & $19 \% \mathrm{KH}_{2} \mathrm{PO}_{4}, 81 \% \mathrm{~K}_{2} \mathrm{HPO}_{4}$ \\
\hline PBS (phosphate-buffered saline) & $\begin{array}{l}137 \mathrm{mM} \mathrm{NaCl}, 2.7 \mathrm{mM} \mathrm{KCl}, 10 \mathrm{mM} \mathrm{Na}_{2} \mathrm{HPO}_{4} \text {, } \\
1.8 \mathrm{mM} \mathrm{KH}_{2} \mathrm{PO}_{4} \text { with or without } 1 \mathrm{mM} \mathrm{EDTA} \\
\text { (autoclaved) }\end{array}$ \\
\hline Resolving gel (BN-PAGE) & $\begin{array}{l}\text { 4-16.5\% acrylamide/bisacrylamide (49.5\%/3\%), } \\
\text { 1x BN gel buffer (see above), 2-30\% Glycerol }\end{array}$ \\
\hline Resolving gel (SDS-PAGE) & $\begin{array}{l}10-16 \% \text { acrylamide/bisacrylamide } \quad(30 \% \text {, } \\
37.5 / 1), 380 \mathrm{mM} \text { Tris- } \mathrm{HCl} \mathrm{pH} 8.8,0.1 \% \text { SDS }\end{array}$ \\
\hline Resolving gel (Tricine-SDS-PAGE) & $\begin{array}{l}\text { 10-18\% acrylamide/bisacrylamide }(49.5 \% / 3 \%) \text {, } \\
\text { 1x Tris-Tricine gel buffer (see below), } 0-13 \% \\
\text { glycerol }\end{array}$ \\
\hline Resolving gel (Urea-SDS-PAGE) & $\begin{array}{l}30 \% \text { acrylamide/bisacrylamide }(60 \% / 0.8 \%) \\
5.4 \mathrm{M} \text { urea, } 680 \mathrm{mM} \text { Tris- } \mathrm{HCl} \mathrm{pH} 8.8,8 \mathrm{mM} \\
\mathrm{NaCl}, 0.09 \% \text { SDS }\end{array}$ \\
\hline Stacking gel (BN-PAGE) & $\begin{array}{l}2 \% \text { acrylamide/bisacrylamide }(49.5 \% / 3 \%), 1 \mathrm{x} \\
\text { BN gel buffer (see above) }\end{array}$ \\
\hline Stacking gel (SDS-PAGE) & $\begin{array}{l}\text { 5\% acrylamide/bisacrylamide }(37.5 / 1), 80 \mathrm{mM} \\
\text { Tris-HCl pH 6.8, 0.1\% SDS }\end{array}$ \\
\hline Stacking gel (Tricine-SDS-PAGE) & $\begin{array}{l}4 \% \text { acrylamide/bisacrylamide ( } 49.5 \% / 3 \%), 1 \mathrm{x} \\
\text { Tris-Tricine gel buffer (see below) }\end{array}$ \\
\hline Stacking gel (Urea-SDS-PAGE) & $\begin{array}{l}9 \% \text { acrylamide/bisacrylamide }(60 \% / 0.8 \%), 3.6 \\
\text { M urea, } 100 \mathrm{mM} \text { Tris-HCl pH } 6.8,0.12 \% \text { SDS }\end{array}$ \\
\hline SDS running buffer & $25 \mathrm{mM}$ Tris, $192 \mathrm{mM}$ glycine, $0.1 \%$ SDS \\
\hline SDS sample buffer & $\begin{array}{l}10 \% \text { glycerol, } 2 \% \text { SDS, } 0.01 \% \text { bromophenol } \\
\text { blue, 60mM Tris/HCl pH 6.8, } 1 \% \text { beta- } \\
\text { mercaptoethanol }\end{array}$ \\
\hline SEM buffer & $\begin{array}{l}\text { 250mM sucrose, 1mM EDTA, 10mM EDTA, } \\
\text { pH } 7.2\end{array}$ \\
\hline TAE buffer & $40 \mathrm{mM}$ Tris/acetate $\mathrm{pH} 8.0,2 \mathrm{mM}$ EDTA \\
\hline TBS (Tris-buffered saline) & $20 \mathrm{mM}$ Tris/HCl, $\mathrm{pH} 7.5,125 \mathrm{mM} \mathrm{NaCl}$ \\
\hline TBS-T & $\begin{array}{l}20 \mathrm{mM} \text { Tris/ } \mathrm{HCl}, \mathrm{pH} 7.5,125 \mathrm{mM} \mathrm{NaCl}, 0.1 \% \\
\text { Tween-20 }\end{array}$ \\
\hline THE-buffer & $\begin{array}{l}10 \mathrm{mM} \text { Hepes, } 10 \mathrm{mM} \mathrm{KCl}, 300 \mathrm{mM} \text { trehalose } \\
\text { with or without } 0.1 \% \mathrm{BSA} \text { (filtered) }\end{array}$ \\
\hline Tris-Tricine anode buffer & $0.2 \mathrm{M}$ Tris, $\mathrm{pH} 8.9$ \\
\hline Tris-Tricine cathode buffer & 0.1M Tricine, $0.1 \mathrm{M}$ Tris, $0.1 \%$ SDS, $\mathrm{pH} 8.25$ \\
\hline
\end{tabular}




\begin{tabular}{|l|l|}
\hline Tris-Tricine gel buffer & $1 \mathrm{M}$ Tris, $0.1 \%$ SDS (autoclaved), $\mathrm{pH} 8.45$ \\
\hline Urea running buffer & $50 \mathrm{mM}$ Tris, $192 \mathrm{mM}$ glycine, $0.1 \%$ SDS \\
\hline YPD medium & $1 \%$ yeast extract, $2 \%$ peptone, $2 \%$ glucose \\
\hline
\end{tabular}

\subsubsection{Kits and disposables}

Commercial kits and disposables are listed in Table 2.3. Manufacturer's instructions were followed regarding usage and storage.

Table 2.3: Kits and disposables

\begin{tabular}{|c|c|}
\hline Product & Supplier \\
\hline Blotting paper & Heinemann Labortechnik \\
\hline $\begin{array}{l}\text { Complex IV Human Specific Activity Microplate } \\
\text { Assay Kit }\end{array}$ & abcam \\
\hline FastDigest restriction enzymes & Thermo Scientific \\
\hline Flexi ${ }^{\circledR}$ Rabbit Reticulocyte Lysate System & Promega \\
\hline GeneRuler DNA Ladder Mix & Fermentas \\
\hline KOD Hot Start DNA Polymerase & Novagen \\
\hline Microtube $1.5 \mathrm{~mL}$ and $2 \mathrm{~mL}$ & Sarstedt \\
\hline $\begin{array}{l}\text { MITOSOX } \\
\text { indicator for live-cell imaging }\end{array}$ & Invitrogen \\
\hline Pierce $^{\circ}$ ECL Western Blotting Detection Reagent & Thermo Scientific \\
\hline Pipette tips $10,200 \mu \mathrm{L}, 1 \mathrm{~mL}$ & Sarstedt \\
\hline $\begin{array}{l}\text { Precision Blue Protein }{ }^{\mathrm{TM}} \text { Standards All Blue (10 - } \\
250 \mathrm{kDa})\end{array}$ & BioRad \\
\hline Rapid DNA Ligation Kit & Thermo Scientific \\
\hline SP6 mMESSAGE mMACHINE ${ }^{\circledR}$ Kit & Ambion \\
\hline $\begin{array}{l}\text { TNT } \\
\text { system }\end{array}$ & Promega \\
\hline $\begin{array}{l}\text { Unstained SDS-PAGE Protein marker }(6.5 \text { - } \\
200 \mathrm{kDa})\end{array}$ & Serva \\
\hline $\begin{array}{l}\text { Wizard }{ }^{\circ} \text { Plus SV Gel and PCR DNA Purification } \\
\text { System }\end{array}$ & Promega \\
\hline Wizard ${ }^{\circledR}$ SV Plus Mini-Prep DNA Purification Kit & Promega \\
\hline X-ray films & $\begin{array}{l}\text { Foma Bohemia (Hradec Kralove, } \\
\text { Czech Republic) }\end{array}$ \\
\hline
\end{tabular}




\subsubsection{Equipment and instruments}

Laboratory equipment and instruments used in this study as well their suppliers are listed in Table 2.4.

Table 2.4: Equipment and instruments used

\begin{tabular}{|c|c|}
\hline Instrument & Supplier \\
\hline $5415 \mathrm{R}$ (centrifuge) & Eppendorf \\
\hline 5417 R (centrifuge) & Eppendorf \\
\hline 5424 (centrifuge) & Eppendorf \\
\hline 5804 R (centrifuge) & Eppendorf \\
\hline Cary 50 Bio UV-Visible Spectrophotometer & Varian \\
\hline Countess $^{\mathrm{TM}}$ automated cell counter & Thermo Scientific \\
\hline Curix 60 (developing machine) & AGFA \\
\hline Dounce homogenizer (glass-glass, BBI-8540705) & Sartorius \\
\hline EPS 601 power supply & GE Healthcare \\
\hline FACS Canto ${ }^{\mathrm{TM}} \mathrm{II}$ & BD Biosciences \\
\hline Fluorescence scanner FLAG-9000 & Fujifilm \\
\hline GeneAmp PCR System 9700 (thermo cycler) & Applied Biosystems \\
\hline GD-5040 vacuum gel dryer & Scie-Plas \\
\hline Heraeus $^{\oplus}$ Biofuge pico (centrifuge) & Thermo Scientific \\
\hline Heraeus ${ }^{\oplus}$ Hera cell 150 (incubator) & Thermo Scientific \\
\hline Heraeus ${ }^{\oplus}$ Hera safe (sterile hood) & Thermo Scientific \\
\hline Hoefer SE600 Ruby Blue native system & GE Healthcare \\
\hline HPTLC Silicagel $60 \mathrm{~F}_{254}$ glass plates & Merck \\
\hline Light microscope & Zeiss \\
\hline NanoVue ${ }^{\mathrm{TM}}$ Spectrophotometer & GE Healthcare \\
\hline Potter S (Dounce homogenizer) & Sartorius \\
\hline Semi Dry Blotting Chamber & PEQLAB Biotechnologie \\
\hline Storm ${ }^{\mathrm{TM}} 820$ Phosphoimager & GE Healthcare \\
\hline Storage Phosphor screen & GE Healthcare \\
\hline Synergy H1 microplate reader & BioTek \\
\hline Thermomixer comfort & Eppendorf \\
\hline Typhoon FLA 9500 Phosphoimager & GE Healthcare \\
\hline Universal 320 (centrifuge) & Hettich \\
\hline Vaccubrand ${ }^{\oplus} 2 \mathrm{C}$ Gel pump & Scie-Plas \\
\hline VortexGenie2 & Scientific Industries \\
\hline
\end{tabular}




\subsubsection{Software}

Table 2.5 lists software used for image processing or data analysis and documentation.

Table 2.5: Software used

\begin{tabular}{|l|l|}
\hline Software & Producer \\
\hline Microsoft Office & Microsoft \\
\hline Adobe Illustrator CS6 & Adobe \\
\hline Adobe Photoshop CS6 & Adobe \\
\hline Genious Pro & Biomatters Ltd. \\
\hline FiJi/ImageJ & OpenSource \\
\hline ImageQuant TL & GE Healthcare \\
\hline DataGraph & Visual Data Tools, Inc. \\
\hline
\end{tabular}

\subsubsection{Antibodies}

For protein detection, rabbit or mouse monoclonal/polyclonal antisera were used as primary antibodies listed in Table 2.6. For detection and amplification of the signal, secondary antibodies raised in goat against rabbit or mouse immunoglobulin coupled to HRP (horseradishperoxidase) or to an infrared dye were used (Table 2.7).

Table 2.6: Primary antibodies used

\begin{tabular}{|l|l|}
\hline Antibody & Source \\
\hline Rabbit polyclonal ANTI-AFG3L & Sigma, HPA004480 \\
\hline Mouse monoclonal ANTI-OPA1 & BD Biosciences, Cat\#612607 \\
\hline Rabbit polyclonal ANTI-ROMO1 & ProteinTech, Cat\#24200-1-AP \\
\hline Rabbit polyclonal ANTI-SDHA & Cell Signaling, \#5839 \\
\hline Rabbit polyclonal ANTI-TIM17A & ProteinTech, Cat\#11189-1-AP \\
\hline Rabbit polyclonal ANTI-YME1L & ProteinTech, Cat\#11510-1-AP \\
\hline Rabbit polyclonal ANTI-ATP5B & Home-made \\
\hline Rabbit polyclonal ANTI-COX1 & Home-made \\
\hline Rabbit polyclonal ANTI-COX4I-1 & Home-made \\
\hline Rabbit polyclonal ANTI-COX6A1 & Home-made \\
\hline Rabbit polyclonal ANTI-COX6C & Home-made \\
\hline
\end{tabular}




\begin{tabular}{|l|l|}
\hline Rabbit polyclonal ANTI-FLAG & Home-made \\
\hline Rabbit polyclonal ANTI-LETM1 & Home-made \\
\hline Rabbit polyclonal ANTI-MITRAC7 & Home-made \\
\hline Rabbit polyclonal ANTI-MITRAC12 & Home-made \\
\hline Rabbit polyclonal ANTI-NDUFA4 & Home-made \\
\hline Rabbit polyclonal ANTI-NDUFA9 & Home-made \\
\hline Rabbit polyclonal ANTI-NDUFA10 & Home-made \\
\hline Rabbit polyclonal ANTI-Rieske & Home-made \\
\hline Rabbit polyclonal ANTI-TIM21 & Home-made \\
\hline Rabbit polyclonal ANTI-TIM23 & Home-made \\
\hline Rabbit polyclonal ANTI-TIM50 & Home-made \\
\hline Rabbit polyclonal ANTI-TOM70 & Home-made \\
\hline Rabbit polyclonal ANTI-VDAC & Home-made \\
\hline Rabbit polyclonal ANTI-Aco1 & Home-made \\
\hline Rabbit polyclonal ANTI-Mgr2 & Home-made \\
\hline Rabbit polyclonal ANTI-Pcp1 & Home-made* \\
\hline Rabbit polyclonal ANTI-Tim23 & Home-made \\
\hline Rabbit polyclonal ANTI-Tim50 & Home-made \\
\hline Rabbit polyclonal ANTI-Ups2 & Home-made* \\
\hline Rabbit polyclonal ANTI-Yme1 & Home-made \\
\hline Rabbit polyclonal ANTI-Yta10 & Home-made \\
\hline Rabbit polyclonal ANTI-Yta12 & Home-made \\
\hline
\end{tabular}

${ }^{\star}$ kind gift by Thomas Langer, Cologne

Table 2.7: Secondary antibodies used

\begin{tabular}{|l|l|}
\hline Antibody & Source \\
\hline Goat anti-rabbit HRP & Dianova, Hamburg, Germany \\
\hline Goat anti-mouse HRP & Dianova, Hamburg, Germany \\
\hline Goat anti-rabbit IR880 & LI-COR, Lincoln, NE, USA \\
\hline Goat anti-mouse IR880 & LI-COR, Lincoln, NE, USA \\
\hline
\end{tabular}

\subsubsection{Cell lines}

Cell lines used in this study are listed in Table 2.8.

Table 2.8: Cell lines used

\begin{tabular}{|l|l|}
\hline Cell line & Source \\
\hline HEK293-Flp-In T-Rex WT & ThermoFisher Scientific, R78007 \\
\hline
\end{tabular}




\begin{tabular}{|l|l|}
\hline HEK293-Flp-In T-Rex ROMO1 & This study \\
\hline $\begin{array}{l}\text { HEK293-Flp-In T-Rex } \text { ROMO1 }^{-/-}+ \\
\text {ROMO1 }\end{array}$ & This study \\
\hline HEK293-Flp-In T-Rex-ROMO1 ${ }^{\text {FLAG }}$ & This study \\
\hline HEK293-Flp-In T-Rex-TIM21 & FLAG \\
\hline HEK293-Flp-In T-Rex-TIM23 & (Mick et al., 2012) \\
\hline
\end{tabular}

\subsubsection{Microorganisms}

The Saccharomyces cerevisiae strain YPH499 was used as wild-type strain. Genotype: MATa ura3-52 lys2-801amber ade2-101ochre trp1- $\Delta 63$ his3- $\Delta 200$ leu2- $\Delta 1$ (Sikorski \& Hieter, 1989). The Saccharomyces cerevisiae strain mgr2 $\Delta$ was used. Genotype: MAT1 ura3-52 lys2801amber ade2-101ochre trp1- $\Delta 63$ his3- $\Delta 200$ leu2- $\Delta 1$ mgr2::KANMX6 (Gebert et al., 2012).

E. coli strain XL1-Blue from Stratagene was used for cloning. Genotype: recA1 endA1 gyrA96 thi-1 hsdR17 supE44 relA1 lac [F' proAB laclqZ4M15 Tn10 (Tetr)].

\subsubsection{Oligonucleotides and plasmids}

All plasmids used were propagated in E. coli XL1 Blue and are listed in Table 2.9. Cloning was performed as described in section 2.2.2.7.

Table 2.9: Plasmids used

\begin{tabular}{|l|l|l|l|l|}
\hline Plasmid name & Purpose & Features & Marker & Reference \\
\hline pOG44 & $\begin{array}{l}\text { Flp- } \\
\text { Recombinase } \\
\text { Expression } \\
\text { Vector }\end{array}$ & CMV promoter & $\begin{array}{l}\text { Ampicillin } \\
\text { (Amp) }\end{array}$ & $\begin{array}{l}\text { Thermo } \\
\text { Fisher } \\
\text { Scientific }\end{array}$ \\
\hline pcDNA5/FRT/TO & $\begin{array}{l}\text { Genomic } \\
\text { integration } \\
\text { vector for } \\
\text { tetracycline- } \\
\text { inducible } \\
\text { expression of }\end{array}$ & CMV promoter & $\begin{array}{l}\text { Amp, } \\
\text { Hygromycin }\end{array}$ & $\begin{array}{l}\text { Fisher } \\
\text { Scientific }\end{array}$ \\
\hline
\end{tabular}




\begin{tabular}{|c|c|c|c|c|}
\hline & $\begin{array}{l}\text { proteins in } \\
\text { mammalian } \\
\text { cells }\end{array}$ & & & \\
\hline pTNT & $\begin{array}{l}\text { Vector for in } \\
\text { vitro } \\
\text { transcription } \\
\text { and } \\
\text { translation }\end{array}$ & SP6, T7 promoter & Amp & Promega \\
\hline pGEM4Z & $\begin{array}{l}\text { Vector for in } \\
\text { vitro } \\
\text { transcription } \\
\text { and } \\
\text { translation }\end{array}$ & SP6, T7 promoter & Amp & Promega \\
\hline pGEM4 & $\begin{array}{l}\text { Vector for in } \\
\text { vitro } \\
\text { transcription } \\
\text { and } \\
\text { translation }\end{array}$ & SP6, T7 promoter & Amp & Promega \\
\hline pX330 & $\begin{array}{l}\text { Expression } \\
\text { vector for } \\
\text { CRISPR/Cas9- } \\
\text { mediated gene } \\
\text { editing }\end{array}$ & U6 promoter & Amp & $\begin{array}{l}\text { Kind gift of } \\
\text { Stefan } \\
\text { Jakobs } \\
\text { (Göttingen) }\end{array}$ \\
\hline pEGFP-N1 & $\begin{array}{l}\text { Expression } \\
\text { vector of } \\
\text { EGFP used for } \\
\text { transient } \\
\text { transfections }\end{array}$ & CMV promoter & Kanamycin & $\begin{array}{l}\text { Clonetech } \\
\text { Laboratories }\end{array}$ \\
\hline $\begin{array}{l}\text { pX330-ROMO1- } \\
\text { CRISPR/Cas }\end{array}$ & $\begin{array}{l}\text { Expression } \\
\text { vector for } \\
\text { CRISPR/Cas9- } \\
\text { mediated } \\
\text { knockout of } \\
\text { ROMO1 }\end{array}$ & $\begin{array}{l}\text { Guide sequences } \\
\text { targeting ROMO1 } \\
\text { gene in pX330 }\end{array}$ & Amp & This study \\
\hline S02 & $\begin{array}{l}\text { in vitro } \\
\text { translation of } \\
\text { Su9(1-69)- } \\
\text { DHFR }\end{array}$ & $\begin{array}{l}\text { SP6 promoter, in } \\
\text { pGEM4x }\end{array}$ & Amp & $\begin{array}{l}\text { (Pfanner et } \\
\text { al., 1987) }\end{array}$ \\
\hline $\begin{array}{l}\text { pcDNA5/FRT/TO- } \\
\text { TIM23 } 3^{\text {FLAG }}\end{array}$ & $\begin{array}{l}\text { tetracycline- } \\
\text { inducible } \\
\text { expression of } \\
\text { TIM } 23^{\text {FLAG }}\end{array}$ & $\begin{array}{l}\text { TIM23 } 3^{\text {FLAG }} \text { in } \\
\text { pcDNA5/FRT/TO }\end{array}$ & $\begin{array}{l}\text { Amp, } \\
\text { Hygromycin }\end{array}$ & $\begin{array}{l}\text { (Mick et al., } \\
\text { 2012) }\end{array}$ \\
\hline $\begin{array}{l}\text { pcDNA5/FRT/TO- } \\
\text { TIM21 } 1^{\mathrm{FAAG}}\end{array}$ & $\begin{array}{l}\text { tetracycline- } \\
\text { inducible }\end{array}$ & $\begin{array}{l}\text { TIM21 } 1 \text { FLAG in } \\
\text { pcDNA5/FRT/TO }\end{array}$ & $\begin{array}{l}\text { Amp, } \\
\text { Hygromycin }\end{array}$ & $\begin{array}{l}\text { (Mick et al., } \\
\text { 2012) }\end{array}$ \\
\hline
\end{tabular}




\begin{tabular}{|c|c|c|c|c|}
\hline & $\begin{array}{l}\text { expression of } \\
\text { TIM } 21^{\text {FLAG }}\end{array}$ & & & \\
\hline $\begin{array}{l}\text { pcDNA5/FRT/TO- } \\
\text { ROMO1 }^{\text {FLAG }}\end{array}$ & $\begin{array}{l}\text { tetracycline- } \\
\text { inducible } \\
\text { expression of } \\
\text { ROMO1 }{ }^{\text {FLAG }}\end{array}$ & $\begin{array}{l}\text { ROMO1 }^{\mathrm{FLAG}} \text { in } \\
\text { pcDNA5/FRT/TO }\end{array}$ & $\begin{array}{l}\text { Amp, } \\
\text { Hygromycin }\end{array}$ & This study \\
\hline $\begin{array}{l}\text { pcDNA5/FRT/TO- } \\
\text { ROMO1 }\end{array}$ & $\begin{array}{l}\text { tetracycline- } \\
\text { inducible } \\
\text { expression of } \\
\text { ROMO1 }\end{array}$ & $\begin{array}{l}\text { ROMO1 in } \\
\text { pcDNA5/FRT/TO }\end{array}$ & $\begin{array}{l}\text { Amp, } \\
\text { Hygromycin }\end{array}$ & This study \\
\hline OTC & $\begin{array}{l}\text { in vitro } \\
\text { transcription } \\
\text { and } \\
\text { translation of } \\
\text { rat OTC }\end{array}$ & SP6 promoter & Amp & $\begin{array}{l}\text { (Mick et al., } \\
\text { 2012) }\end{array}$ \\
\hline pOTB7-COX6A1 & $\begin{array}{l}\text { in vitro } \\
\text { transcription } \\
\text { and } \\
\text { translation of } \\
\text { COX6A1 }\end{array}$ & $\begin{array}{l}\text { SP6 promoter, } \\
\text { COX6A1 in } \\
\text { pOTB7 }\end{array}$ & Chloramphenicol & $\begin{array}{l}\text { (Mick et al., } \\
\text { 2012) }\end{array}$ \\
\hline pOTB7-COX4I-1 & $\begin{array}{l}\text { in vitro } \\
\text { transcription } \\
\text { and } \\
\text { translation of } \\
\text { COX4I-1 }\end{array}$ & $\begin{array}{l}\text { SP6 promoter, } \\
\text { COX4I-1 in } \\
\text { pOTB7 }\end{array}$ & Chloramphenicol & $\begin{array}{l}\text { (Mick et al., } \\
2012 \text { ) }\end{array}$ \\
\hline pGEM4-YME1L & $\begin{array}{l}\text { in vitro } \\
\text { transcription } \\
\text { and } \\
\text { translation of } \\
\text { YME1L }\end{array}$ & $\begin{array}{l}\text { SP6 promoter, } \\
\text { YME1L in pGEM4 }\end{array}$ & Amp & $\begin{array}{l}\text { Kind gift of } \\
\text { Thomas } \\
\text { Langer } \\
\text { (Cologne) }\end{array}$ \\
\hline$\underset{613}{\text { pGEM4Z-YME1L }{ }^{1-}}$ & $\begin{array}{l}\text { in vitro } \\
\text { transcription } \\
\text { and } \\
\text { translation of } \\
\text { YME1L } \\
\end{array}$ & $\begin{array}{l}\text { SP6 promoter, } \\
\text { YME1L } 1 L^{1-613} \text { in } \\
\text { pGEM } 4 Z\end{array}$ & Amp & This study \\
\hline$\underset{529}{\text { pGEM4Z-YME1L }{ }^{1-}}$ & $\begin{array}{l}\text { in vitro } \\
\text { transcription } \\
\text { and } \\
\text { translation of } \\
\text { YME1L } L^{1-529}\end{array}$ & $\begin{array}{l}\text { SP6 promoter, } \\
\text { YME1L L-529 in } \\
\text { pGEM } 4 Z\end{array}$ & Amp & This study \\
\hline pTNT-YME1L ${ }^{1-395}$ & $\begin{array}{l}\text { in vitro } \\
\text { transcription } \\
\text { and }\end{array}$ & $\begin{array}{l}\text { SP6 promoter, } \\
\text { YME1L L-395 in } \\
\text { pTNT }\end{array}$ & Amp & This study \\
\hline
\end{tabular}




\begin{tabular}{|c|c|c|c|c|}
\hline & $\begin{array}{l}\text { translation of } \\
\text { YME1L } L^{1-395}\end{array}$ & & & \\
\hline $\begin{array}{l}\text { pTNT-YME1L } L^{1-238}- \\
\text { COX6A }^{140-59}- \\
\text { YME1L }^{260-716}\end{array}$ & $\begin{array}{l}\text { in vitro } \\
\text { transcription } \\
\text { and } \\
\text { translation of } \\
\text { YME1L }^{1-238_{-}} \\
\text {COX6A }^{140-59} \text { - } \\
\text { YME1L }^{260-716}\end{array}$ & $\begin{array}{l}\text { SP6 promoter, } \\
\text { YME1L } L^{1-238_{-}} \\
\text {COX6A }{ }^{140-59}- \\
\text { YME1L } L^{260-716} \text { in } \\
\text { pTNT }\end{array}$ & Amp & This study \\
\hline pTNT-LETM1 & $\begin{array}{l}\text { in vitro } \\
\text { transcription } \\
\text { and } \\
\text { translation of } \\
\text { LETM1 }\end{array}$ & $\begin{array}{l}\text { SP6 promoter, } \\
\text { LETM1 in pTNT }\end{array}$ & Amp & This study \\
\hline pTNT-COQ8A & $\begin{array}{l}\text { in vitro } \\
\text { transcription } \\
\text { and } \\
\text { translation of } \\
\text { COQ8A }\end{array}$ & $\begin{array}{l}\text { SP6 promoter, } \\
\text { COQ8A in pTNT }\end{array}$ & Amp & This study \\
\hline $\begin{array}{l}\text { pTNT-COX6A1 }{ }^{1-} \\
{ }^{25} \text {-YME1L } 151-716\end{array}$ & $\begin{array}{l}\text { in vitro } \\
\text { transcription } \\
\text { and } \\
\text { translation of } \\
\text { COX6A } 1^{1-25} \text { - } \\
\text { YME1L } 151-716\end{array}$ & $\begin{array}{l}\text { SP6 promoter, } \\
\text { COX6A1 } 1^{1-25} \text { - } \\
\text { YME1L }{ }^{151-716} \text { in } \\
\text { pTNT }\end{array}$ & Amp & This study \\
\hline $\begin{array}{l}\text { pTNT-YME1L } L^{1-151} \\
\text { COX6A } 1^{25-110}\end{array}$ & $\begin{array}{l}\text { in vitro } \\
\text { transcription } \\
\text { and } \\
\text { translation of } \\
\text { YME1L } L^{1-151} \text { - } \\
\text { COX6A } 1^{25-110}\end{array}$ & $\begin{array}{l}\text { SP6 promoter, } \\
\text { YME1L }{ }^{1-151} \text { - } \\
\text { COX6A } 1^{25-110} \text { in } \\
\text { pTNT }\end{array}$ & Amp & This study \\
\hline
\end{tabular}

Duplex oligonucleotides (siRNAs) were produced by Eurogentec (Liege, Belgium) and are listed in Table 2.10. siRNA transfections were performed as in section 2.2.1.5.

Table 2.10: siRNAs used

\begin{tabular}{|l|l|l|}
\hline Oligonucleotide & Sequence & Target/Function/Concentration \\
\hline siROMO1 & UCU-GUC-CCU-UCC-CAU- & $\begin{array}{l}\text { Sense siRNA for transiently } \\
\text { silencing ROMO1 (8.25nM) }\end{array}$ \\
\hline siYME1L & UUA-U & $\begin{array}{l}\text { Sense siRNA for transiently } \\
\text { silencing YME1L (33nM) }\end{array}$ \\
\hline
\end{tabular}


Non-targeting

Non-targeting control siRNA

Oligonucleotides used to generate plasmids for CRISPR/Cas9-mediated gene editing, sequencing primers, primers used for cloning or to generate DNA fragments for subsequent RNA synthesis were synthesized by Microsynth SEQLAB (Göttingen, Germany) and are listed in Table 2.11.

Table 2.11: Oligonucleotides used

\begin{tabular}{|c|c|c|}
\hline Oligonucleotide & Sequence & Target/Function \\
\hline FR1 & $\begin{array}{l}\text { CACCGTTCGTGATGGGTT } \\
\text { GCGCCGT }\end{array}$ & $\begin{array}{l}\text { Guide sequence } 1 \text { for CRISPR-Cas9 } \\
\text { targeting ROMO1 }\end{array}$ \\
\hline FR2 & $\begin{array}{l}\text { AAACACGGCGCAACCCAT } \\
\text { CACGAAC }\end{array}$ & $\begin{array}{l}\text { Complement to guide sequence } 1 \text { for } \\
\text { CRISPR-Cas9 targeting ROMO1 }\end{array}$ \\
\hline FR85 & $\begin{array}{l}\text { GCTACCCACTGATTTTCCT } \\
\text { TC }\end{array}$ & $\begin{array}{l}\text { Forward primer to amplify genomic } \\
\text { region of ROMO1 }\end{array}$ \\
\hline FR86 & $\begin{array}{l}\text { TGCTTTATCTCTGTATCCT } \\
\text { GTATCC }\end{array}$ & $\begin{array}{l}\text { Reverse primer to amplify genomic } \\
\text { region of ROMO1 }\end{array}$ \\
\hline FR88 & $\begin{array}{l}\text { TATAGTCGACTCATCTCAC } \\
\text { TTCCAACTTTTTCCCC }\end{array}$ & $\begin{array}{l}\text { Reverse primer to amplify open } \\
\text { reading frame of YME1L }\end{array}$ \\
\hline FR101 & $\begin{array}{l}\text { TATAGGTACCATGTTTTCC } \\
\text { TTGTCGAGCACGG }\end{array}$ & $\begin{array}{l}\text { Forward primer to amplify open } \\
\text { reading frame of YME1L }\end{array}$ \\
\hline FR102 & $\begin{array}{l}\text { TATATCTAGACTAAATATG } \\
\text { GTCGGTTCCAAATATAAG } \\
\text { C }\end{array}$ & Reverse primer to amplify YME1L $\mathrm{L}^{1-613}$ \\
\hline FR103 & $\begin{array}{l}\text { TATATCTAGACTACACACT } \\
\text { TCTTCTTTCAGGCCCC }\end{array}$ & o amplify Y \\
\hline FR113 & $\begin{array}{l}\text { TATAGCGGCCGCCTACAT } \\
\text { CATCATCATTGGAGATTCA } \\
\text { ATTCTCTTCCC }\end{array}$ & Reverse primer to amplify YME1L ${ }^{1-395}$ \\
\hline FR115 & $\begin{array}{l}\text { AGGTGAGAGTCAGACGGG } \\
\text { TTCGCCTTAGGG }\end{array}$ & $\begin{array}{l}\text { Reverse primer } 1 \text { to amplify YME1L }{ }^{1-} \\
{ }^{238} \text {-COX6A }{ }^{140-59}-{ }^{-} \text {ME1L }{ }^{260-71}\end{array}$ \\
\hline FR116 & $\begin{array}{l}\text { AACCCGTCTGACTCTCACC } \\
\text { TTCTTCGTCGC }\end{array}$ & $\begin{array}{l}\text { Forward primer } 2 \text { to amplify YME1L } \\
\text { 238-COX6A }{ }^{140-59} \text {-YME1L }{ }^{260-716}\end{array}$ \\
\hline FR117 & $\begin{array}{l}\text { TCCGGAAGCGCAGGTACA } \\
\text { CATTCAGCATGC }\end{array}$ & $\begin{array}{l}\text { Reverse primer } 2 \text { to amplify YME1L } \\
\text { 238-COX6A }{ }^{140-59} \text {-YME1L } \mathrm{L}^{260-716}\end{array}$ \\
\hline FR118 & $\begin{array}{l}\text { TGTGTACCTGCGCTTCCGG } \\
\text { ACAACAACAGG }\end{array}$ & $\begin{array}{l}\text { Forward primer } 3 \text { to amplify YME1L } \\
\text { 238-COX6A }{ }^{140-59} \text {-YME1L }{ }^{260-716}\end{array}$ \\
\hline FR119 & $\begin{array}{l}\text { TATAGGTACCATGGCGGT } \\
\text { AGTTGGTGTGTCC }\end{array}$ & $\begin{array}{l}\text { Forward primer } 1 \text { to amplify } \\
\text { COX6A1 1-25-YME1L L151-716 }\end{array}$ \\
\hline
\end{tabular}




\begin{tabular}{|c|c|c|}
\hline FR124 & $\begin{array}{l}\text { TATAGTCGACTTATTCATC } \\
\text { TTCGTAGCCAGTTGGA }\end{array}$ & $\begin{array}{l}\text { Reverse primer } 2 \text { to amplify YME1L }{ }^{1-} \\
{ }^{151}-\text { COX6A } 1^{25-110}\end{array}$ \\
\hline FR125 & $\begin{array}{l}\text { TATAGGTACCATGGCTGC } \\
\text { CATATTGGGAGACACC }\end{array}$ & $\begin{array}{l}\text { Forward primer to amplify open } \\
\text { reading frame of COQ8A }\end{array}$ \\
\hline FR126 & $\begin{array}{l}\text { TATAGTCGACCTACTGCTG } \\
\text { GGCCTGCCTCTTGC }\end{array}$ & $\begin{array}{l}\text { Reverse primer to amplify open } \\
\text { reading frame of COQ8A }\end{array}$ \\
\hline FR127 & $\begin{array}{l}\text { TATAGGTACCATGGCGTC } \\
\text { CATCTTACTGAGGAGCTG } \\
\text { C }\end{array}$ & $\begin{array}{l}\text { Forward primer to amplify open } \\
\text { reading frame of LETM1 }\end{array}$ \\
\hline FR128 & $\begin{array}{l}\text { TATAGTCGACCTAGCTCTT } \\
\text { CACCTCTGCGACCTCC }\end{array}$ & $\begin{array}{l}\text { Reverse primer to amplify open } \\
\text { reading frame of LETM1 }\end{array}$ \\
\hline FR135 & $\begin{array}{l}\text { GGCGCCACTCGAAAAACC } \\
\text { CCGAGACTGTAT }\end{array}$ & $\begin{array}{l}\text { Reverse primer } 1 \text { to amplify YME1L } \\
\text { 151-COX6A }{ }^{25-110}\end{array}$ \\
\hline FR136 & $\begin{array}{l}\text { TCTCGGGGTTTTTCGAGTG } \\
\text { GCGCCCATA }\end{array}$ & $\begin{array}{l}\text { Forward primer } 2 \text { to amplify YME1L } \\
\text { 151-COX6A } 1^{25-110}\end{array}$ \\
\hline FR137 & $\begin{array}{l}\text { AAAGTTTTAAACGACATA } \\
\text { GGCCGCCCCAG }\end{array}$ & $\begin{array}{l}\text { Reverse primer } 1 \text { to amplify COX6A1 } \\
{ }^{25} \text {-YME1L } L^{151-716}\end{array}$ \\
\hline FR138 & $\begin{array}{l}\text { GCGGCCTATGTCGTTTAA } \\
\text { AACTTTGAAATC }\end{array}$ & $\begin{array}{l}\text { Forward primer } 2 \text { to amplify } \\
\text { COX6A1 1-25-YME1L } \text { L }^{151-716}\end{array}$ \\
\hline priJD189 & $\begin{array}{l}\text { AGAAGAGAATTCTCGATT } \\
\text { TAGGTGACACTATAGAAT } \\
\text { ACGCCGCCGCCATGGCGT } \\
\text { CCGGAGCGGC }\end{array}$ & $\begin{array}{l}\text { Forward primer to amplify open } \\
\text { reading frame of EMRE }\end{array}$ \\
\hline priJD190 & $\begin{array}{l}\text { ATAAGAGTCGACTTACAT } \\
\text { GTCATCATCATCATCATCC } \\
\text { TC }\end{array}$ & $\begin{array}{l}\text { Reverse primer to amplify open } \\
\text { reading frame of EMRE }\end{array}$ \\
\hline SD155 & $\begin{array}{l}\text { TATAAAGCTTATGCCGGT } \\
\text { GGCCGTGGGTC }\end{array}$ & $\begin{array}{l}\text { Forward primer to amplify open } \\
\text { reading frame of ROMO1 }\end{array}$ \\
\hline SD156 & $\begin{array}{l}\text { TATAGGATCCTTACTTGTC } \\
\text { ATCGTCGTCCTTGTAGTCG } \\
\text { CATCGGATGCCCATCCCA } \\
\text { ATG }\end{array}$ & Reverse primer to amplify ROMO1 ${ }^{\mathrm{FLAG}}$ \\
\hline SD333 & $\begin{array}{l}\text { TATAGGATCCTTAGCATCG } \\
\text { GATGCCCATCCCAATG }\end{array}$ & $\begin{array}{l}\text { Reverse primer to amplify open } \\
\text { reading frame of ROMO1 }\end{array}$ \\
\hline
\end{tabular}




\subsection{Methods}

\subsubsection{Human cell culture and preparation of mitochondria}

\subsubsection{Cultivation of human cells}

Human embryonic kidney cell lines (HEK293-Flp-In T-Rex; HEK293T) were cultured in DMEM (Dulbecco's Modified Eagle Medium) supplemented as described in Table 2.2 under a $5 \% \mathrm{CO}_{2}$ humidified atmosphere at $37^{\circ} \mathrm{C}$. To passage the cells, the medium was removed and sterile PBS was added to detach the cells. Once detached, an equal volume of medium was added and cells were centrifuged at $1500 \mathrm{rpm}$ for 5-10 minutes at room temperature. Containers with medium were prepared and the obtained cell pellet was resuspended in a small volume of fresh medium. Then, the appropriate amount of cell suspension was added to the container. Cells were harvested in PBS as before and centrifuged at $4600 \mathrm{rpm}$ for 15 minutes at $4^{\circ} \mathrm{C}$. Obtained pellets were frozen or processed right away.

\subsubsection{Cytosolic inhibition by emetine}

To study effects on protein levels upon inhibition of cytosolic translation, cells were seeded into containers a day before. Medium was supplemented with $20 \mu \mathrm{g} / \mathrm{mL}$ emetine dihydrochloride hydrate dissolved in medium for 1-5 hours. Cells were harvested, mitochondria were isolated (2.2.1.8) and protein levels were analyzed by SDS-PAGE and immunoblotting (2.2.3.2 and 2.2.3.8).

\subsubsection{Generation of stable cell lines}

Stable HEK293T cell lines were generated as described previously (Mick et al., 2012). Prior to transfection, cells were seeded into wells of a six well plate until confluency of $40-50 \%$ was 
reached. GeneJuice was used as a transfection reagent and the manufacturer's instructions were followed. Briefly, $100 \mu \mathrm{L}$ Opti-Mem and $5 \mu \mathrm{L}$ GeneJuice were mixed and incubated for 5 minutes at room temperature. Then $400 \mathrm{ng}$ of pcDNA5/FRT/TO plasmid and 1000ng of pOG44 were added, mixed and let stand for 20 minutes. Subsequently, $600 \mu \mathrm{L}$ of medium without antibiotics were added, to the transfection mix cells were retrieved, medium covering the cells removed and the transfection mix applied. After 2-3 hours, $2 \mathrm{~mL}$ of medium were added. Hygromycin $(100 \mu \mathrm{g} / \mathrm{mL})$ was applied two to three days later for selection. Single clones were selected and expanded and screened for the presence of described proteins by immunoblotting.

\subsubsection{Generation of knockout cell lines}

HEK293T cells lacking ROMO1 were generated using CRISPR/Cas9 genome editing (Ran et al., 2013). Using the CRISPR Design tool (http://crispr.mit.edu), guide sequences targeting the ROMO1 gene were obtained and appropriate oligonucleotides were ordered (Table 2.11). $100 \mu \mathrm{M}$ of each oligonucleotide $(5 \mu \mathrm{L})$ were mixed with $10 \mu \mathrm{L} 5 \mathrm{x}$ ligase buffer (Rapid DNA Ligation Kit, Thermo Scientific) and $30 \mu \mathrm{L} \mathrm{ddH}_{2} \mathrm{O}$ and annealed at $95^{\circ} \mathrm{C}$ for 5 minutes to form a duplex. Then, the temperature was decreased by $5^{\circ} \mathrm{C} / \mathrm{min}$ until $20^{\circ} \mathrm{C}$ were reached. Using the restriction enzyme BbsI (Thermo Scientific), the pX330 vector was digested following the instructions given and then purified with the Wizard ${ }^{\circ}$ Plus SV Gel and PCR DNA Purification System (Promega). $2 \mu \mathrm{L}$ of the annealed oligonucleotides were ligated into 50ng of the digested vector. Following transformation into XL1-Blue E. coli competent cells, plasmid purification followed with the Wizard ${ }^{\star}$ SV Plus Mini-Prep DNA Purification Kit (Promega) and the successful cloning was analyzed by sequencing.

24 hours prior to transient transfection, HEK293T WT cells were seeded into wells of a six well plate. For the transfection reaction $100 \mu \mathrm{L}$ Opti-MEM and $5 \mu \mathrm{L}$ GeneJuice were mixed and incubated at room temperature for 5 minutes before $2 \mu \mathrm{g}$ of pX330-ROMO1-CRISPR/Cas and $400 \mathrm{ng}$ of pEGFP-N1 were added and incubated at room temperature for 20 minutes. Subsequently, it was mixed with $600 \mu \mathrm{L}$ medium, medium from cells was removed and it was 
added to the cells drop by drop. After $2-3$ hours in $37^{\circ} \mathrm{C}, 2 \mathrm{~mL}$ of medium were added and incubation continued.

Three days after the transfection, cells were harvested using PBS and centrifugation and kept at $37^{\circ} \mathrm{C}$. In collaboration with Sandra Becker of the University Medical Center Göttingen Cell Sorting Facility, single GFP-positive cells were sorted by a FACS Vantage SE into a 96 well plate. Clones were expanded and screened by immunoblotting for loss of ROMO1. Additionally, genomic DNA was extracted (2.2.1.7), the open reading frame was amplified by PCR and sequenced.

\subsubsection{5 siRNA treatment}

One day prior to siRNA treatment, cells were harvested as described above and seeded back to ensure exponential growth phase one day later. Approximately 24 hours later, cells were harvested and diluted in cell culture medium without antibiotics. Cells were counted using a Neubauer chamber. siRNA oligonucleotides were purchased from Eurogentec and Lipofectamine RNAiMAX was used as transfection reagent following manufacturer's instructions. Briefly, the transfection mix was prepared given exemplified here for 800,000 cells and a final concentration of siRNA of $8.25 \mathrm{nM}: 20 \mu \mathrm{M}$ siRNA: $3.2 \mu \mathrm{L}$, Lipofectamine RNAiMAX: $6.4 \mu \mathrm{L}$, OptiMem: $1600 \mu \mathrm{L}$ carefully mixed and incubated for 20 minutes. Subsequently, cells were added to the mixture, carefully mixed and added to a flask filled with medium $(6.4 \mathrm{~mL}-$ volume of cells). Cells were incubated at $37^{\circ} \mathrm{C}$ under a $5 \% \mathrm{CO}_{2}$ humidified atmosphere for 72 hours.

\subsubsection{Assessing cell growth}

Cell growth was measured by trypan blue exclusion assay. Cells were seeded at an initial number of $2 \times 10^{5}$ in wells of a 6 well plate and harvested after one, two or three days. Cell pellet was resuspended in PBS, stained with 0.04\% trypan blue (Life Technologies) and counted using 
Countess $^{\mathrm{TM}}$ automated cell counter (Thermo Scientific). Three technical and experimental replicates were performed.

\subsubsection{Extraction of genomic DNA}

HEK293 ROMO1- ${ }^{-/}$cells were seeded into wells of a six well plate and harvested upon reaching confluence. Cell pellets were resuspended in $400 \mu \mathrm{L}$ TE buffer (10mM Tris, pH 7.4, 1mM EDTA, $\mathrm{pH} 8$ ) and SDS was added to a final concentration of $1 \%$. Subsequently, $50 \mu \mathrm{L}$ proteinase $\mathrm{K}$ $\left(20 \mathrm{mg} / \mathrm{mL}\right.$ in TE buffer) were added and the cells were incubated at $800 \mathrm{rpm}, 37^{\circ} \mathrm{C}$, overnight. $500 \mu \mathrm{L}$ of the lower phase of phenol were added to the clear lysate and the mixture was vortexed for one minute followed by centrifugation at 3000rpm for 5 minutes at room temperature. The upper phase was carefully transferred into a new tube and $500 \mu \mathrm{L}$ of the lower phase of phenolchloroform were added followed by 1 minute of vortexing. Upon a 5-minute centrifugation step at $3000 \mathrm{rpm}$, this was repeated. Then, $500 \mu \mathrm{L}$ of chloroform were added, vortexed for one minute, centrifuged as before and the upper clear phase was transferred into a new tube. Upon the addition of two volumes of cold $100 \%$ ethanol and gentle mixing incubation at $-80^{\circ} \mathrm{C}$ overnight followed. Precipitated genomic DNA was harvested by centrifugation at maximum speed for 30 minutes, pellet was dried and resuspended in $\mathrm{dd}_{2} \mathrm{O}$.

\subsubsection{Isolation of mitochondria I}

Mitochondria were isolated similar to as described before (Lazarou et al., 2009; Mick et al., 2012). Harvested cells were resuspended in cold THE-buffer (Table 2.2) containing 0.1\% BSA and transferred into a cooled Dounce homogenizer. To homogenize the cells, the potter passed through the solution 30 times at $700 \mathrm{U} / \mathrm{min}$. Debris and unopened cells were removed by centrifugation at $400 \mathrm{x}$ g for 10 minutes and the supernatant was saved. The pellet was resuspended again, homogenized and centrifuged as before. Both supernatants were pooled and centrifuged for 7 minutes at $800 \mathrm{x}$ g to remove debris and mitochondria were collected by centrifugation at 10,000 $\mathrm{x}$ for 10 minutes. The obtained mitochondrial pellet was resuspended 
in THE-buffer without BSA and centrifuged at $10,000 \mathrm{x} \mathrm{g}$ for 5 minutes. The isolated mitochondria were resuspended again and directly used for experiments or shock frozen and stored at $-80^{\circ} \mathrm{C}$.

\subsubsection{Isolation of mitochondria II}

In case isolated mitochondria were used for subsequent import reactions or small amounts of cells were used, a different protocol for the isolation of mitochondria was followed based on Panov, 2013. Cells were harvested in PBS at $1000 \mathrm{x}$ g for 5 minutes at $4^{\circ} \mathrm{C}$. Cells were then resuspended in cold isolation buffer (Table 2.2) with 2mM PMSF and centrifuged again. Pellets were weighed and cells were incubated in cold hypotonic buffer with 2mM PMSF for 7 minutes (5mL/1g cells). Subsequently, cells were gently homogenized 10-15 times in Dounce homogenizer (glass-glass) if used for import experiments, otherwise homogenized 25-30 times. Cold hypertonic buffer $(1.1 \mathrm{~mL} / 5 \mathrm{~mL})$ was added to homogenized cells before the volume was

tripled with isolation buffer containing $2 \mathrm{mM}$ PMSF and $2 \mathrm{mg} / \mathrm{mL}$ BSA. Suspension was centrifuged at $1000 \mathrm{x} \mathrm{g} / 10 \mathrm{~min} / 4^{\circ} \mathrm{C}$. The supernatant was again centrifuged and then divided into $2 \mathrm{~mL}$ tubes. After centrifugation at $10,000 \mathrm{x} \mathrm{g} / 10 \mathrm{~min} / 4^{\circ} \mathrm{C}$, pellets were resuspended in isolation buffer without PMSF and fractions were pooled. After another centrifugation step, harvested crude mitochondrial extracts were resuspended in isolation buffer and the protein concentration was determined (2.2.3.1). Mitochondria were used directly for experiments, i.e. import, or shock frozen and stored at $-80^{\circ} \mathrm{C}$.

\subsubsection{Molecular Biology techniques}

\subsubsection{Cultivation of $E$. coli}

E. coli were grown and cultivated in liquid culture according to standard procedures using LB medium (lysogeny broth) (Green \& Sambrook, 2012) or on plates (15g/L agar). Ampicillin or 
Chloramphenicol were used as selection markers at concentrations of $0.1 \mathrm{~g} / \mathrm{L}$ or $0.025 \mathrm{~g} / \mathrm{L}$ respectively. For storage of plasmids, $800 \mu \mathrm{L}$ of an E. coli overnight culture with the respective plasmid in selective medium were mixed with $200 \mu \mathrm{L}$ sterile $80 \%$ glycerol in a cryo vial and frozen at $-80^{\circ} \mathrm{C}$.

\subsubsection{Transformation of $E$. coli via heat shock}

Competent cells were defrosted on ice and carefully mixed with 100-200ng of plasmid DNA or $6 \mu \mathrm{L}$ of ligation reaction. After incubation of 30 minutes on ice, cells and DNA were heat shocked to $42^{\circ} \mathrm{C}$ for 50 seconds and subsequently put on ice for 3 minutes. $300 \mu \mathrm{L}$ of warm, antibioticfree LB medium were added and the mixture was incubated shaking for one hour at $37^{\circ} \mathrm{C}$. Transformation mixture was plated on agar plates with the appropriate selection antibiotics and incubated at $37^{\circ} \mathrm{C}$ overnight until single colonies appeared.

\subsubsection{Isolation of plasmid DNA from E. coli}

The Wizard ${ }^{\circledR}$ SV Plus Mini-Prep DNA Purification Kit by Promega was used to isolate plasmid DNA from E. coli. Instructions by the manufacturer were followed. In brief, cells in $3 \mathrm{~mL}$ of an overnight liquid culture were harvested ( $5000 \mathrm{xg}, 5 \mathrm{~min}$ ) at room temperature and resuspended in $250 \mu \mathrm{L}$ resuspension buffer. Cells were lysed by adding $250 \mu \mathrm{L}$ lysis buffer and inverting the sample four times. Upon clearance of the lysate, $10 \mu \mathrm{L}$ alkaline protease were added, mixed again and incubated for 5 minutes. $350 \mu \mathrm{L}$ neutralization buffer were added, mixed again and immediately centrifuged at $16,000 \mathrm{xg}$ for 10 minutes. The cleared lysate was transferred into a spin column and centrifuged for $1 \mathrm{~min}$ at $16,000 \mathrm{x}$ g. Subsequently, columns were washed by centrifugation with $750 \mu \mathrm{L}$ and $250 \mu \mathrm{L}$ of wash solution and briefly dried on air. To elute isolated plasmid DNA, $60 \mu \mathrm{L}$ of water were applied onto the filter followed by one minute of incubation. Finally, the spin column was centrifuged for one minute at $16,000 \mathrm{xg}$, the DNA concentration was measured and the DNA was stored at $-20^{\circ} \mathrm{C}$. 


\subsubsection{Polymerase chain reaction (PCR)}

DNA fragments were amplified using the KOD Hot Start DNA Polymerase kit following the instructions given by the manufacturer. The reaction mixture contained $1 \mathrm{x}$ KOD reaction buffer, cDNA or plasmid as template, $0.2 \mathrm{mM}$ dNTPs, $1 \mathrm{mM} \mathrm{MgSO}_{4}, 0.3 \mu \mathrm{M}$ forward and reverse

primers and 1 unit of KOD DNA polymerase in a total volume of $50 \mu \mathrm{L}$. PCR conditions were $2-3$ minutes at $95^{\circ} \mathrm{C}$ followed by 35 cycles of $95^{\circ} \mathrm{C}\left(10^{\prime \prime}\right)$, annealing for 10 seconds at $48^{\circ}-55^{\circ} \mathrm{C}$ (depending on primers used) and 15-120 seconds (depending on product size) at $70^{\circ} \mathrm{C}$ for elongation. PCR products were stored at $4^{\circ} \mathrm{C}$.

\subsubsection{Agarose gel electrophoresis}

Agarose gel electrophoresis was carried out to confirm the presence of a specific product of the correct size after PCR amplification. To cast a 1\% agarose gel, dry agarose was dissolved in TAE buffer (Table 2.2) under gentle heating and mixing and the solution was left to cool. Ethidium bromide was added to a final concentration of $1 \mu \mathrm{g} / \mathrm{mL}$ and the gel solidified. $4 \mu \mathrm{L}$ of the PCR reaction were mixed with $5 \mu \mathrm{L}$ of $50 \%$ glycerol and loaded onto the gel along with DNA ladder mix “Gene Ruler” in a separate lane. After the run, DNA fragments were visualized by UV-light.

\subsubsection{Purification of PCR products}

PCR products were purified using the Wizard ${ }^{\oplus}$ Plus SV Gel and PCR DNA Purification System following the given instructions. $400 \mu \mathrm{L}$ of membrane-binding buffer were carefully mixed with the PCR and transferred to the provided column. If multiple products had formed, the correct band was excised from the gel, mixed with membrane binding buffer, heated until dissolved and transferred to the provided column. The minicolumn was centrifuged for 1 minute at 13200 rpm, the flow-through was discarded and $750 \mu \mathrm{L}$ of wash solution were added. After another spin, columns were washed again with $250 \mu \mathrm{L}$ wash solution. After centrifugation at $13200 \mathrm{rpm}$ for one minute, 5-minute centrifugation at top speed followed. Remaining ethanol was allowed 
to evaporate by transferring the column to an RNase free tube and incubation at room temperature for three minutes. To elute, $50 \mu \mathrm{L}$ nuclease free water were added and incubated for two minutes at room temperature. The purified PCR product was collected via spinning at 13200 rpm for two minutes and DNA was quantified using a NanoVue ${ }^{\mathrm{TM}}$ Spectrophotometer.

\subsubsection{Cloning}

To insert purified PCR products into plasmids, standard procedures by Green \& Sambrook (2012) were followed. Both underwent restriction digest using restriction enzymes (FastDigest; Thermo Scientific) in a reaction of $20 \mu \mathrm{L}(16 \mu \mathrm{L}$ PCR reaction, $1 \mu \mathrm{L}$ of each enzyme and $1 \mathrm{x}$ FastDigest buffer). The reaction was incubated for 30 minutes at $37^{\circ} \mathrm{C}$ under mild agitation (450rpm). The digested plasmid further underwent dephosphorylation using $1 \mu \mathrm{L}$ of alkaline phosphatase in $1 \mathrm{x}$ phosphatase buffer during 45 minutes at $37^{\circ} \mathrm{C}$ at $450 \mathrm{rpm}$. Following cleanup just as for PCR reactions (2.2.2.6), digested inserts and plasmids were ligated using the Rapid DNA Ligation Kit (Thermo Scientific): 60ng of digested PCR product were mixed with $1.5 \mu \mathrm{L}$ of digested vector as well as $1 \mathrm{x}$ ligation buffer and $1 \mu \mathrm{L}$ T4 DNA ligase in $20 \mu \mathrm{L}$. After incubation for 30 minutes at $22^{\circ} \mathrm{C}$ at $450 \mathrm{rpm}$ agitation, transformation into $50 \mu \mathrm{L}$ XL1 Blue E. coli cells via heat shock followed (2.2.2.2). Upon plasmid isolation from grown colonies (2.2.2.3), cloned constructs were tested by restriction digest followed by agarose gel electrophoresis and sequencing (SEQLAB, Göttingen, Germany).

\subsubsection{In vitro mutagenesis}

In order to introduce point mutations into purified plasmids, partially overlapping primers harboring the desired mutations were designed according to Zheng et al. (2004). PCR was performed using the KOD Hot Start DNA Polymerase kit as in section 2.2.2.4 with 10-20ng plasmid. PCR conditions were 3 minutes at $95^{\circ} \mathrm{C}$ followed by 20 cycles of $95^{\circ} \mathrm{C}\left(20^{\prime \prime}\right)$, annealing for 10 seconds at $60^{\circ} \mathrm{C}$ and 180 seconds at $70^{\circ} \mathrm{C}$ for elongation. Upon cooling down of the reaction to $4^{\circ} \mathrm{C}, 1 \mu \mathrm{L}$ of the enzyme Dpn1 (Thermo Scientific) was added to the whole reaction 
to digest parental DNA for 60 minutes at $37^{\circ} \mathrm{C}$. $5 \mu \mathrm{L}$ of digested plasmid were used for subsequent transformation followed by plasmid isolation and sequencing to assess the success of the mutagenesis.

\subsubsection{In vitro mRNA synthesis}

Purified PCR products containing an SP6 promoter were used to produce mRNA with the SP6 mMESSAGE mMACHINE ${ }^{\circledast}$ Kit (Ambion). In a total volume of $20 \mu \mathrm{L}, 1 \mu \mathrm{g}$ of purified PCR product was mixed with provided $1 \mathrm{x}$ NTP/CAP, $1 \mathrm{x}$ reaction buffer and $2 \mu \mathrm{L}$ of enzyme mix and incubated for 90 minutes at $37^{\circ} \mathrm{C}$. Then, $1 \mu \mathrm{L}$ Turbo DNase was added for 15 minutes at $37^{\circ} \mathrm{C}$. $30 \mu \mathrm{L}$ of nuclease free water were added as well as the same volume of $\mathrm{LiCl}$ precipitation solution (7.5M lithium chloride, $50 \mathrm{mM}$ EDTA) to precipitate the RNA. After incubation at $-20^{\circ} \mathrm{C}$ overnight, samples were centrifuged for 15 minutes at top speed and the supernatant removed. After washing the pellet with $70 \%$ ethanol and removal of the ethanol, the pellet was left to dry at room temperature. Subsequently, the dried pellet was resuspended in nuclease free water, incubated on ice for 30 minutes and the dissolved RNA was quantified using a NanoVue ${ }^{\mathrm{TM}}$ Spectrophotometer and stored at $-80^{\circ} \mathrm{C}$.

\subsubsection{In vitro translation}

Protein precursor was transcribed as well as translated in vitro from the plasmid containing its open reading frame using the $\mathrm{TNT}^{\oplus}$ Quick coupled Transcription/Translation system (Promega). $1 \mu$ g of plasmid was incubated with $50 \mu \mathrm{L}$ of TNT ${ }^{\varpi}$ Quick Master Mix as well as $50 \mu \mathrm{Ci}$ ${ }^{35} \mathrm{~S}$-methionine for 60 to 90 minutes at $30^{\circ} \mathrm{C}$ under mild agitation. Unlabeled methionine was added for one minute before sucrose was added for stabilization and the product was kept on ice for further use on the same day.

To synthesize precursor proteins from mRNA, in vitro translation was performed using the Flexi ${ }^{\circledast}$ Rabbit Reticulocyte Lysate System (Promega). The manufacturer's instructions were 
followed and 200ng of mRNA were incubated in a final volume of $50 \mu \mathrm{L}$ with $33 \mu \mathrm{L}$ of Flexi ${ }^{\oplus}$ Rabbit Reticulocyte Lysate, $1 \mu \mathrm{L}$ of $1 \mathrm{mM}$ amino acid mixture without methionine, $\mathrm{KCl}$ (70$120 \mathrm{mM})$, magnesium acetate $(0-2 \mathrm{mM})$ as well as $50 \mu \mathrm{Ci}{ }^{35} \mathrm{~S}$-methionine for 90 minutes at $30^{\circ} \mathrm{C}$ under mild agitation. Unlabeled methionine was added for one minute before sucrose was added for stabilization and the product was kept on ice for further use on the same day.

\subsubsection{Protein and protein complex analysis}

\subsubsection{Protein concentration determination}

The protein concentration of isolated mitochondria or cells was determined using Roti ${ }^{\circ}$-Quant (Serva). Using $0,7.5,15,30$ and $60 \mu \mathrm{g} / \mu \mathrm{l}$ bovine immunoglobulin, a standard curve was established and the mitochondrial or cell suspension was diluted 1:5. 5, 10 and $20 \mu \mathrm{L}$ were added to water to give a final volume of $86 \mu \mathrm{L}$. After adding $1 \mathrm{~mL}$ of Roti ${ }^{-}$-Quant reagent (diluted 1:10 in water), a Cary 50 Bio UV-visible spectrophotometer (Varian) was used to measure the optical density at $595 \mathrm{~nm}$. The protein concentration of the sample was determined using the calibration curve.

\subsubsection{SDS-PAGE}

SDS polyacrylamide gel electrophoresis (SDS-PAGE), similarly to Laemmli (1970), was used to separate proteins according to their molecular weight under denaturing conditions. Separating gels with $10-16 \%$ polyacrylamide concentrations were prepared using $30 \% / 0.8 \%$ acrylamide/bisacrylamide solution (Roth) along with $386 \mathrm{mM}$ Tris $/ \mathrm{HCl}, \mathrm{pH} 8.8$ and $0.1 \%$ SDS. A stacking gel containing $4 \%$ acrylamide, $80 \mathrm{mM}$ Tris/ $/ \mathrm{HCl}, \mathrm{pH} 6.8$ and $0.1 \%$ SDS was cast on top of the resolving gel. APS and TEMED were used for polymerization. SDS sample buffer (Table 2.2) was added to samples and they were incubated for 15 minutes at $37^{\circ} \mathrm{C}$ under mild agitation or 
at $95^{\circ} \mathrm{C}$ for 5 minutes. Electrophoretic separation was performed at $30 \mathrm{~mA} / \mathrm{gel}$ in SDS running buffer (Table 2.2) in the MINI-Protean II (BioRad) system or in custom-made midi gel systems.

\subsubsection{Urea-SDS-PAGE}

For enhanced detection of proteins of low molecular weight, Urea-SDS-PAGE was performed. Resolving gels contained $17 \%$ acrylamide $(60 \% / 0.8 \%$ acrylamide/bis-acrylamide mixture), $683 \mathrm{mM}$ Tris/ $\mathrm{HCl}, \mathrm{pH} 8.8,7.77 \mathrm{mM} \mathrm{NaCl}, 5.4 \mathrm{M}$ urea and $0.1 \%$ SDS while the stacking gel contained 5.4\% acrylamide (60\%/0.8\%), 108mM Tris/HCl, pH 6.8, 3.3M urea and 0.12\% SDS. APS and TEMED were used for polymerization. The handling of samples was identical as for SDS-PAGE (2.2.3.2) and electrophoresis was carried out in Urea running buffer (Table 2.2) at $35 \mathrm{~mA} / \mathrm{gel}$.

\subsubsection{Tricine-SDS-PAGE}

For a better resolution of proteins below $15 \mathrm{kDa}$ in size as well as a good separation of the whole range, Tris-Tricine polyacrylamide gels containing a gradient of $10-18 \%$ were used, similar to Schägger (2006). Resolving gels with 10 and $18 \%$ polyacrylamide concentrations were prepared using 49.5\%/3\% acrylamide/bis-acrylamide solution along with $1 \mathrm{M}$ Tris/ $\mathrm{HCl}, \mathrm{pH} 8.45,0.1 \%$ SDS and $13 \%$ glycerol for the $18 \%$ solution. The gel was cast using a custom-made gradient mixer. A stacking gel containing $4 \%$ acrylamide, $1 \mathrm{M}$ Tris/ $\mathrm{HCl}, \mathrm{pH} 8.45$ and $0.1 \%$ SDS was cast on top of the resolving gel. APS and TEMED were used for polymerization. Handling of the samples was identical to SDS-PAGE. Electrophoretic separation was carried out in custommade midi gel systems at $25 \mathrm{~mA} /$ gel in Tris-Tricine cathode and anode buffer (Table 2.2).

\subsubsection{Blue-Native-PAGE}

To separate native protein complexes, Blue Native polyacrylamide gel electrophoresis (BNPAGE) (Schägger \& Jagow, 1991; Wittig et al., 2006) similar to Dekker et al. (1996) was 
performed. Resolving gels with an acrylamide gradient of $4-13 \%, 4-14 \%, 6-16.5 \%$ or $2.5-10 \%$ were used containing 49.5\%/3\% acrylamide/bis-acrylamide solution along with $50 \mathrm{mM}$ BisTris/HCl, pH 7.0, 66.67mM 6 -aminocaproic acid and 20\% glycerol for the higher percentage solution. Gels were cast using a custom-made gradient mixer. The stacking gel contained 3.96\% or $2.5 \%$ acrylamide along with $50 \mathrm{mM}$ Bis-Tris/HCl, $\mathrm{pH} 7.0,66.67 \mathrm{mM} 6$-aminocaproic acid. APS and TEMED were used for polymerization. Mitochondria were incubated in solubilization buffer containing digitonin (Table 2.2) for 20 minutes on ice ( $1 \mu \mathrm{g}$ protein $/ 1 \mu \mathrm{L}$ buffer) and mixed periodically. Then, centrifugation $\left(20,000 \mathrm{x} \mathrm{g}, 15 \mathrm{~min}, 4^{\circ} \mathrm{C}\right)$ removed insoluble material and the supernatant was mixed with BN sample loading buffer (Table 2.2). All running buffers were precooled to $4^{\circ} \mathrm{C}$ and gel loading was performed at $4^{\circ} \mathrm{C}$ as well. Electrophoretic separation was performed in a SE600 Ruby system (Hoefer, GE Healthcare) that maintained a constant temperature of $4^{\circ} \mathrm{C}$. Using BN cathode buffer containing 0.02\% Coomassie Brilliant Blue G-250, gels were run at $15 \mathrm{~mA} /$ gel and $100 \mathrm{~V}$ for 1-2 hours. Subsequently, the buffer was replaced with cathode buffer without Coomassie Brilliant Blue G-250.

\subsubsection{Coomassie Brilliant Blue staining}

Coomassie staining solution (Table 2.2) was used to visualize separated protein bands on acrylamide gels or on PVDF membranes. Under mild agitation, membranes were stained for ten minutes and gels for at least one hour. Subsequently, the staining solution was exchanged for destaining solution (Table 2.2) until proteins became detectable. Methanol was used to entirely destain PVDF membranes before western blotting to not interfere with immunodetection.

\subsubsection{Ponceau-S staining}

In order to use secondary antibodies couples to an infrared dye, proteins on PVDF membranes were visualized with a Ponceau-S staining solution $(0.1 \%(w / v)$ Ponceau-S in 5\% (w/v) acetic acid) shaking for 10 minutes. Destaining occurred by repeated washing with water. 


\subsubsection{Western blotting and immunodetection}

To perform immunodetection using antibodies standard protocols as in Gallagher et al. (2004) were used. Semi-dry blotting in PEQLAB chambers was used to transfer proteins separated by electrophoresis onto PVDF membranes (Merck). Upon short activation in methanol, the membrane was assembled with the gel and filter papers (Heinemann Labortechnik) soaked in blotting buffer (Table 2.2). Transfer occurred for 2.5 hours at 25V and 250mA for SDS-PAGE and 3 hours, $25 \mathrm{~V}$ and $400 \mathrm{~mA}$ for BN-PAGE. Then, the membrane was stained in Coomassie Brilliant Blue (2.2.3.6) and destained until protein bands as well as the protein molecular weight marker were visible. The membrane was cut in pieces according to the size of proteins, which were to be analyzed by immunodetection. Methanol was used to completely destain and activate the membrane, followed by incubation in TBS-T (Table 2.2) containing 5\% milk powder for at least one hour at room temperature under mild agitation. Home-made primary antibodies diluted in TBS-T containing 5\% milk powder or commercial primary antibodies diluted in TBS$\mathrm{T}$ (Table 2.6) were applied and incubated at $4^{\circ} \mathrm{C}$ overnight under mild agitation. Membranes were washed in TBS-T briefly once and then three times for 10 minutes before a secondary antibody (Table 2.7, diluted 1:5000 or 1:10,000) was applied for one hour at room temperature. Following the same washing procedures, the signals were visualized using the Pierce ECL Western Blotting Detection Reagent (Thermo Scientific) on X-ray films. For detection of infrared-dye coupled secondary antibodies, the blots were scanned using an FLA-9000 scanner.

\subsubsection{Digital autoradiography}

To analyze and visualize radioactively labeled proteins separated by electrophoresis, gels were put in fresh destaining solution for 10 minutes for dehydration. Urea- or Tricine-SDS-PAGE gels were blotted as described above. Both membranes and gels were put on two blotting papers and gels were covered with a plastic bag on the other side before they were dried using a GD5040 vacuum gel dryer and a Vaccubrand ${ }^{\circledR} 2 \mathrm{C}$ gel pump (Scie-Plas) at $65^{\circ} \mathrm{C}$ for $2-4$ hours. On both membranes and gels, the protein size standard was marked with radioactive ink, covered 
with tape and exposed on storage phosphor screens (GE Healthcare) before signals were digitized using a Storm820 scanner. Signals were quantified using ImageQuant TL software (GE Healthcare) and rolling ball background subtraction.

\subsubsection{Specialized assays}

\subsubsection{Radiolabeled precursor protein import and assembly into mitochondria}

Radiolabeled precursor import into mitochondria was performed similar to Lazarou et al. (2009) with modifications. Precursor proteins were synthesized in vitro as described in section 2.2.2.10. Radiolabeled protein precursors were incubated with freshly isolated mitochondria (2.2.1.9) in import buffer (Table 2.2) and 5mM ATP to give a final concentration of $1 \mu \mathrm{g} / \mathrm{mL}$. AVO mix (final: $8 \mu \mathrm{M}$ antimycin, $1 \mu \mathrm{M}$ valinomycin and $20 \mu \mathrm{M}$ oligomycin) was added to one reaction to dissipate the membrane potential as a negative control. Samples were incubated at $30 / 37^{\circ} \mathrm{C}$ at $450 \mathrm{rpm}$ for three minutes and radiolabeled protein precursors (2-10\%) were added to start the import reaction. Import was stopped at various time points by adding AVO mix and the samples were put on ice. Upon import, mitochondria were either treated with $20 \mu \mathrm{g} / \mathrm{mL}$ proteinase $\mathrm{K}$ for 10 minutes to remove unimported precursor protein and with 2mM PMSF to inactivate proteinase $\mathrm{K}$ or directly harvested and washed with SEM-buffer (Table 2.2). Mitochondria were pelleted at 20,000 $\mathrm{x}$ g for 10 minutes at $4{ }^{\circ} \mathrm{C}$, SEM buffer was added, and mitochondria were pelleted again. Samples were taken up in SDS sample buffer and analyzed by SDS-PAGE. To analyze the incorporation of radiolabeled precursor proteins into mitochondrial protein complexes, samples were resuspended in BN solubilization buffer and incubated for 20 minutes before the supernatant was obtained by centrifugation at 20,000 $\mathrm{x}$ g for 15 minutes and loaded onto BN-PAGE (2.2.3.5). Finally, samples were analyzed by digital autoradiography (2.2.3.9) using Phosphorimager screens and a Storm 820 scanner (GE Healthcare). Quantifications were performed using ImageQuant TL 7.0 software (GE Healthcare) with a rolling ball background subtraction. 


\subsubsection{Protein stability assay}

Stability of freshly imported precursor proteins was assessed as described before (Reinhold et al., 2011; Rottgers et al., 2002) with modifications. Import buffer was supplemented with 5mM creatine phosphate and $0.1 \mathrm{mg} / \mathrm{mL}$ creatine kinase and import reactions were carried out as described. Upon SEM wash, mitochondria were again resuspended in supplemented import buffer and incubated at $37^{\circ} \mathrm{C}$ at $450 \mathrm{rpm}$ and harvested at $4^{\circ} \mathrm{C}$ at indicated time points. Samples were taken up in SDS sample buffer and analyzed by SDS-PAGE and autoradiography. Quantifications were performed using ImageQuant TL 7.0 software (GE Healthcare) with a rolling ball background subtraction.

\subsubsection{Co-immunoprecipitation using isolated mitochondria}

Co-immunoprecipitations were carried out as described before (Dennerlein et al., 2015) with modifications. HEK293T cells containing C-terminally tagged TIM23 ${ }^{\mathrm{FLAG}}$ or TIM21 ${ }^{\mathrm{FLAG}}$ under a tetracycline inducible promoter were kept in culture (2.2.2.1). 24 hours prior to harvesting, the expression of the respective protein was induced by adding tetracycline (final conc. $0.25 \mu \mathrm{g} / \mathrm{mL}$ ). Mitochondria were isolated as described in 2.2.1.8 and were lysed 15 minutes shaking at $4^{\circ} \mathrm{C}$ in solubilization buffer (50mM Tris/ $\mathrm{HCl}$ (pH 7.4), 50-150mM NaCl, 10\% glycerol, 1mM EDTA, 1\% Digitonin) and protease inhibitor cocktail (Roche). Lysates were cleared by centrifugation (8 minutes, 20,000 $\mathrm{xg}$ at $4^{\circ} \mathrm{C}$ ) and the supernatant was applied onto equilibrated anti-FLAG M2 Affinity Gel (Sigma), final concentration $1 \mu \mathrm{g}$ protein $/ \mu \mathrm{L}$. After incubation for 30 minutes at $4{ }^{\circ} \mathrm{C}$ on an overhead rotator, beads were washed in wash buffer $(50 \mathrm{mM}$ Tris/ $\mathrm{HCl}$ ( $\mathrm{pH} 7.4), 50$ $150 \mathrm{mM} \mathrm{NaCl}, 10 \%$ glycerol, $1 \mathrm{mM}$ EDTA, $0.1 \%$ digitonin, protease inhibitor cocktail) ten times by centrifugation for 30 seconds. Bound proteins were eluted with FLAG peptide in solubilization buffer without detergent 20 minutes shaking at $4^{\circ} \mathrm{C}$. Samples were taken up in SDS sample buffer (with $1 \% \quad \beta$-mercaptoethanol) and analyzed by SDS-PAGE and immunoblotting. 


\subsubsection{Co-immunoprecipitation following siRNA using cells}

HEK293T cells containing C-terminally tagged TIM23 $3^{\text {FLAG }}$ and TIM $21^{\text {FLAG }}$ under a tetracycline inducible promoter underwent siRNA treatment (2.2.1.5). 24 hours prior to harvesting, the expression of the respective protein was induced by adding tetracycline (final conc. $0.25 \mu \mathrm{g} / \mathrm{mL}$ ). 72 hours after siRNA application, cells were harvested and resuspended in PBS. Protein concentration was determined (2.2.3.1) and cells were lysed for 30 minutes shaking at $4^{\circ} \mathrm{C}$ in solubilization buffer (50mM Tris/ $\mathrm{HCl}$ ( $\mathrm{pH} 7.4), 150 \mathrm{mM} \mathrm{NaCl}, 10 \%$ glycerol, $1 \mathrm{mM}$ EDTA, $1 \%$ Digitonin, $1 \mathrm{mM}$ PMSF). Lysates were cleared by centrifugation ( 15 minutes, $20,000 \mathrm{x} \mathrm{g}$ at $4^{\circ} \mathrm{C}$ ) and the supernatant was applied onto equilibrated anti-FLAG beads (Sigma). After incubation for 60 minutes at $4^{\circ} \mathrm{C}$ rotating overhead, beads were washed in wash buffer $(50 \mathrm{mM}$ Tris/ $\mathrm{HCl}$ ( $\mathrm{pH} 7.4$ ), 150mM NaCl, 10\% glycerol, $1 \mathrm{mM}$ EDTA, $0.1 \%$ digitonin, $1 \mathrm{mM} \mathrm{PMSF}$ ) ten times. Bound proteins were eluted with FLAG peptide in solubilization buffer without detergent 20 minutes shaking at $4^{\circ} \mathrm{C}$. Samples were taken up in SDS sample buffer and analyzed by SDSPAGE and immunoblotting using infrared-dye coupled secondary antibodies. Blots were scanned using an FLA-9000 scanner and quantifications were performed using ImageQuant TL 7.0 software (GE Healthcare) with a rolling ball background subtraction.

\subsubsection{Cytochrome $c$ oxidase activity and quantification assay}

Activity and relative amount of cytochrome $c$ oxidase was analyzed by Complex IV Human Specific Activity Microplate Assay Kit (Mitosciences, Abcam) and the manufacturer's instructions were followed. Cells were harvested and resuspended in provided "Solution 1" before protein concentration determination (2.2.3.1). The concentration of all samples was adjusted to $5 \mu \mathrm{g} / \mu \mathrm{L}$ and $1 / 10$ volume of provided Detergent was added, mixed and incubation on ice for 30 minutes followed. Cell lysates were cleared by centrifugation (20 minutes, 16,000 x g) and the protein concentration was determined again. Samples were diluted to $15 \mu \mathrm{g} / 200 \mu \mathrm{L}$ and were prepared in triplicates onto the provided plate. After incubation for three hours at room temperature, wells were washed three times with Solution 1 and the appropriate amount 
of diluted cytochrome $c$ in Solution 1 was added. Absorbance at $550 \mathrm{~nm}$ at $30^{\circ} \mathrm{C}$ was measured for two hours taking measurements every minute using a Synergy H1 microplate reader (BioTek). Its decrease correlated to oxidation of cytochrome $c$ and cytochrome $c$ oxidase activity.

To assess the amount of cytochrome $c$ oxidase, wells were incubated with primary antibody solution for one hour at room temperature followed by one wash with Solution 1. After incubation with secondary antibody solution for one hour at room temperature, wells were washed twice with Solution 1 and once with Solution 2 before Developing Solution was added. Absorbance at $405 \mathrm{~nm}$ was measured for 30 minutes at room temperature taking 20 measurements using a Synergy H1 microplate reader (BioTek). Its increase correlated to the relative amount of cytochrome $c$ oxidase.

\subsubsection{Succinate dehydrogenase activity assay}

The assessment of succinate dehydrogenase activity was performed as described in Dudek et al. (2016). Isolated mitochondria were harvested, frozen in liquid nitrogen and thawed on ice twice and then resuspended in hypotonic buffer $(5 \mathrm{mM} \mathrm{MgCl} 2$ in $25 \mathrm{mM}$ potassium phosphate buffer, $\mathrm{pH} 7.2)$ to a final concentration of $1 \mathrm{mg} / \mathrm{mL}$. Assay buffer $(2.5 \mu \mathrm{M}$ rotenone, $10 \mu \mathrm{M}$ antimycin $\mathrm{A}$, $1 \mathrm{mM}$ potassium cyanide, $10 \mathrm{mM}$ sodium succinate in $50 \mathrm{mM}$ potassium phosphate buffer, $\mathrm{pH}$ 7.4) was equilibrated to $30^{\circ} \mathrm{C}$ in a cuvette before lysed mitochondria were added in a dilution of 1:5 and further incubation at $30^{\circ} \mathrm{C}$ for 10 minutes followed. Upon blanking, the reaction was started by adding $50 \mu \mathrm{M}$ coenzyme $\mathrm{Q}_{1}(\mathrm{CoQ} 1)$ and following the absorbance at $280 \mathrm{~nm}$ using a Cary 50 Bio UV-visible spectrophotometer (Varian). Succinate dehydrogenase activity was analyzed by following the reduction of the ubiquinone analogue CoQ1 upon the oxidation of succinate to fumarate taking measurements every second for three minutes. 


\subsubsection{Malate dehydrogenase activity assay}

This assay is based on Barrie Kitto (1969) and was performed similarly to Dudek et al. (2016). Isolated mitochondria were lysed in solubilization buffer $(0.5 \%$ Triton-X-100 in $0.1 \mathrm{M}$ potassium phosphate, $\mathrm{pH} 7.6$ ) to $1 \mathrm{mg} / \mathrm{mL}$ (final concentration). A Cary 50 Bio UV-visible spectrophotometer (Varian) was blanked using 0.1M potassium phosphate, $\mathrm{pH}$ 7.6, before adding oxaloacetic acid and NADH to a final concentration of $0.2 \mathrm{mM}$ and $0.1 \mathrm{mM}$ respectively. Upon thorough mixing, measurements at 340nm were started and solubilized mitochondria were added in a final dilution of 1:40. The disappearance of $\mathrm{NADH}$ at $340 \mathrm{~nm}$ was measured for 2 minutes taking measurements every second.

\subsubsection{Reactive oxygen species measurements}

Reactive oxygen species were measured using MitoSOX ${ }^{\mathrm{TM}}$ Red mitochondrial superoxide indicator (Molecular Probes, Invitrogen) and instructions by the manufacturer were followed. Cells were seeded a few days in advance in wells of a 6 well plate. One well was treated with hydrogen peroxide for one hour as a positive control. A 5mM MitoSOX stock was prepared in $13 \mu \mathrm{L}$ DMSO and $3 \mu \mathrm{M}$ MitoSOX were added. Cells were incubated at $37^{\circ} \mathrm{C}$ for 10 minutes, washed with PBS, detached with 0.05\% Trypsin-EDTA (Gibco), harvested and resuspended in PBS before processed by fluorescence-activated cell sorting (FACS Canto ${ }^{\mathrm{TM}}$ II, BD Biosciences) at Ex/Em 510/580nm.

\subsubsection{Respiratory chain complexes in gel activity assay}

In gel activity assays were performed similar as described before in Wittig et al. (2007). Solubilized mitochondria were separated on BN-PAGE (2.2.3.5) and the gel was cut vertically to allow for specific complex activity assay. To assess complex I activity, the gel strip was incubated in complex I incubation buffer $(5 \mathrm{mM}$ Tris/ $\mathrm{HCl}, \mathrm{pH} 7.4)$ for ten minutes, then transferred into freshly prepared complex I staining solution (5mM Tris/HCl, $\mathrm{pH} 7.4,2.5 \mathrm{mg} / \mathrm{mL}$ NBT (4-Nitro blue tetrazolium chloride), $0.1 \mathrm{mg} / \mathrm{mL} \mathrm{NADH}$ ) and kept at mild agitation at $30^{\circ} \mathrm{C}$ for $1-2$ hours. 
To assess complex II activity, the gel strip was incubated in complex II incubation buffer ( $5 \mathrm{mM}$ Tris/ $\mathrm{HCl}, \mathrm{pH}$ 7.4) for ten minutes, then transferred into freshly prepared complex II staining solution $(5 \mathrm{mM}$ Tris $/ \mathrm{HCl}, \mathrm{pH} 7.4,2.5 \mathrm{mg} / \mathrm{mL} \mathrm{NBT}, 20 \mathrm{mM}$ sodium succinate, $0.2 \mathrm{mM}$ PMS (phenazine methosulfate)) and kept at mild agitation at $30^{\circ} \mathrm{C}$ for $1-2$ hours. To assess complex IV activity, the gel strip was incubated in complex IV incubation buffer $(50 \mathrm{mM}$ potassium phosphate buffer, $\mathrm{pH}$ 7.4) for ten minutes, then transferred into freshly prepared complex IV staining solution $\left(50 \mathrm{mM}\right.$ potassium phosphate buffer, $\mathrm{pH} 7.4,0.5 \mathrm{mg} / \mathrm{mL}$ DAB $\left(3,3^{\prime}\right.$ diaminobenzidine), $1 \mathrm{mg} / \mathrm{mL}$ reduced cytochrome $c$ (bovine heart)) and kept at mild agitation at $30^{\circ} \mathrm{C}$ overnight. To assess complex $\mathrm{V}$ activity, the gel strip was incubated in complex $\mathrm{V}$ incubation buffer (35mM Tris, $220 \mathrm{mM}$ Glycine, $\mathrm{pH} 8.3$ ) for thirty minutes, then transferred into freshly prepared complex V staining solution (35mM Tris, 220mM Glycine, $\mathrm{pH} 8.3,14 \mathrm{mM}$ magnesium sulfate, $\left.8 \mathrm{mM} \mathrm{ATP}, 0.2 \% \mathrm{~Pb}\left(\mathrm{NO}_{3}\right)_{2}\right)$ and kept at mild agitation at $30^{\circ} \mathrm{C}$ for $1-2$ hours. When precipitations had appeared, reactions were stopped and Coomassie dye was washed out by incubation in SDS running buffer. Then gel stripes were scanned and dried.

\subsubsection{In vivo radiolabeling of mitochondrial translation products}

${ }^{35} \mathrm{~S}$-methionine labeling of mitochondrial-encoded proteins was performed as described previously (Chomyn, 1996). HEK293T WT and ROMO1- cells were grown in $25 \mathrm{~cm}^{2}$ flasks and the medium was exchanged for ${ }^{35}$ S-labeling medium without FCS (Table 2.2) followed by incubation for 10 minutes at $37^{\circ} \mathrm{C}$ twice. Subsequently, ${ }^{35} \mathrm{~S}$-labeling medium with FCS together with $100 \mu \mathrm{g} / \mathrm{mL}$ emetine dihydrochloride hydrate to inhibit cytosolic translation was added followed by incubation for 10 minutes. Then, mitochondrial-encoded proteins were labeled with $200 \mu \mathrm{Ci} / \mathrm{mL}{ }^{35} \mathrm{~S}$-methionine for one hour. Cells were harvested at 5000rpm for two minutes, washed with PBS and pelleted again. Upon protein concentration determination (2.2.3.1), cells were taken up in SDS sample buffer and analyzed by SDS-PAGE and immunoblotting followed by digital autoradiography. 


\subsubsection{Lipid extraction and thin-layer chromatography}

This assay is based on Leray et al. (1987) and Masella \& Cantafora (1988). Mitochondria were isolated from HEK293T WT and $\mathrm{ROMO1}^{-/}$cells (2.2.1.8). To extract the lipids, 1mg of mitochondria were mixed with $1.5 \mathrm{~mL}$ chloroform-methanol $(2: 1 ; \mathrm{v} / \mathrm{v})$ in a small glass test tube and sealed with parafilm before shaking at 1000rpm for one hour at $4^{\circ} \mathrm{C}$. After adding $300 \mu \mathrm{L}$ of $\mathrm{ddH}_{2} \mathrm{O}$, samples were vortexed for one minute and centrifuged at 1000rpm for 5 minutes. Upon discarding the upper aqueous phase, the lower solvent phase was washed with $250 \mu \mathrm{L}$ methanolwater $(1: 1 ; \mathrm{v} / \mathrm{v})$. Samples were vortexed and centrifuged as before and the lower solvent phase was transferred to a new glass tube. The glass tube was kept in the fume hood overnight to dry. The following day, dried extracted lipids were dissolved in $100 \mu \mathrm{L}$ chloroform and stored at $80^{\circ} \mathrm{C}$ until further use.

To analyze the composition of the isolated lipids of mitochondria, an HPTLC Silicagel60 $\mathrm{F}_{254}$ glass plate was used. $3 \mu \mathrm{L}$ of isolated lipids were spotted five times on the plate along with the lipid standards cardiolipin, phosphatidylglycerol, phosphatidylcholine and phosphatidylethanolamine (Avanti). The plate was put into a TLC chamber filled with the solvent phase (chloroform-triethylamine-ethanol-water (30:35:35:7)) and sealed tightly. Upon completion of the run, the plate was taken out of the solvent phase and left to dry for 5-8 minutes under the fume hood. Subsequently, the plate was submerged into staining solution $\left(10 \% \mathrm{CuSO}_{4}\right.$ in $10 \%$ o-phosphoric acid) for 3-5 seconds and incubated at $180^{\circ} \mathrm{C}$ for 10 minutes until black spots became visible.

\subsubsection{Cycloheximide treatment}

To study effects on protein levels upon inhibition of cytosolic translation of yeast cells, YPH499 yeast cells were grown in YPD medium (Table 2.2). 150 $\mathrm{gg} / \mathrm{mL}$ of cycloheximide dissolved in ethanol were added to separate yeast cultures of OD 1. Samples were shaken at $900 \mathrm{rpm}$ at $30^{\circ} \mathrm{C}$ and harvested at respective time points by centrifugation at $10,000 \mathrm{x} \mathrm{g}, 4^{\circ} \mathrm{C}, 5$ minutes. To 


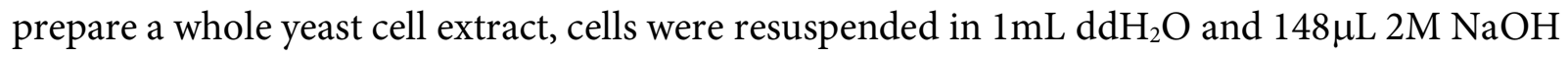
and $12 \mu \mathrm{L} 2$-mercaptoethanol were added, mixed and incubated for 10 minutes. Then, $160 \mu \mathrm{L}$ $50 \%$ trichloroacetic acid were added, mixed and incubated for 30 minutes on ice. Subsequently, the sample was centrifuged for 15 minutes at full speed at $4^{\circ} \mathrm{C}$ and the cell pellet was resuspended in SDS sample buffer and protein levels were analyzed by SDS-PAGE and immunoblotting. 


\section{Results}

\subsection{ROMO1 is a constituent of the TIM23 complex}

The molecular architecture of the mitochondrial translocation machinery is conserved and has been well characterized in yeast (for review, see Chacinska et al., 2009; Dudek et al., 2013; Wiedemann \& Pfanner, 2017). In recent years, more and more studies have focused on the differences between the TIM23 complex of Saccharomyces cerevisiae and Homo sapiens (for current review, see Kang et al., 2018). One open question has been whether there are further components acting in TIM23-mediated protein import in human. To find new candidate proteins, cell lines with genomically integrated C-terminally FLAG-tagged versions of the translocase components TIM23, TIM21 and TIM50 were generated. Their expression was controlled by a tetracycline inducible promoter and the FLAG octapeptide with the sequence DYKDDDDK could be used for affinity purification. Upon differential stable isotope labeling with amino acids in cell culture (SILAC; Ong et al., 2002), followed by anti-FLAG immunoisolations, the interactome of TIM $23^{\mathrm{FLAG}}$, TIM $21^{\mathrm{FLAG}}$ and TIM $50^{\mathrm{FLAG}}$ was identified using mass spectrometry. Analyses from all three proteins showed a high enrichment of the protein ROMO1.

ROMO1, the human orthologue of the yeast TIM23 complex component Mgr2, had been hypothesized to play a role in protein import in human. However, its role in the translocase had never been addressed experimentally. To validate the results from the mass spectrometric analysis, mitochondria containing C-terminally tagged TIM $23^{\mathrm{FLAG}}$ were solubilized in digitonincontaining buffer and interacting proteins were purified using an anti-FLAG affinity gel. Upon elution with FLAG-peptides, both input (total) and eluate were analyzed by SDS-PAGE and

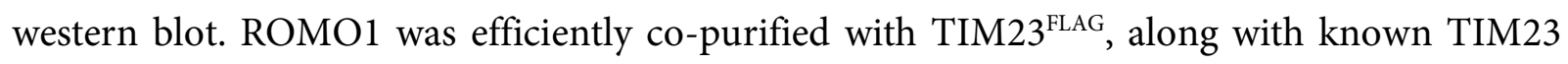
subunits (Figure 3.1A). As expected, TIM21 and TIM50 also co-isolated with TIM23 ${ }^{\text {FLAG, }}$, while other inner membrane proteins associated with the oxidative phosphorylation machinery did not. Immunoisolations using C-terminally tagged TIM $21^{\mathrm{FLAG}}$ also showed that ROMO1 
efficiently co-isolated with TIM21 ${ }^{\mathrm{FLAG}}$, along with its known interaction partners TIM50, TIM23, COX1 and MITRAC12 (Figure 3.1B). TOM70 and Rieske, of the outer and inner membrane respectively, served as negative controls. This shows that ROMO1 interacts with TIM23 and TIM21 and is therefore a new component of the human TIM23 complex.

A

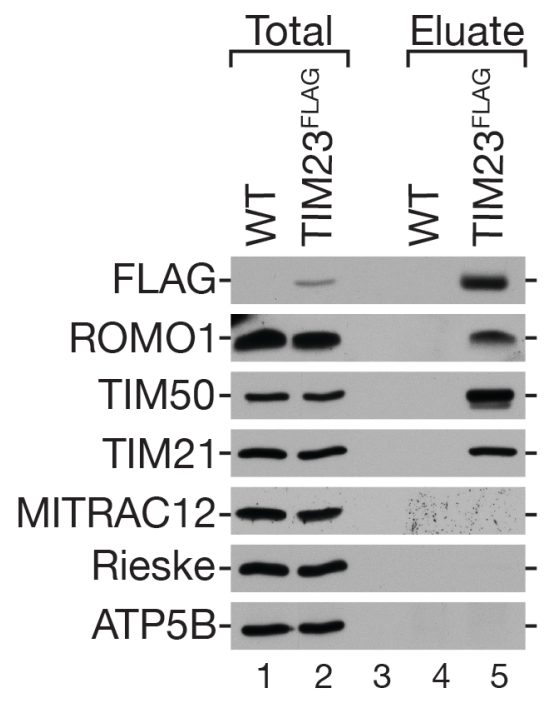

B

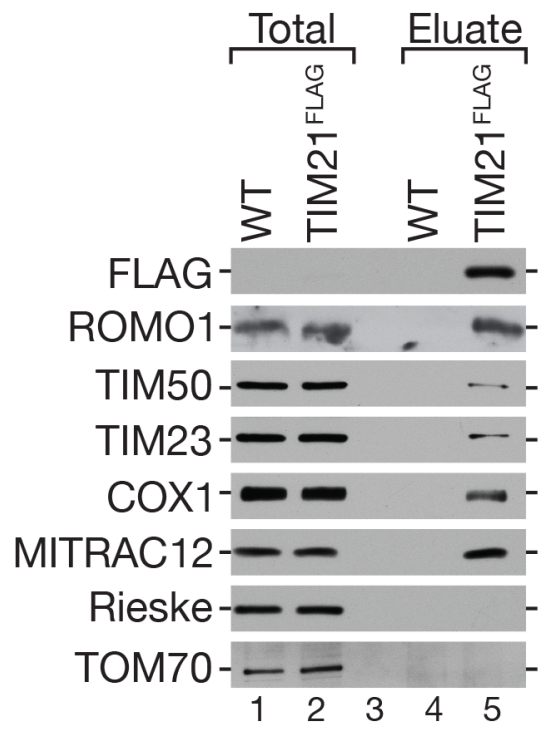

Fig. 3.1: ROMO1 interacts with TIM23 and TIM21 of the human TIM23 complex.

(A) Mitochondria isolated from HEK293T Wild-type (WT) and TIM23 $3^{\text {FLAG }}$ cells were solubilized using digitonin and incubated with anti-FLAG beads. Upon elution by FLAG-peptide, interactions partners were analyzed by SDSPAGE and western blotting using the indicated antibodies. Eluate: $100 \%$, total: $1.6 \%$.

(B) Isolated mitochondria of WT and TIM $21^{\mathrm{FLAG}}$ cells were analyzed as described in A. Eluate: $100 \%$, total: $1.6 \%$.

\subsection{A ROMO1 ${ }^{-/}$cell line can be used to study its molecular function}

\subsubsection{Steady state analysis of the $\mathrm{ROMO1}^{-1-}$ cell line shows differences in mitochondrial protein levels}

To investigate the molecular function of ROMO1, a cell line with a knockout (KO) of ROMO1 was generated using CRISPR/Cas9. The CRISPR/Cas9 system relies on the bacterial Cas9 
nuclease to be guided by a guide RNA to a specific genomic locus, where it induces a doublestranded break (Horvath \& Barrangou, 2010; Ran et al., 2013). This double-stranded break recruits the cell's DNA repair machinery which is very error-prone. Therefore, the gene is often disrupted, preventing protein expression (Ran et al., 2013).

To this end, primers were designed targeting the first exon of the gene. Upon successful cloning into the pX330 vector, transient co-transfection of this plasmid along with a GFP-encoding plasmid into HEK293T cells, cells were sorted for GFP-positive cells. Following expansion, genomic DNA of the knockout clone was isolated for PCR amplification of the open reading frame (ORF) of the ROMO1 gene. The presence of an ORF disruption was confirmed by DNA sequencing of the PCR product (Figure 3.2). Twelve nucleotides had been deleted. While one could hypothesize that this might lead to unstable mRNA, it did not yield a frameshift mutation or a direct premature stop codon.

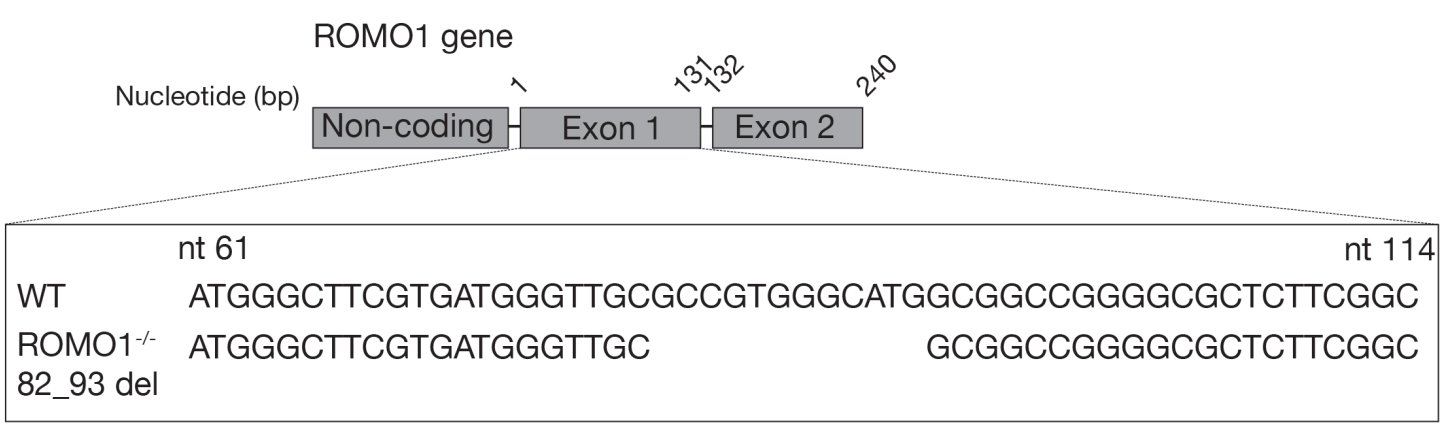

Fig. 3.2: CRISPR/Cas9 mediated deletion of ROMO1 disrupts its open reading frame.

Genomic DNA was isolated from WT and $\mathrm{ROMO1}^{-1}$ cells and the coding region of ROMO1 was amplified by PCR and sequenced. Knockout cells showed a deletion of 12 nucleotides in the first exon.

Therefore, to assess ROMO1 ablation on the protein level, mitochondria were isolated and steady state levels of various inner mitochondrial membrane proteins were analyzed by western blot (Figure 3.3A). Antibody probing against ROMO1 confirmed the loss of ROMO1 on a protein level and therefore a successful knockout. Levels of translocase components TIM21 and TIM50 were not significantly affected. Interestingly, $\mathrm{ROMO}^{-1-}$ mitochondria showed increased levels of TIM23 and decreased levels of complex II (SDHA) and complex IV (COX1, COX6A, 
COX6C) components, while MITRAC components or subunits of complex I (NDUFA4) and complex V (ATP5B) were unaffected (Figure 3.3A).

To ensure that phenotypes observed in the $\mathrm{ROMO}^{-/-}$cell line were specific for the ablation of ROMO1, a complemented cell line was generated. To this end, $\mathrm{ROMO1}^{-1-}$ cells were stably transfected with endogenous ROMO1 under the control of a tetracycline-inducible promotor. Upon addition of tetracycline, the expression of ROMO1 could be turned on, leading to increased levels of ROMO1 in the knockout background (Figure 3.3B). Additionally, the steady state analyses also revealed that the increased levels of TIM23 returned to WT expression levels in the complemented $\mathrm{ROMO}^{-/-}+\mathrm{ROMO} 1$ cell line.

A

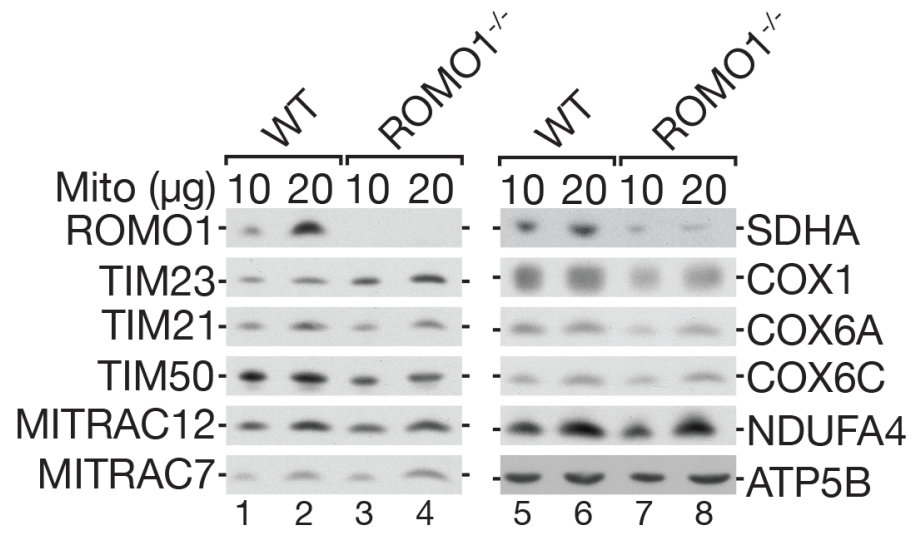

B

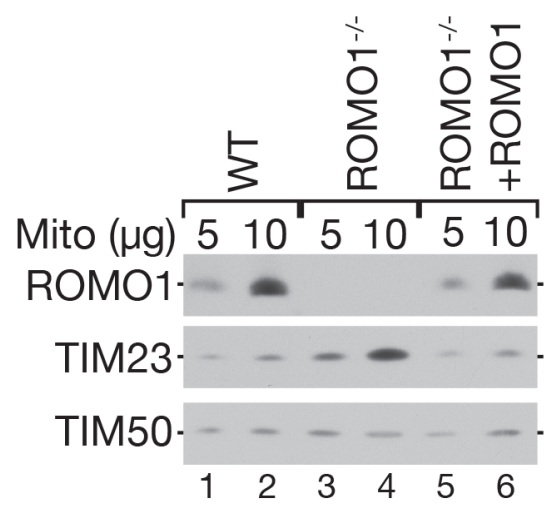

Fig. 3.3: ROMO1 $^{-/-}$mitochondria show different protein levels.

(A) Mitochondria isolated from HEK293T WT and ROMO1 ${ }^{-1}$ cells were lysed and analyzed by SDS-PAGE and immunoblotting against TIM23 complex, MITRAC and OXPHOS components.

(B) Lysed mitochondria from HEK293T WT, ROMO1 ${ }^{-1}$ and ROMO1 ${ }^{-1}+$ ROMO1 cells were analyzed by SDSPAGE and immunoblotting against ROMO1, TIM23 and TIM50.

\subsection{2 $\mathrm{ROMO1}^{-/}$cells exhibit changes in cell proliferation, mitochondrial inner membrane morphology, and OPA1 processing}

To further characterize the $\mathrm{ROMO}^{-/}$cell line, as well as to verify the specificity of the knockout using the $\mathrm{ROMO}^{-1-}+\mathrm{ROMO} 1$ complemented cell line, a cell proliferation assay was performed. 
For this purpose, 200,000 cells of the three cell lines each were seeded and the number of cells were counted after two days using trypan blue and an automated cell counter. While ROMO1 ${ }^{-1}$ cells grew more than 50\% slower than the WT, re-expression of ROMO1 could rescue this phenotype to about $80-90 \%$ (Figure 3.4).

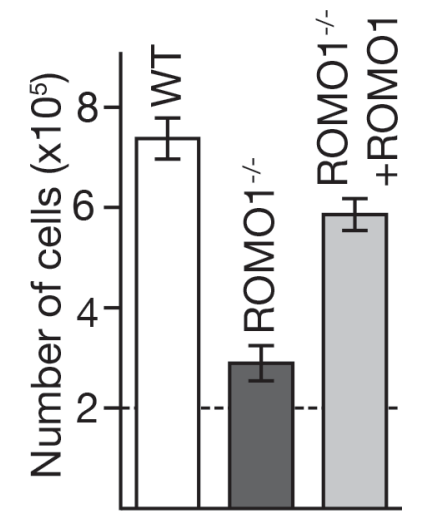

Fig. 3.4: ROMO1 ${ }^{-/}$cells grow more slowly compared to WT cells.

Cell proliferation assay of $\mathrm{WT}$, $\mathrm{ROMO1}^{-1-}$ and $\mathrm{ROMO}^{-1-}$ cells expressing ROMO1 under a tetracycline-inducible promoter using trypan blue and automated cell counting. Starting cell number of 200,000 is represented by dashed line. (mean \pm SEM, $\mathrm{n}=3$ )

It had been published before that knockdown of ROMO1 leads to changes in inner mitochondrial membrane morphology, as well as OPA1 processing (Norton et al., 2014). To check whether this applied to the new knockout model, transmission electron microscopy was carried out in collaboration with Daniel C. Jans and Stefan Jakobs of the Max Planck Institute for Biophysical Chemistry in Göttingen, Germany. WT, ROMO1 ${ }^{-1}$ and ROMO1 ${ }^{-1}+\mathrm{ROMO} 1$ cells were fixed with glutaraldehyde and embedded in agarose before sections were analyzed using transmission electron microscopy. While the inner mitochondrial membrane of the WT cells exhibited proper crista junctions and long cristae, the inner membrane structure of $\mathrm{ROMO1}^{-/}$cells did not show any proper cristae or crista junctions. This phenotype of a disturbed inner membrane could be rescued upon expression of ROMO1 in the KO cell line (Figure 3.5A).

Inner membrane morphology is linked to proper processing of OPA1, as its changes can lead to IM disturbances (Anand et al., 2014). Due to the observed inner membrane phenotype in $\mathrm{ROMO}^{-/}$cells, OPA1 processing in isolated mitochondria was checked by western blot. While WT mitochondria (lanes 1 and 2; Figure 3.5B) showed all expected five OPA 1 forms ( 2 long and 3 short), processing of OPA1 was changed in ROMO1 KO cells, as the longest, often denoted a, and one of the short forms, often denoted d, were missing (lanes 3 and 4; Figure 3.5B). It could 
be confirmed that this phenotype was also specific to the ablation of ROMO1 since all five forms were present again in the rescue cell line (lanes 5 and 6; Figure 3.5B).

A
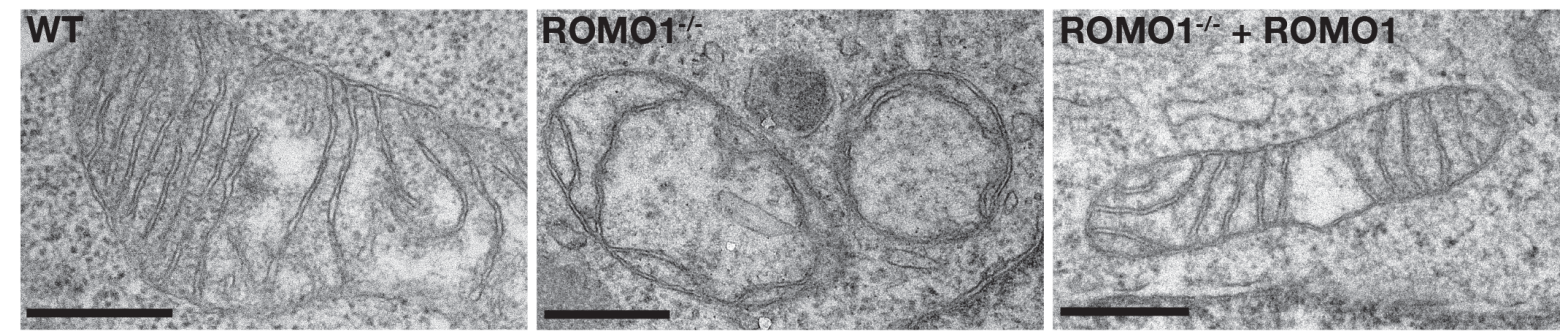

B

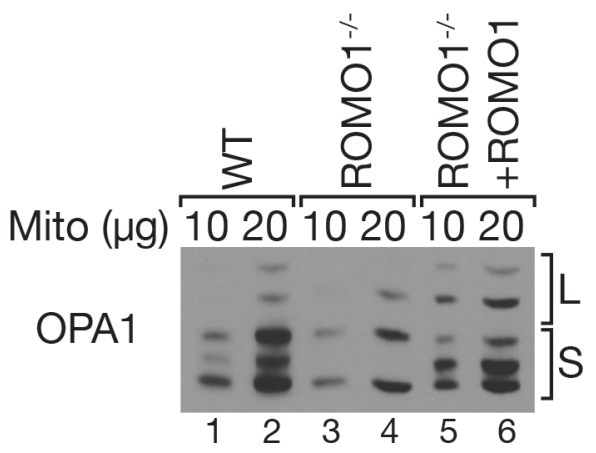

Fig. 3.5: Inner membrane morphology and OPA1 processing are changed in $\mathrm{ROMO1}^{-/-}$mitochondria.

(A) WT, $\mathrm{ROMO1}^{-/-}$and $\mathrm{ROMO1}^{-/}$cells expressing ROMO1 were analyzed by transmission electron microscopy to assess inner membrane morphology. Scale bar 500nm. Courtesy of Daniel C. Jans and Stefan Jakobs.

(B) Mitochondria from HEK293T WT, ROMO1 ${ }^{-/}$and ROMO1 ${ }^{-1-}$ + ROMO1 were analyzed by SDS-PAGE and western blot for OPA1.

Due to the drastic changes in inner membrane morphology, one could hypothesize that the lipids present in the inner membrane might have undergone changes. Therefore, the lipid composition of WT and $\mathrm{ROMO}^{-1-}$ mitochondria was analyzed by thin-layer chromatography (TLC). Lipids were extracted from isolated mitochondria using chloroform-methanol $(2: 1 ; \mathrm{v} / \mathrm{v})$, dried and dissolved in chloroform, applied onto a TLC plate and separated by the solvent phase (chloroform-triethylamine-ethanol-water (30:35:35:7)). Lipid standards of phosphatidylglycerol (PG), phosphatidylethanolamine (PE), cardiolipin (CL) and phosphatidylcholine (PC) were applied alongside the samples. After the run, the plate was stained in $10 \% \mathrm{CuSO}_{4}$ in $10 \%$ o-phosphoric acid and dried to visualize the lipids. Comparing the running behavior of the lipids extracted from WT and ROMO1 ${ }^{-1-}$ mitochondria, no difference could be detected (Figure 3.6). It therefore seemed as if the aberrant inner membrane morphology did not have major effects on lipid composition. 

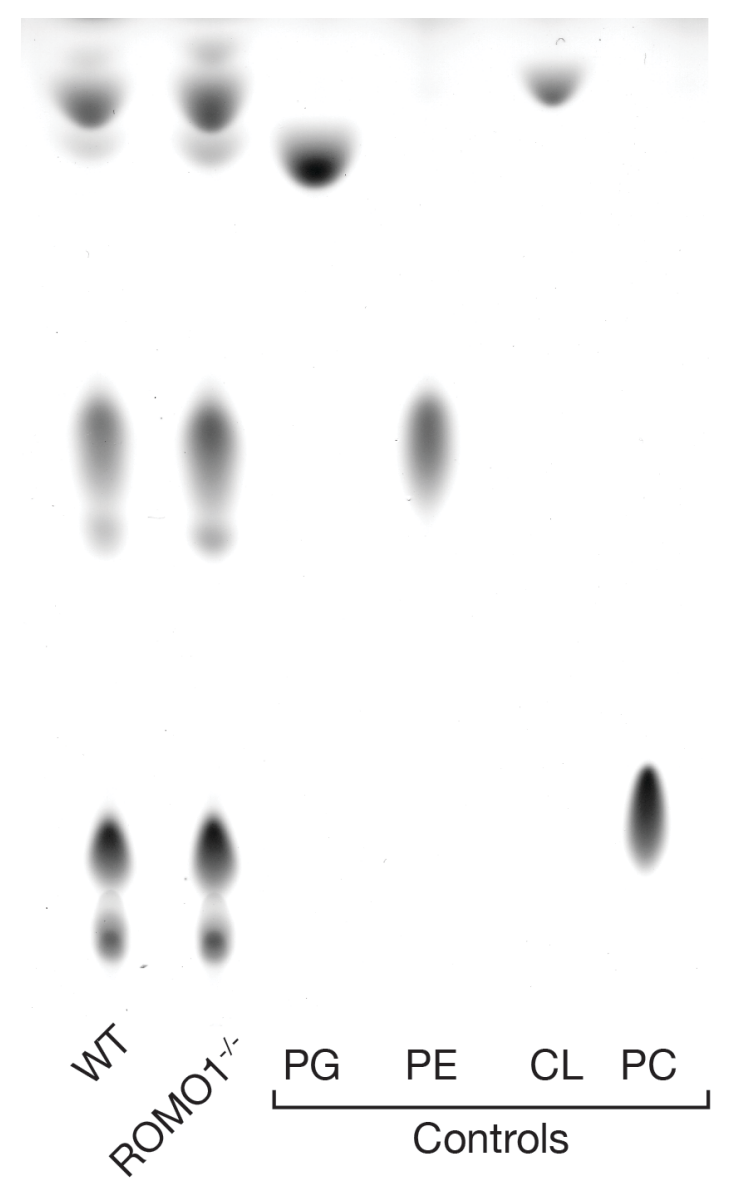

Fig. 3.6: Lipid composition does not change in $\mathrm{ROMO1}^{-1-}$ mitochondria.

Lipids were extracted from WT and ROMO1 ${ }^{-1-}$ mitochondria and separated by thin-layer chromatography (TLC). Lipid standards were used as control (PG, phosphatidylglycerol; PE, phosphatidylethanolamine; CL, cardiolipin; PC, phosphatidylcholine).

\subsection{3 $\mathrm{ROMO}^{-/}$cells show changes in respiratory chain quantity and activity}

It has been reported that changes of the inner membrane morphology can have drastic effects on mitochondrial respiration (Cogliati et al., 2013; Stiburek et al., 2012). Since the knockout of ROMO1 led to severe changes in cristae structure, as well as a destabilization of certain complex II and complex IV proteins, respiratory chain complexes were analyzed by Blue-Native PAGE (BN-PAGE). This method allows membrane complexes to stay intact and active due to the mild solubilization strategy using the detergent digitonin (Schägger \& Jagow, 1991; Wittig et al., 
2006). It therefore enables a semi-quantitative assessment of OXPHOS complexes. Upon mitochondrial isolation from WT and $\mathrm{ROMO}^{-/}$cells, solubilized mitochondria were separated on BN-PAGE and analyzed by western blot (Figure 3.7). Complex II (succinate dehydrogenase) has a molecular weight of about $200 \mathrm{kDa}$ and was analyzed using antibodies against its subunit SDHA. Here, a slight decrease was detected (lanes 1 and 2; Figure 3.7), which is consistent with the reduced steady state levels of SDHA observed in Figure 3.3A. The most drastic respiratory complex phenotype from $\mathrm{ROMO}^{-1-}$ mitochondria was seen for complex IV (cytochrome $c$ oxidase), which has a molecular weight of about $400 \mathrm{kDa}$, and was detected with antibodies against COX1 and COX4I-1 (lanes 5/6 and 11/12; Figure 3.7). Complex I, detected using NDUFA9, the monomeric complex III, detected with Rieske, and complex V (ATP5B), were only marginally affected. This was similar to the outer membrane protein VDAC. Complex I, III and IV form supercomplexes present in the MDa region. The levels of these supercomplexes are decreased for both Rieske and COX1 probing most likely since the overall levels of complex IV are reduced (Figure 3.7).

Since levels of the mitochondrial-encoded protein COX1 were affected on SDS- and BN-PAGE, the efficiency of mitochondrial translation was addressed next. For this purpose, WT and $\mathrm{ROMO}^{-/}$cells were cultured in methionine-free medium and cytosolic translation was inhibited using emetine dihydrochloride hydrate. Emetine binds to the 40S subunit of the cytosolic ribosome and inhibits mRNA movement along the ribosome, resulting in inhibited protein synthesis (Delves \& Roitt, 1998). Since protein biogenesis in the cytosol is stalled, the only newly synthesized proteins are mitochondrial-encoded. These were labeled with radioactive ${ }^{35} \mathrm{~S}$-methionine for one hour. Subsequently, cells were lysed and the labeled mitochondrial translation products were analyzed by SDS-PAGE and autoradiography. Comparing the intensities of the autoradiography signals between WT and $\mathrm{ROMO}^{-/}$cells, no difference could be detected (Figure 3.8) and one could therefore conclude that mitochondrial translation is not affected by the absence of ROMO1. 

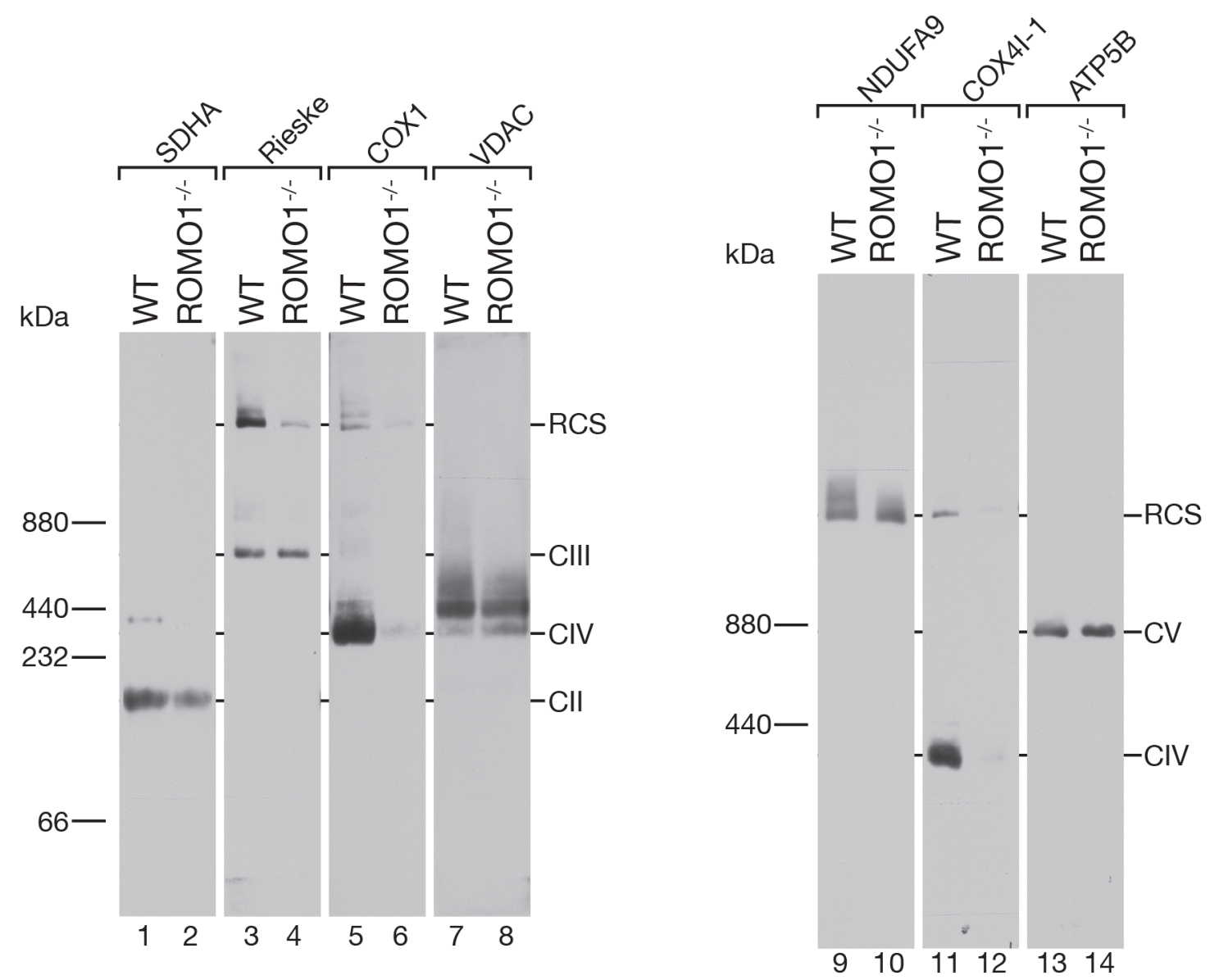

Fig. 3.7: Amounts of complex II and IV are reduced in ROMO1 ${ }^{-/}$mitochondria on BN-PAGE.

Mitochondria were solubilized in digitonin and membrane complexes were separated on BN-PAGE, followed by immunoprobing with the indicated antibodies. CII, complex II; CIV, complex IV; CIII, complex III; RCS, Respiratory chain supercomplexes; CV, complex V.

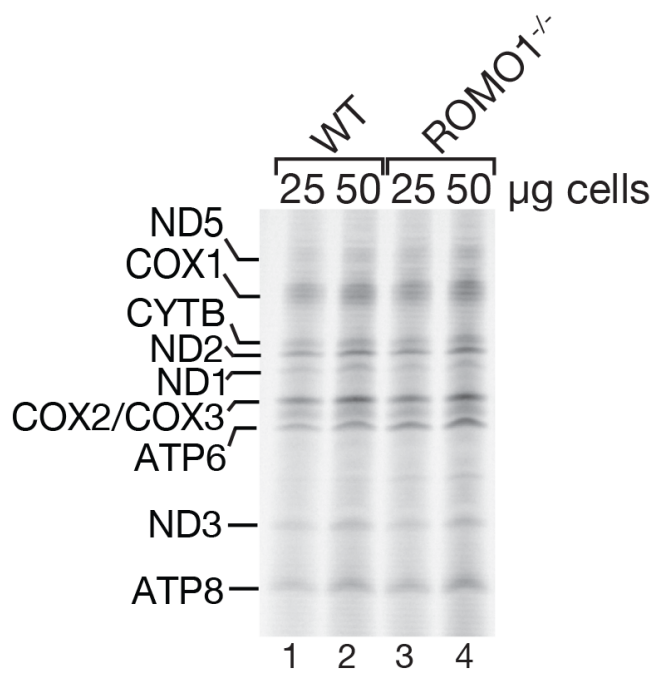

Fig. 3.8: Mitochondrial translation efficiency is not changed in $\mathrm{ROMO1}^{-/}$cells.

Cytosolic translation was inhibited in WT and ROMO1 ${ }^{-1}$ cells by addition of emetine dihydrochloride hydrate followed by labeling of mitochondrial translation products with ${ }^{35} \mathrm{~S}$-methionine for one hour and subsequent analysis by SDS-PAGE and autoradiography. 
While BN-PAGE analysis, followed by western blot had shown decreases in complex II and complex IV quantity (Figure 3.7), in-gel activity staining was performed to assess the activity of the solubilized OXPHOS complexes (Wittig et al., 2007). To this end, solubilized complexes were separated on BN-PAGE, just as before, and gel strips were incubated in buffer containing NADH (to measure complex I activity), sodium succinate (complex II activity), reduced cytochrome $c$ (complex IV activity) or ATP (complex V). These substrates are converted by the respective complexes and the product is visible as precipitations in the gel. The intensity of these precipitations can be correlated to complex activity. In-gel activity staining of ROMO1 ${ }^{-}$ mitochondria revealed a severe decrease of complex IV activity compared to WT mitochondria (lane 5 and 6; Figure 3.9), while complex II was also affected (lanes 3 and 4). Both complex I and complex V showed precipitations of similar intensity for $\mathrm{WT}$ and $\mathrm{ROMO1}^{-1-}$ mitochondria (lanes 1 and 2 and 7 and 8 respectively; Figure 3.9).

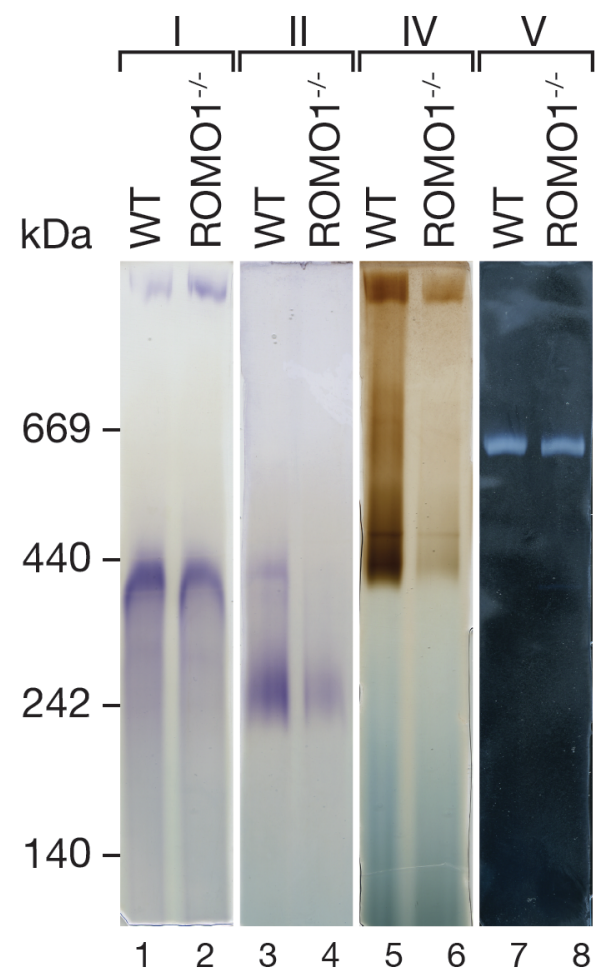

Fig. 3.9: In-gel activity staining reveals reduced complex II and IV activity in $\mathrm{ROMO1}^{-1-}$ mitochondria.

Isolated $\mathrm{WT}$ and $\mathrm{ROMO1}^{-1-}$ mitochondria were solubilized in digitonin and membrane complexes were separated on BNPAGE, followed by in-gel activity staining of oxidative phosphorylation complexes I, II, IV and V. Performed with technical assistance by Christin Ronsör.

To corroborate the effects of ROMO1 ablation on the respiratory chain, in vitro assays were carried out to quantitatively assess the activity of specific complexes. Complex IV Human Specific Activity Microplate Assay Kit was used to assess the activity and quantity of complex IV. WT and $\mathrm{ROMO1}^{-1}$ cells were solubilized and applied to the provided plate which 
immunocaptures complex IV. Subsequently, reduced cytochrome $c$ was added, which is oxidized by the complex and can be colorimetrically assessed by an absorbance decrease at $500 \mathrm{~nm}$. In a following step, the amount of enzyme complex is measured by addition of an antibody, which is conjugated with alkaline phosphatase. The added substrate changes from colorless to yellow, which is time dependent and proportional to complex IV quantity and can again be assessed colorimetrically. This analysis mirrored the phenotype seen on BN-PAGE (Figure 3.7 and 3.9), since both complex IV activity and quantity were about 40-50\% reduced when ROMO1 was absent (Figure 3.10a). It should be noted that the decrease in activity correlates with the decrease in quantity. This most likely means that the activity of complex IV remained the same and only the quantity is reduced.

Furthermore, BN-PAGE analysis had revealed a decrease in complex II amount and activity (Figures 3.7 and 3.9). Therefore, complex II activity was assessed quantitatively in a cuvette using isolated mitochondria from both cell lines. The ubiquinone analogue CoQ1 was used as a readout for complex II activity, since its reduction can be followed photometrically at $280 \mathrm{~nm}$. Due to the oxidation of succinate to fumarate, CoQ1 is reduced, which reflects the activity of complex II. As indicated by the BN-PAGE analyses, this quantitative assay revealed that complex II activity was reduced by about $40 \%$ in $\mathrm{ROMO}^{-1-}$ mitochondria (Figure $3.10 \mathrm{~B}$ ).

In order to validate these specific results, the activity of malate dehydrogenase was measured. Malate dehydrogenase $(\mathrm{MDH})$ plays a role in many different metabolic pathways, i.e. the citric acid cycle. Its activity reflects the overall, general energy status of the cell. In this assay, oxalacetic acid and NADH are converted to malate and NAD. The disappearance of NADH at 340nm can be measured using a photometer and is correlated to the MDH activity. In mitochondria lacking ROMO1, MDH activity was only minorly affected (Figure 3.10C), which showed that respiration in general in mitochondria was not disturbed. 

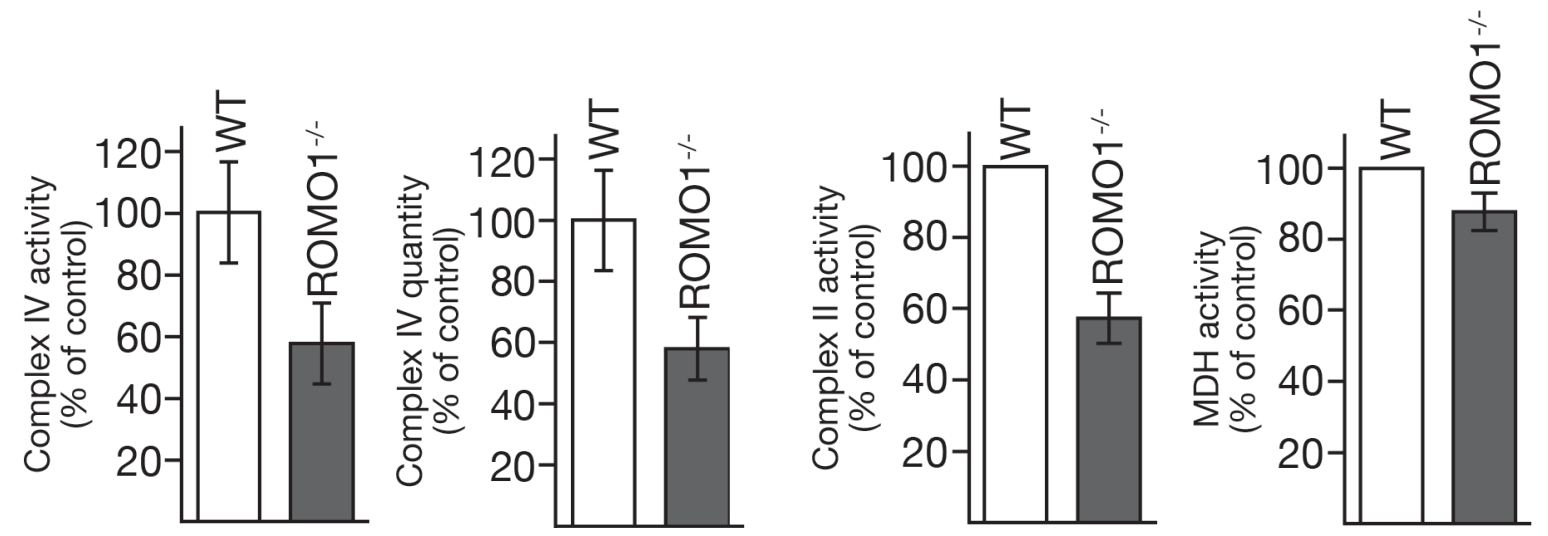

Fig. 3.10: Quantitative respiratory chain analysis of $\mathrm{WT}$ and $\mathrm{ROMO1}^{-/}$cells or mitochondria confirms $\mathrm{BN}-$ PAGE analysis.

(A) Measurement of enzyme activity and relative amount of cytochrome $c$ oxidase (complex IV) of solubilized and immobilized WT and ROMO1 ${ }^{-/}$cells by Complex IV Human Specific Activity Microplate Assay Kit.

(B) Enzyme activity of succinate dehydrogenase (complex II) of WT and $\mathrm{ROMO}^{-1-}$ mitochondria was measured photometrically.

(C) Malate dehydrogenase $(\mathrm{MDH})$ activity of solubilized WT and $\mathrm{ROMO1}^{-/}$mitochondria was measured photometrically.

For all analyses, WT was set to $100 \%$ and the mean \pm SEM of three independent experiments is shown.

\subsubsection{Analysis of reactive oxygen species production hints at secondary effects}

To analyze the cellular physiological effects of a knockout of ROMO1, the presence of reactive oxygen species (ROS) in whole cells was determined. As its name indicates, the overexpression of ROMO1 has been correlated to a high increase in ROS production in many tissues (i.e. Chung et al., 2006). However, conflicting evidence has been provided regarding the abolishment of ROMO1 and its effects. While most studies reported decreasing ROS with decreasing ROMO1 expression (i.e. Chung et al., 2008; Lee et al., 2011; Shin et al., 2013; Shyamsunder et al., 2015), Norton et al. (2014) reported a two-fold increase in ROS in their knockdown model. The abundance of ROS in this new ROMO1 knockout model was assayed by MitoSOX ${ }^{\mathrm{TM}}$ Red mitochondrial superoxide indicator. This reagent is targeted to mitochondria and is oxidized by superoxide present in mitochondria. Upon oxidation, the dye exhibits red fluorescence, which can be measured and its intensity can be correlated to ROS production. 

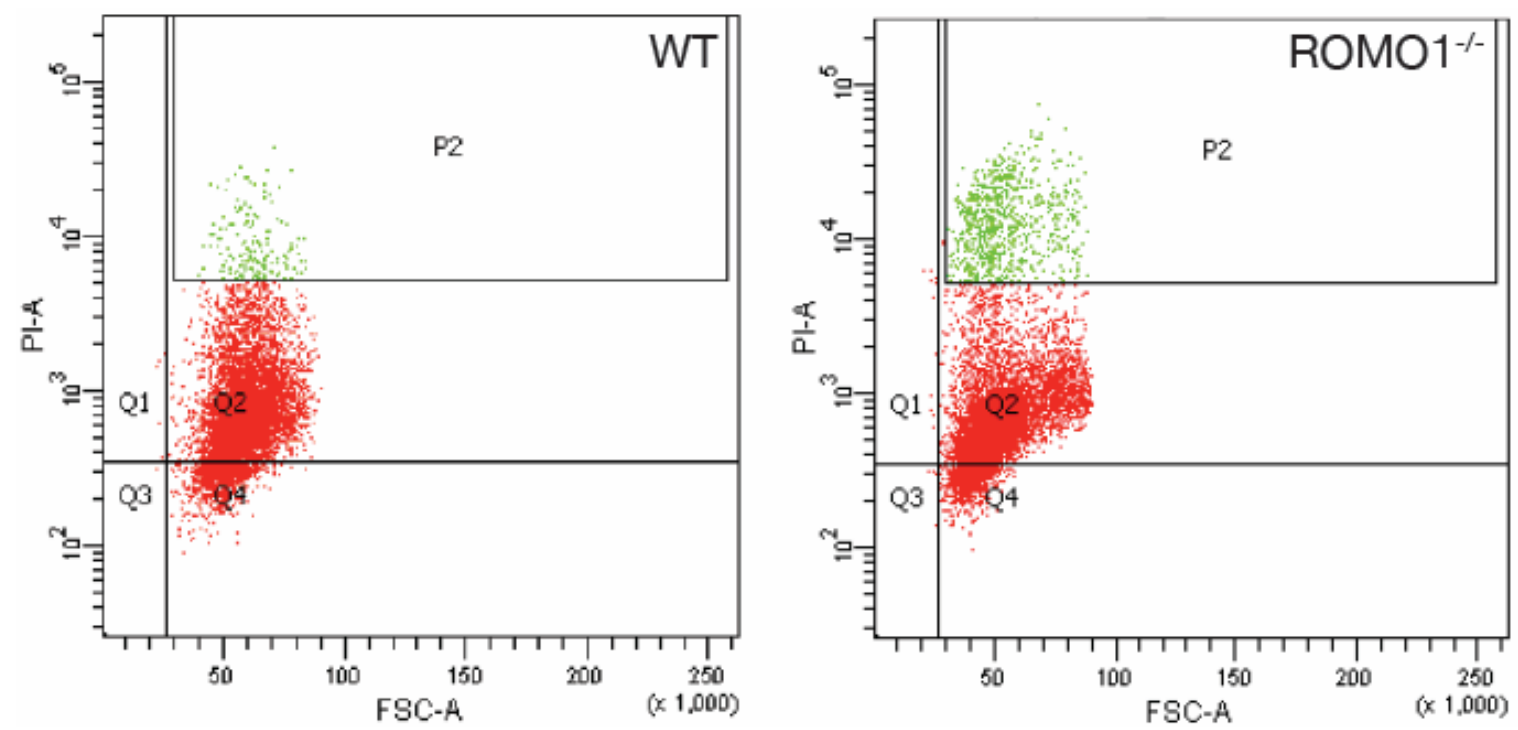

B

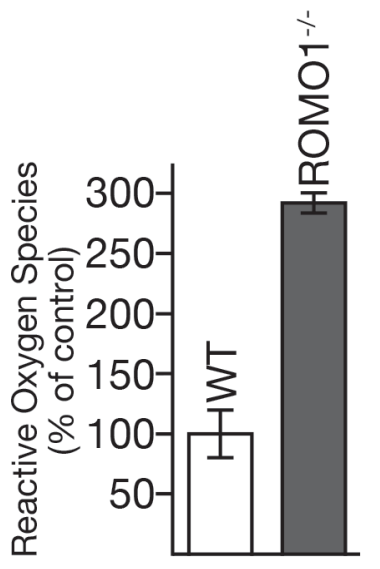

Fig. 3.11: ROS levels are drastically increased in ROMO1 ${ }^{-1-}$ cells.

(A) Reactive oxygen species production was measured in whole WT and $\mathrm{ROMO}^{-1-}$ cells using MitoSOX ${ }^{\mathrm{TM}}$ Red mitochondrial superoxide indicator. Each dot represents one cell. Forward scatter (FSC-A) is a measure for the size of the cells. Emission at 580nm is displayed as PI-A. Higher ROS levels are detected by higher emission.

(B) Percentages of cells present in P2 were normalized to WT and are presented as mean $\pm S E M, n=3$.

$\mathrm{ROMO}^{-1-}$ cells showed a much higher emission of red fluorescence, which can be seen by the higher number of cells in P2 (Figure 3.11A). Quantifications from three independent experiments showed a three-fold increase as compared to WT cells (Figure 3.11B). This was very surprising and in contrast to almost all published data. Not only in the respect that most studies had reported decreasing ROS in the absence of ROMO1, but even Norton et al. (2014) had only reported a two-fold increase in ROS in their knockdown model. This could hint at possible secondary effects and questioned the suitability of this knockout cell line as a good model to study the molecular function of ROMO1. It would be difficult to predict which observed 
phenotypes were a direct consequence of ROMO1 ablation and which were due to secondary effects. Therefore, other possible models to study the molecular function of ROMO1 had to be explored.

\subsection{Transient depletion of ROMO1 mimics the knockout phenotype but does not produce ROS}

\subsubsection{ROMO1 has a rapid turnover and is required for cell proliferation}

The knockout of ROMO1 included the possibility of secondary effects which were not necessarily directly linked to the ablation of ROMO1. To explore other models to study the

phenotypes of ROMO1 depletion, the stability and turnover of ROMO1 was assessed as a first step. For this purpose, HEK293T WT cells were treated with emetine dihydrochloride hydrate. As described above, emetine inhibits cytosolic protein synthesis (Delves \& Roitt, 1998). Since protein biogenesis is stopped, the turnover of proteins can be assessed.

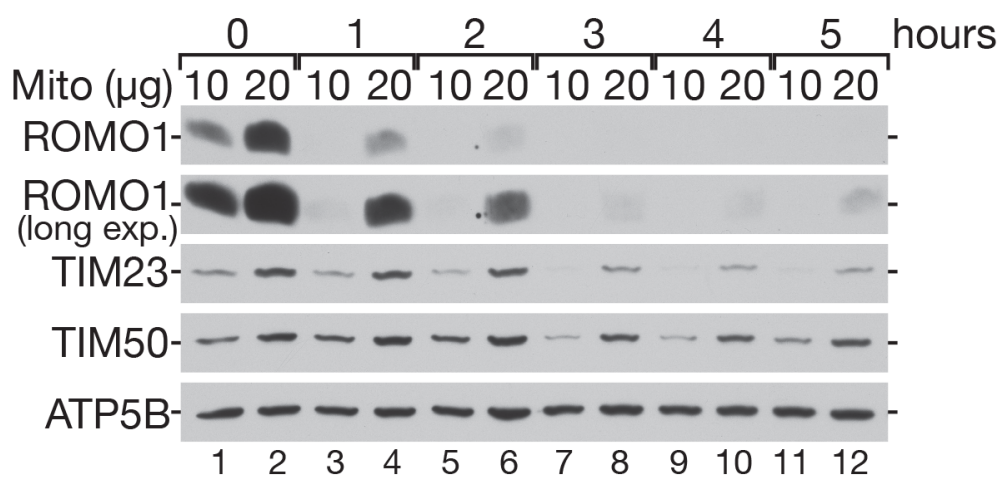

Fig. 3.12: Stability assay of mitochondrial proteins using emetine reveals that ROMO1 is quickly degraded. HEK293T WT cells were treated with $20 \mu \mathrm{g} / \mu \mathrm{L}$ emetine dihydrochloride hydrate for the indicated time points. Cells were harvested, isolated mitochondria were lysed and analyzed by SDS-PAGE and immunoblotting.

Steady state levels of ROMO1 were analyzed alongside a few other mitochondrial proteins. ATP5B and TIM50 seemed rather stable, as their levels did not change much, even five hours after translation had been inhibited (Figure 3.12). TIM23 started to be degraded after three 
hours. However, ROMO1 showed the most drastic effects, as already after one hour, ROMO1 was almost completely degraded (Figure 3.12). This shows that ROMO1 is a very unstable protein, with a very fast turnover. Therefore, a more transient knockdown approach might be better suited to study the immediate effects of ROMO1 ablation, minimizing the risk of secondary effects that a knockout approach might entail.

To verify ROMO1 phenotypes during a transient knockdown (KD), HEK293T WT cells were treated with siRNA oligonucleotides specifically targeting ROMO1. Cells were transfected with siRNA targeting ROMO1, or control siRNA (non-targeting, siNT), by transient forward transfection using Lipofectamine and cells were harvested after 72 hours. Western blot analysis of isolated mitochondria revealed that ROMO1 was absent on a protein level, while levels of translocase components, such as TIM21, TIM23 and TIM50 did not change (Figure 3.13A). In general, effects on the respiratory chain components, COX1, COX4I-1, COX6C of complex IV and SDHA of complex II, mirrored what had been observed in $\mathrm{ROMO}^{-/-}$mitochondria (see Figure 3.3). Protein levels of MITRAC12 and the complex V component, ATP5B, did not change as before.

A

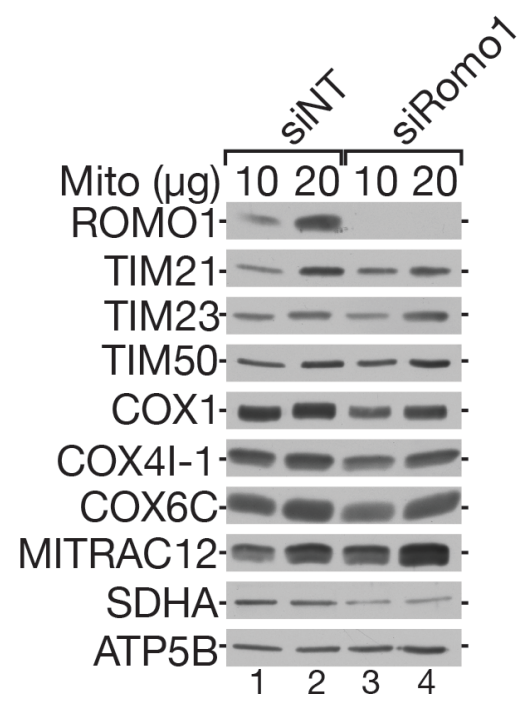

B

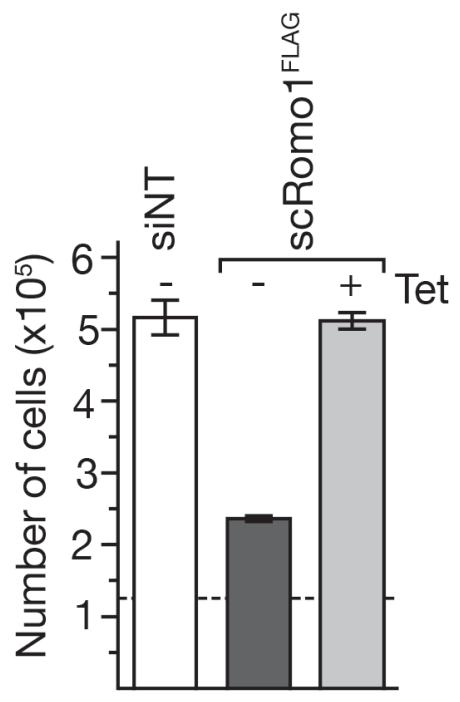

Fig. 3.13: siRomo1 cells mimic phenotypes of ROMO1 ${ }^{-/-}$cell line.

(A) siRNA oligonucleotides targeting Romo1 or non-targeting control siRNA (NT) were applied onto WT cells for 72 hours. Mitochondria were isolated, lysed and analyzed by SDS-PAGE and western blot.

(B) Proliferation assay of cells expressing inducible siRNA resistant ROMO1 ${ }^{\text {FLAG }}$ (scROMO1 ${ }^{\text {FLAG }}$ ), treated with NT siRNA and siRNA against Romo1 in the presence or absence of tetracycline (Tet). Starting cell number of 125,000 cells represented by dashed line (mean \pm SEM, $n=3$ ). Courtesy of Sven Dennerlein. 
To validate our knockdown approach further, cell proliferation upon siRNA treatment was assessed. To this end, a cell line expressing siRNA resistant, C-terminally tagged, ROMO1 $1^{\mathrm{FLAG}}$ under a tetracycline-inducible promoter $\left(\mathrm{scROMO1}{ }^{\mathrm{FLAG}}\right)$ was produced in collaboration with Sven Dennerlein from the University Medical Center Göttingen, Germany. This enables verification of whether the observed phenotype is specific to the transient depletion of ROMO1. These cells underwent siRNA treatment as before, while one cohort was treated with tetracycline, while the other one was not. Cells were counted after 72 hours. Cells treated with siRNA targeting ROMO1 without tetracycline administration grew more than $50 \%$ slower than siNT treated cells, however, re-expression of ROMO1 ${ }^{\mathrm{FLAG}}$ could rescue this phenotype almost completely (Figure 3.13B). Both steady state analysis and cell proliferation assays indicated that transient depletion of ROMO1 was a suitable way to study the effects of ROMO1 ablation, since the phenotypes between $\mathrm{KO}$ and $\mathrm{KD}$ were comparable.

\subsubsection{Transient depletion of ROMO1 does not lead to increased ROS production but mimics respiratory chain phenotypes of ROMO1 ${ }^{-/-}$cells}

While initial experiments seemed to validate the knockdown approach as a suitable model to study the molecular function of ROMO1, the production of reactive oxygen species had to be assessed. ROMO1 was transiently depleted by siRNA as before and MitoSOX ${ }^{\mathrm{TM}}$ Red mitochondrial superoxide indicator was used, followed by fluorescence emission detection to measure ROS. In line with previously published data, siRomol cells showed a slight decrease in ROS production, evident in window P2 which contains fewer cells (Figure 3.14). This again underlines the fact that ROMO1 KD is a more suitable model to study ROMO1 function since secondary effects, most likely present in the KO cells, could be avoided.

$\mathrm{ROMO}^{-\digamma}$ cells had exhibited respiratory chain defects. Most notably, the quantity and activity of complex IV were drastically reduced, while the quantity and activity of complex II were slightly reduced (Figure 3.7, 3.9 and 3.10). To confirm this phenotype in ROMO1-KD cells, the same analyses were performed. Upon siRNA treatment, isolated mitochondria were solubilized 
in digitonin and membrane complexes were analyzed by BN-PAGE. Probing with SDHA to visualize complex II revealed very minor effects upon transient ROMO1 KD (Figure 3.15A) and, by far, not as pronounced as in the ROMO1 KO (Figure 3.7). The most drastic effect had been seen on complex IV, visualized by antibody probing against COX1 and COX4I-1 (Figure 3.7). Although complex IV was not as affected during transient ablation of ROMO1 as was seen with the KO, complex IV quantity was still visibly affected, while complex I (detected with NDUFA10) showed no alterations (Figure 3.15A).

A
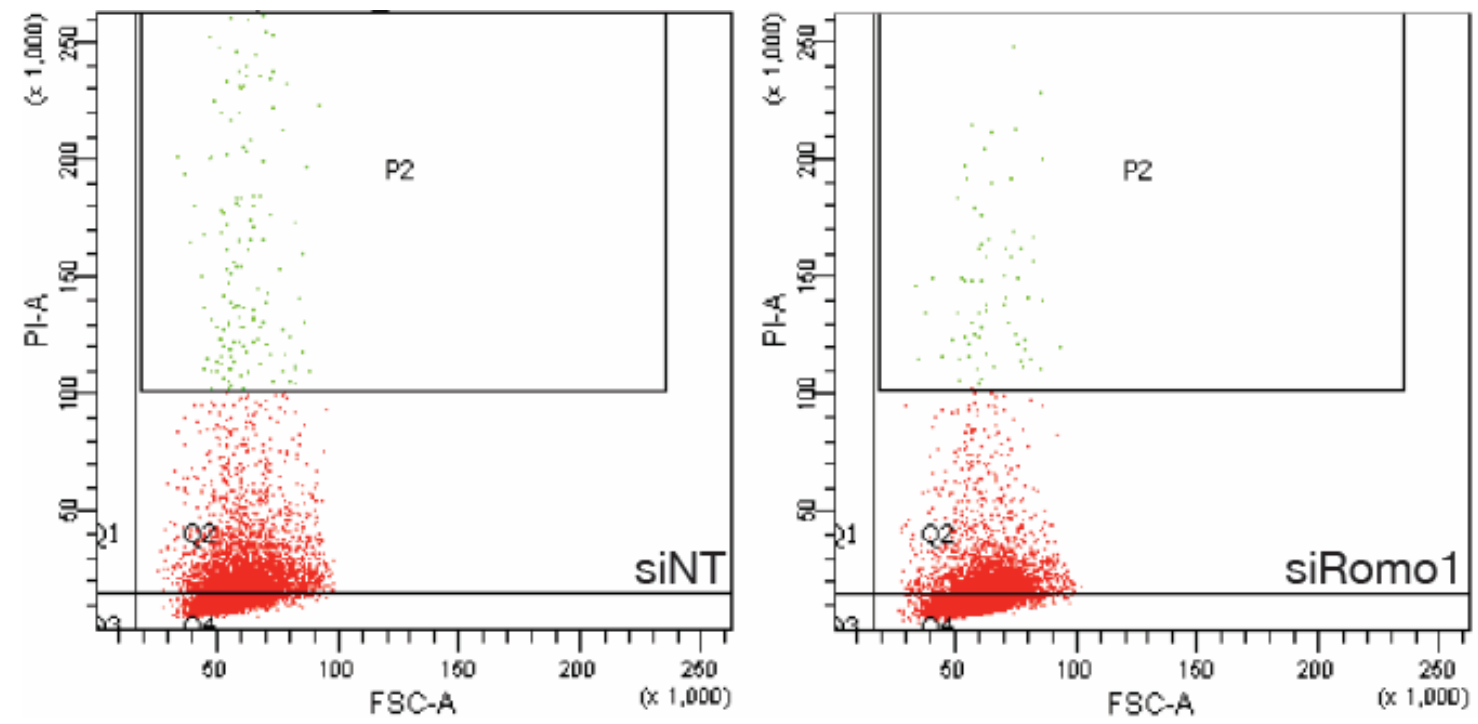

B

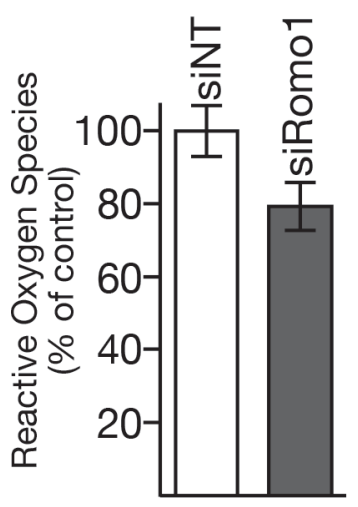

Fig. 3.14: ROS levels are slightly reduced in siRomo 1 cells.

(A) Reactive oxygen species production was measured in whole siNT and siRomol cells using MitoSOX ${ }^{\mathrm{TM}}$ Red mitochondrial superoxide indicator. Each dot represents one cell. Forward scatter (FSC-A) is a measure of the size of the cells. Emission at $580 \mathrm{~nm}$ is displayed as PI-A. Higher ROS levels are detected by higher emission.

(B) Percentages of cells present in P2 were normalized to siNT and are presented as mean \pm SEM, $n=3$. 
To assess activity of the respiratory complexes, solubilized complexes were separated on BNPAGE and gel strips were incubated in a buffer containing sodium succinate (to measure complex II activity), or a buffer containing reduced cytochrome $c$ (to measure complex IV activity), just as before. In-gel activity staining of siRomol mitochondria revealed a severe decrease of complex IV activity, while complex II activity was not affected (Figure 3.15B).

As was performed with ROMO1 knockout cells, the effects of transient ROMO1 ablation on the respiratory chain were further assessed by quantitative in vitro assays. Complex II activity was again assayed following the reduction of CoQ1. Consistent with the in-gel activity staining (Figure 3.15B), complex II activity was not reduced in siRomol mitochondria (Figure 3.15C). Furthermore, malate dehydrogenase activity did not reveal any changes, confirming that respiration in general is not disturbed (Figure 3.15D). Finally, Complex IV Human Specific Activity Microplate Assay Kit was again used to assess the activity and quantity of complex IV. This analysis mirrored the phenotype seen on BN-PAGE, since both complex IV activity and quantity were about 40-50\% reduced when ROMO1 was depleted (Figure 3.15E). As observed for the $\mathrm{KO}$, the activity of complex IV most likely remained the same upon siRomol treatment but the quantity in general was reduced.

All in all, it can be concluded that due to the fast turnover rate of ROMO1, transient siRNA mediated depletion is a very suitable option to study the molecular function of ROMO1. It mirrors the effects on cell proliferation and respiratory chain activity of the knockout model, while minimizing possible secondary effects such as high ROS production. 


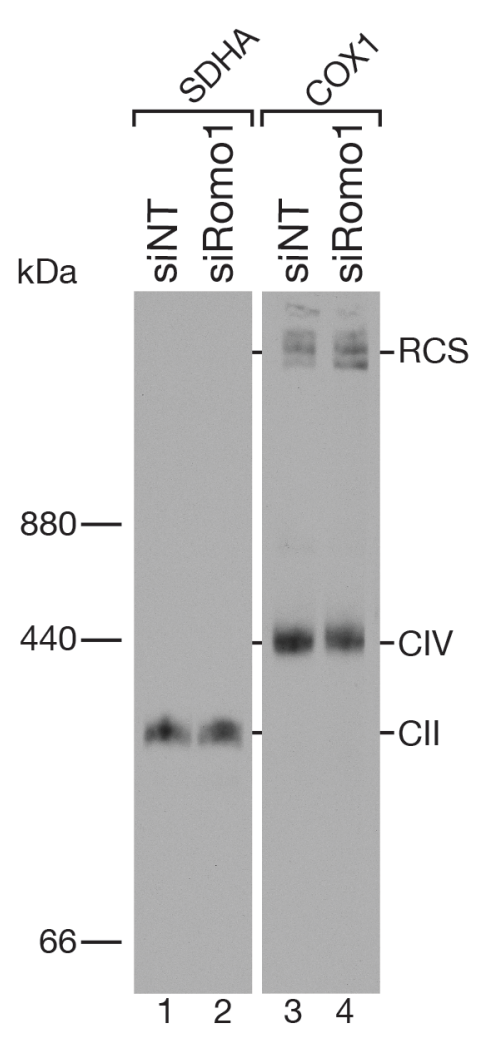

C

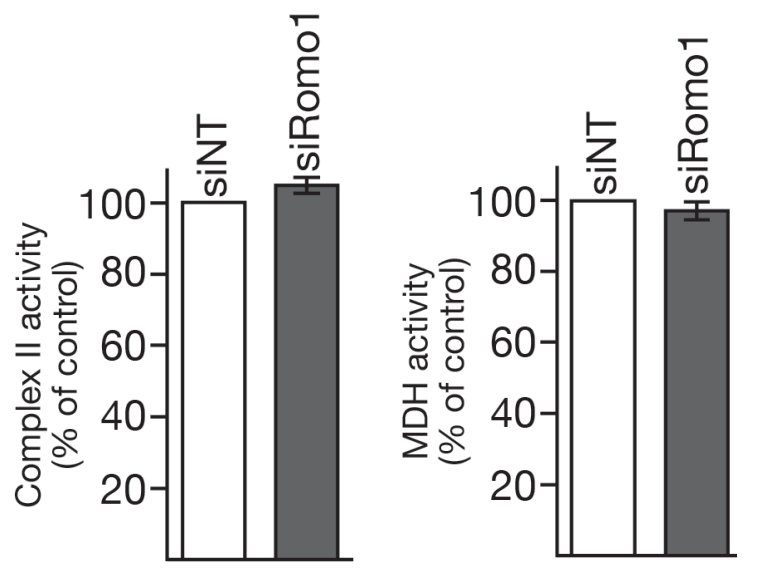

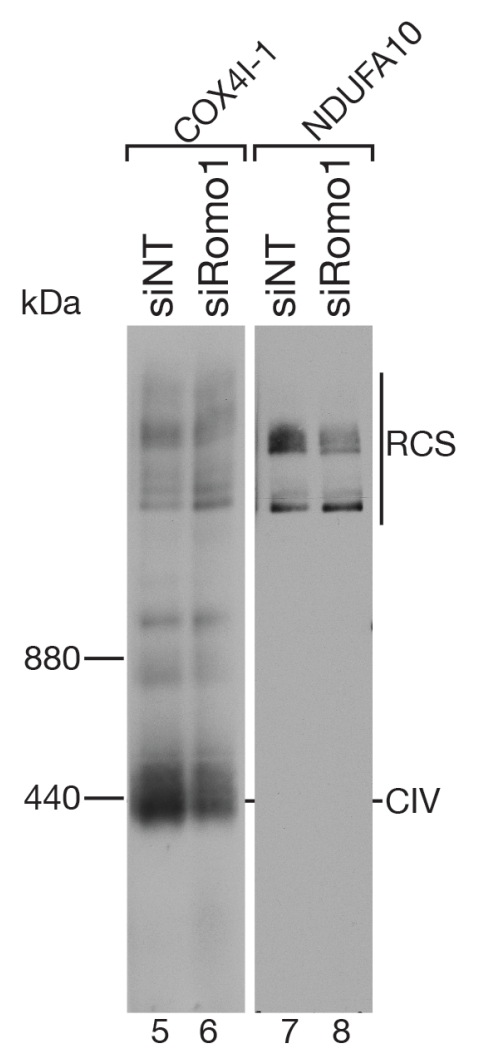

E

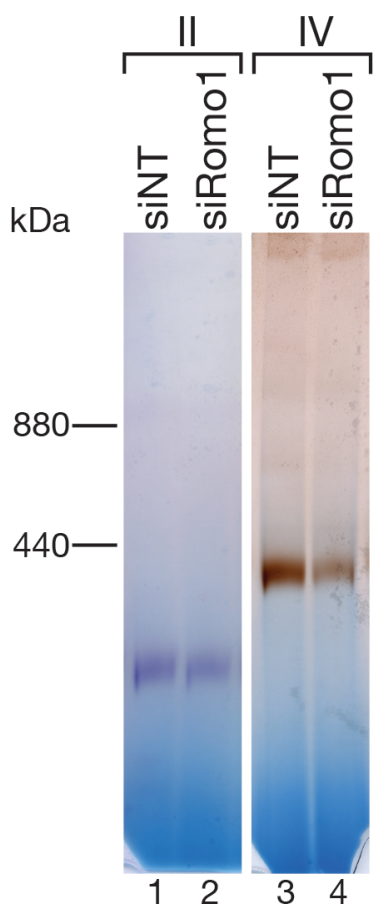

Fig. 3.15: OXPHOS complex analysis of siRomol mitochondria mimics ROMO1 ${ }^{-/-}$phenotypes.

(A) Cells underwent siRNA treatment; isolated mitochondria were solubilized in digitonin and membrane complexes were separated on BN-PAGE followed by immunoprobing with the indicated antibodies. CII, complex II; CIV, complex IV; RSC, Respiratory chain supercomplexes.

(B) In-gel activity staining of oxidative phosphorylation complexes. Mitochondria were lysed as in A, analyzed by BN-PAGE, followed by in-gel activity assays for complexes II and IV.

(C) Measurement of enzyme activity of succinate dehydrogenase (complex II) of siNT and siRomol mitochondria (mean \pm SEM, $\mathrm{n}=3$ ).

(D) Measurement of MDH activity of solubilized siNT and siRomo1 mitochondria (mean \pm SEM, $n=3$ ).

(E) Measurement of enzyme activity and relative amount of cytochrome $c$ oxidase (complex IV) of solubilized and immobilized siNT and siRomol cells (mean \pm SEM, $n=3$ ). 


\subsection{ROMO1 couples TIM21 onto the translocase while it does not affect protein import in general}

\subsubsection{ROMO1 dynamically interacts with the TIM23 complex}

The analyses described above confirmed ROMO1 as a TIM23 constituent, but its role at the translocase of the inner membrane had not been defined. In yeast, Mgr2 couples Tim21 and Tim23 to one another (Gebert et al., 2012) and due to their high sequence similarity, it seemed conceivable that ROMO1 might have a similar function. To this end, HEK293T cells expressing tetracycline-inducible C-terminally tagged TIM23 ${ }^{\mathrm{FLAG}}$, along with WT cells, were used. WT cells were only treated with non-targeting siRNA, while TIM $23^{\mathrm{FLAG}}$ underwent both NT and Romo1 siRNA treatment. Using immunoprecipitation, TIM $23^{\mathrm{FLAG}}$ interacting proteins were isolated via anti-FLAG beads. Subsequently, the immunoisolations were analyzed by SDS-PAGE and western blot and respective bands were quantified. This allowed the assessment of interaction changes within the translocase in the absence of ROMO1. The amount of TIM21 copurified with TIM23 ${ }^{\text {FLAG }}$ drastically reduced upon Romo1 knockdown, while the amount of TIM50 copurified remained similar (Figure 3.16A). This became more obvious when quantified from three independent experiment, where the interaction between TIM23 and TIM21 was decreased by $45 \%$ compared to the siNT treated sample, while the interaction between TIM23 and TIM50 was barely decreased (Figure 3.16A).

TIM21 has been shown to be a dynamic subunit of the TIM23 complex, since it is also present in major assembly intermediates of cytochrome $c$ oxidase (MITRAC) (Mick et al., 2012). When immunoisolating the interaction partners of TIM $21^{\text {FLAG }}$ upon ROMO1 depletion, just as before, we observed a reduction in co-purified TIM23 (Figure 3.16B), confirming that ROMO1 is required for TIM23 association with TIM21. In contrast, COX1 or MITRAC12 amounts coisolated with TIM $21^{\mathrm{FLAG}}$ were only marginally affected upon ROMO1 depletion. 

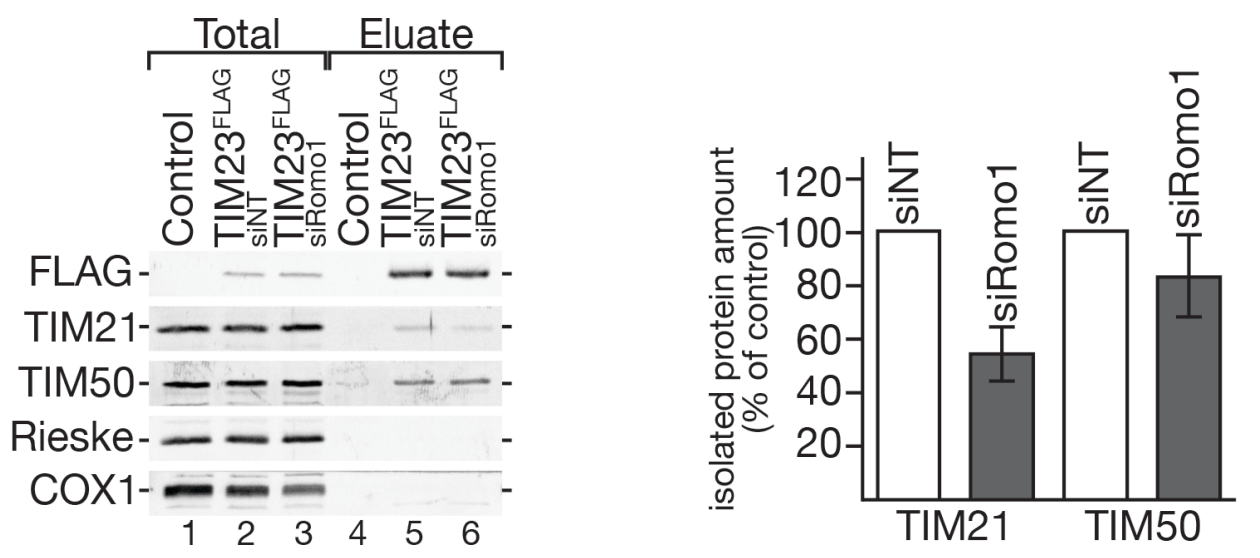

B

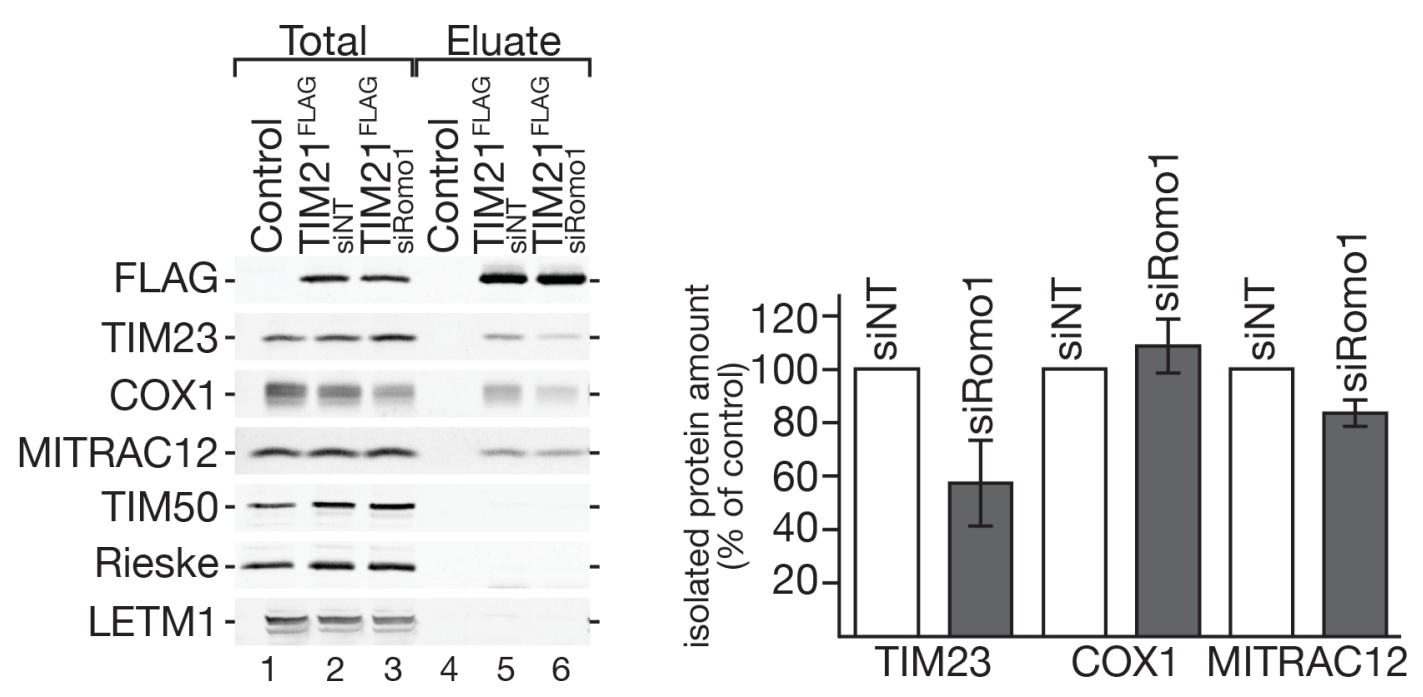

Fig. 3.16: ROMO1 couples TIM21 onto TIM23.

(A) HEK293T WT and TIM23 $3^{\mathrm{FLAG}}$ cells underwent treatment with siRNA oligonucleotides targeting Romo1 or non-targeting siRNA (NT) for 72 hours. Cells were solubilized using digitonin and incubated with anti-FLAG beads. Upon elution by FLAG-peptide, interaction partners were analyzed by SDS-PAGE and immunoblotting using the indicated antibodies. Eluate: $100 \%$, total: $5 \%$.

(B) HEK293T WT and TIM21 $1^{\mathrm{FLAG}}$ cells were treated as in (A).

Results are presented as quantification of eluate/total, normalized to efficiency of immunoprecipitation (FLAG signal in eluate). Values of siNT were set to $100 \%$ (mean \pm SEM, $n=3$ ).

Taken together, it can be concluded that ROMO1 couples TIM21 onto TIM23, while it does not have an effect on the interactions between TIM23 and TIM50. The reverse experiment showed 
the same, clearly indicating that ROMO1 couples TIM23 onto TIM21, while it is not required for the association between TIM21 and COX1 or MITRAC12.

\subsubsection{ROMO1 plays a minor role in general protein import}

Following these interaction studies, a role of ROMO1 in the TIM23-mediated import of proteins into the mitochondrial matrix, as well as the inner membrane was studied. For this purpose, open reading frames of various TIM23 import substrates were cloned into expression vectors and underwent in vitro transcription and translation in the presence of radioactively-labeled ${ }^{35} S$ methionine. Alternatively, RNA was synthesized, followed by in vitro translation in the presence

of radioactively-labeled ${ }^{35} \mathrm{~S}$-methionine. These radiolabeled precursor proteins were then imported in vitro into freshly isolated, energized mitochondria from siNT and siRomol treated cells. The reactions were stopped at different time points by the addition of a drug mix (antimycin, valinomycin, oligomycin) that dissipates the membrane potential $(\Delta \psi)$. One sample was treated with the same mixture at the beginning to act as an import deficient negative control. The reactions were then analyzed by SDS-PAGE and autoradiography. Since these presequencebearing proteins are processed, the import efficiency can be assessed by comparing the intensity of the accumulated, faster migrating, mature form of the protein. Matrix targeted ornithine transcarbamylase (OTC), a protein functioning in the urea cycle, was imported as described above. Comparing the intensities of the mature forms, it appeared that OTC import efficiency was not affected in the absence of ROMO1 (Figure 3.17A). This was quantified and confirmed that the import of OTC was not dependent on ROMO1 (Figure 3.17A). As a second matrixtargeted model protein, the import of the fusion protein Su9-dihydrofolate reductase (Su9DHFR) was assessed in the same way. As for OTC, the import of Su9-DHFR also did not depend on ROMO1, as intensities of the mature form of Su9-DHFR were similar between siNT and siRomo1 samples (Figure 3.17B).

Since ROMO1 was not required for the import of matrix-targeted proteins, it was assessed if it was involved in the sorting and lateral release of membrane targeted proteins. Laterally sorted 
proteins do not only have a presequence targeting them to mitochondria, but also contain a hydrophobic stop-transfer signal, which anchors them to the membrane. This stop-transfer signal arrests import in the translocase and leads to lateral release into the membrane. To assess the function of ROMO1 in the import of inner membrane targeted proteins, radioactively labeled EMRE (Essential mitochondrial $\mathrm{Ca}^{2+}$ uniporter regulator) was used as a substrate. EMRE is a small transmembrane protein and a subunit of the mitochondrial $\mathrm{Ca}^{2+}$ uniporter (MCU) (König et al., 2016; Sancak et al., 2013). When comparing the intensity of the faster-migrating mature form, the import efficiency of EMRE was not affected in the absence of ROMO1 (Figure 3.18A). As a second transmembrane substrate, the import efficiency of the complex IV component, COX6A1, a peripheral late-associating subunit (Lazarou et al., 2009; Mick et al., 2012) was assessed. The import efficiency of COX6A1 was also not affected in the absence of ROMO1 (Figure 3.18B). Quantification confirmed that the import of COX6A1 was not dependent on ROMO1 (Figure 3.18B).

A
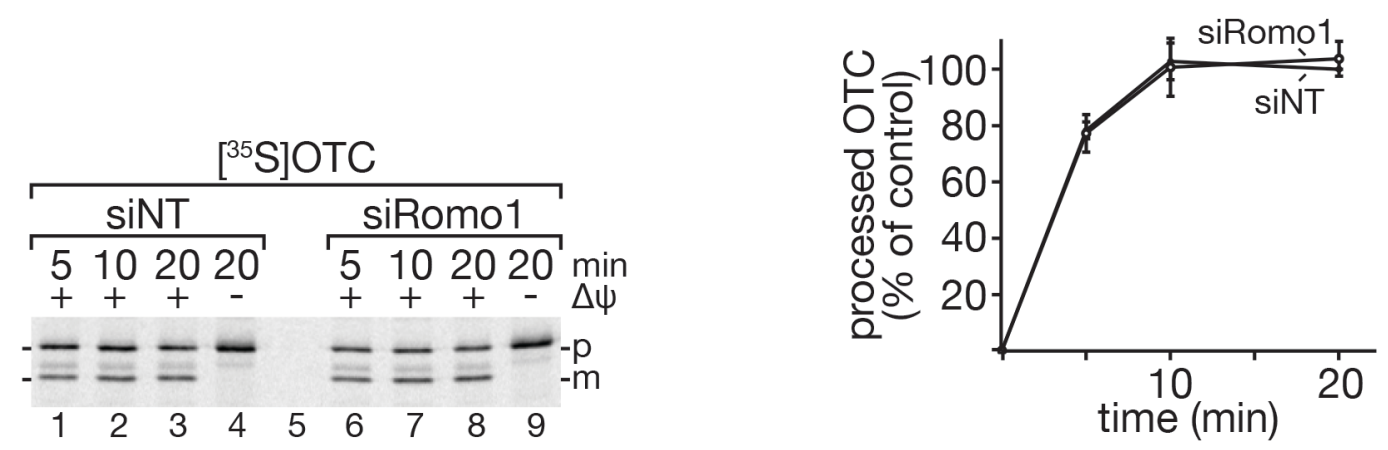

B

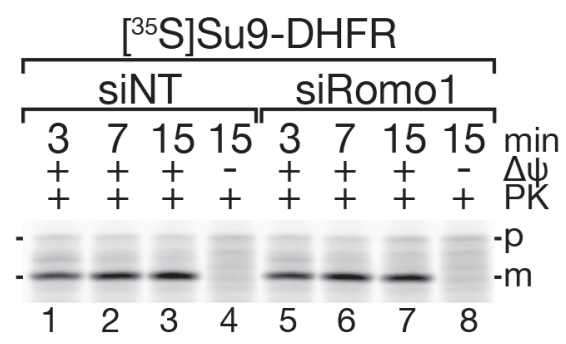

Fig. 3.17: Import of matrix targeted proteins is not dependent on ROMO1.

${ }^{[35}$ S]OTC (A) and $\left[{ }^{35}\right.$ S]Su9-DHFR (B) were imported into energized HEK293T mitochondria isolated from siNT and siRomol cells. Import was stopped when indicated and samples were treated with proteinase K (PK) where stated. Analysis was carried out by SDS-PAGE and autoradiography. Import of siNT sample at 20 minutes was set to $100 \%$. The mean \pm SEM $(n=3)$ is shown. p, precursor; $m$, mature protein. 
In contrast to COX6A1, which is a late-stage assembling subunit of complex IV, COX4I-1 assembles early into complex IV and interacts with the assembly intermediate MITRAC (Lazarou et al., 2009; Mick et al., 2012; Nijtmans et al., 1998; Stiburek et al., 2005; Williams et al., 2004). Since ROMO1 is involved in the coupling of TIM21, a MITRAC component, to TIM23, it seemed conceivable that the import of COX4I-1 may depend on ROMO1. Using the same assay as before, radioactively labeled COX4I-1 was imported into ROMO1 depleted mitochondria. While quantification of OTC and COX6A1 import showed almost identical import efficiency for siNT and siRomol mitochondria (Figure 3.17A and 3.18B respectively), the efficiency of COX4I-1 import was mildly reduced when ROMO1 was absent (Figure 3.19A).

The previously described experiments assess the import of the presequence-containing precursors and the processing of the presequence to yield a mature form. However, they do not enable an assessment of lateral release and membrane integration of sorted transmembrane proteins. For this purpose, one has to analyze the assembly of selected proteins into complexes within the inner membrane. This can be determined by BN-PAGE analyses of solubilized mitochondria after the import reaction.

A

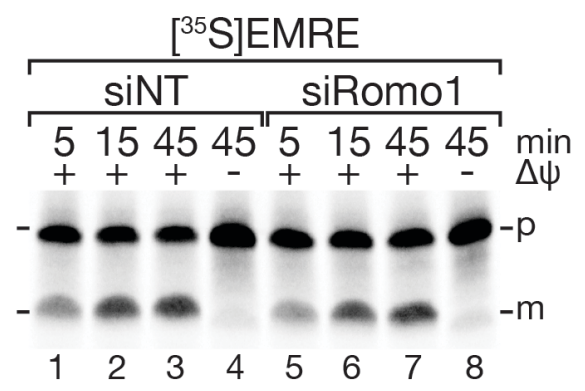

Fig. 3.18: Import of selected inner membrane targeted proteins is not dependent on ROMO1.

$\left[{ }^{35}\right.$ S]EMRE (A) and $\left[{ }^{35}\right.$ S]COX6A1 (B) were imported into energized HEK293T mitochondria isolated from siNT or siRomol cells. Import was stopped at 5, 15 or 45 minutes. Samples were analyzed by SDS-PAGE and autoradiography. Import of siNT sample at 45 minutes was set to $100 \%$. The mean \pm SEM $(n=3)$ is shown. $p$, precursor; $m$, mature protein.
B
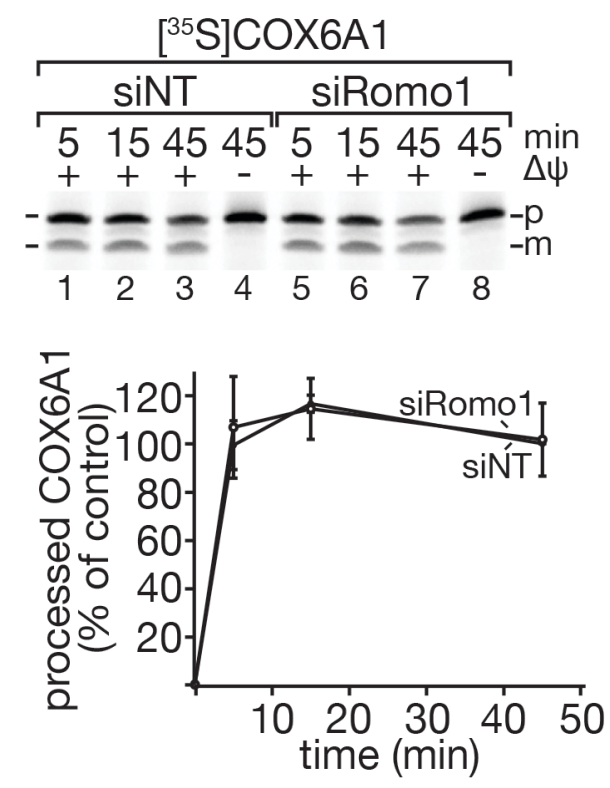
COX6A1 is a subunit of complex IV which has a molecular weight of approximately $400 \mathrm{kDa}$ (see Figure 3.7). To assess its release into the inner membrane and integration into complex IV, radioactively labeled COX6A1 was imported into siRomol mitochondria, as before, and analyzed by BN-PAGE and autoradiography. Assembly of COX6A1 into complex IV seemed slower in siRomol mitochondria. However, the final time point showed very similar intensities for siNT and siRomol mitochondria (Figure 3.19B). Furthermore, taking into account the reduced quantity of complex IV (Figure 3.15A and C), it could be concluded that the lateral sorting and assembly of COX6A1 into complex IV was not ROMO1-dependent. Similarly, the lateral sorting of COX4I-1 was tested. Unlike COX6A1, the assembly of COX4I-1 into mature complex IV occurs via the assembly intermediate MITRAC, at about 200kDa (Mick et al., 2012). Upon radioactive import of 45 minutes into siNT and siRomo 1 mitochondria and subsequent analysis by BN-PAGE, the autoradiography showed the capacity of COX4I-1 to assemble into MITRAC was significantly affected in ROMO1-depleted mitochondria (Figure 3.19C). This is plausible since COX4I-1 is a protein highly dependent on the efficient handover from the translocase to MITRAC (Mick et al., 2012). It could therefore be a functional consequence of ROMO1 coupling of TIM21 to TIM23 that COX4I-1 assembly is less efficient in siRomo1 mitochondria.

In conclusion, ROMO1 couples TIM23 and TIM21 to each other. When assessing the import capacity of ROMO1-depleted mitochondria by in vitro import assays, neither of the tested matrix-targeted, nor inner membrane targeted, proteins depended on ROMO1 for their import. This is in stark contrast to Mgr2 in yeast (Gebert et al., 2012; Ieva et al., 2014). However, the role of ROMO1 at the translocase did become apparent when analyzing the assembly of COX4I-1, whose import efficiency relies on the ROMO1-dependent coupling of TIM21 to TIM23. 
A

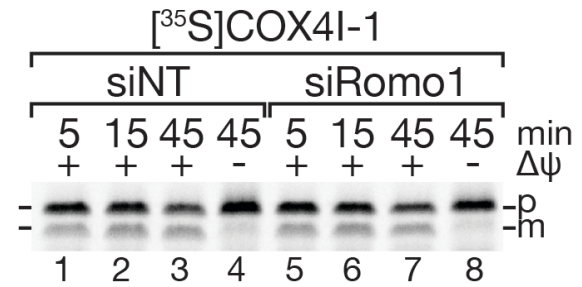

B

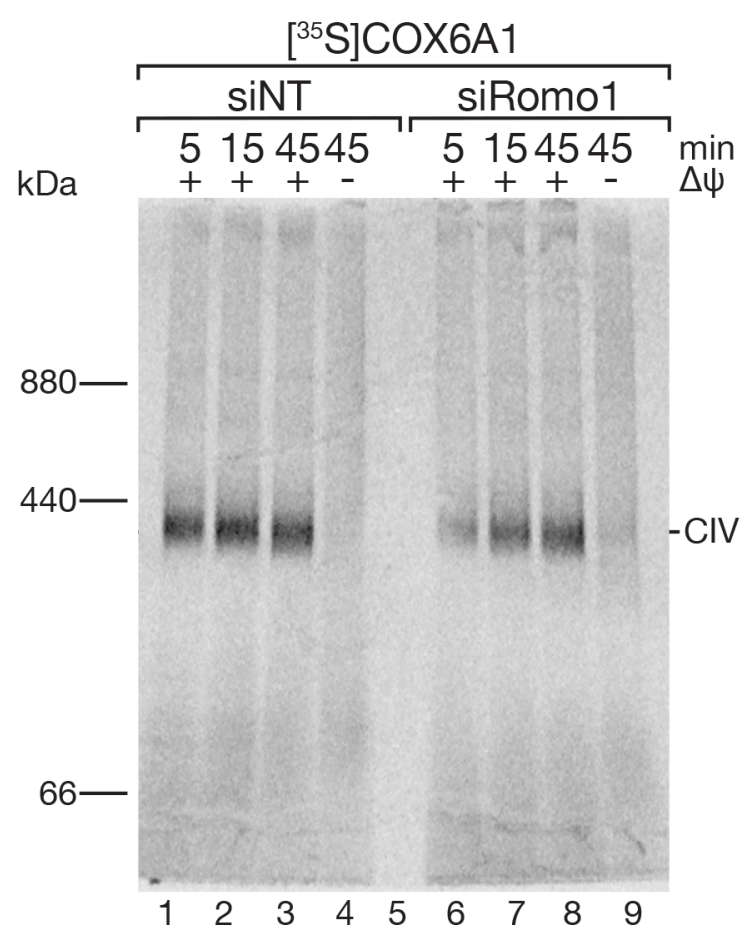

C
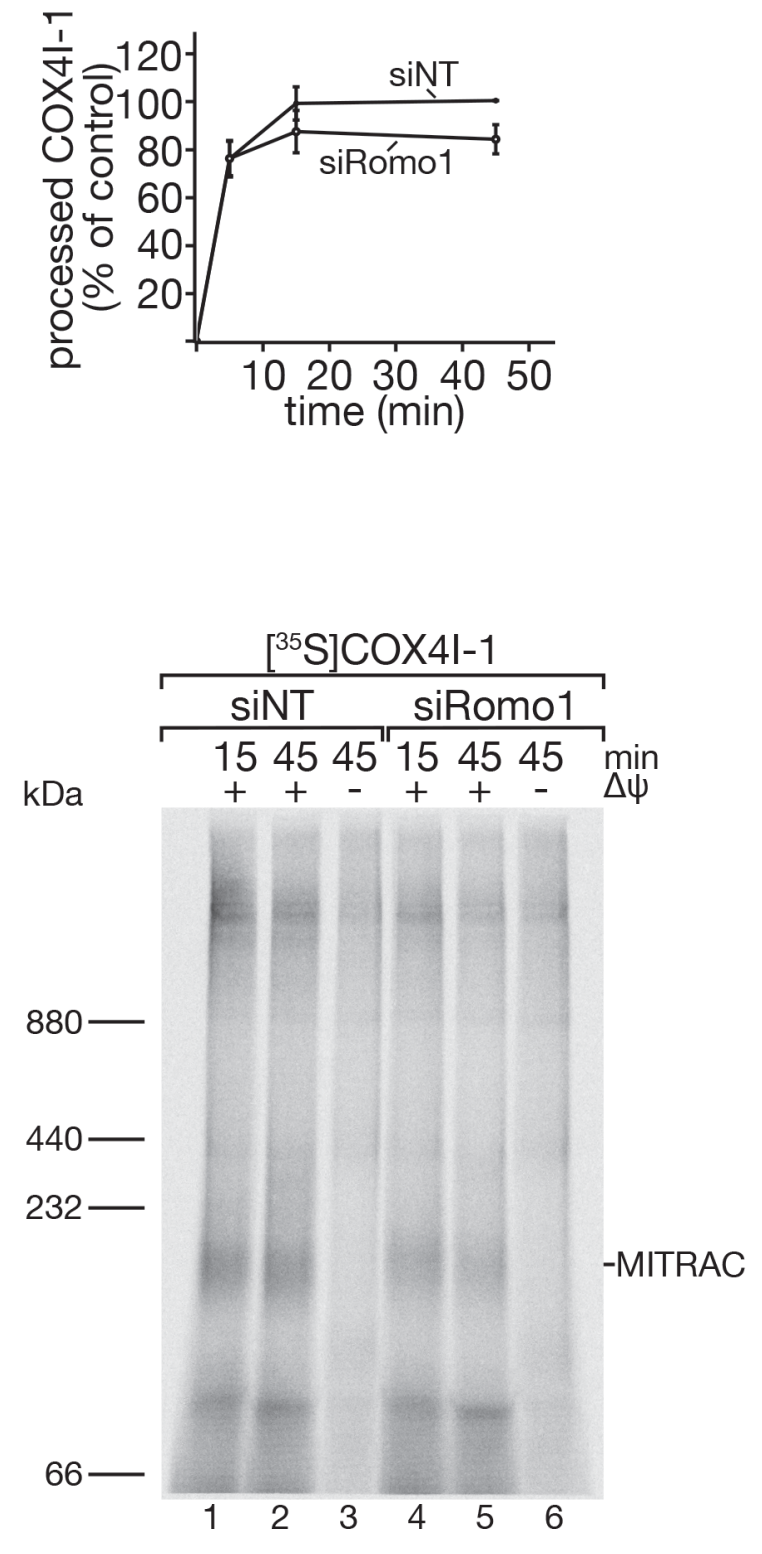

Fig. 3.19: Inner membrane sorting efficiency of COX4I-1 is dependent on ROMO1.

(A) $\left.{ }^{35} \mathrm{~S}\right] \mathrm{COX} 4 \mathrm{I}-1$ was imported into isolated energized mitochondria from siNT and siRomol cells. Import was stopped when indicated. Samples were analyzed by SDS-PAGE and autoradiography. Import of siNT sample at 45 minutes was set to $100 \%$. The mean $\pm \operatorname{SEM}(\mathrm{n}=3)$ is shown. $\mathrm{p}$, precursor; $\mathrm{m}$, mature protein.

$\left[{ }^{35} \mathrm{~S}\right] \mathrm{COX} 6 \mathrm{~A} 1$ (B) and $\left[{ }^{35} \mathrm{~S}\right] \mathrm{COX} 4 \mathrm{~A}-1$ (C) were imported as before. Samples were analyzed by autoradiography following BN-PAGE. CIV, complex IV. 


\subsection{ROMO1 is required for the import of the $i$-AAA protease YME1L}

\subsubsection{ROMO 1 is rapidly degraded by the $i$-AAA protease YME1L}

During the initial functional studies of ROMO1, ROMO1 displayed an unusually fast turnover when cytosolic translation was halted by emetine treatment (Figure 3.12). To verify whether this was a unique feature, the protein stability of the putative yeast ROMO1 homolog, Mgr2, was analyzed in S. cerevisiae, along with other translocase components and the matrix protein aconitate hydratase (Aco1). To this end, WT yeast cells were kindly provided by Ridhima Gomkale (University Medical Center, Göttingen, Germany) and grown until exponential growth phase, treated with the translation inhibitor cycloheximide, harvested and analyzed by immunoblotting. Cycloheximide interferes with eukaryotic protein synthesis by inhibiting the tRNA/mRNA translocation step, blocking elongation (Schneider-Poetsch et al., 2010). Western blot analysis revealed that unlike ROMO1, Mgr2 was not an unstable protein, as its steady state levels barely varied within 2 hours (Figure 3.20). Therefore, the rapid turnover of ROMO1 is an intriguing feature that warranted further investigation.

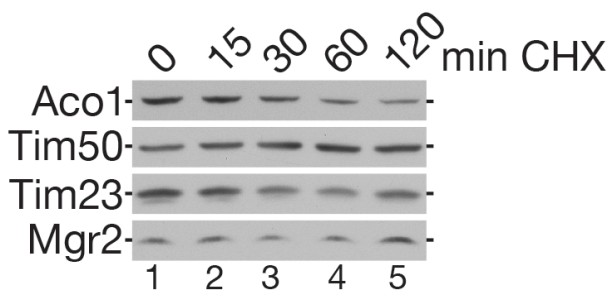

Fig. 3.20: Yeast Mgr2 is a stable protein. Yeast WT cells were treated with $0.15 \mu \mathrm{g} / \mu \mathrm{L}$ cycloheximide $(\mathrm{CHX})$ for the indicated time points. Cells were harvested, lysed and analyzed by SDS-PAGE and immunoblotting.

Since ROMO1 is found in the inner membrane, it seemed plausible that ROMO1 is rapidly degraded by one of the mitochondrial proteases. Upon siRNA-mediated knockdown of known mitochondrial proteases, cells were analyzed by SDS-PAGE and western blot. High levels of ROMO1 could be detected in cells depleted for the $i$-AAA protease YME1L, along with its known substrate TIM17A (Figure 3.21; Rainbolt et al., 2013). With further work done in collaboration with Thomas MacVicar and Thomas Langer of the Max Planck Institute for Aging 
in Cologne, Germany, ROMO1 could be established as a newly found substrate of the $i$-AAA protease YME1L in human.

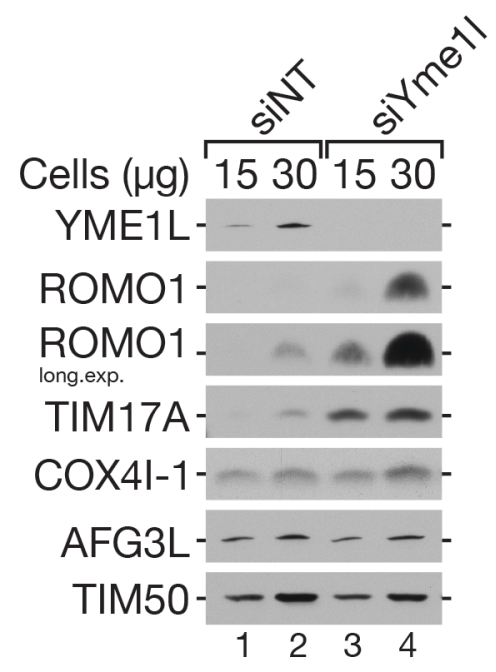

Fig. 3.21: ROMO1 accumulates in siYmell cells.

HEK293T WT cells were treated with siRNA oligonucleotides against Yme1l or non-targeting control siRNA (NT) for 72 hours. Cells were lysed and analyzed by SDS-PAGE and western blot.

\subsubsection{YME1L levels are diminished in the absence of ROMO1}

YME1L in human is best known for its role in processing of OPA1 (Ishihara et al., 2006; Song et al., 2007). Another previous observation in connection with YME1L had been aberrant OPA1 processing and cristae morphology in $\mathrm{ROMO1}^{-/}$cells (Figure 3.5). The observed OPA1 processing was similar to one that had been previously reported in a YME1L knockout in MEF cells (Anand et al., 2014). Assessing the protein levels of YME1L by western blot revealed a reduction of YME1L protein in $\mathrm{ROMO1}^{-/}$mitochondria, which was restored in $\mathrm{ROMO}^{-1-}+$ ROMO1 mitochondria (Figure 3.22A). TIM23 is a known substrate of YME1L (Wai et al., 2016) and while its levels were increased in the absence of ROMO1, they returned to WT levels in $\mathrm{ROMO1}^{--}+\mathrm{ROMO} 1$ mitochondria. Interestingly, when assessing YME1L levels in siRomo1 depleted mitochondria, its levels, along with TIM23 levels, were barely changed (Figure 3.22B). This showed that YME1L levels, OPA1 processing and cristae structure seem to be a consequence of long-term ROMO1 ablation.

The fast turnover of human ROMO1 had been shown to be specific for human ROMO1 and not occur for yeast Mgr2 (Figure 3.20). However, Mgr2 plays a role in the import and processing of 
the OPA1 ortholog, Mgm1, which has two hydrophobic stretches (Ieva et al., 2014). Lateral release of the first hydrophobic segment leads to the formation of long (l)-Mgm1. Transport of the first segment into the matrix and lateral release of the second segment leads to processing by the rhomboid protease Pcp1 which releases short (s)-Mgm1 into the IMS. Having a proper balance of the long and short form is necessary for proper mitochondrial morphology (Herlan et al., 2004). Cells lacking Mgr2 have a higher ratio of 1-Mgm1 because the lateral release is favored, leading to deregulated mitochondrial morphology (Ieva et al., 2014). In human cells lacking ROMO1, the lateral release of proteins in general was not affected (Figure 3.19), but the levels of the OPA1 processing protease YME1L were (Figure 3.22A). This hinted at a different regulation of OPA1 in human as compared to Mgm1 in yeast.

A

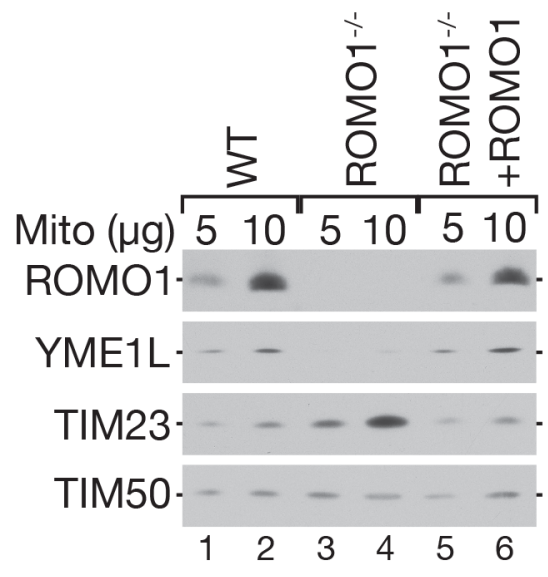

\section{B}

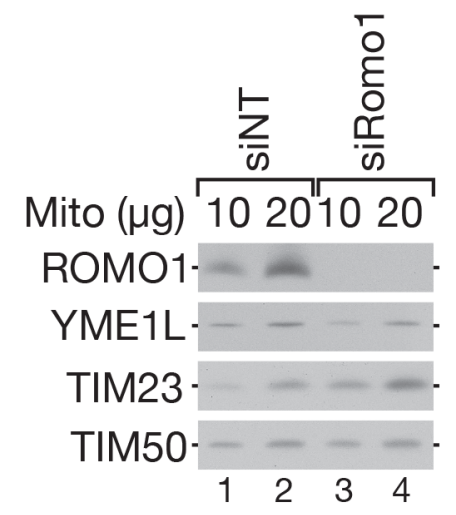

C

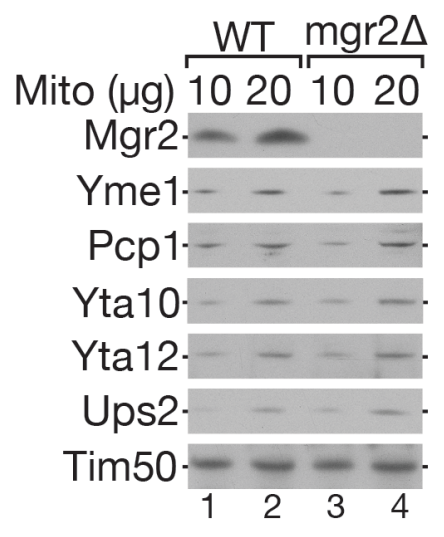

Fig. 3.22: YME1L levels are reduced in $\mathrm{ROMO1}^{-/-}$mitochondria. (A) Mitochondria from HEK293T WT, ROMO1 ${ }^{-1}$ cells and $\mathrm{ROMO1}^{-/}+\mathrm{ROMO1}$ were analyzed by SDS-PAGE and immunoblotting.

(B) HEK293T WT cells were treated with siRNA oligonucleotides against Romol or non-targeting control siRNA (NT) for 72 hours. Mitochondria were isolated, lysed and analyzed by SDS-PAGE and western blot.

(C) Mitochondria from yeast WT and $m g r 2 \Delta$ cells were analyzed by SDS-PAGE and western blot. 
To confirm this, steady state levels of proteases were analyzed by western blot in yeast mitochondria lacking Mgr2 (Figure 3.22C). Yeast WT and mgr2A mitochondria were kindly provided by Alexander Schendzielorz (University Medical Center, Göttingen, Germany). Levels of yeast Yme1 were not affected, which did not seem surprising as its substrates in yeast are quite different from human (Levytskyy et al., 2017). Mgm1 is processed by Pcp1 whose levels were also not affected, confirming that the change in long-/short-Mgm1 ratio is due to aberrant sorting and not processing by Pcp1. Furthermore, levels of $m$-AAA protease components Yta10 and Yta12 were not affected, along with Ups2, another protein which might be involved in the processing of Mgm1 (Osman et al., 2009).

\subsubsection{Import of YME1L is dependent on ROMO1}

Since YME1L levels were reduced in $\mathrm{ROMO}^{-/}$cells (Figure 3.22A) and ROMO1 is a component of the TIM23 complex (Figure 3.1), one could speculate that import of YME1L depends on ROMO1. To address this, we used mitochondria from siRomo1 treated cells, since here steady state levels of YME1L were barely changed (Figure 3.22B). After synthesizing radioactively labeled ${ }^{35}$ S]YME1L, in vitro import assays into energized isolated mitochondria were carried out. Upon analysis by autoradiography, it could be observed that the import efficiency of YME1L was drastically reduced in the absence of ROMO1 (Figure 3.23).
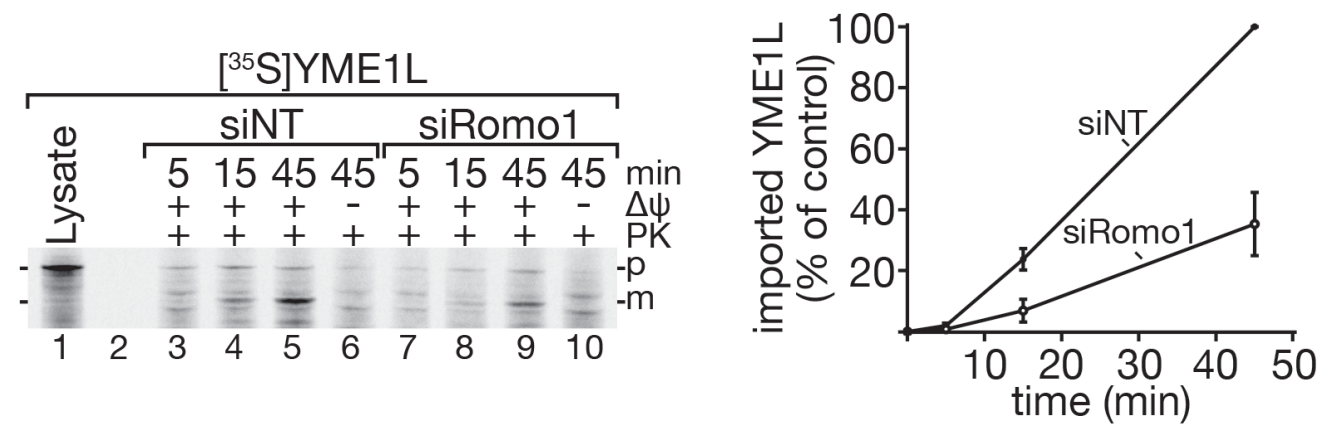

Fig. 3.23: Import of YME1L protein is dependent on ROMO1.

$\left[{ }^{35} \mathrm{~S}\right]$ YME1L was imported into isolated energized HEK293T mitochondria from siNT or siRomol cells. Import was stopped at 5, 15 and 45 minutes. Samples were treated with PK and analyzed by autoradiography following SDS-PAGE. Import of siNT sample at 45 minutes was set to $100 \%$. The mean \pm SEM $(n=3)$ is shown. Lysate, radioactively labeled $\left[{ }^{35} \mathrm{~S}\right] \mathrm{YME} 1 \mathrm{~L}$ in reticulocyte lysate (input); $\mathrm{p}$, precursor; $\mathrm{m}$, mature protein. 
Quantification showed that YME1L import is highly dependent on ROMO1, as its import efficiency was reduced by $60 \%$ in siRomo 1 mitochondria (Figure 3.23 ).

To verify whether the observed lower levels of imported YME1L were directly linked to its import and not to its reduced stability, YME1L levels were followed after import for up to 4 hours. For this purpose, $\left.{ }^{35} \mathrm{~S}\right] \mathrm{YME} 1 \mathrm{~L}$ was imported as before, mitochondria were re-isolated and incubated further in the absence of $\left[{ }^{35} \mathrm{~S}\right]$ YME1L (Chase). Samples were taken at different time points and reactions were analyzed by SDS-PAGE and autoradiography. The stability of imported YME1L decreased equally for both siNT and siRomo1 samples at the beginning and did not significantly change much over the time course of 240 minutes (Figure 3.24). This showed that the stability of imported YME1L did not differ between siRNA control and siRomol treated mitochondria, which might explain the normal YME1L levels after transient depletion of ROMO1 (Figure 3.22B).
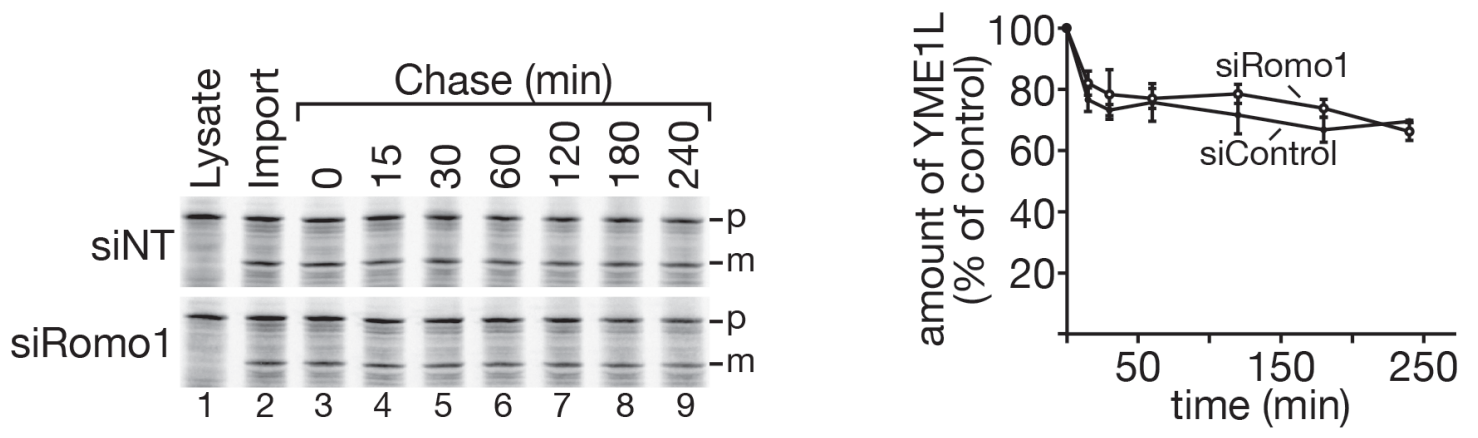

Fig. 3.24: YME1L is stable upon import in siRomol mitochondria.

$\left[{ }^{35} \mathrm{~S}\right]$ labeled YME1L was imported into isolated mitochondria from siNT or siRomol cells for 45 min (import). The reaction was stopped, re-isolated mitochondria were resuspended in import buffer and incubated further (chase). Samples were harvested at indicated time points and analyzed by autoradiography following SDS-PAGE. Amounts of mature YME1L were plotted against time and the respective amount at 0 min chase was set to $100 \%$. The mean \pm SEM $(n=3)$ is shown. Lysate, radioactively labeled $\left[{ }^{35} \mathrm{~S}\right] Y M E 1 L$ in reticulocyte lysate (initial input); $\mathrm{p}$, precursor; $m$, mature protein.

Taken together, an unexpected link between the mitochondrial protein import machinery and the $i$-AAA protease YME1L was discovered. While ROMO1 is rapidly degraded by YME1L, YME1L levels are decreased in the absence of ROMO1, an effect that can be attributed to an import defect. However, the molecular reason for this import phenotype needed to be addressed. 


\subsection{ROMO1 plays a role in the import of precursors with long presequences}

\subsubsection{The long C-terminus of YME1L does not impact its import efficiency}

Mature YME1L has a very unique topology. Even though its sequence is quite long, it only has one transmembrane domain and a very large C-terminus facing the intermembrane space (Hartmann et al., 2016; Shi et al., 2016). This is in contrast to the previously used constructs for import studies (Figure 3.17-3.19). One could therefore hypothesize that ROMO1 is required for efficient import of this long C-terminus. To investigate this and narrow down the molecular reason for the observed import defect, C-terminally shortened constructs of YME1L were generated, trimming the C-terminus by about $10 \mathrm{kDa}$ (Figure 3.25A). A secondary structure prediction tool was used to avoid disturbing possible secondary structures.

The C-terminally truncated YME1L constructs were radioactively labeled $\left(\left[{ }^{35} \mathrm{~S}\right] \mathrm{YME} 1 \mathrm{~L}^{1-613}\right.$, $\left[{ }^{35} \mathrm{~S}\right] \mathrm{YME} 1 \mathrm{~L}^{1-529}$ and $\left.\left.{ }^{35} \mathrm{~S}\right] \mathrm{YME}^{1} \mathrm{~L}^{1-395}\right)$, imported into siRomo1 mitochondria and analyzed by SDS-PAGE and autoradiography. However, despite their truncations, import defects were still observed (Figure 3.25 B-D). Import of these constructs still depended on ROMO1 to a similar extent as the full length YME1L, suggesting that the large $\mathrm{C}$-terminus is not the molecular reason for the observed import defect. 
A

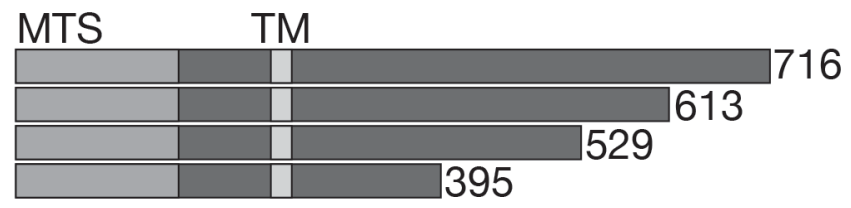

B

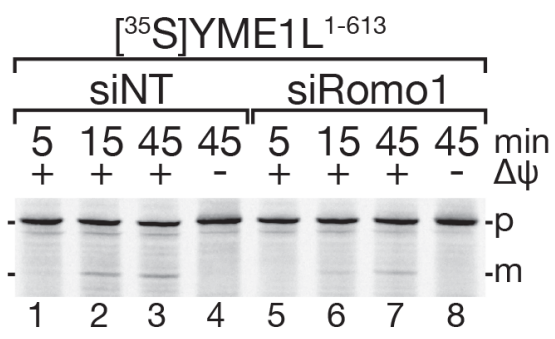

D

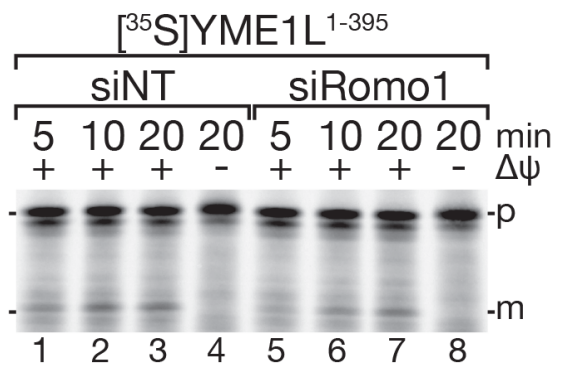

C

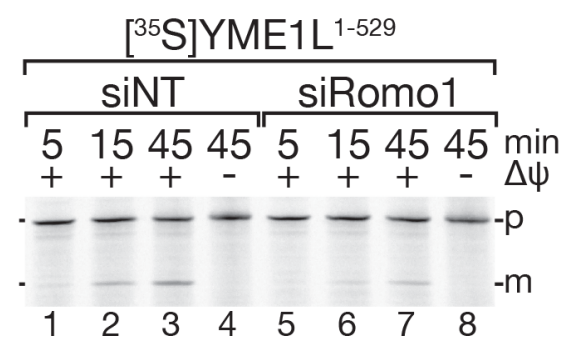

Fig. 3.25: C-terminal shortening of YME1L does not abolish its import dependence on ROMO1

(A) Schematic depiction of precursor proteins used in Figures $3.23 / 24$ and 3.25B-D. The full-length protein (716) was truncated C-terminally as indicated. MTS, mitochondrial targeting sequence; TM, transmembrane span.

(B-D) Depicted constructs were imported into isolated energized mitochondria from siNT or siRomol cells. Import was stopped at given time points. Samples were analyzed by SDS-PAGE and autoradiography. p, precursor; $m$, mature protein.

\subsubsection{Exchanging the transmembrane domain does not alleviate the import phenotype of YME1L}

Since the transmembrane domain of a protein is usually involved in its lateral release, it seemed plausible that the transmembrane domain of YME1L could play a role for its ROMO1dependent import. To answer this question, the transmembrane domain of YME1L was exchanged with that of COX6A1 (Figure 3.26A). COX6A1 is a precursor protein whose import had not been affected by the absence of ROMO1 (Figure 3.18B). Upon synthesis of radioactively 
labeled $\left[{ }^{35} \mathrm{~S}\right] \mathrm{YME} \mathrm{L}^{1-238}-\mathrm{COX} 6 \mathrm{~A} 1^{40-59}-\mathrm{YME}^{2} \mathrm{~L}^{260-716}$, subsequent import into siRomo1 mitochondria, and analysis by SDS-PAGE and autoradiography, import defects were still observed (Figure 3.26B). The clearly visible import defect suggested that the transmembrane domain was not the molecular reason for the import defect.

A

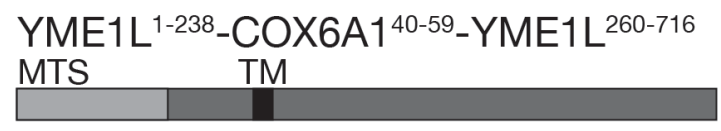

B

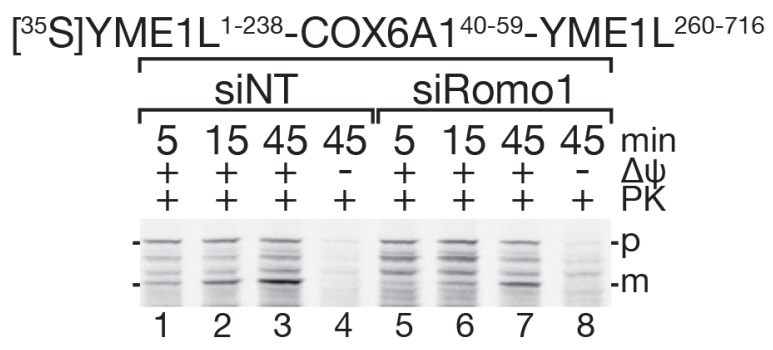

Fig. 3.26: The COX6A1 transmembrane domain in YME1L does not abolish its import dependence on ROMO1.

(A) Schematic representation of the precursor used in B. The transmembrane domain (TM) of YME1L was exchanged for the transmembrane domain of COX6A1.

(B) $\left[{ }^{35} \mathrm{~S}\right]$ labeled precursor proteins were imported into energized mitochondria isolated from siNT and siRomo1 cells, treated with PK and analyzed by autoradiography following SDS-PAGE. p, precursor; m, mature protein.

\subsubsection{YME1L is dependent on ROMO1 for its import due to its long presequence}

Since neither the C-terminus, nor the transmembrane domain of YME1L seemed to be the molecular reason for its import dependence on ROMO1, the N-terminus became the focus of the investigation. When analyzing the sequence of premature, unprocessed YME1L, a rather unusually long mitochondrial targeting sequence/presequence (MTS) was noticed (Hartmann et al., 2016). One could therefore hypothesize that this could be the molecular reason for this 
A

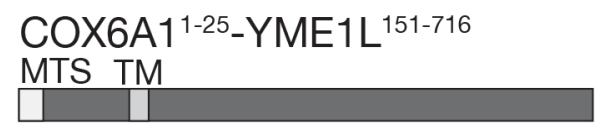

YME1L 1 151-COX6A125-110

MTS TM

B
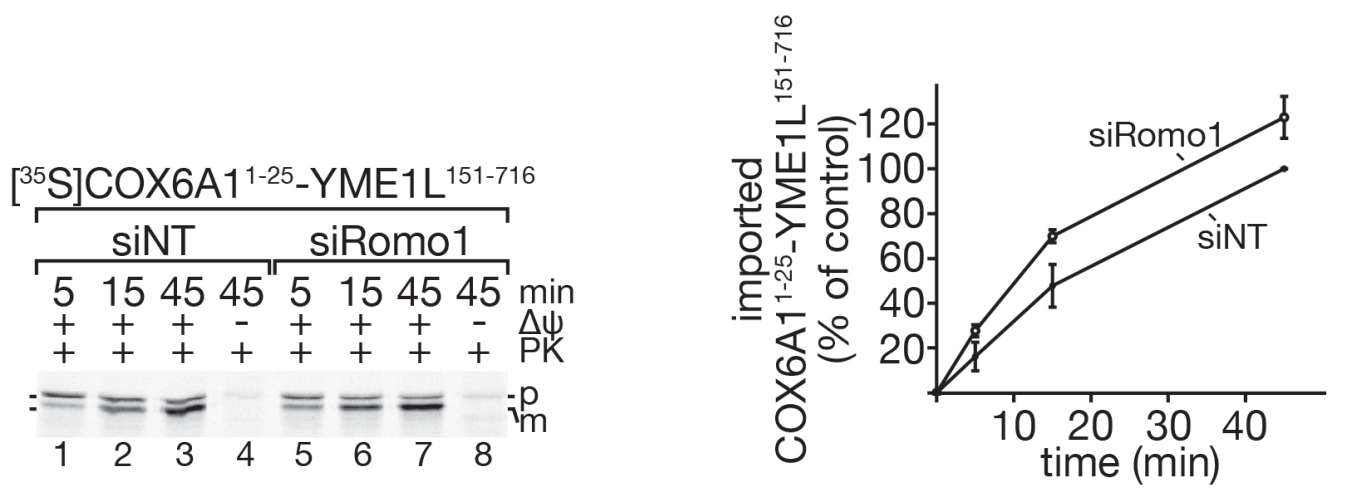

C
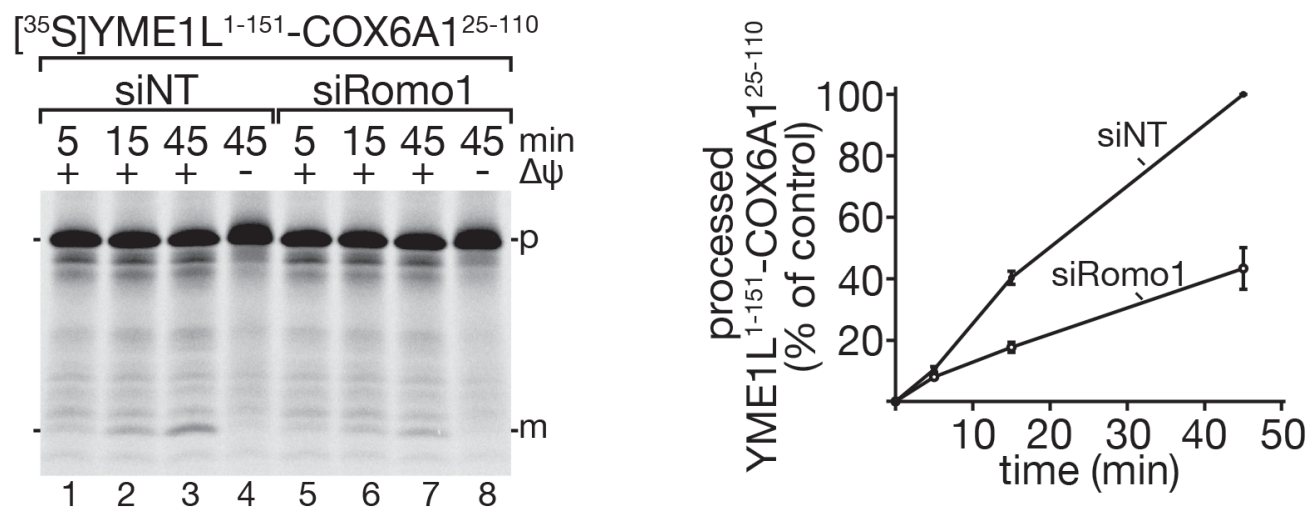

Fig. 3.27: The presequence of COX6A1 on YME1L abolishes its import dependence on ROMO1.

(A) Schematic depiction of precursors used in B and C. The mitochondrial targeting sequence (MTS) of COX6A1 (first 25 amino acids) was fused to the mature part of YME1L (151 to end). The MTS of YME1L (first 151 amino acids) was fused to the mature part of COX6A1 (25 to end). TM, transmembrane domain.

(B and C) $\left[{ }^{35} \mathrm{~S}\right]$ labeled precursor proteins were imported into energized mitochondria isolated from siNT or siRomol cells. Reactions were stopped at 5, 15 or 45 minutes, samples were treated with PK where indicated and analyzed by SDS-PAGE and autoradiography. Import of siNT sample at 45 minutes was set to $100 \%$. The mean \pm $\operatorname{SEM}(n=3)$ is shown. $p$, precursor; $m$, mature protein. 
specific import phenotype of YME1L. To ascertain whether the import of YME1L depended on ROMO1 due to its unusually long presequence, the MTS of YME1L and COX6A1 were exchanged. For this purpose, the respective presequence was fused onto the mature form of the other by overlapping PCR and cloning (Figure 3.27A). COX6A1 has a presequence of 25 amino acids, which is in line with the average lengths of 15-55 amino acids (Vögtle et al., 2009). Again using in vitro import assays with radioactively-labeled precursor proteins followed by quantification, it was observed that the import of COX6A1(MTS) - mature YME1L (COX6A1 ${ }^{1-}$

${ }^{25}$-YME1L ${ }^{151-716}$ ) was no longer dependent on ROMO1, since its import efficiency into siRomo mitochondria was at WT levels (Figure 3.27B). Full length COX6A1 did not show any import defect in the absence of ROMO1 (Figure 3.18B). In contrast, when the targeting sequence of YME1L was fused onto mature COX6A1 (YME1L ${ }^{1-151}-\mathrm{COX}_{6} \mathrm{~A} 1^{25-110}$ ), its import efficiency drastically decreased (Figure 3.27C) and resembled the import efficiency of full length YME1L in siRomo1 mitochondria (Figure 3.23).

It could therefore be concluded that the drastic import defect of YME1L, observed in siRomo1 mitochondria, is due to its long presequence. The import defect could be rescued upon exchanging the YME1L presequence with the presequence of a protein whose import was not affected (COX6A1). Furthermore, the presequence of YME1L could induce an import phenotype in a protein that had not shown any dependence on ROMO1 for its import before.

\subsubsection{ROMO1 plays a role for the import of precursors with long presequences}

To study whether the import dependence of YME1L due to its long presequence was a general effect, literature and databases were searched for proteins with similar long presequences. Using $\mathrm{N}$-proteome studies (Calvo et al., 2017; Vaca Jacome et al., 2015), as well as UniProt, only five proteins were identified as having a presequence of more than 100 amino acids. Two of these proteins also had a similar topology to YME1L. LETM1 is a mitochondrial inner membrane protein that functions as a proton/calcium antiporter, is involved in the maintenance of mitochondrial tubular networks and binds the mitochondrial ribosome (Jiang et al., 2009; Piao 
et al., 2009; Tamai et al., 2008). COQ8A, or ADCK3, is a large inner membrane protein known as an atypical kinase involved in coenzyme Q biosynthesis (Stefely et al., 2015; Wheeler \& Jia, 2015). After synthesizing radioactively-labeled precursor proteins of these two proteins, in vitro import assays into ROMO1 depleted mitochondria were performed.

A
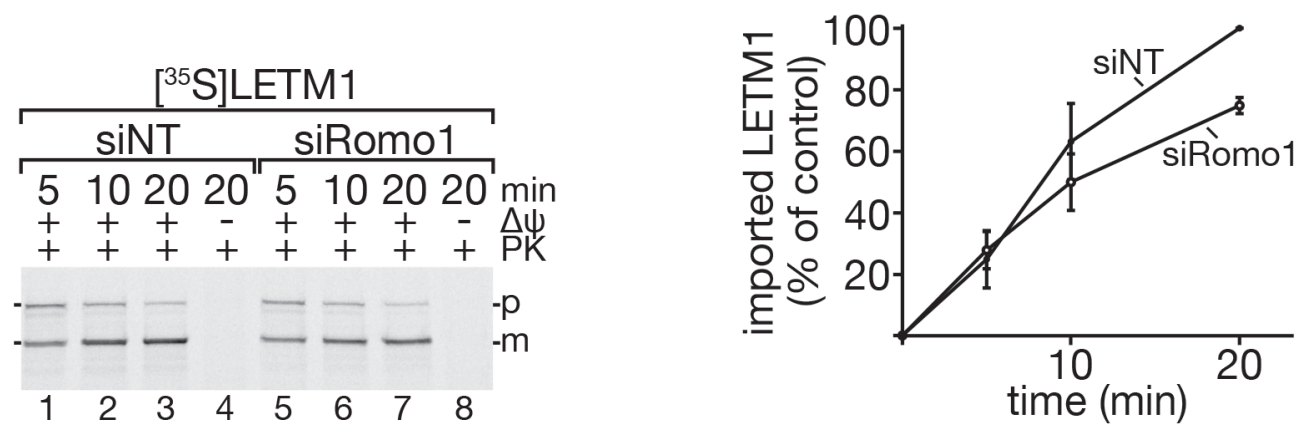

B
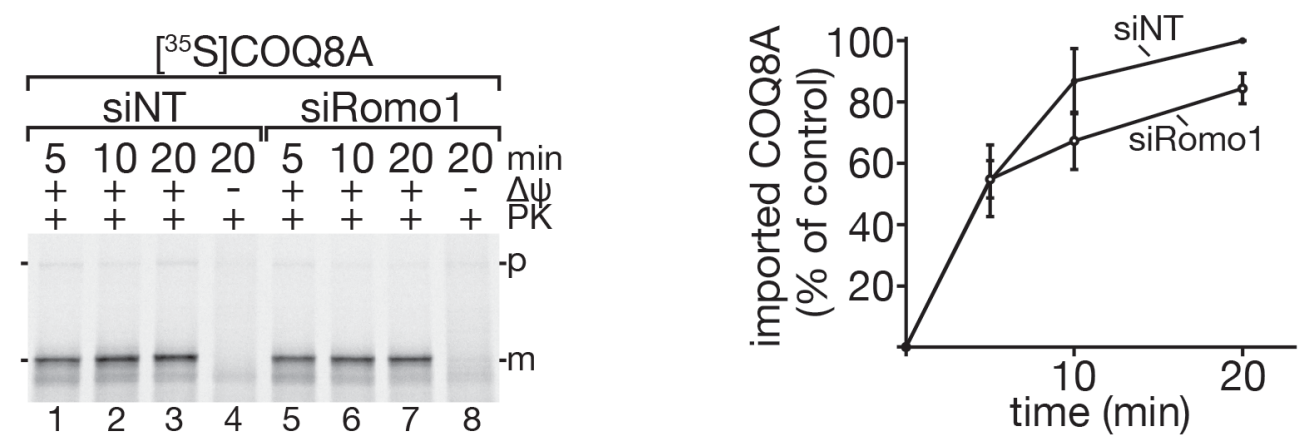

Fig. 3.28: Other proteins with long presequences show a mild import dependence on ROMO1.

(A-B) $\left[{ }^{35} \mathrm{~S}\right]$ labeled precursor proteins were imported into energized mitochondria isolated from siNT or siRomol cells, treated with PK and analyzed by SDS-PAGE and autoradiography. Import of siNT sample at 20 minutes was set to $100 \%$. The mean \pm SEM $(n=3)$ is shown. $p$, precursor; $m$, mature protein.

Analysis by SDS-PAGE, autoradiography and quantifications revealed that the import efficiency of LETM1 was reduced by about 30\% in siRomo1 mitochondria (Figure 3.28A). The import efficiency of COQ8A was reduced by about 20\% in siRomo1 mitochondria (Figure 3.28B). While this mild import defect did not compare to the one seen for YME1L, significant 
differences were apparent and this data suggests that both precursors depended on ROMO1 for their import.

This data confirmed that the novel subunit ROMO1 of the TIM23 complex plays a specific role in the import of the $i$-AAA protease YME1L, due to its presequence. Furthermore, there is evidence that also other proteins with long presequences partly depend on ROMO1 for their import. All in all, this reveals the underlying mechanism for the effects of ROMO1 ablation on OPA1 processing and mitochondrial inner membrane morphology, which can now be traced back to the long presequence of YME1L and its dependence on ROMO1 for efficient import. 


\section{Discussion}

\subsection{Functions of ROMO1 as a TIM23 complex component}

\subsubsection{Human ROMO1, the potential orthologue of Mgr2, is a component of the TIM23 complex}

The mitochondrion is an organelle of central importance in almost all eukaryotic cells. Its functions depend on the biogenesis of its proteins and protein complexes, which is almost exclusively dependent on protein import from the cytosol into the correct compartment of the mitochondrion. Due to its easy genetic manipulation, the model organism Saccharomyces cerevisiae has been used for decades to elucidate the intricate architecture and function of the protein import machinery (for recent review, see Wiedemann \& Pfanner, 2017). That research has provided invaluable insights into the mechanistic details of protein biogenesis in mitochondria. However, reports from the last five to ten years have pointed out that many mechanistic and structural details are different in metazoans, i.e. Homo sapiens, and therefore require separate attention (for a current review, see Kang et al., 2018). This is even more interesting, as many proteins involved in mitochondrial protein import are associated with environmental responses, cancer and other diseases (Demishtein-Zohary \& Azem, 2017; Kang et al., 2018; Sokol et al., 2014), making them even more crucial to study in human.

This study focused on the TIM23 complex present in the inner membrane of mitochondria, which is responsible for the import of up to $70 \%$ of all mitochondrial proteins. The most recently discovered component of the TIM23 complex has been Mgr2 in yeast (Gebert et al., 2012). It had been identified by a SILAC MS analysis of C-terminally tagged Tim $21^{\text {ProtA }}$ and further confirmed, by affinity purification of Tim $23^{\text {ProtA }}$ and Tim $21^{\text {ProtA }}$, to be a subunit of the TIM 23 complex (Gebert et al., 2012). Similarly, a SILAC MS analysis of C-terminally tagged human 
TIM23 ${ }^{\mathrm{FLAG}}$, TIM21 ${ }^{\mathrm{FLAG}}$ and TIM50 ${ }^{\mathrm{FLAG}}$ identified Mgr2's potential orthologue, ROMO1, as an interaction partner of all three proteins. This observation was followed up in this study and ROMO1 could be confirmed to be a new component of the human TIM 23 complex by affinity purification of TIM23 $3^{\mathrm{FLAG}}$ and TIM21 ${ }^{\mathrm{FLAG}}$ (Figure 3.1).

ROMO1 had long been thought to interact with the TIM23 complex in human, especially after Žárský \& Dolezal (2016) found Tim17 family homology in both Mgr2 and ROMO1 using bioinformatical tools. The sequences of Mgr2 and ROMO1 possess only the first two transmembrane domains of this family, but orthologues of Mgr2 and ROMO1 are present in very diverse groups, suggesting a conserved role, even though their potential functions in mitochondria described so far have been very different (Žárský \& Dolezal, 2016). While their sequences are quite similar, there are also some fundamental differences. Mgr2 contains a Cterminal targeting sequence, which has a net positive charge and targets Mgr2 to mitochondria. This sequence is cleaved by Imp1 and not by MPP, which is necessary for WT levels of Mgr2 and assembly and function of the TIM23 complex (Ieva et al., 2013). The C-terminal extension is absent in human, marking a big difference. However, the mature form of Mgr2 is also partly targeted to mitochondria, meaning that weak targeting information is also internally present in the protein (Ieva et al., 2013). However, how ROMO1 is targeted to mitochondria could also not be resolved in this study. On the other hand, ROMO1 contains two cysteine residues, which are highly conserved in metazoan but not present in yeast (Norton et al., 2014).

Despite the evidence presented in this study, it has recently been published that ROMO1 forms a cation channel in the inner membrane (Lee et al., 2018). They showed that ROMO1 oligomerizes in mitochondria and further in vitro approaches, such as reconstitutions in artificial membranes and liposomes of synthesized ROMO1, showed that ROMO1 exhibits channel function. Furthermore, their data is complemented by computational modeling and prediction algorithms. Yeast Mgr2 interacts with precursor proteins in transit and has been hypothesized to be part of the presequence translocase channel (Ieva et al., 2014). It is therefore possible that ROMO1 could be part of a channel, however, the data presented in this study make it more likely to act on the TIM23 complex. The ROMO1 oligomers reported in Lee et al. (2018) 
could also represent ROMO1 as part of the TIM23 complex. Further 2-D analyses could complement this part of their study.

\subsubsection{ROMO1 and its involvement in translocase coupling and protein import}

The molecular function of Mgr2 has been the subject of recent studies. It was first described as a factor, responsible for efficient TOM-TIM23 coupling and for the association of Tim21 and the respiratory chain to TIM23 (Gebert et al., 2012). However, a following study gave Mgr2 a more active role in precursor sorting, as they showed that it is part of the active translocase, whereby it recognizes and interacts with precursors while they are being imported. They called Mgr2 a gatekeeper because it acts in quality control of transmembrane proteins by delaying their lateral release (Ieva et al., 2014). In general, it should be noted that in $m g r 2 \Delta$ mitochondria, the import motor is just as active as in WT and an import defect of matrix-targeted proteins is only detectable after heat shock (Ieva et al., 2014; Schulz \& Rehling, 2014). In this case, newly imported Pam18 is recruited a lot less efficiently to the translocase, possibly explaining the phenotype (Schulz \& Rehling, 2014). On the other hand, Mgr2 slows down inner membrane sorting, as faster sorting is observed in $m g r 2 \Delta$ mitochondria and very slow sorting when Mgr2 is overexpressed (Ieva et al., 2014). In those studies, it is postulated that ROMO1 probably acts by a similar mechanism as in yeast and also has a coupling and gatekeeper function.

These hypotheses prompted the presented work to focus on the role of ROMO1 on the translocase. Using immunoprecipitations following a knockdown of ROMO1, this study could show that ROMO1 is involved in coupling the dynamic subunit TIM21 onto TIM23 (Figure 3.16), hinting at a similar function as in yeast. However, following experiments addressing the involvement in ROMO1 in the import of laterally sorted proteins did not reveal a direct sorting defect (Figure 3.18). On the other hand, it needs to be noted that the presented import experiments do not directly address the lateral release of proteins. Therefore, assembly studies were carried out for COX6A1 and COX4I-1. The coupling function of ROMO1 did become apparent when analyzing COX4I-1, which requires the dynamics of TIM21 for its sorting 
(Figure 3.19; 4.1A). Unfortunately, this study could not address the assembly and lateral release of further proteins, which would be of high interest. Import conditions and BN-PAGE protocols need to be optimized to test a large range of inner membrane proteins and more systematically assess this question. When Mgr2 was abolished in yeast mitochondria, the interaction between Tim23 and Tim21 was lost (Gebert et al., 2012), while in siRomo1 mitochondria, it was only weakened (Figure 3.16). Therefore, one can conclude that ROMO1 has a weak coupling function (Figure 4.1A). On the other hand, this study could not provide any evidence that a deletion of ROMO1 speeds up lateral sorting, as seen in $m g r 2 \Delta$ (Ieva et al., 2014). It therefore seems conceivable that ROMO1 does not act in quality control at the human translocase, but has acquired further functions.

\subsubsection{ROMO1 - part of a specific translocase?}

Most published data, as well as the results from this study, hint at a different role of ROMO1 compared to its yeast counterpart, Mgr2. This does not seem surprising, as a number of other subunits of the TIM23 complex also have diversified roles. While the function of the subunits TIM50, TIM23, TIM44 and Magmas (Pam16 in yeast) are conserved, other proteins have diversified (Kang et al., 2018). Even Magmas has a further function, as it does not just tether Jproteins to the translocase, but also regulates the distribution of J-proteins (Sinha et al., 2014). This diversification becomes more evident when looking at TIM17, as there are two paralogs of TIM17, TIM17A and TIM17B, and two isoforms, TIM17B1 and TIM17B2, which show

diversifications at the C-terminus (Bauer et al., 1999; Sinha et al., 2014). Both paralogs have different functions. TIM17B, interacting with DNAJC19, is critical for cell viability, Fe-S cluster biogenesis, efficient import and respiration. On the other hand, TIM17A interacts with DNAJC15 and seems dispensable for all those functions, having a more supportive role (Sinha et al., 2014). However, even this observation is disputed since another study showed that TIM17A is involved in protein import (Rainbolt et al., 2013). Furthermore, TIM21 has attained a different function, coupling import to mitochondrial translation and assembly of OXPHOS 
components, something not present in yeast (Mick et al., 2012). It therefore does not seem surprising that the function of ROMO1 could also have diversified.

This study showed that the $i$-AAA protease YME1L depends on ROMO1 for its efficient import (Figure $3.23 ; 4.1 \mathrm{~B})$. Interestingly, the reason for this dependency was its unusually long presequence of about 150 amino acids (Figure 3.27). Generally, presequences of mitochondrial proteins have a length of 15-55 amino acids, although exact predictions, especially for human proteins, are still lacking. Even recently published mitochondrial N-proteomic studies could not cover a large portion of mitochondrial proteins and also suggested highly unlikely $\mathrm{N}$-termini for a number of proteins (Calvo et al., 2017; Vaca Jacome et al., 2015). Nevertheless, the currently known number of proteins with a presequence that is longer than 100 amino acids is very low. This study tested the import of two proteins, LETM1 (presequence of 115 amino acids) and COQ8A (presequence of 160 amino acids) and could show a slight dependence on ROMO1 (Figure 3.28). This dependence was not as pronounced as for YME1L, however, other tested substrates, such as EMRE or COX6A1, showed identical import efficiency compared to WT conditions in siRomo1 mitochondria (Figure 3.18).

The idea of specific translocases for specific proteins, or a class of proteins, has been postulated a few times. It has been suggested that separate pools of TOM complexes exist and that MIA and TIM23 substrates use different TOM complexes for their entry into mitochondria (Gornicka et al., 2014). Furthermore, it has been shown that TIM17A is essential for import of oncoproteins that do not possess a targeting sequence, such as p53, Erk2 and STAT6 (Sinha et al., 2014). That study hypothesized that TIM17A could be part of a specific translocase for proteins without a presequence. Similarly, one could conjecture that ROMO1 is possibly part of a specific translocase, where ROMO1 is essential for the import of YME1L and possibly other proteins with long presequences (Figure 4.1B). This could be reconciled with the observation that no other tested substrate depended on ROMO1 for its import as drastically (Figure 3.17 - 3.19). Nevertheless, the question remains why YME1L, LETM1 and COQ8A are, to such different degrees, dependent on ROMO1. Interestingly, the net positive charge of the presequence of COX6A1 is much higher as compared to the net positive charge of the presequences of YME1L 
and COQ8A. This could mean that these substrates are less attracted by the negative membrane potential and therefore need ROMO1 to aid in their import. Obviously, this needs to be addressed in more detail with more substrates that have presequences of variable charges. A mass-spectrometric study of the mitoproteome of ROMO1 ${ }^{-/}$cells compared to WT cells could help identify further substrates and, complemented by import studies, possibly address the dependence of further proteins on ROMO1.

The findings of this study show that it is crucial to study phenomena already studied in yeast in mammalian models, since large differences become more and more apparent. Human ROMO1 is a weak coupling factor of TIM21 onto the translocase, demonstrated by a delayed assembly of COX4I-1 into MITRAC (Figure 4.1A). Furthermore, it is possibly part of a specific translocase that is specialized for importing YME1L, as well as further substrates with extremely long presequences (Figure 4.1B).

A

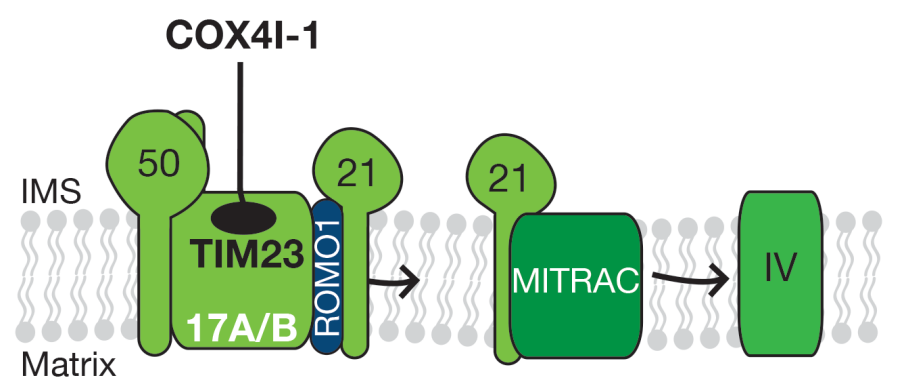

COX4l-1

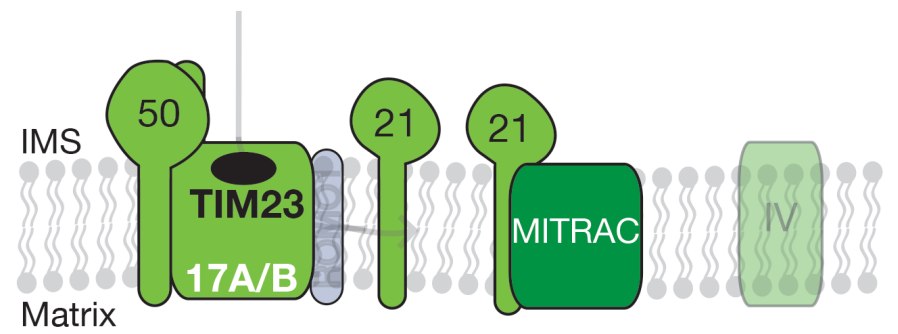

B

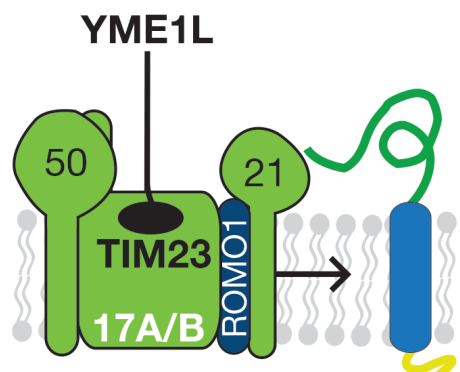

YME1L

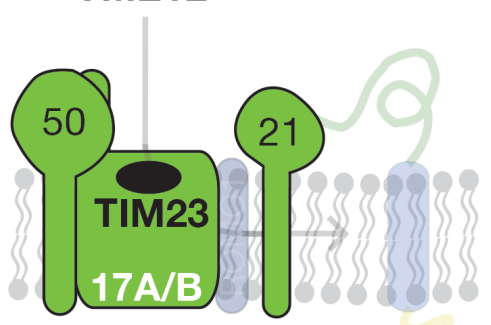

Fig. 4.1: ROMO1, a novel subunit of the TIM23 complex.

(A) ROMO1 couples TIM21 onto TIM23. This becomes evident when studying the MITRAC dependent complex IV subunit COX4I-1 which is dependent on proper TIM21 coupling for its assembly. As a result, complex IV activity is reduced.

(B) The import of YME1L is dependent on ROMO1. 


\subsection{ROMO1 and its effects on inner membrane morphology and respiratory chain activity}

\subsubsection{Observed phenotypes in OPA1 processing and cristae structure are related to YME1L}

The fact that the depletion of ROMO1 has an effect on inner membrane structure had already been observed in 2014 (Norton et al., 2014). The curvature of crista junctions is mediated by a complex called MICOS (Schorr \& van der Laan, 2018). It therefore seems conceivable that there could be a connection between ROMO1 and MICOS, or that the absence of ROMO1 affects the integrity of this complex. Norton et al. performed an immunoprecipitation experiment using the MICOS component MIC60 as a bait and showed ROMO1 to interact with MIC60. They therefore concluded that ROMO1 and MICOS form a complex and that ROMO1 is positioned at crista junctions. However, their analysis lacked negative controls and the ablation of ROMO1 did not affect steady state levels of MIC60 and MIC19, as well as MICOS complex integrity, shown by gel fractionation (Norton et al., 2014). In ROMO1 ${ }^{-1}$ cells presented in this study, the integrity of the MICOS complex was also not affected, based on an immunoprecipitation experiment using endogenous MIC60 antibodies (data not shown). One could therefore be doubtful about the conclusion that ROMO1 interacts with MICOS and its positioning at crista junctions. Since MICOS is involved in various other processes, such as lipid and protein transfer, or inner-outer membrane contacts (Schorr \& van der Laan, 2018), it is likely that ROMO1 has an effect on cristae structure via a different mechanism.

In their study Norton et al. further showed that OPA1 processing is disturbed in the absence of ROMO1, leading to changes in inner membrane structure. They therefore conclude that ROMO1 is involved in OPA1 processing giving this a higher importance in regard to inner membrane structure than its interaction with MICOS. Moreover, ROMO1 displayed many high-molecular weight species on non-reducing SDS-PAGE, most likely oxidized forms. They 
were no longer present in cysteine mutants of ROMO1, leading them to hypothesize that ROMO1 functions as a redox switch. As an explanation regarding the disturbed OPA1 processing, they hypothesized that the redox status of ROMO1 helps to regulate the opening and closing of crista junctions and that the Cys-Cys bridges, not present in yeast, help to sense oxidative stress and contain it. While this brought some interesting ideas forward, Norton et al. could not present a convincing direct molecular link between ROMO1, OPA1 processing and inner membrane morphology. Based on data from this study, it seems more likely that ROMO1's function in the TIM23 complex has an effect on OPA1 processing and cristae structure.

Ieva et al. (2014) showed that yeast Mgr2 sits at the lateral gate of the presequence translocase and acts in quality control of the lateral release of transmembrane proteins. They exemplified their finding by showing that Mgr2 has an influence on the lateral release of Mgm1, the homolog of human OPA1. In $m g r 2 \Delta$ cells, a faster lateral release leads to a higher abundance of long Mgm1, causing disturbed mitochondrial morphology. However, in yeast, the level and activity of the Mgm1 processing peptidase Pcp1 are not affected. This narrows down the reason for this accumulation of long Mgm1 forms to the quality control function of Mgr2 on the translocase. Also, in the presented study, levels of Pcp1, along with a number of other mitochondrial proteases, were not affected in $m g r 2 \Delta$ mitochondria (Figure 3.22), complementing the already published data that the observed phenotype is the result of defective quality control and not processing.

The processing of human OPA1 is much more complex than the processing of Mgm1 (MacVicar \& Langer, 2016; Song et al., 2007), but its regulation follows the same pattern. OPA1 processing and cristae structure are disturbed in the absence of ROMO1 (Norton et al., 2014; this study). It is difficult to assess on the molecular level precisely what isoforms and which processing steps are affected. The five bands visible on a gel are a mixture of different splice variants and therefore one cannot assign exact bands. For example, the two L-bands represent at least 4 long forms (Song et al., 2007). However, this study could show that the ablation of ROMO1 leads to a very similar processing defect in OPA1, as shown in a knockout of YME1L (Anand et al., 2014). Furthermore, in contrast to Mgr2, ROMO1 has a direct effect on the import 
and steady state levels of the OPA1 processing protease YME1L (Figure 3.22 and 3.23). The reduced levels of YME1L seem to lead to aberrant processing of OPA1 and therefore a disturbed cristae structure in $\mathrm{ROMO}^{-/}$cells (Figure $3.5 ; 4.2$ ). Therefore, in stark contrast to yeast, ROMO1 does not have a quality control function when it comes to protein sorting. The observed changes in OPA1 processing in the absence of ROMO1 are a result of defective processing by YME1L following reduced steady state levels caused by its import defect (Figure 4.2).

This in turn shows that the regulation of OPA1 and cristae structure is not only much more complex in human than in yeast, but also emphasizes a more intricate regulation by protease levels. This is conceivable, as changes in mitochondrial morphology can have drastic effects on the cell's viability and should therefore be tightly regulated. By adjusting the activity of proteases, this allows the cells to react more rapidly to different environmental stimuli, an idea already brought forward more than 10 years ago (Song et al., 2007). This hypothesis is further supported by the fact that ROMO1 is rapidly degraded (Figure 3.12). This also means that steady state levels of ROMO1 are tightly regulated allowing translocases to rapidly adjust their efficiency of YME1L import and biogenesis.

Most published work regarding ROMO1 has focused on its role in ROS production and cancer progression. The effects of ROMO1 ablation on ROS production were not a focus of this study, but it can be said that the depletion of ROMO1 can lead to pleiotropic effects. Knockdown approaches, including results presented here, led to a very small reduction of ROS (Chung et al., 2010; Chung et al., 2008; Kim et al., 2014; Lee et al., 2009; Lee et al., 2011; Shin et al., 2013; Shyamsunder et al., 2015; Figure 3.14). However, the shRNA mediated knockdown presented in Norton et al. (2014) and the knockout cell line presented here, showed a drastic increase in ROS production (Figure 3.11). Furthermore, both approaches led to an aberrant inner membrane structure. It has been known that ROS production and changes in the mitochondrial inner membrane are closely linked. While inner membrane aberrations can lead to higher ROS levels, ROS has also been shown to induce morphological changes (Brand, 2016; Ježek et al., 2018). It therefore seems conceivable that the changed inner membrane architecture leads to higher ROS production in $\mathrm{ROMO}^{-/}$cells (Figure 4.2B). It would be interesting to assess the 
inner membrane structure under conditions of ROMO1 overexpression, when ROS levels are increased. Unfortunately, this went beyond the scope of this study.

The question of whether siRomo1 mitochondria also display changes in inner membrane morphology was not addressed here. In fact, a comprehensive analysis of mitochondria of siRomo 1 cells by electron microscopy seems very difficult. Unlike in the knockout model, not all cells might be depleted of ROMO1 since siRNA treatment is carried out by transient transfection. Therefore, observed phenotypes cannot be directly linked to the presence or absence of ROMO1. However, steady state levels of YME1L (Figure 3.22), as well as OPA1 processing (data not shown), were comparable to WT mitochondria in siRomo1 mitochondria. These results, together with the lack of significant changes in ROS levels, mean that alterations in inner membrane morphology would not be expected. Therefore, a transient depletion of ROMO1 leads to slightly decreased levels of ROS, but a permanent depletion leads to defects in OPA1 processing, followed by changes in inner membrane morphology and increased ROS production (Figure 4.2).

\subsubsection{ROMO1 and respiratory chain activity}

A connection between ROMO1 and OXPHOS activity was initially addressed by Norton et al. (2014). The study showed that ATP levels were unchanged in their ROMO1 KD model and that basal respiration was not affected. However, the maximum capacity of the OXPHOS machinery was reduced (Norton et al., 2014). The results presented here confirmed that respiration and oxidative phosphorylation in general are not affected in the absence of ROMO1. However, a decrease in both quantity and activity was observed for complex IV (Figure 3.15). This could be explained by the defective coupling of TIM21 to TIM23 in the absence of ROMO1 (Figure 4.1). The assembly of complex IV is highly dependent on TIM21, since it recruits the early assembly factor MITRAC (Mick et al., 2012). This was shown here by a defective assembly of the complex IV subunit, COX4I-1, into MITRAC in the absence of ROMO1 (Figure 3.19; 4.1). The fact that the effect on respiration seemed more severe in the KO model as compared to the KD model 
could be attributed to a stronger coupling defect of TIM21 onto TIM23. Furthermore, one could also hypothesize that the majorly disturbed cristae structure could lead to decreased quantity and activity of respiratory chain complexes. Due to the changes in inner membrane morphology, complexes are not compartmentalized as in WT mitochondria and are therefore less efficient, leading to defective respiration (Norton et al., 2014). Finally, increased ROS levels could also have a negative effect on the activity of respiratory chain complexes.

\section{A}

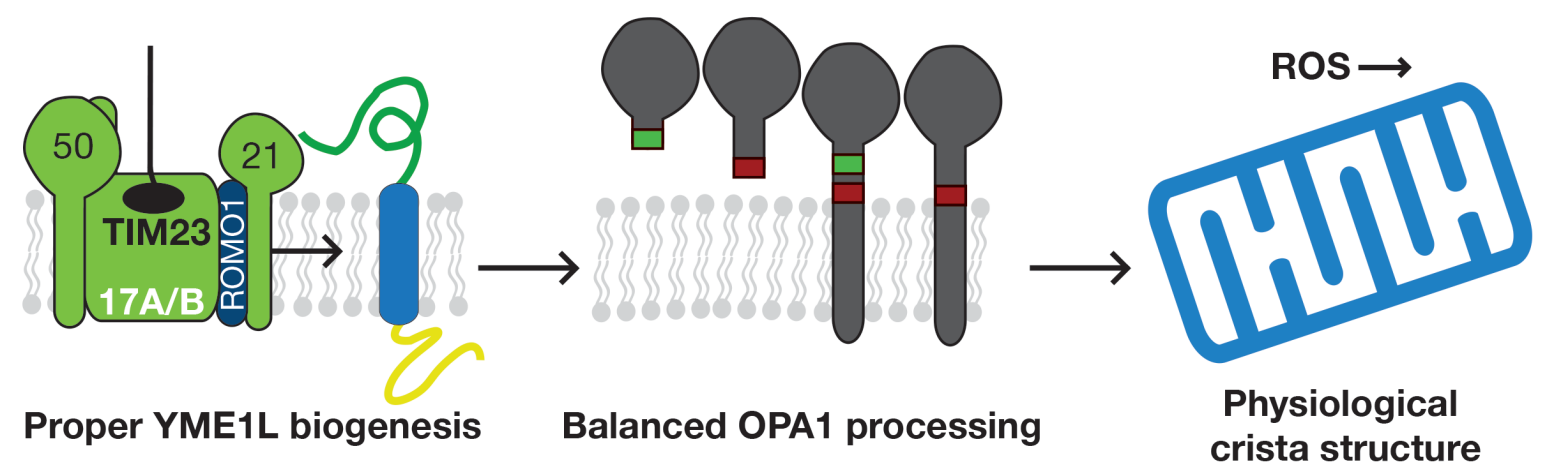

B

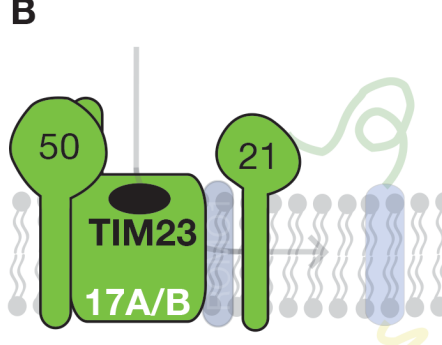

Defective YME1L biogenesis

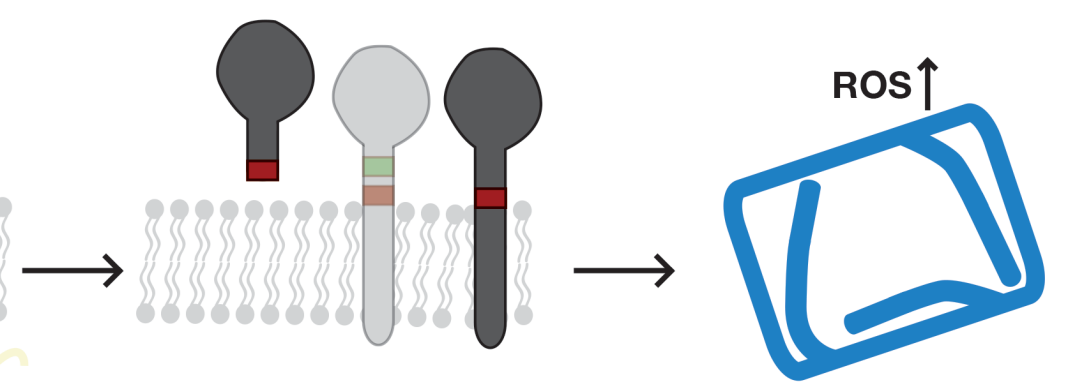

Aberrant OPA1 processing
Disturbed crista structure

Fig. 4.2: ROMO1 dependent YME1L import defects have pleiotropic effects.

(A) In WT mitochondria, YME1L is imported in a ROMO1-dependant manner and can properly process OPA1. As a result, physiological inner membrane structure keeps ROS levels normal.

(B) In ROMO1-depleted mitochondria, YME1L is not efficiently imported. As a result, OPA1 does not get properly processed leading to aberrant inner membrane structure. This can lead to increases in ROS. 


\subsection{ROMO1 and YME1L seem to be functionally linked}

\subsubsection{ROMO1 as a new YME1L substrate}

An experiment using the cytosolic translational inhibitor emetine showed that ROMO1 has a fast turnover in HEK293T cells. This was in contrast to other translocase components, as well as the yeast Mgr2 (Figure 3.12 and 3.20). This unusual finding prompted further investigation and the data presented here show that ROMO1 is specifically degraded by YME1L. The levels of ROMO1 increased dramatically upon transient knockdown of YME1L, along with the known substrate TIM17A (Rainbolt et al., 2013). Furthermore, the sequence of ROMO1 displays an FG-T-F motif in each of its transmembrane domains. It has been postulated that human YME1L recognizes its substrates by the specific recognition signal F-h-h-F, where $\mathrm{h}$ is a hydrophobic amino acid (Shi et al., 2016). While threonine is not strictly classified as a hydrophobic amino acid, the presence of these very similar degron sequences further indicates that ROMO1 is indeed degraded by YME1L. Interestingly, regarding other known YME1L substrates, only PRELID contains an F-A-A-F sequence, while both TIM23 and TIM17A do not have a similar motif in their sequence.

One can only speculate about the mechanism or underlying cause for the observed degradation of ROMO1 by YME1L. Overexpression of ROMO1 has been correlated with increased ROS production and severe malignancies. One study even named ROMO1 an oncomarker (Shyamsunder et al., 2015). It is therefore possible that the fast turnover of ROMO1 acts as a

protective mechanism to prevent the accumulation of ROMO1. This would also allow the cell to downregulate YME1L and regulate OPA1 processing in response to environmental stress. However, ROMO1 is a deeply membrane-embedded protein. It would therefore be interesting to address the mechanism of how ROMO1 is extracted from the membrane and then degraded. 


\subsubsection{Microdomains might connect different processes within the inner mitochondrial membrane}

This study showed that YME1L import is dependent on ROMO1 but that it also degrades ROMO1. This hints at a self-regulatory or feedback mechanism with yet to be addressed implications. It seems reasonable that a tight control of both proteins is necessary since their effects on ROS production or mitochondrial morphology can have a huge impact on the whole cell or organism.

There is evidence which suggests that Yme1 in yeast is in close proximity to the TIM23 complex and possibly even actively plays a role in the translocation of certain proteins (Rainey et al., 2006). Furthermore, there is also data that YME1L is associated with the human translocase (SILAC mass spectrometry data to be published) and therefore in vicinity of ROMO1. However, it still remains to be determined if and how ROMO1, or the translocase in general, interact with YME1L. For this purpose, immunoprecipitation approaches will have to be optimized, since the tagging of both proteins remains difficult and the interaction could be rather transient.

A recent idea in the field concerns the presence of microdomains within the protein-rich inner membrane. This seems conceivable since the clustering of proteins and complexes that carry out related functions makes these processes more efficient. Known examples include the organization of respiratory chain supercomplexes (Letts \& Sazanov, 2017), or the MICOS complex (Wollweber et al., 2017). Furthermore, the idea of a "proteolysis hub" spatially organizing mitochondrial proteases has also been suggested (Wai et al., 2016). This data indicates that within the SPY complex (STOML2, PARL, YME1L), the stomatin-like protein, STOML2, spatially organizes YME1L and therefore might contribute to YME1L processing during high substrate load. Along these lines, it could be possible that YME1L specific translocases, containing ROMO1, are localized in close vicinity to the SPY complex, forming a microdomain within the inner membrane. This would make the regulation of mitochondrial protein import and proteolysis more efficient and easily adaptable during stress and environmental influences. Furthermore, OPA1 needs to be processed right after import. It is 
therefore plausible that YME1L is found in close proximity to the translocase so that it can process OPA1 right away.

It has been postulated for some time that the mitochondrial import machinery is integrated into multiple processes, as well as integrated into a dynamic network within mitochondria (i.e. (Harbauer et al., 2014; Wiedemann \& Pfanner, 2017). This study brings further evidence that protein biogenesis is linked to quality control and membrane morphology. The fact that the translocase and YME1L are functionally linked is present in multiple kingdoms; human YME1L degrades TIM23, TIM17A and ROMO1 (Rainbolt et al., 2013; Wai et al., 2016; this study); yeast Yme1 degrades the small Tims, Tim9 and Tim10 (Baker et al., 2012) and Tom22 (Wu et al., 2018); and in plants, the $i$-AAA protease, FTSH4, degrades essential Tim17-2 (Opalińska et al., 2018).

In general, it seems feasible that many processes are not separate and independent but rather connected functionally, as well as physically. Partly, due to its high abundance (Morgenstern et al., 2017), the TIM23 complex can form a hub and it has already been shown to not only interact with components of other import pathways (Albrecht et al., 2006; Chacinska et al., 2010; Gold et al., 2014; Waegemann et al., 2015), but also the respiratory chain (van der Laan et al., 2006; Wiedemann et al., 2007) and the ADP/ATP carrier (Dienhart \& Stuart, 2008; Mehnert et al., 2014). These interactions make the import process more efficient and link protein import to bioenergetics. In human, the presequence translocase is also connected to respiratory chain assembly and mitochondrial translation by a complex called MITRAC (Dennerlein et al., 2015; Mick et al., 2012; Richter-Dennerlein et al., 2016).

In this thesis, novel evidence is provided that the TIM23 complex is also connected to protein processing and quality control in the inner membrane. These networks between different mitochondrial processes might be especially valuable to mediate a quick response to stress or pathological conditions. The exact implications will have to be addressed by further studies. 


\section{Conclusions and Perspectives}

The presented work has shown that ROMO1 is a constituent of the human TIM23 complex. Moreover, a novel $\mathrm{ROMO}^{-\digamma}$ cell line in HEK293 $\mathrm{T}$ cells was generated, which can be used for further studies of the molecular function of ROMO1. This cell line demonstrated that ROMO1 ablation affects cell proliferation, mitochondrial inner membrane morphology, OPA1 processing, as well as respiratory chain activity, especially complex IV. ROMO1 couples TIM21 to the translocase and its absence affects the assembly of complex IV, most likely explaining the observed changes in complex IV quantity and activity.

Following the observation that steady state levels of the $i$-AAA protease YME1L were decreased in $\mathrm{ROMO}^{--}$mitochondria, import studies revealed that the import of YME1L is dependent on ROMO1 due to its long presequence. Although a tendency was observed for precursors with a long presequence to rely on ROMO1 for import, this study could not satisfactorily resolve this. A proteomic study of ROMO1 ${ }^{-1}$ mitochondria could analyze the role of ROMO1 on the translocase further. Proteins with a lower expression level would be potential candidates for import studies of more substrates with different topologies, different overall lengths and variable presequence lengths. This would provide an important insight into the class of proteins that require ROMO1 for their import.

ROMO1 was also shown to be an unstable protein, which is degraded by YME1L. It would be interesting to characterize the relationship between ROMO1 and YME1L further. SILAC mass spectrometry analyses have given the indication that they might interact physically but this hasn't been proven. Addressing if the whole TIM23 complex is part of a bigger network connecting protein biogenesis, quality control and inner membrane morphology would add further evidence regarding the spatial and functional organization of different processes in mitochondria. These networks might be especially important for understanding the development of human diseases. 


\section{Bibliography}

Abe, Y., Shodai, T., Muto, T., Mihara, K., Torii, H., Nishikawa, S., et al. (2000). Structural basis of presequence recognition by the mitochondrial protein import receptor Tom20. Cell, 100(5), 551560 .

Aich, A., Wang, C., Chowdhury, A., Ronsör, C., Pacheu-Grau, D., Richter-Dennerlein, R., et al. (2018). COX16 promotes COX2 metallation and assembly during respiratory complex IV biogenesis. eLife, 7,34 .

Albrecht, R., Rehling, P., Chacinska, A., Brix, J., Cadamuro, S. A., Volkmer, R., et al. (2006). The Tim21 binding domain connects the preprotein translocases of both mitochondrial membranes. EMBO Reports, 7(12), 1233-1238.

Alconada, A., Kübrich, M., Moczko, M., Hönlinger, A., \& Pfanner, N. (1995). The mitochondrial receptor complex: the small subunit Mom8b/Isp6 supports association of receptors with the general insertion pore and transfer of preproteins. Molecular and Cellular Biology, 15(11), 6196-6205.

Alder, N. N., Jensen, R. E., \& Johnson, A. E. (2008). Fluorescence mapping of mitochondrial TIM23 complex reveals a water-facing, substrate-interacting helix surface. Cell, 134(3), 439-450.

Alexander, C., Votruba, M., Pesch, U. E., Thiselton, D. L., Mayer, S., Moore, A., et al. (2000). OPA1, encoding a dynamin-related GTPase, is mutated in autosomal dominant optic atrophy linked to chromosome 3q28. Nature Genetics, 26(2), 211-215.

Ammelburg, M., Frickey, T., \& Lupas, A. N. (2006). Classification of AAA ${ }^{+}$proteins. Journal of Structural Biology, 156(1), 2-11.

Anand, R., Wai, T., Baker, M. J., Kladt, N., Schauss, A. C., Rugarli, E., \& Langer, T. (2014). The i-AAA protease YME1L and OMA1 cleave OPA1 to balance mitochondrial fusion and fission. The Journal of Cell Biology, 204(6), 919-929. 
Bae, Y. S., Oh, H., Rhee, S. G., \& Yoo, Y. D. (2011). Regulation of reactive oxygen species generation in cell signaling. Molecules and Cells, 32(6), 491-509.

Bajaj, R., Jaremko, Ł., Jaremko, M., Becker, S., \& Zweckstetter, M. (2014). Molecular basis of the dynamic structure of the TIM23 complex in the mitochondrial intermembrane space. Structure (London, England: 1993), 22(10), 1501-1511.

Baker, M. J., Lampe, P. A., Stojanovski, D., Korwitz, A., Anand, R., Tatsuta, T., \& Langer, T. (2014). Stress-induced OMA1 activation and autocatalytic turnover regulate OPA1-dependent mitochondrial dynamics. The EMBO Journal, 33(6), 578-593.

Baker, M. J., Mooga, V. P., Guiard, B., Langer, T., Ryan, M. T., \& Stojanovski, D. (2012). Impaired folding of the mitochondrial small TIM chaperones induces clearance by the i-AAA protease. Journal of Molecular Biology, 424(5), 227-239.

Ballmoos, von, C., Cook, G. M., \& Dimroth, P. (2008). Unique Rotary ATP Synthase and Its Biological Diversity. Annual Review of Biophysics, 37(1), 43-64.

Banerjee, R., Gladkova, C., Mapa, K., Witte, G., \& Mokranjac, D. (2015). Protein translocation channel of mitochondrial inner membrane and matrix-exposed import motor communicate via two-domain coupling protein. eLife, 4, e11897.

Barrie Kitto, G. (1969). [19] Intra- and extramitochondrial malate dehydrogenases from chicken and tuna heart: [EC 1.1.1.37 1-Malate: NAD oxidoreductase]. Methods in Enzymology, 13, 106-116.

Bauer, M. F., Gempel, K., Reichert, A. S., Rappold, G. A., Lichtner, P., Gerbitz, K. D., et al. (1999). Genetic and structural characterization of the human mitochondrial inner membrane translocase. Journal of Molecular Biology, 289(1), 69-82.

Bauer, M. F., Sirrenberg, C., Neupert, W., \& Brunner, M. (1996). Role of Tim23 as voltage sensor and presequence receptor in protein import into mitochondria. Cell, 87(1), 33-41. 
Becker, T., Pfannschmidt, S., Guiard, B., Stojanovski, D., Milenkovic, D., Kutik, S., et al. (2008). Biogenesis of the mitochondrial TOM complex: Mim1 promotes insertion and assembly of signalanchored receptors. Journal of Biological Chemistry, 283(1), 120-127.

Becker, T., Wenz, L.-S., Krüger, V., Lehmann, W., Müller, J. M., Goroncy, L., et al. (2011). The mitochondrial import protein Mim1 promotes biogenesis of multispanning outer membrane proteins. The Journal of Cell Biology, 194(3), 387-395.

Benz, R. (1994). Permeation of hydrophilic solutes through mitochondrial outer membranes: review on mitochondrial porins. Biochimica Et Biophysica Acta, 1197(2), 167-196.

Bhangoo, M. K., Tzankov, S., Fan, A. C. Y., Dejgaard, K., Thomas, D. Y., \& Young, J. C. (2007). Multiple $40-\mathrm{kDa}$ heat-shock protein chaperones function in Tom70-dependent mitochondrial import. Molecular Biology of the Cell, 18(9), 3414-3428.

Bien, M., Longen, S., Wagener, N., Chwalla, I., Herrmann, J. M., \& Riemer, J. (2010). Mitochondrial disulfide bond formation is driven by intersubunit electron transfer in Erv1 and proofread by glutathione. Molecular Cell, 37(4), 516-528.

Bohnert, M., Rehling, P., Guiard, B., Herrmann, J. M., Pfanner, N., \& van der Laan, M. (2010). Cooperation of stop-transfer and conservative sorting mechanisms in mitochondrial protein transport. Current Biology: CB, 20(13), 1227-1232.

Bolliger, L., Junne, T., Schatz, G., \& Lithgow, T. (1995). Acidic receptor domains on both sides of the outer membrane mediate translocation of precursor proteins into yeast mitochondria. The EMBO Journal, 14(24), 6318-6326.

Botelho, S. C., Österberg, M., Reichert, A. S., Yamano, K., Björkholm, P., Endo, T., et al. (2011). TIM23mediated insertion of transmembrane \&alpha;-helices into the mitochondrial inner membrane. The EMBO Journal, 30(6), 1003-1011.

Brand, M. D. (2016). Mitochondrial generation of superoxide and hydrogen peroxide as the source of mitochondrial redox signaling. Free Radical Biology and Medicine, 100(C), 14-31. 
Brix, J., Dietmeier, K., \& Pfanner, N. (1997). Differential recognition of preproteins by the purified cytosolic domains of the mitochondrial import receptors Tom20, Tom22, and Tom70. Journal of Biological Chemistry, 272(33), 20730-20735.

Brix, J., Rüdiger, S., Bukau, B., Schneider-Mergener, J., \& Pfanner, N. (1999). Distribution of binding sequences for the mitochondrial import receptors Tom20, Tom22, and Tom70 in a presequencecarrying preprotein and a non-cleavable preprotein. Journal of Biological Chemistry, 274(23), 1652216530.

Callegari, S., Richter, F., Chojnacka, K., Jans, D. C., Lorenzi, I., Pacheu-Grau, D., et al. (2016). TIM29 is a subunit of the human carrier translocase required for protein transport. FEBS Letters, 590(23), $4147-4158$.

Calvo, S. E., Julien, O., Clauser, K. R., Shen, H., Kamer, K. J., Wells, J. A., \& Mootha, V. K. (2017). Comparative Analysis of Mitochondrial N-Termini from Mouse, Human, and Yeast. Molecular \& Cellular Proteomics, 16(4), 512-523.

Chacinska, A., Guiard, B., Müller, J. M., Schulze-Specking, A., Gabriel, K., Kutik, S., \& Pfanner, N. (2008). Mitochondrial biogenesis, switching the sorting pathway of the intermembrane space receptor Mia40. Journal of Biological Chemistry, 283(44), 29723-29729.

Chacinska, A., Koehler, C. M., Milenkovic, D., Lithgow, T., \& Pfanner, N. (2009). Importing Mitochondrial Proteins: Machineries and Mechanisms. Cell, 138(4), 628-644.

Chacinska, A., Lind, M., Frazier, A. E., Dudek, J., Meisinger, C., Geissler, A., et al. (2005). Mitochondrial presequence translocase: switching between TOM tethering and motor recruitment involves Tim2 1 and Tim17. Cell, 120(6), 817-829.

Chacinska, A., Pfannschmidt, S., Wiedemann, N., Kozjak, V., Sanjuán Szklarz, L. K., Schulze-Specking, A., et al. (2004). Essential role of Mia40 in import and assembly of mitochondrial intermembrane space proteins. The EMBO Journal, 23(19), 3735-3746. 
Chacinska, A., van der Laan, M., Mehnert, C. S., Guiard, B., Mick, D. U., Hutu, D. P., et al. (2010). Distinct forms of mitochondrial TOM-TIM supercomplexes define signal-dependent states of preprotein sorting. Molecular and Cellular Biology, 30(1), 307-318.

Chandel, N. S., Maltepe, E., Goldwasser, E., Mathieu, C. E., Simon, M. C., \& Schumacker, P. T. (1998). Mitochondrial reactive oxygen species trigger hypoxia-induced transcription. Proceedings of the National Academy of Sciences of the United States of America, 95(20), 11715-11720.

Chen, X., Zhang, N., Dong, J., \& Sun, G. (2017). Reactive oxygen species modulator 1, a novel protein, combined with carcinoembryonic antigen in differentiating malignant from benign pleural effusion. Tumor Biology, 39(5), 101042831769837-8.

Chomyn, A. (1996). In vivo labeling and analysis of human mitochondrial translation products. Methods in Enzymology, 264, 197-211.

Chung, J. S., Lee, S. B., Park, S. H., Kang, S. T., Na, A. R., Chang, T.-S., et al. (2010). Mitochondrial reactive oxygen species originating from Romol exert an important role in normal cell cycle progression by regulating p27 Kiplexpression. Free Radical Research, 43(8), 729-737.

Chung, J. S., Park, S. H., Park, S. H., Park, E. R., Cha, P. H., Kim, B. Y., et al. (2012). Overexpression of Romo1 Promotes Production of Reactive Oxygen Species and Invasiveness of Hepatic Tumor Cells. Ygast, 143(4), 1084-1094.e7.

Chung, Y. M., Kim, J. S., \& Yoo, Y. D. (2006). A novel protein, Romo1, induces ROS production in the mitochondria. Biochemical and Biophysical Research Communications, 347(3), 649-655.

Chung, Y. M., Lee, S. B., Kim, H. J., Park, S. H., Kim, J. J., Chung, J. S., \& Yoo, Y. D. (2008). Replicative senescence induced by Romol-derived reactive oxygen species. Journal of Biological Chemistry, 283(48), 33763-33771.

Claros, M. G., \& Vincens, P. (1996). Computational Method to Predict Mitochondrially Imported Proteins and their Targeting Sequences. European Journal of Biochemistry, 241(3), 779-786. 
Cogliati, S., Frezza, C., Soriano, M. E., Varanita, T., Quintana-Cabrera, R., Corrado, M., et al. (2013). Mitochondrial Cristae Shape Determines Respiratory Chain Supercomplexes Assembly and Respiratory Efficiency. Cell, 155(1), 160-171.

Coppola, M., Pizzigoni, A., Banfi, S., Bassi, M. T., Casari, G., \& Incerti, B. (2000). Identification and characterization of YME1L1, a novel paraplegin-related gene. Genomics, 66(1), 48-54.

Corral-Debrinski, M., Blugeon, C., \& Jacq, C. (2000). In yeast, the 3' untranslated region or the presequence of ATM1 is required for the exclusive localization of its mRNA to the vicinity of mitochondria. Molecular and Cellular Biology, 20(21), 7881-7892.

Curran, S. P., Leuenberger, D., Oppliger, W., \& Koehler, C. M. (2002a). The Tim9p-Tim10p complex binds to the transmembrane domains of the ADP/ATP carrier. The EMBO Journal, 21(5), 942-953.

Curran, S. P., Leuenberger, D., Schmidt, E., \& Koehler, C. M. (2002b). The role of the Tim8p-Tim13p complex in a conserved import pathway for mitochondrial polytopic inner membrane proteins. The Journal of Cell Biology, 158(6), 1017-1027.

Dabir, D. V., Leverich, E. P., Kim, S.-K., Tsai, F. D., Hirasawa, M., Knaff, D. B., \& Koehler, C. M. (2007). A role for cytochrome $c$ and cytochrome $c$ peroxidase in electron shuttling from Erv1. The EMBO Journal, 26(23), 4801-4811.

Daithankar, V. N., Farrell, S. R., \& Thorpe, C. (2009). Augmenter of liver regeneration: substrate specificity of a flavin-dependent oxidoreductase from the mitochondrial intermembrane space. Biochemistry, 48(22), 4828-4837.

Davis, A. J., Alder, N. N., Jensen, R. E., \& Johnson, A. E. (2007). The Tim9p/10p and Tim8p/13p complexes bind to specific sites on Tim23p during mitochondrial protein import. Molecular Biology of the Cell, 18(2), 475-486.

de Duve, C. (2007). The origin of eukaryotes: a reappraisal. Nature Reviews. Genetics, 8(5), 395-403. 
De Los Rios, P., Ben-Zvi, A., Slutsky, O., Azem, A., \& Goloubinoff, P. (2006). Hsp70 chaperones accelerate protein translocation and the unfolding of stable protein aggregates by entropic pulling. Proceedings of the National Academy of Sciences of the United States of America, 103(16), 6166-6171.

De Mena, L., Coto, E., Sánchez-Ferrero, E., Ribacoba, R., Guisasola, L. M., Salvador, C., et al. (2009). Mutational screening of the mortalin gene (HSPA9) in Parkinson's disease. Journal of Neural Transmission, 116(10), 1289-1293.

Dekker, P. J., Keil, P., Rassow, J., Maarse, A. C., Pfanner, N., \& Meijer, M. (1993). Identification of MIM23, a putative component of the protein import machinery of the mitochondrial inner membrane. FEBS Letters, 330(1), 66-70.

Dekker, P. J., Müller, H., Rassow, J., \& Pfanner, N. (1996). Characterization of the preprotein translocase of the outer mitochondrial membrane by blue native electrophoresis. Biological Chemistry, 377(78), 535-538.

Delettre, C., Griffoin, J.-M., Kaplan, J., Dollfus, H., Lorenz, B., Faivre, L., et al. (2001). Mutation spectrum and splicing variants in the OPA1 gene. Human Genetics, 109(6), 584-591.

Delettre, C., Lenaers, G., Griffoin, J. M., Gigarel, N., Lorenzo, C., Belenguer, P., et al. (2000). Nuclear gene OPA1, encoding a mitochondrial dynamin-related protein, is mutated in dominant optic atrophy. Nature Genetics, 26(2), 207-210.

Delves, P. J., \& Roitt, I. M. (1998). Encyclopedia of Immunology.

Demishtein-Zohary, K., \& Azem, A. (2017). The TIM23 mitochondrial protein import complex: function and dysfunction. Cell and Tissue Research, 367(1), 33-41.

Dennerlein, S., Oeljeklaus, S., Jans, D., Hellwig, C., Bareth, B., Jakobs, S., et al. (2015). MITRAC7 Acts as a COX1-Specific Chaperone and Reveals a Checkpoint during Cytochrome $c$ Oxidase Assembly. Cell Reports, 12(10), 1644-1655. 
Dienhart, M. K., \& Stuart, R. A. (2008). The yeast Aac2 protein exists in physical association with the cytochrome $b c_{1}$-COX supercomplex and the TIM23 machinery. Molecular Biology of the Cell, 19(9), $3934-3943$.

Dietmeier, K., Hönlinger, A., Bömer, U., Dekker, P. J., Eckerskorn, C., Lottspeich, F., et al. (1997). Tom5 functionally links mitochondrial preprotein receptors to the general import pore. Nature, 388(6638), 195-200.

Dimmer, K. S., Papić, D., Schumann, B., Sperl, D., Krumpe, K., Walther, D. M., \& Rapaport, D. (2012). A crucial role for Mim2 in the biogenesis of mitochondrial outer membrane proteins. Journal of Cell Science, 125(Pt 14), 3464-3473.

Dudek, J., Cheng, I.-F., Chowdhury, A., Wozny, K., Balleininger, M., Reinhold, R., et al. (2016). Cardiacspecific succinate dehydrogenase deficiency in Barth syndrome. EMBO Molecular Medicine, 8(2), $139-154$.

Dudek, J., Rehling, P., \& van der Laan, M. (2013). Mitochondrial protein import: Common principles and physiological networks. BBA - Molecular Cell Research, 1833(2), 274-285.

Elgass, K., Pakay, J., Ryan, M. T., \& Palmer, C. S. (2013). Recent advances into the understanding of mitochondrial fission. Biochimica Et Biophysica Acta, 1833(1), 150-161.

Ellenrieder, L., Mårtensson, C. U., \& Becker, T. (2015). Biogenesis of mitochondrial outer membrane proteins, problems and diseases. Biological Chemistry, 396(11), 1199-1213.

Erşahin, C., Szpaderska, A. M., Orawski, A. T., \& Simmons, W. H. (2005). Aminopeptidase P isozyme expression in human tissues and peripheral blood mononuclear cell fractions. Archives of Biochemistry and Biophysics, 435(2), 303-310.

Esaki, M., Kanamori, T., Nishikawa, S. I., Shin, I., Schultz, P. G., \& Endo, T. (2003). Tom40 protein import channel binds to non-native proteins and prevents their aggregation. Nature Structural Biology, 10(12), 988-994. 
Fernández-Vizarra, E., Tiranti, V., \& Zeviani, M. (2009). Assembly of the oxidative phosphorylation system in humans: What we have learned by studying its defects. BBA - Molecular Cell Research, 1793(1), 200-211.

Fischer, M., \& Riemer, J. (2013). The mitochondrial disulfide relay system: roles in oxidative protein folding and beyond. International Journal of Cell Biology, 2013(23), 742923-12.

Frazier, A. E., Dudek, J., Guiard, B., Voos, W., Li, Y., Lind, M., et al. (2004). Pam16 has an essential role in the mitochondrial protein import motor. Nature Structural \& Molecular Biology, 11(3), 226-233.

Frezza, C., Cipolat, S., Martins de Brito, O., Micaroni, M., Beznoussenko, G. V., Rudka, T., et al. (2006). OPA1 Controls Apoptotic Cristae Remodeling Independently from Mitochondrial Fusion. Cell, 126(1), 177-189.

Friedman, J. R., \& Nunnari, J. (2014). Mitochondrial form and function. Nature, 505(7483), 335-343.

Gallagher, S., Winston, S. E., Fuller, S. A., \& Hurrell, J. G. R. (2004). Immunoblotting and immunodetection. Current Protocols in Neuroscience, Chapter 5(1), Unit 5.19-5.19.24.

Garcia, M., Delaveau, T., Goussard, S., \& Jacq, C. (2010). Mitochondrial presequence and open reading frame mediate asymmetric localization of messenger RNA. EMBO Reports, 11(4), 285-291.

Gärtner, F., Bömer, U., Guiard, B., \& Pfanner, N. (1995). The sorting signal of cytochrome b $b_{2}$ promotes early divergence from the general mitochondrial import pathway and restricts the unfoldase activity of matrix Hsp70. The EMBO Journal, 14(23), 6043-6057.

Gebert, M., Schrempp, S. G., Mehnert, C. S., Heißwolf, A. K., Oeljeklaus, S., Ieva, R., et al. (2012). Mgr2 promotes coupling of the mitochondrial presequence translocase to partner complexes. The Journal of Cell Biology, 197(5), 595-604.

Gebert, N., Chacinska, A., Wagner, K., Guiard, B., Koehler, C. M., Rehling, P., et al. (2008). Assembly of the three small Tim proteins precedes docking to the mitochondrial carrier translocase. EMBO Reports, 9(6), 548-554. 
Gebert, N., Gebert, M., Oeljeklaus, S., Malsburg, von der, K., Stroud, D. A., Kulawiak, B., et al. (2011). Dual Function of Sdh3 in the Respiratory Chain and TIM22 Protein Translocase of the Mitochondrial Inner Membrane. Molecular Cell, 44(5), 811-818.

Geissler, A., Chacinska, A., Truscott, K. N., Wiedemann, N., Brandner, K., Sickmann, A., et al. (2002). The mitochondrial presequence translocase: an essential role of Tim50 in directing preproteins to the import channel. Cell, 111(4), 507-518.

Geissler, A., Rassow, J., Pfanner, N., \& Voos, W. (2001). Mitochondrial import driving forces: enhanced trapping by matrix Hsp70 stimulates translocation and reduces the membrane potential dependence of loosely folded preproteins. Molecular and Cellular Biology, 21(20), 7097-7104.

Glick, B. S., Brandt, A., Cunningham, K., Müller, S., Hallberg, R. L., \& Schatz, G. (1992). Cytochromes $c_{1}$ and $b_{2}$ are sorted to the intermembrane space of yeast mitochondria by a stop-transfer mechanism. Cell, 69(5), 809-822.

Gold, V. A. M., Ieva, R., Walter, A., Pfanner, N., van der Laan, M., \& Kühlbrandt, W. (2014). Visualizing active membrane protein complexes by electron cryotomography. Nature Communications, 5(1), 4129.

Gold, V. A., Chroscicki, P., Bragoszewski, P., \& Chacinska, A. (2017). Visualization of cytosolic ribosomes on the surface of mitochondria by electron cryo-tomography. EMBO Reports, 18(10), 1786-1800.

Gornicka, A., Bragoszewski, P., Chroscicki, P., Wenz, L.-S., Schulz, C., Rehling, P., \& Chacinska, A. (2014). A discrete pathway for the transfer of intermembrane space proteins across the outer membrane of mitochondria. Molecular Biology of the Cell, 25(25), 3999-4009.

Graef, M., Seewald, G., \& Langer, T. (2007). Substrate recognition by AAA ${ }^{+}$ATPases: distinct substrate binding modes in ATP-dependent protease Yme1 of the mitochondrial intermembrane space. Molecular and Cellular Biology, 27(7), 2476-2485. 
Gray, M. W., Burger, G., \& Lang, B. F. (1999). Mitochondrial evolution. Science, 283(5407), 1476-1481.

Green, M. R., \& Sambrook, J. (2012). Molecular Cloning: A Laboratory Manual. Cold Spring Harbor Lab Press.

Griparic, L., van der Wel, N. N., Orozco, I. J., Peters, P. J., \& van der Bliek, A. M. (2004). Loss of the intermembrane space protein Mgm1/OPA1 induces swelling and localized constrictions along the lengths of mitochondria. Journal of Biological Chemistry, 279(18), 18792-18798.

Guo, R., Gu, J., Zong, S., Wu, M., \& Yang, M. (2018). Structure and mechanism of mitochondrial electron transport chain. Biomedical Journal, 41(1), 9-20.

Guo, Y., Cheong, N., Zhang, Z., De Rose, R., Deng, Y., Farber, S. A., et al. (2004). Tim50, a component of the mitochondrial translocator, regulates mitochondrial integrity and cell death. Journal of Biological Chemistry, 279(23), 24813-24825.

Gustafsson, C. M., Falkenberg, M., \& Larsson, N.-G. (2016). Maintenance and Expression of Mammalian Mitochondrial DNA. Annual Review of Biochemistry, 85(1), 133-160.

Harbauer, A. B., Zahedi, R. P., Sickmann, A., Pfanner, N., \& Meisinger, C. (2014). The Protein Import Machinery of Mitochondria-A Regulatory Hub in Metabolism, Stress, and Disease. Cell Metabolism, 19(3), 357-372.

Hartl, F. U., Schmidt, B., Wachter, E., Weiss, H., \& Neupert, W. (1986). Transport into mitochondria and intramitochondrial sorting of the Fe/S protein of ubiquinol-cytochrome $c$ reductase. Cell, 47(6), 939-951.

Hartmann, B., Wai, T., Hu, H., MacVicar, T., Musante, L., Fischer-Zirnsak, B., et al. (2016). Homozygous YME1L1 mutation causes mitochondriopathy with optic atrophy and mitochondrial network fragmentation. eLife, 5, 919.

Hällberg, B. M., \& Larsson, N.-G. (2014). Making Proteins in the Powerhouse. Cell Metabolism, 20(2), 226-240. 
Heijne, von, G. (1986). Mitochondrial targeting sequences may form amphiphilic helices. The EMBO Journal, 5(6), 1335-1342.

Heijne, von, G., Steppuhn, J., \& Herrmann, R. G. (1989). Domain structure of mitochondrial and chloroplast targeting peptides. European Journal of Biochemistry, 180(3), 535-545.

Hell, K., Neupert, W., \& Stuart, R. A. (2001). Oxa1p acts as a general membrane insertion machinery for proteins encoded by mitochondrial DNA. The EMBO Journal, 20(6), 1281-1288.

Herlan, M., Bornhövd, C., Hell, K., Neupert, W., \& Reichert, A. S. (2004). Alternative topogenesis of Mgm1 and mitochondrial morphology depend on ATP and a functional import motor. The Journal of Cell Biology, 165(2), 167-173.

Hill, K., Model, K., Ryan, M. T., Dietmeier, K., Martin, F., Wagner, R., \& Pfanner, N. (1998). Tom40 forms the hydrophilic channel of the mitochondrial import pore for preproteins. Nature, 395(6701), $516-521$.

Hines, V., \& Schatz, G. (1993). Precursor binding to yeast mitochondria. A general role for the outer membrane protein Mas70p. Journal of Biological Chemistry, 268(1), 449-454.

Hines, V., Brandt, A., Griffiths, G., Horstmann, H., Brütsch, H., \& Schatz, G. (1990). Protein import into yeast mitochondria is accelerated by the outer membrane protein MAS70. The EMBO Journal, 9(10), 3191-3200.

Hofmann, S., Rothbauer, U., Mühlenbein, N., Baiker, K., Hell, K., \& Bauer, M. F. (2005). Functional and mutational characterization of human MIA40 acting during import into the mitochondrial intermembrane space. Journal of Molecular Biology, 353(3), 517-528.

Holmström, K. M., \& Finkel, T. (2014). Cellular mechanisms and physiological consequences of redoxdependent signalling. Nature Publishing Group, 15(6), 411-421. 
Hoppins, S. (2014). The regulation of mitochondrial dynamics. Current Opinion in Cell Biology, 29, 4652.

Hoppins, S. C., \& Nargang, F. E. (2004). The Tim8-Tim 13 complex of Neurospora crassa functions in the assembly of proteins into both mitochondrial membranes. Journal of Biological Chemistry, 279(13), 12396-12405.

Horst, M., Jenö, P., Kronidou, N. G., Bolliger, L., Oppliger, W., Scherer, P., et al. (1993). Protein import into yeast mitochondria: the inner membrane import site protein ISP45 is the MPI1 gene product. The EMBO Journal, 12(8), 3035-3041.

Horst, M., Oppliger, W., Rospert, S., Schönfeld, H. J., Schatz, G., \& Azem, A. (1997). Sequential action of two hsp70 complexes during protein import into mitochondria. The EMBO Journal, 16(8), 18421849.

Horvath, P., \& Barrangou, R. (2010). CRISPR/Cas, the immune system of bacteria and archaea. Science, 327(5962), 167-170.

Höhr, A. I. C., Lindau, C., Wirth, C., Qiu, J., Stroud, D. A., Kutik, S., et al. (2018). Membrane protein insertion through a mitochondrial $\beta$-barrel gate. Science, 359(6373), eaah6834-14.

Hönlinger, A., Bömer, U., Alconada, A., Eckerskorn, C., Lottspeich, F., Dietmeier, K., \& Pfanner, N. (1996). Tom7 modulates the dynamics of the mitochondrial outer membrane translocase and plays a pathway-related role in protein import. The EMBO Journal, 15(9), 2125-2137.

Huang, S., Taylor, N. L., Whelan, J., \& Millar, A. H. (2009). Refining the Definition of Plant Mitochondrial Presequences through Analysis of Sorting Signals, N-Terminal Modifications, and Cleavage Motifs. Plant Physiology, 150(3), 1272-1285.

Huynen, M. A., Mühlmeister, M., Gotthardt, K., Guerrero-Castillo, S., \& Brandt, U. (2016). Evolution and structural organization of the mitochondrial contact site (MICOS) complex and the mitochondrial intermembrane space bridging (MIB) complex. Biochimica Et Biophysica Acta, 1863(1), 91-101. 
Ieva, R., Schrempp, S. G., Opaliński, Ł., Wollweber, F., Höß, P., Heißwolf, A. K., et al. (2014). Mgr2 Functions as Lateral Gatekeeper for Preprotein Sorting in the Mitochondrial Inner Membrane. Molecular Cell, 56(5), 641-652.

Ieva, R., Heißwolf, A. K., Gebert, M., Vögtle, F. N., Wollweber, F., Mehnert, C. S., et al. (2013). Mitochondrial inner membrane protease promotes assembly of presequence translocase by removing a carboxy-terminal targeting sequence. Nature Communications, 4, 2853.

Ishihara, N., Fujita, Y., Oka, T., \& Mihara, K. (2006). Regulation of mitochondrial morphology through proteolytic cleavage of OPA1. The EMBO Journal, 25(13), 2966-2977.

Ježek, J., Cooper, K., \& Strich, R. (2018). Reactive Oxygen Species and Mitochondrial Dynamics: The Yin and Yang of Mitochondrial Dysfunction and Cancer Progression. Antioxidants, 7(1), 13-24.

Jiang, D., Zhao, L., \& Clapham, D. E. (2009). Genome-wide RNAi screen identifies Letm1 as a mitochondrial $\mathrm{Ca}^{2+} / \mathrm{H}^{+}$antiporter. Science, 326(5949), 144-147.

John, A. M. S. P., Kundu, S., Pushpakumar, S., Fordham, M., Weber, G., Mukhopadhyay, M., \& Sen, U. (2017). GYY4137, a Hydrogen Sulfide Donor Modulates miR194-Dependent Collagen Realignment in Diabetic Kidney. Scientific Reports, 7(1), 10924.

Jores, T., Klinger, A., Groß, L. E., Kawano, S., Flinner, N., Duchardt-Ferner, E., et al. (2016). Characterization of the targeting signal in mitochondrial $\beta$-barrel proteins. Nature Communications, 7, 12036.

Kang, P. J., Ostermann, J., Shilling, J., Neupert, W., Craig, E. A., \& Pfanner, N. (1990). Requirement for hsp70 in the mitochondrial matrix for translocation and folding of precursor proteins. Nature, 348(6297), 137-143.

Kang, Y., Baker, M. J., Liem, M., Louber, J., McKenzie, M., Atukorala, I., et al. (2016). Tim29 is a novel subunit of the human TIM22 translocase and is involved in complex assembly and stability. eLife, 5, 313. 
Kang, Y., Fielden, L. F., \& Stojanovski, D. (2018). Mitochondrial protein transport in health and disease. Seminars in Cell and Developmental Biology, 76, 142-153.

Kang, Y., Stroud, D. A., Baker, M. J., De Souza, D. P., Frazier, A. E., Liem, M., et al. (2017). Sengers Syndrome-Associated Mitochondrial Acylglycerol Kinase Is a Subunit of the Human TIM22 Protein Import Complex. Molecular Cell, 67(3), 457-470.e5.

Käser, M., Kambacheld, M., Kisters-Woike, B., \& Langer, T. (2003). Oma1, a novel membrane-bound metallopeptidase in mitochondria with activities overlapping with the m-AAA protease. Journal of Biological Chemistry, 278(47), 46414-46423.

Kemper, C., Habib, S. J., Engl, G., Heckmeyer, P., Dimmer, K. S., \& Rapaport, D. (2008). Integration of tail-anchored proteins into the mitochondrial outer membrane does not require any known import components. Journal of Cell Science, 121(Pt 12), 1990-1998.

Kiebler, M., Pfaller, R., Söllner, T., Griffiths, G., Horstmann, H., Pfanner, N., \& Neupert, W. (1990). Identification of a mitochondrial receptor complex required for recognition and membrane insertion of precursor proteins. Nature, 348(6302), 610-616.

Kim, H. J., Jo, M. J., Kim, B. R., Kim, J. L., Jeong, Y. A., Na, Y. J., et al. (2017). Reactive oxygen species modulator-1 (Romo1) predicts unfavorable prognosis in colorectal cancer patients. PLoS ONE, 12(5), e0176834.

Kim, I. G., Kim, S. Y., Kim, H. A., Kim, J. Y., Lee, J. H., Choi, S. I., et al. (2014). Disturbance of DKK1 level is partly involved in survival of lung cancer cells via regulation of ROMO1 and $\gamma$-radiation sensitivity. Biochemical and Biophysical Research Communications, 443(1), 49-55.

Komiya, T., Rospert, S., Koehler, C., Looser, R., Schatz, G., \& Mihara, K. (1998). Interaction of mitochondrial targeting signals with acidic receptor domains along the protein import pathway: evidence for the "acid chain" hypothesis. The EMBO Journal, 17(14), 3886-3898. 
Kozany, C., Mokranjac, D., Sichting, M., Neupert, W., \& Hell, K. (2004). The J domain-related cochaperone Tim16 is a constituent of the mitochondrial TIM23 preprotein translocase. Nature Structural \& Molecular Biology, 11(3), 234-241.

Kozjak-Pavlovic, V., Ross, K., Benlasfer, N., Kimmig, S., Karlas, A., \& Rudel, T. (2007). Conserved roles of Sam50 and metaxins in VDAC biogenesis. EMBO Reports, 8(6), 576-582.

König, T., Tröder, S. E., Bakka, K., Korwitz, A., Richter-Dennerlein, R., Lampe, P. A., et al. (2016). The m-AAA Protease Associated with Neurodegeneration Limits MCU Activity in Mitochondria. Molecular Cell, 64(1), 148-162.

Krayl, M., Lim, J. H., Martin, F., Guiard, B., \& Voos, W. (2007). A cooperative action of the ATPdependent import motor complex and the inner membrane potential drives mitochondrial preprotein import. Molecular and Cellular Biology, 27(2), 411-425.

Krimmer, T., Rapaport, D., Ryan, M. T., Meisinger, C., Kassenbrock, C. K., Blachly-Dyson, E., et al. (2001). Biogenesis of porin of the outer mitochondrial membrane involves an import pathway via receptors and the general import pore of the TOM complex. The Journal of Cell Biology, 152(2), 289300.

Kronidou, N. G., Oppliger, W., Bolliger, L., Hannavy, K., Glick, B. S., Schatz, G., \& Horst, M. (1994). Dynamic interaction between Isp45 and mitochondrial hsp70 in the protein import system of the yeast mitochondrial inner membrane. Proceedings of the National Academy of Sciences of the United States of America, 91(26), 12818-12822.

Krüger, V., Becker, T., Becker, L., Montilla-Martinez, M., Ellenrieder, L., Vögtle, F. N., et al. (2017). Identification of new channels by systematic analysis of the mitochondrial outer membrane. The Journal of Cell Biology, 216(11), 3485-3495.

Kübrich, M., Keil, P., Rassow, J., Dekker, P. J., Blom, J., Meijer, M., \& Pfanner, N. (1994). The polytopic mitochondrial inner membrane proteins MIM17 and MIM23 operate at the same preprotein import site. FEBS Letters, 349(2), 222-228. 
la Cruz, de, L., Bajaj, R., Becker, S., \& Zweckstetter, M. (2010). The intermembrane space domain of Tim23 is intrinsically disordered with a distinct binding region for presequences. Protein Science : a Publication of the Protein Society, 19(11), 2045-2054.

Laemmli, U. K. (1970). Cleavage of structural proteins during the assembly of the head of bacteriophage T4. Nature, 227(5259), 680-685.

Laloraya, S., Gambill, B. D., \& Craig, E. A. (1994). A role for a eukaryotic GrpE-related protein, Mge1p, in protein translocation. Proceedings of the National Academy of Sciences of the United States of America, 91(14), 6481-6485.

Lane, N., \& Martin, W. (2010). The energetics of genome complexity. Nature, 467(7318), 929-934.

Lazarou, M., Smith, S. M., Thorburn, D. R., Ryan, M. T., \& McKenzie, M. (2009). Assembly of nuclear DNA-encoded subunits into mitochondrial complex IV, and their preferential integration into supercomplex forms in patient mitochondria. FEBS Journal, 276(22), 6701-6713.

Lee, C. M., Sedman, J., Neupert, W., \& Stuart, R. A. (1999). The DNA helicase, Hmilp, is transported into mitochondria by a C-terminal cleavable targeting signal. Journal of Biological Chemistry, 274(30), 20937-20942.

Lee, G. Y., You, D.-G., Lee, H.-R., Hwang, S. W., Lee, C. J., \& Yoo, Y. D. (2018). Romo1 is a mitochondrial nonselective cation channel with viroporin-like characteristics. The Journal of Cell Biology, 267, jcb.201709001-13.

Lee, S. B., Kim, J. J., Chung, J. S., Lee, M. S., Lee, K. H., Kim, B. S., \& Do Yoo, Y. (2011). Romo1 is a negative-feedback regulator of Myc. Journal of Cell Science, 124(14), 2512-2512.

Lee, S. B., Kim, J. J., Kim, T. W., Kim, B. S., Lee, M.-S., \& Yoo, Y. D. (2009). Serum deprivation-induced reactive oxygen species production is mediated by Romol. Apoptosis, 15(2), 204-218. 
Lee, S. H., Min, J. W., Lee, J. S., Kim, C. H., Do Yoo, Y., Lee, E. J., et al. (2015). Reactive oxygen species modulator 1 (Romo1) overexpression is an independent predictor of poor survival in NSCLC patients who undergo surgical resection. Lung Cancer, 87(1), 45-52.

Leray, C., Pelletier, X., Hemmendinger, S., \& Cazenave, J. P. (1987). Thin-layer chromatography of human platelet phospholipids with fatty acid analysis. Journal of Chromatography, 420(2), 411-416.

Lesnik, C., Cohen, Y., Atir-Lande, A., Schuldiner, M., \& Arava, Y. (2014). OM14 is a mitochondrial receptor for cytosolic ribosomes that supports co-translational import into mitochondria. Nature Communications, 5(1), 5711.

Letts, J. A., \& Sazanov, L. A. (2017). Clarifying the supercomplex: the higher-order organization of the mitochondrial electron transport chain. Nature Structural \& Molecular Biology, 24(10), 800-808.

Levytskyy, R. M., Bohovych, I., \& Khalimonchuk, O. (2017). Metalloproteases of the Inner Mitochondrial Membrane. Biochemistry, 56(36), 4737-4746.

Li, Y., Dudek, J., Guiard, B., Pfanner, N., Rehling, P., \& Voos, W. (2004). The presequence translocaseassociated protein import motor of mitochondria. Pam16 functions in an antagonistic manner to Pam18. Journal of Biological Chemistry, 279(36), 38047-38054.

Lill, R., \& Mühlenhoff, U. (2008). Maturation of Iron-Sulfur Proteins in Eukaryotes: Mechanisms, Connected Processes, and Diseases. Annual Review of Biochemistry, 77(1), 669-700.

Lill, R., Hoffmann, B., Molik, S., Pierik, A. J., Rietzschel, N., Stehling, O., et al. (2012). The role of mitochondria in cellular iron-sulfur protein biogenesis and iron metabolism. Biochimica Et Biophysica Acta, 1823(9), 1491-1508.

Lithgow, T., Junne, T., Suda, K., Gratzer, S., \& Schatz, G. (1994). The mitochondrial outer membrane protein Mas22p is essential for protein import and viability of yeast. Proceedings of the National Academy of Sciences of the United States of America, 91(25), 11973-11977. 
Liu, Q., D'Silva, P., Walter, W., Marszalek, J., \& Craig, E. A. (2003). Regulated cycling of mitochondrial Hsp70 at the protein import channel. Science, 300(5616), 139-141.

Lorenzi, I., Oeljeklaus, S., Aich, A., Ronsör, C., Callegari, S., Dudek, J., et al. (2018). The mitochondrial TMEM177 associates with COX20 during COX2 biogenesis. Biochimica Et Biophysica Acta, 1865(2), $323-333$.

Losón, O. C., Song, Z., Chen, H., \& Chan, D. C. (2013). Fis1, Mff, MiD49, and MiD51 mediate Drp1 recruitment in mitochondrial fission. Molecular Biology of the Cell, 24(5), 659-667.

López-Pelegrín, M., Cerdà-Costa, N., Martínez-Jiménez, F., Cintas-Pedrola, A., Canals, A., Peinado, J. R., et al. (2013). A novel family of soluble minimal scaffolds provides structural insight into the catalytic domains of integral membrane metallopeptidases. Journal of Biological Chemistry, 288(29), 21279-21294.

Lu, W.-J., Lee, N. P., Kaul, S. C., Lan, F., Poon, R. T. P., Wadhwa, R., \& Luk, J. M. (2011). Mortalin-p53 interaction in cancer cells is stress dependent and constitutes a selective target for cancer therapy. Cell Death and Differentiation, 18(6), 1046-1056.

Luk, E., Yang, M., Jensen, L. T., Bourbonnais, Y., \& Culotta, V. C. (2005). Manganese Activation of Superoxide Dismutase 2 in the Mitochondria of Saccharomyces cerevisiae. Journal of Biological Chemistry, 280(24), 22715-22720.

Luo, W., Fang, H., \& Green, N. (2006). Substrate specificity of inner membrane peptidase in yeast mitochondria. Molecular Genetics and Genomics : MGG, 275(5), 431-436.

Lytovchenko, O., Melin, J., Schulz, C., Kilisch, M., Hutu, D. P., \& Rehling, P. (2013). Signal recognition initiates reorganization of the presequence translocase during protein import. The EMBO Journal, $32(6), 886-898$.

Maarse, A. C., Blom, J., Grivell, L. A., \& Meijer, M. (1992). MPI1, an essential gene encoding a mitochondrial membrane protein, is possibly involved in protein import into yeast mitochondria. The EMBO Journal, 11(10), 3619-3628. 
Maarse, A. C., Blom, J., Keil, P., Pfanner, N., \& Meijer, M. (1994). Identification of the essential yeast protein MIM17, an integral mitochondrial inner membrane protein involved in protein import. FEBS Letters, 349(2), 215-221.

MacVicar, T., \& Langer, T. (2016). OPA1 processing in cell death and disease - the long and short of it. Journal of Cell Science, 129(12), 2297-2306.

Margeot, A., Blugeon, C., Sylvestre, J., Vialette, S., Jacq, C., \& Corral-Debrinski, M. (2002). In Saccharomyces cerevisiae, ATP2 mRNA sorting to the vicinity of mitochondria is essential for respiratory function. The EMBO Journal, 21(24), 6893-6904.

Margeot, A., Garcia, M., Wang, W., Tetaud, E., di Rago, J. P., \& Jacq, C. (2005). Why are many mRNAs translated to the vicinity of mitochondria: a role in protein complex assembly? Gene, 354, 64-71.

Marom, M., Dayan, D., Demishtein-Zohary, K., Mokranjac, D., Neupert, W., \& Azem, A. (2011). Direct interaction of mitochondrial targeting presequences with purified components of the TIM23 protein complex. Journal of Biological Chemistry, 286(51), 43809-43815.

Martin, J., Mahlke, K., \& Pfanner, N. (1991). Role of an energized inner membrane in mitochondrial protein import. Delta psi drives the movement of presequences. Journal of Biological Chemistry, 266(27), 18051-18057.

Martinez-Caballero, S., Grigoriev, S. M., Herrmann, J. M., Campo, M. L., \& Kinnally, K. W. (2007). Tim $17 \mathrm{p}$ regulates the twin pore structure and voltage gating of the mitochondrial protein import complex TIM23. Journal of Biological Chemistry, 282(6), 3584-3593.

Masella, R., \& Cantafora, A. (1988). Determination of phospholipids in biological samples by an improved densitometric method on thin-layer chromatograms. Clinica Chimica Acta; International Journal of Clinical Chemistry, 176(1), 63-70.

Mayer, M. P., \& Bukau, B. (2005). Hsp70 chaperones: Cellular functions and molecular mechanism. Cellular and Molecular Life Sciences, 62(6), 670-684. 
Mehnert, C. S., Rampelt, H., Gebert, M., Oeljeklaus, S., Schrempp, S. G., Kochbeck, L., et al. (2014). The mitochondrial ADP/ATP carrier associates with the inner membrane presequence translocase in a stoichiometric manner. Journal of Biological Chemistry, 289(39), 27352-27362.

Meier, S., Neupert, W., \& Herrmann, J. M. (2005). Conserved N-terminal negative charges in the Tim 17 subunit of the TIM23 translocase play a critical role in the import of preproteins into mitochondria. Journal of Biological Chemistry, 280(9), 7777-7785.

Meinecke, M., Wagner, R., Kovermann, P., Guiard, B., Mick, D. U., Hutu, D. P., et al. (2006). Tim50 maintains the permeability barrier of the mitochondrial inner membrane. Science, 312(5779), $1523-$ 1526.

Melin, J., Kilisch, M., Neumann, P., Lytovchenko, O., Gomkale, R., Schendzielorz, A., et al. (2015). A presequence-binding groove in Tom70 supports import of Mdl1 into mitochondria. Biochimica Et Biophysica Acta, 1853(8), 1850-1859.

Melin, J., Schulz, C., Wrobel, L., Bernhard, O., Chacinska, A., Jahn, O., et al. (2014). Presequence Recognition by the Tom 40 Channel Contributes to Precursor Translocation into the Mitochondrial Matrix. Molecular and Cellular Biology, 34(18), 3473-3485.

Miao, B., Davis, J. E., \& Craig, E. A. (1997). Mge1 functions as a nucleotide release factor for Ssc1, a mitochondrial Hsp70 of Saccharomyces cerevisiae. Journal of Molecular Biology, 265(5), 541-552.

Mick, D. U., Dennerlein, S., Wiese, H., Reinhold, R., Pacheu-Grau, D., Lorenzi, I., Sasarman, F., Weraarpachai, W., Shoubridge, E. A., Warscheid, B., \& Rehling, P. (2012). MITRAC Links Mitochondrial Protein Translocation to Respiratory-Chain Assembly and Translational Regulation. Cell, 151(7), 1528-1541.

Mick, D. U., Fox, T. D., \& Rehling, P. (2011). Inventory control: cytochrome c oxidase assembly regulates mitochondrial translation. Nature Reviews Molecular Cell Biology, 12(1), 14-20. 
Milenkovic, D., Ramming, T., Müller, J. M., Wenz, L.-S., Gebert, N., Schulze-Specking, A., et al. (2009). Identification of the signal directing Tim9 and Tim10 into the intermembrane space of mitochondria. Molecular Biology of the Cell, 20(10), 2530-2539.

Mishra, P., Carelli, V., Manfredi, G., \& Chan, D. C. (2014). Proteolytic Cleavage of Opa1 Stimulates Mitochondrial Inner Membrane Fusion and Couples Fusion to Oxidative Phosphorylation. Cell Metabolism, 19(4), 630-641.

Moczko, M., Bömer, U., Kübrich, M., Zufall, N., Hönlinger, A., \& Pfanner, N. (1997). The intermembrane space domain of mitochondrial Tom22 functions as a trans binding site for preproteins with N-terminal targeting sequences. Molecular and Cellular Biology, 17(11), 65746584 .

Moczko, M., Dietmeier, K., Söllner, T., Segui, B., Steger, H. F., Neupert, W., \& Pfanner, N. (1992). Identification of the mitochondrial receptor complex in Saccharomyces cerevisiae. FEBS Letters, 310(3), 265-268.

Mokranjac, D., \& Neupert, W. (2015). Cell biology: Architecture of a protein entry gate. Nature, 528(7581), 201-202.

Mokranjac, D., Paschen, S. A., Kozany, C., Prokisch, H., Hoppins, S. C., Nargang, F. E., et al. (2003a). Tim50, a novel component of the TIM23 preprotein translocase of mitochondria. The EMBO Journal, 22(4), 816-825.

Mokranjac, D., Sichting, M., Neupert, W., \& Hell, K. (2003b). Tim14, a novel key component of the import motor of the TIM23 protein translocase of mitochondria. The EMBO Journal, 22(19), 49454956.

Mokranjac, D., Sichting, M., Popov-Celeketić, D., Mapa, K., Gevorkyan-Airapetov, L., Zohary, K., et al. (2009). Role of Tim50 in the transfer of precursor proteins from the outer to the inner membrane of mitochondria. Molecular Biology of the Cell, 20(5), 1400-1407. 
Morgenstern, M., Stiller, S. B., Lübbert, P., Peikert, C. D., Dannenmaier, S., Drepper, F., et al. (2017). Definition of a High-Confidence Mitochondrial Proteome at Quantitative Scale. Cell Reports, 19(13), 2836-2852.

Mossmann, D., Meisinger, C., \& Vögtle, F. N. (2012). Processing of mitochondrial presequences. BBA Gene Regulatory Mechanisms, 1819(9-10), 1098-1106.

Murphy, M. P. (2009). How mitochondria produce reactive oxygen species. Biochemical Journal, 417(1), $1-13$.

Mühlenbein, N., Hofmann, S., Rothbauer, U., \& Bauer, M. F. (2004). Organization and Function of the Small Tim Complexes Acting along the Import Pathway of Metabolite Carriers into Mammalian Mitochondria. Journal of Biological Chemistry, 279(14), 13540-13546.

Na, A. R., Chung, Y. M., Lee, S. B., Park, S. H., Lee, M.-S., \& Yoo, Y. D. (2008). A critical role for Romo1derived ROS in cell proliferation. Biochemical and Biophysical Research Communications, 369(2), $672-678$.

Nemoto, S., Takeda, K., Yu, Z. X., Ferrans, V. J., \& Finkel, T. (2000). Role for mitochondrial oxidants as regulators of cellular metabolism. Molecular and Cellular Biology, 20(19), 7311-7318.

Nijtmans, L. G., Taanman, J. W., Muijsers, A. O., Speijer, D., \& Van den Bogert, C. (1998). Assembly of cytochrome-c oxidase in cultured human cells. European Journal of Biochemistry, 254(2), 389-394.

Nolden, M., Ehses, S., Koppen, M., Bernacchia, A., Rugarli, E. I., \& Langer, T. (2005). The m-AAA protease defective in hereditary spastic paraplegia controls ribosome assembly in mitochondria. Cell, 123(2), 277-289.

Norton, M., Ng, A. C.-H., Baird, S., Dumoulin, A., Shutt, T., Mah, N., et al. (2014). ROMO1 is an essential redox-dependent regulator of mitochondrial dynamics. Science Signaling, 7(310), ra10-ra10.

Nunnari, J., \& Suomalainen, A. (2012). Mitochondria: In Sickness and in Health. Cell, 148(6), 1145-1159. 
Olichon, A., Guillou, E., Delettre, C., Landes, T., Arnauné-Pelloquin, L., Emorine, L. J., et al. (2006). Mitochondrial dynamics and disease, OPA1. Biochimica Et Biophysica Acta, 1763(5-6), 500-509.

Ong, S.-E., Blagoev, B., Kratchmarova, I., Kristensen, D. B., Steen, H., Pandey, A., \& Mann, M. (2002). Stable isotope labeling by amino acids in cell culture, SILAC, as a simple and accurate approach to expression proteomics. Molecular \& Cellular Proteomics, 1(5), 376-386.

Opalińska, M., Parys, K., Murcha, M. W., \& Jańska, H. (2018). The plant i-AAA protease controls the turnover of an essential mitochondrial protein import component. Journal of Cell Science, 131(2), jcs200733.

Osman, C., Haag, M., Potting, C., Rodenfels, J., Dip, P. V., Wieland, F. T., et al. (2009). The genetic interactome of prohibitins: coordinated control of cardiolipin and phosphatidylethanolamine by conserved regulators in mitochondria. The Journal of Cell Biology, 184(4), 583-596.

Otera, H., Ishihara, N., \& Mihara, K. (2013). New insights into the function and regulation of mitochondrial fission. Biochimica Et Biophysica Acta, 1833(5), 1256-1268.

Ott, M., Amunts, A., \& Brown, A. (2016). Organization and Regulation of Mitochondrial Protein Synthesis. Annual Review of Biochemistry, 85(1), 77-101.

Pacheu-Grau, D., Bareth, B., Dudek, J., Juris, L., Vögtle, F. N., Wissel, M., et al. (2015). Cooperation between COA6 and SCO2 in COX2 maturation during cytochrome $c$ oxidase assembly links two mitochondrial cardiomyopathies. Cell Metabolism, 21(6), 823-833.

Palade, G. E. (1964). The Organization of Living Matter. Proceedings of the National Academy of Sciences of the United States of America, 52(2), 613-634.

Palmer, C. S., Elgass, K. D., Parton, R. G., Osellame, L. D., Stojanovski, D., \& Ryan, M. T. (2013). Adaptor proteins MiD49 and MiD51 can act independently of Mff and Fis1 in Drp1 recruitment and are specific for mitochondrial fission. Journal of Biological Chemistry, 288(38), 27584-27593.

Panov, A. (2013). Practical Mitochondriology. Createspace Independent Pub. 
Pareek, G., Krishnamoorthy, V., \& D'Silva, P. (2013). Molecular insights revealing interaction of Tim23 and channel subunits of presequence translocase. Molecular and Cellular Biology, 33(23), 46414659.

Paschen, S. A., Waizenegger, T., Stan, T., Preuss, M., Cyrklaff, M., Hell, K., et al. (2003). Evolutionary conservation of biogenesis of beta-barrel membrane proteins. Nature, 426(6968), 862-866.

Petrovic, M. G., Kruzliak, P., \& Petrovic, D. (2015). The rs6060566 of the reactive oxygen species modulator 1 (Romo-1) gene affects Romo-1 expression and the development of diabetic retinopathy in Caucasians with type 2 diabetes. Acta Ophthalmologica, 93(8), e654-7.

Pfanner, N., Tropschug, M., \& Neupert, W. (1987). Mitochondrial protein import: nucleoside triphosphates are involved in conferring import-competence to precursors. Cell, 49(6), 815-823.

Pfeffer, S., Woellhaf, M. W., Herrmann, J. M., \& Förster, F. (2015). Organization of the mitochondrial translation machinery studied in situ by cryoelectron tomography. Nature Communications, 6(1), 6019.

Piao, L., Li, Y., Kim, S. J., Byun, H. S., Huang, S. M., Hwang, S.-K., et al. (2009). Association of LETM1 and MRPL36 contributes to the regulation of mitochondrial ATP production and necrotic cell death. Cancer Research, 69(8), 3397-3404.

Poveda-Huertes, D., Mulica, P., \& Vögtle, F. N. (2017). The versatility of the mitochondrial presequence processing machinery: cleavage, quality control and turnover. Cell and Tissue Research, 367(1), 7381.

Prieto-Ruiz, J. A., Alis, R., García-Benlloch, S., Sáez-Atiénzar, S., Ventura, I., Hernández-Andreu, J. M., et al. (2018). Expression of the human TIMM23 and TIMM23B genes is regulated by the GABP transcription factor. BBA - Gene Regulatory Mechanisms, 1861(2), 80-94. 
Puchades, C., Rampello, A. J., Shin, M., Giuliano, C. J., Wiseman, R. L., Glynn, S. E., \& Lander, G. C. (2017). Structure of the mitochondrial inner membrane $\mathrm{AAA}^{+}$protease YME1 gives insight into substrate processing. Science, 358(6363), eaao0464-12.

Quiros, P. M., Ramsay, A. J., Sala, D., Fernández-Vizarra, E., Rodríguez, F., Peinado, J. R., et al. (2012). Loss of mitochondrial protease OMA1 alters processing of the GTPase OPA1 and causes obesity and defective thermogenesis in mice. The EMBO Journal, 31(9), 2117-2133.

Rahman, B., Kawano, S., Yunoki-Esaki, K., Anzai, T., \& Endo, T. (2014). NMR analyses on the interactions of the yeast Tim50 C-terminal region with the presequence and Tim50 core domain. FEBS Letters, 588(5), 678-684.

Rainbolt, T. K., Atanassova, N., Genereux, J. C., \& Wiseman, R. L. (2013). Stress-Regulated Translational Attenuation Adapts Mitochondrial Protein Import through Tim17A Degradation. Cell Metabolism, 18(6), 908-919.

Rainbolt, T. K., Lebeau, J., Puchades, C., \& Wiseman, R. L. (2016). Reciprocal Degradation of YME1L and OMA1 Adapts Mitochondrial Proteolytic Activity during Stress. Cell Reports, 14(9), 2041-2049.

Rainbolt, T. K., Saunders, J. M., \& Wiseman, R. L. (2015). YME1L degradation reduces mitochondrial proteolytic capacity during oxidative stress. EMBO Reports, 16(1), 97-106.

Rainey, R. N., Glavin, J. D., Chen, H.-W., French, S. W., Teitell, M. A., \& Koehler, C. M. (2006). A new function in translocation for the mitochondrial $i$-AAA protease Yme1: import of polynucleotide phosphorylase into the intermembrane space. Molecular and Cellular Biology, 26(22), 8488-8497.

Rampello, A. J., \& Glynn, S. E. (2017). Identification of a Degradation Signal Sequence within Substrates of the Mitochondrial i-AAA Protease. Journal of Molecular Biology, 429(6), 873-885.

Ran, F. A., Hsu, P. D., Wright, J., Agarwala, V., Scott, D. A., \& Zhang, F. (2013). Genome engineering using the CRISPR-Cas9 system. Nature Protocols, 8(11), 2281-2308. 
Rehling, P., Brandner, K., \& Pfanner, N. (2004). Mitochondrial import and the twin-pore translocase. Nature Reviews Molecular Cell Biology, 5(7), 519-530.

Rehling, P., Model, K., Brandner, K., Kovermann, P., Sickmann, A., Meyer, H. E., et al. (2003). Protein insertion into the mitochondrial inner membrane by a twin-pore translocase. Science, 299(5613), $1747-1751$.

Reinhold, R., Bareth, B., Balleininger, M., Wissel, M., Rehling, P., \& Mick, D. U. (2011). Mimicking a SURF1 allele reveals uncoupling of cytochrome $c$ oxidase assembly from translational regulation in yeast. Human Molecular Genetics, 20(12), 2379-2393.

Reinhold, R., Krüger, V., Meinecke, M., Schulz, C., Schmidt, B., Grunau, S. D., et al. (2012). The ChannelForming Sym1 Protein Is Transported by the TIM23 Complex in a Presequence-Independent Manner. Molecular and Cellular Biology, 32(24), 5009-5021.

Richter-Dennerlein, R., Korwitz, A., Haag, M., Tatsuta, T., Dargazanli, S., Baker, M., et al. (2014). DNAJC19, a Mitochondrial Cochaperone Associated with Cardiomyopathy, Forms a Complex with Prohibitins to Regulate Cardiolipin Remodeling. Cell Metabolism, 20(1), 158-171.

Richter-Dennerlein, R., Oeljeklaus, S., Lorenzi, I., Ronsör, C., Bareth, B., Schendzielorz, A. B., et al. (2016). Mitochondrial Protein Synthesis Adapts to Influx of Nuclear-Encoded Protein. Cell, 167(2), 471-483.

Rissler, M., Wiedemann, N., Pfannschmidt, S., Gabriel, K., Guiard, B., Pfanner, N., \& Chacinska, A. (2005). The essential mitochondrial protein Erv1 cooperates with Mia40 in biogenesis of intermembrane space proteins. Journal of Molecular Biology, 353(3), 485-492.

Roise, D., Horvath, S. J., Tomich, J. M., Richards, J. H., \& Schatz, G. (1986). A chemically synthesized pre-sequence of an imported mitochondrial protein can form an amphiphilic helix and perturb natural and artificial phospholipid bilayers. The EMBO Journal, 5(6), 1327-1334. 
Rojo, E. E., Guiard, B., Neupert, W., \& Stuart, R. A. (1998). Sorting of D-lactate dehydrogenase to the inner membrane of mitochondria. Analysis of topogenic signal and energetic requirements. Journal of Biological Chemistry, 273(14), 8040-8047.

Rojo, E. E., Stuart, R. A., \& Neupert, W. (1995). Conservative sorting of F0-ATPase subunit 9: export from matrix requires delta $\mathrm{pH}$ across inner membrane and matrix ATP. The EMBO Journal, 14(14), $3445-3451$.

Rottgers, K., Zufall, N., Guiard, B., \& Voos, W. (2002). The ClpB homolog Hsp78 is required for the efficient degradation of proteins in the mitochondrial matrix. Journal of Biological Chemistry, 277(48), 45829-45837.

Saitoh, T., Igura, M., Obita, T., Ose, T., Kojima, R., Maenaka, K., et al. (2007). Tom20 recognizes mitochondrial presequences through dynamic equilibrium among multiple bound states. The EMBO Journal, 26(22), 4777-4787.

Sancak, Y., Markhard, A. L., Kitami, T., Kovács-Bogdán, E., Kamer, K. J., Udeshi, N. D., et al. (2013). EMRE is an essential component of the mitochondrial calcium uniporter complex. Science, $342(6164), 1379-1382$.

Santel, A., \& Fuller, M. T. (2001). Control of mitochondrial morphology by a human mitofusin. Journal of Cell Science, 114(Pt 5), 867-874.

Scharfenberg, F., Serek-Heuberger, J., Coles, M., Hartmann, M. D., Habeck, M., Martin, J., et al. (2015). Structure and evolution of N-domains in AAA metalloproteases. Journal of Molecular Biology, 427(4), 910-923.

Schägger, H. (2006). Tricine-SDS-PAGE. Nature Protocols, 1(1), 16-22.

Schägger, H., \& Jagow, von, G. (1991). Blue native electrophoresis for isolation of membrane protein complexes in enzymatically active form. Analytical Biochemistry, 199(2), 223-231. 
Schägger, H., \& Pfeiffer, K. (2000). Supercomplexes in the respiratory chains of yeast and mammalian mitochondria. The EMBO Journal, 19(8), 1777-1783.

Schendzielorz, A. B., Schulz, C., Lytovchenko, O., Clancy, A., Guiard, B., Ieva, R., et al. (2017). Two distinct membrane potential-dependent steps drive mitochondrial matrix protein translocation. The Journal of Cell Biology, 216(1), 83-92.

Schiller, D. (2009). Pam17 and Tim44 act sequentially in protein import into the mitochondrial matrix. The International Journal of Biochemistry \& Cell Biology, 41(11), 2343-2349.

Schneider, A., Behrens, M., Scherer, P., Pratje, E., Michaelis, G., \& Schatz, G. (1991a). Inner membrane protease I, an enzyme mediating intramitochondrial protein sorting in yeast. The EMBO Journal, $10(2), 247-254$.

Schneider, G., Sjöling, S., Wallin, E., Wrede, P., Glaser, E., \& Heijne, von, G. (1998). Feature-extraction from endopeptidase cleavage sites in mitochondrial targeting peptides. Proteins, 30(1), 49-60.

Schneider, H. C., Berthold, J., Bauer, M. F., Dietmeier, K., Guiard, B., Brunner, M., \& Neupert, W. (1994). Mitochondrial Hsp70/MIM44 complex facilitates protein import. Nature, 371(6500), 768-774.

Schneider, H., Söllner, T., Dietmeier, K., Eckerskorn, C., Lottspeich, F., Trülzsch, B., et al. (1991b). Targeting of the master receptor MOM19 to mitochondria. Science, 254(5038), 1659-1662.

Schneider-Poetsch, T., Ju, J., Eyler, D. E., Dang, Y., Bhat, S., Merrick, W. C., et al. (2010). Inhibition of eukaryotic translation elongation by cycloheximide and lactimidomycin. Nature Chemical Biology, 6(3), 209-217.

Schorr, S., \& van der Laan, M. (2018). Integrative functions of the mitochondrial contact site and cristae organizing system. Seminars in Cell and Developmental Biology, 76, 191-200.

Schulz, C., \& Rehling, P. (2014). Remodelling of the active presequence translocase drives motordependent mitochondrial protein translocation. Nature Communications, 5, 4349. 
Schulz, C., Lytovchenko, O., Melin, J., Chacinska, A., Guiard, B., Neumann, P., et al. (2011). Tim50's presequence receptor domain is essential for signal driven transport across the TIM 23 complex. The Journal of Cell Biology, 195(4), 643-656.

Schulz, C., Schendzielorz, A., \& Rehling, P. (2015). Unlocking the presequence import pathway. Trends in Cell Biology, 25(5), 265-275.

Schusdziarra, C., Blamowska, M., Azem, A., \& Hell, K. (2013). Methylation-controlled J-protein MCJ acts in the import of proteins into human mitochondria. Human Molecular Genetics, 22(7), 13481357.

Schwartz, M. P., \& Matouschek, A. (1999). The dimensions of the protein import channels in the outer and inner mitochondrial membranes. Proceedings of the National Academy of Sciences of the United States of America, 96(23), 13086-13090.

Sena, L. A., \& Chandel, N. S. (2012). Physiological roles of mitochondrial reactive oxygen species. Molecular Cell, 48(2), 158-167.

Shah, Z. H., Hakkaart, G. A., Arku, B., de Jong, L., van der Spek, H., Grivell, L. A., \& Jacobs, H. T. (2000). The human homologue of the yeast mitochondrial AAA metalloprotease Ymelp complements a yeast yme1 disruptant. FEBS Letters, 478(3), 267-270.

Shariff, K., Ghosal, S., \& Matouschek, A. (2004). The force exerted by the membrane potential during protein import into the mitochondrial matrix. Biophysical Journal, 86(6), 3647-3652.

Shi, H., Rampello, A. J., \& Glynn, S. E. (2016). Engineered AAA+ proteases reveal principles of proteolysis at the mitochondrial inner membrane. Nature Communications, 7, 13301.

Shin, J. A., Chung, J. S., Cho, S.-H., Kim, H. J., \& Do Yoo, Y. (2013). Romo1 expression contributes to oxidative stress-induced death of lung epithelial cells. Biochemical and Biophysical Research Communications, 439(2), 315-320. 
Shiota, T., Imai, K., Qiu, J., Hewitt, V. L., Tan, K., Shen, H.-H., et al. (2015). Molecular architecture of the active mitochondrial protein gate. Science, 349(6255), 1544-1548.

Shiota, T., Mabuchi, H., Tanaka-Yamano, S., Yamano, K., \& Endo, T. (2011). In vivo protein-interaction mapping of a mitochondrial translocator protein Tom22 at work. Proceedings of the National Academy of Sciences of the United States of America, 108(37), 15179-15183.

Shyamsunder, P., Verma, R. S., \& Lyakhovich, A. (2015). ROMO1 regulates RedOx states and serves as an inducer of NF-кB-driven EMT factors in Fanconi anemia. Cancer Letters, 361(1), 33-38.

Sideris, D. P., Petrakis, N., Katrakili, N., Mikropoulou, D., Gallo, A., Ciofi-Baffoni, S., et al. (2009). A novel intermembrane space-targeting signal docks cysteines onto Mia40 during mitochondrial oxidative folding. The Journal of Cell Biology, 187(7), 1007-1022.

Sikorski, R. S., \& Hieter, P. (1989). A system of shuttle vectors and yeast host strains designed for efficient manipulation of DNA in Saccharomyces cerevisiae. Genetics, 122(1), 19-27.

Sinha, D., Joshi, N., Chittoor, B., Samji, P., \& D'Silva, P. (2010). Role of Magmas in protein transport and human mitochondria biogenesis. Human Molecular Genetics, 19(7), 1248-1262.

Sinha, D., Srivastava, S., \& D'Silva, P. (2016). Functional Diversity of Human Mitochondrial J-proteins Is Independent of Their Association with the Inner Membrane Presequence Translocase. Journal of Biological Chemistry, 291(33), 17345-17359.

Sinha, D., Srivastava, S., Krishna, L., \& D'Silva, P. (2014). Unraveling the Intricate Organization of Mammalian Mitochondrial Presequence Translocases: Existence of Multiple Translocases for Maintenance of Mitochondrial Function. Molecular and Cellular Biology, 34(10), 1757-1775.

Sokol, A. M., Sztolsztener, M. E., Wasilewski, M., Heinz, E., \& Chacinska, A. (2014). Mitochondrial protein translocases for survival and wellbeing. FEBS Letters, 588(15), 2484-2495. 
Song, Z., Chen, H., Fiket, M., Alexander, C., \& Chan, D. C. (2007). OPA1 processing controls mitochondrial fusion and is regulated by mRNA splicing, membrane potential, and Yme1L. The Journal of Cell Biology, 178(5), 749-755.

Stefely, J. A., Reidenbach, A. G., Ulbrich, A., Oruganty, K., Floyd, B. J., Jochem, A., et al. (2015). Mitochondrial ADCK3 employs an atypical protein kinase-like fold to enable coenzyme Q biosynthesis. Molecular Cell, 57(1), 83-94.

Stiburek, L., Cesnekova, J., Kostkova, O., Fornuskova, D., Vinsova, K., Wenchich, L., et al. (2012). YME1L controls the accumulation of respiratory chain subunits and is required for apoptotic resistance, cristae morphogenesis, and cell proliferation. Molecular Biology of the Cell, 23(6), 10101023.

Stiburek, L., Vesela, K., Hansikova, H., Pecina, P., Tesarova, M., Cerna, L., et al. (2005). Tissue-specific cytochrome $c$ oxidase assembly defects due to mutations in SCO2 and SURF1. Biochemical Journal, 392(3), 625-632.

Stiller, S. B., Höpker, J., Oeljeklaus, S., Schütze, C., Schrempp, S. G., Vent-Schmidt, J., et al. (2016). Mitochondrial OXA Translocase Plays a Major Role in Biogenesis of Inner-Membrane Proteins. Cell Metabolism, 23(5), 901-908.

Strauss, M., Hofhaus, G., Schröder, R. R., \& Kühlbrandt, W. (2008). Dimer ribbons of ATP synthase shape the inner mitochondrial membrane. The EMBO Journal, 27(7), 1154-1160.

Swarnabala, S., Gattu, M., Perry, B., Cho, Y., Lockey, R. F., \& Kolliputi, N. (2014). ROMO1 links oxidative stress to mitochondrial integrity. Journal of Cell Communication and Signaling, 9(1), 73-75.

Szklarczyk, R., Wanschers, B. F., Cuypers, T. D., Esseling, J. J., Riemersma, M., van den Brand, M. A., et al. (2012). Iterative orthology prediction uncovers new mitochondrial proteins and identifies C12orf62 as the human ortholog of COX14, a protein involved in the assembly of cytochrome $c$ oxidase. Genome Biology, 13(2), R12. 
Taanman, J. W. (1999). The mitochondrial genome: structure, transcription, translation and replication. Biochimica Et Biophysica Acta, 1410(2), 103-123.

Tamai, S., Iida, H., Yokota, S., Sayano, T., Kiguchiya, S., Ishihara, N., et al. (2008). Characterization of the mitochondrial protein LETM1, which maintains the mitochondrial tubular shapes and interacts with the AAA-ATPase BCS1L. Journal of Cell Science, 121(Pt 15), 2588-2600.

Tamura, Y., Harada, Y., Shiota, T., Yamano, K., Watanabe, K., Yokota, M., et al. (2009). Tim23-Tim50 pair coordinates functions of translocators and motor proteins in mitochondrial protein import. The Journal of Cell Biology, 184(1), 129-141.

Tasaki, T., Sriram, S. M., Park, K. S., \& Kwon, Y. T. (2012). The N-end rule pathway. Annual Review of Biochemistry, 81(1), 261-289.

Taylor, A. B., Smith, B. S., Kitada, S., Kojima, K., Miyaura, H., Otwinowski, Z., et al. (2001). Crystal structures of mitochondrial processing peptidase reveal the mode for specific cleavage of import signal sequences. Structure (London, England : 1993), 9(7), 615-625.

Timón-Gómez, A., Nývltová, E., Abriata, L. A., Vila, A. J., Hosler, J., \& Barrientos, A. (2018). Mitochondrial cytochrome $c$ oxidase biogenesis: Recent developments. Seminars in Cell and Developmental Biology, 76, 163-178.

Ting, S.-Y., Schilke, B. A., Hayashi, M., \& Craig, E. A. (2014). Architecture of the TIM23 Inner Mitochondrial Translocon and Interactions with the Matrix Import Motor. Journal of Biological Chemistry, 289(41), 28689-28696.

Tondera, D., Grandemange, S., Jourdain, A., Karbowski, M., Mattenberger, Y., Herzig, S., et al. (2009). SLP-2 is required for stress-induced mitochondrial hyperfusion. The EMBO Journal, 28(11), 15891600.

Truscott, K. N., Kovermann, P., Geissler, A., Merlin, A., Meijer, M., Driessen, A. J., et al. (2001). A presequence- and voltage-sensitive channel of the mitochondrial preprotein translocase formed by Tim23. Nature Structural Biology, 8(12), 1074-1082. 
Truscott, K. N., Voos, W., Frazier, A. E., Lind, M., Li, Y., Geissler, A., et al. (2003). A J-protein is an essential subunit of the presequence translocase-associated protein import motor of mitochondria. The Journal of Cell Biology, 163(4), 707-713.

Vaca Jacome, A. S., Rabilloud, T., Schaeffer-Reiss, C., Rompais, M., Ayoub, D., Lane, L., et al. (2015). Nterminome analysis of the human mitochondrial proteome. Proteomics, 15(14), 2519-2524.

van der Laan, M., Bohnert, M., Wiedemann, N., \& Pfanner, N. (2012). Role of MINOS in mitochondrial membrane architecture and biogenesis. Trends in Cell Biology, 22(4), 185-192.

van der Laan, M., Chacinska, A., Lind, M., Perschil, I., Sickmann, A., Meyer, H. E., et al. (2005). Pam17 is required for architecture and translocation activity of the mitochondrial protein import motor. Molecular and Cellular Biology, 25(17), 7449-7458.

van der Laan, M., Meinecke, M., Dudek, J., Hutu, D. P., Lind, M., Perschil, I., et al. (2007). Motor-free mitochondrial presequence translocase drives membrane integration of preproteins. Nature Cell Biology, 9(10), 1152-1159.

van der Laan, M., Wiedemann, N., Mick, D. U., Guiard, B., Rehling, P., \& Pfanner, N. (2006). A role for Tim21 in membrane-potential-dependent preprotein sorting in mitochondria. Current Biology: $C B$, 16(22), 2271-2276.

Vidoni, S., Harbour, M. E., Guerrero-Castillo, S., Signes, A., Ding, S., Fearnley, I. M., et al. (2017). MR1S Interacts with PET100 and PET117 in Module-Based Assembly of Human Cytochrome $c$ Oxidase. Cell Reports, 18(7), 1727-1738.

Vogel, F., Bornhövd, C., Neupert, W., \& Reichert, A. S. (2006). Dynamic subcompartmentalization of the mitochondrial inner membrane. The Journal of Cell Biology, 175(2), 237-247.

Voisine, C., Craig, E. A., Zufall, N., Ahsen, von, O., Pfanner, N., \& Voos, W. (1999). The protein import motor of mitochondria: unfolding and trapping of preproteins are distinct and separable functions of matrix Hsp70. Cell, 97(5), 565-574. 
Voos, W., Gambill, B. D., Laloraya, S., Ang, D., Craig, E. A., \& Pfanner, N. (1994). Mitochondrial GrpE is present in a complex with hsp70 and preproteins in transit across membranes. Molecular and Cellular Biology, 14(10), 6627-6634.

Vögtle, F. N., Prinz, C., Kellermann, J., Lottspeich, F., Pfanner, N., \& Meisinger, C. (2011). Mitochondrial protein turnover: role of the precursor intermediate peptidase Octl in protein stabilization. Molecular Biology of the Cell, 22(13), 2135-2143.

Vögtle, F. N., Wortelkamp, S., Zahedi, R. P., Becker, D., Leidhold, C., Gevaert, K., et al. (2009). Global Analysis of the Mitochondrial N-Proteome Identifies a Processing Peptidase Critical for Protein Stability. Cell, 139(2), 428-439.

Vukotic, M., Nolte, H., König, T., Saita, S., Ananjew, M., Krüger, M., et al. (2017). Acylglycerol Kinase Mutated in Sengers Syndrome Is a Subunit of the TIM22 Protein Translocase in Mitochondria. Molecular Cell, 67(3), 471-483.e7.

Waegemann, K., Popov-Celeketić, D., Neupert, W., Azem, A., \& Mokranjac, D. (2015). Cooperation of TOM and TIM23 complexes during translocation of proteins into mitochondria. Journal of Molecular Biology, 427(5), 1075-1084.

Wagner, K., Gebert, N., Guiard, B., Brandner, K., Truscott, K. N., Wiedemann, N., et al. (2008). The assembly pathway of the mitochondrial carrier translocase involves four preprotein translocases. Molecular and Cellular Biology, 28(13), 4251-4260.

Wai, T., \& Langer, T. (2016). Mitochondrial Dynamics and Metabolic Regulation. Trends in Endocrinology and Metabolism: TEM, 27(2), 105-117.

Wai, T., Saita, S., Nolte, H., Müller, S., König, T., Richter-Dennerlein, R., et al. (2016). The membrane scaffold SLP2 anchors a proteolytic hub in mitochondria containing PARL and the $i$-AAA protease YME1L. EMBO Reports, 17(12), 1844-1856. 
Wasilewski, M., Chojnacka, K., \& Chacinska, A. (2017). Protein trafficking at the crossroads to mitochondria. BBA - Molecular Cell Research, 1864(1), 125-137.

Webb, C. T., Gorman, M. A., Lazarou, M., Ryan, M. T., \& Gulbis, J. M. (2006). Crystal structure of the mitochondrial chaperone TIM9.10 reveals a six-bladed alpha-propeller. Molecular Cell, 21(1), 123133.

Wheeler, B., \& Jia, Z. (2015). Preparation and characterization of human ADCK3, a putative atypical kinase. Protein Expression and Purification, 108, 13-17.

Wiedemann, N., \& Pfanner, N. (2017). Mitochondrial Machineries for Protein Import and Assembly. Annual Review of Biochemistry, 86(1), 685-714.

Wiedemann, N., Pfanner, N., \& Ryan, M. T. (2001). The three modules of ADP/ATP carrier cooperate in receptor recruitment and translocation into mitochondria. The EMBO Journal, 20(5), 951-960.

Wiedemann, N., Truscott, K. N., Pfannschmidt, S., Guiard, B., Meisinger, C., \& Pfanner, N. (2004). Biogenesis of the Protein Import Channel Tom40 of the Mitochondrial Outer Membrane. Journal of Biological Chemistry, 279(18), 18188-18194.

Wiedemann, N., van der Laan, M., Hutu, D. P., Rehling, P., \& Pfanner, N. (2007). Sorting switch of mitochondrial presequence translocase involves coupling of motor module to respiratory chain. The Journal of Cell Biology, 179(6), 1115-1122.

Williams, S. L., Valnot, I., Rustin, P., \& Taanman, J.-W. (2004). Cytochrome $c$ Oxidase Subassemblies in Fibroblast Cultures from Patients Carrying Mutations in COX10, SCO1, or SURF1. Journal of Biological Chemistry, 279(9), 7462-7469.

Winge, D. R. (2012). Sealing the Mitochondrial Respirasome. Molecular and Cellular Biology, 32(14), $2647-2652$.

Wittig, I., Braun, H.-P., \& Schägger, H. (2006). Blue native PAGE. Nature Protocols, 1(1), 418-428. 
Wittig, I., Karas, M., \& Schägger, H. (2007). High resolution clear native electrophoresis for in-gel functional assays and fluorescence studies of membrane protein complexes. Molecular \& Cellular Proteomics, 6(7), 1215-1225.

Wollweber, F., Malsburg, von der, K., \& van der Laan, M. (2017). Mitochondrial contact site and cristae organizing system: A central player in membrane shaping and crosstalk. Biochimica Et Biophysica Acta, 1864(9), 1481-1489.

Wu, X., Li, L., \& Jiang, H. (2018). Mitochondrial inner-membrane protease Yme1 degrades outermembrane proteins Tom22 and Om45. The Journal of Cell Biology, 217(1), 139-149.

Yaguchi, T., Aida, S., Kaul, S. C., \& Wadhwa, R. (2007). Involvement of mortalin in cellular senescence from the perspective of its mitochondrial import, chaperone, and oxidative stress management functions. Annals of the New York Academy of Sciences, 1100(1), 306-311.

Yamaguchi, R., Lartigue, L., Perkins, G., Scott, R. T., Dixit, A., Kushnareva, Y., et al. (2008). Opa1mediated cristae opening is Bax/Bak and BH3 dependent, required for apoptosis, and independent of Bak oligomerization. Molecular Cell, 31(4), 557-569.

Yamamoto, H., Esaki, M., Kanamori, T., Tamura, Y., Nishikawa, S. I., \& Endo, T. (2002). Tim50 is a subunit of the TIM23 complex that links protein translocation across the outer and inner mitochondrial membranes. Cell, 111(4), 519-528.

Yamano, K., Yatsukawa, Y.-I., Esaki, M., Hobbs, A. E. A., Jensen, R. E., \& Endo, T. (2008). Tom20 and Tom22 share the common signal recognition pathway in mitochondrial protein import. Journal of Biological Chemistry, 283(7), 3799-3807.

Ye, L., Qian, Y., Li, Q., Fang, S., Yang, Z., Tan, Y., \& Gu, W. (2018). Serum Romo1 is significantly associated with disease severity in patients with obstructive sleep apnea syndrome. Sleep \& Breathing = Schlaf \& Atmung, 165(9), 1217-6.

Yogev, O., Karniely, S., \& Pines, O. (2007). Translation-coupled Translocation of Yeast Fumarase into Mitochondria in Vivo. Journal of Biological Chemistry, 282(40), 29222-29229. 
Youle, R. J., \& van der Bliek, A. M. (2012). Mitochondrial fission, fusion, and stress. Science, 337(6098), 1062-1065.

Young, J. C., Hoogenraad, N. J., \& Hartl, F. U. (2003). Molecular chaperones Hsp90 and Hsp70 deliver preproteins to the mitochondrial import receptor Tom70. Cell, 112(1), 41-50.

Yu, M. O., Song, N.-H., Park, K.-J., Park, D.-H., Kim, S.-H., Chae, Y.-S., et al. (2014). Romo1 is associated with ROS production and cellular growth in human gliomas. Journal of Neuro-Oncology, 121(1), 7381.

Zara, V., Ferramosca, A., Robitaille-Foucher, P., Palmieri, F., \& Young, J. C. (2009). Mitochondrial carrier protein biogenesis: role of the chaperones Hsc70 and Hsp90. Biochemical Journal, 419(2), 369-375.

Zhang, K., Li, H., \& Song, Z. (2014). Membrane depolarization activates the mitochondrial protease OMA1 by stimulating self-cleavage. EMBO Reports, 15(5), 576-585.

Zhao, J., Liu, T., Jin, S. B., Tomilin, N., Castro, J., Shupliakov, O., et al. (2009). The novel conserved mitochondrial inner-membrane protein MTGM regulates mitochondrial morphology and cell proliferation. Journal of Cell Science, 122(13), 2252-2262.

Zheng, L., Baumann, U., \& Reymond, J.-L. (2004). An efficient one-step site-directed and site-saturation mutagenesis protocol. Nucleic Acids Research, 32(14), e115-e115.

Žárský, V., \& Dolezal, P. (2016). Evolution of the Tim17 protein family. Biology Direct, 11:54. 


\section{Acknowledgements}

First and foremost, I would like to thank Peter Rehling who has been a great mentor. I have greatly benefited from his supervision, his time and all his support along the way to help me become an independent and efficient researcher. Thank you for giving me the opportunity to work on this challenging and very interesting project. I'm grateful for all the advice, discussions and guidance at every step of my project.

I have greatly benefited from having Stefan Jakobs and Nils Brose in my thesis advisory committee. Thank you for your time, your suggestions, your ideas and the challenging questions during our meetings. I would also like to express my gratitude to Blanche Schwappach, Henning Urlaub and Detlef Doenecke for agreeing to serve on my extended thesis advisory committee.

I am indebted to Sven Dennerlein for his close supervision especially at the beginning of the project. Thank you for providing me with technical tools, your knowledge and experience.

I owe deepest gratitude to all my collaborators that made this project possible. Thank you to Stefan Jakobs, Daniel Jans and Dietmar Riedel for transmission electron microscopy; Thomas Langer and Thomas MacVicar for fruitful discussions, plasmids and protocols; Henning Urlaub, Miroslav Nikolov and Andreas Linden for MS analysis. I would also like to express my gratitude to Silvio Rizzoli, Sebastian Jähne and Kim-Ann Saal for the collaboration regarding the work on click chemistry and NanoSIMS. I also offer my special thanks to Agnieszka Chacinska for the fruitful discussions and input during our meetings as well as hosting us in her lab. I am grateful to Michal Wasilewski for sharing protocols and plasmids and taking the time to introduce us to the "Polish mitoprep and import".

I would like to show my greatest appreciation to all members of the Department of Cellular Biochemistry. I have greatly benefited from discussions with Sylvie, Isotta, Maria, Christian, Alex, David and Ridhima. Special thanks to Abhishek for help with FACS measurements and 
cell culture and Natasha for help with cloning and yeast work. I would particularly like to thank everyone from the lab in room 1.435: Isotta, Maria, Sylvie, Markus, Jan, Mirjam, Sabine, Roya, Luis and our occasional visitor Cong; you have really helped me a lot throughout these past years by scientific and not so scientific discussions and always kept my spirits high. I have also greatly benefited from supervising Valentina Manzini and Hadil Hamdi. Thank you for all your hard work, questions and ideas.

I want to thank Christin Ronsör, Sandra Becker and Gudrun Heim for technical support as well as Petra Engelmann for her administrative work.

Sylvie Callegari has been extraordinarily supportive regarding any questions with the English language. Thank you for proofreading this thesis and for all your constructive comments.

I also owe my deepest gratitude to all the work Steffen Burkhardt and Kerstin Grüniger from the IMPRS office have done. Thank you for always being available and for all the work you do in the background, especially the extraordinarily well-organized retreats. I received generous support from IMPRS travel grants that allowed me to present my work at international conferences.

I would like to express my gratitude to the Göttingen Graduate School for Neurosciences, Biophysics, and Molecular Biosciences (GGNB) (DFG grant GSC 226) for awarding me the GGNB Excellence Stipend. Furthermore, I am grateful to the Boeringer Ingelheim Fonds for supporting me with a PhD fellowship. Special thanks to Claudia Walther, Anja Petersen, Vera Schlick and Sandra Schedler for organizing great events and retreats. Thank you for introducing me to this network of like-minded bright people.

Special thanks to all the friends I have made during my time in Göttingen, especially from the IMRPS in Molecular Biology and Neuroscience as well as from the MPS. Thank you for all the fun and happy moments and excursions. I would also like to thank the relaxing after work discussions during badminton with Markus, David and Yann as well as Robert and Alex. 
I want to express my greatest appreciation to my family, especially my parents who introduced me to science already as early as I can remember. Thank you also for all the great, stimulating and insightful conversations we've had over the past years. I am also greatly indebted to my brother Michael who has taught me incredibly much all my life and doesn't stop to support and entertain me. I am also grateful to my cousin and best man Julius who has made our time together in Göttingen very fun and memorable.

I cannot express in words how grateful and appreciative I am to my girlfriend, fiancée and wife Rosita. Thank you for making Göttingen our home and for sharing this incredible journey of a $\mathrm{PhD}$ with me. Thank you for always listening to me, bearing with me and my repetitive complaints, helping me and supporting me in every way. I could not have done this without you. 


\section{Curriculum vitae}

Frank Richter

Born on 29 August 1990 in Ludwigshafen, Germany
Address:

Humboldtallee 23

37073 Göttingen, Germany

frank.richter@med.uni-goettingen.de

\section{Education}

$10 / 2014$ to date

Department of Cellular Biochemistry, University Medical Center - Göttingen, Germany

\section{PhD Student}

10/2013 to date

Georg-August-Universität - Göttingen, Germany

M.Sc./PhD Molecular Biology Program of the International Max Planck Research School. MSc grade: 1.0

09/2009 - 08/2012 Jacobs University Bremen - Bremen, Germany

B.Sc. in Biochemistry and Cell Biology. BSc grade: 1.24

08/2000 - 05/2009 Theodor-Heuss-Gymnasium - Ludwigshafen, Germany, Abitur (1.0)

\section{Research Experience}

05/2014 - 06/2014 Department of Primate Genetics, German Primate Center - Göttingen, Germany Lab rotation studying the biogenesis of microRNA-like molecules from small RNAs

03/2014 - 04/2014 Department of Cellular Biochemistry, University Medical Center- Göttingen, Germany

Lab rotation carrying out biochemical characterization of the human TIM23 complex

01/2014 - 02/2014 Department of Cellular Logistics, Max Planck Institute for Biophysical Chemistry Göttingen, Germany

Lab rotation performing purification of Importin4-ribosomal protein S3a complex

03/2013 - 06/2013 Department of Biomedical Sciences, Università degli Studi di Padova - Padua, Italy Analysing the role of heparanase regulating epithelial to mesenchymal transition

06/2011- 08/2011 Department of Microbiology, Tumor and Cell Biology, Karolinska Institutet Stockholm, Sweden

Undergraduate Researcher as part of the Amgen Scholar Program

02/2011 - 05/2011; Department of Chemistry and Biochemistry and Cell Biology, Jacobs University

02/2010 - 05/2010 Bremen - Bremen, Germany Independent undergraduate research projects

\section{Selected Honors and Awards}

06/2018 Funded by the Dieter Schwarz Stiftung for participation in the 68th Lindau Nobel Laureate Meeting

12/2015 - 11/2017 Boehringer Ingelheim Fonds PhD Stipend

10/2013 - 08/2014 Scholarship by the International Max Planck Research School 
10/2013 - 09/2014; Scholarship of the Studienstiftung des deutschen Volkes (German National Merit 02/2010 - 08/2012 Foundation)

09/2009 - 06/2012 Academic Scholarship by Jacobs University Bremen

\section{Teaching Experience}

\begin{tabular}{|c|c|}
\hline 5/2015 to date & $\begin{array}{l}\text { Department of Cellular Biochemistry, University Medical Center - Göttingen, } \\
\text { Germany } \\
\text { Teaching assistant for biochemistry tutorials and practical courses } \\
\text { Supervisor of MSc. student lab rotations }\end{array}$ \\
\hline 12 & $\begin{array}{l}\text { Department of Biochemistry and Cell Biology, Jacobs University Bremen - } \\
\text { Bremen, Germany } \\
\text { Teaching assistant for Advanced Biochemistry and Molecular Biology II }\end{array}$ \\
\hline
\end{tabular}

\section{Leadership Activities}

$\begin{array}{ll}08 / 2016 \text { - 11/2017 } & \text { MSc./PhD Program in Molecular Biology - Göttingen, Germany } \\ & \text { PhD student representative } \\ \text { 10/2014 - 09/2016 } & \text { PhD Symposium and Career Fair: Horizons in Molecular Biology - Göttingen, } \\ & \text { Germany } \\ & \text { Main organizer responsible for planning and coordination (2015/2016) } \\ 09 / 2009 \text { - 05/2012 } & \text { Debating Society, Jacobs University Bremen - Bremen, Germany } \\ & \text { President (2010/2011), Main organizer of debating tournament (2012) } \\ 09 / 2009 \text { - 05/2011 } & \text { Undergraduate Student Government, Jacobs University Bremen - Bremen, } \\ & \text { Germany } \\ & \text { Member of financial committees and facilities committee }\end{array}$

\section{Language Skills}

\begin{tabular}{ll}
\hline German: & mother tongue \\
English: & fluent, university education completely in English \\
French: & working knowledge \\
Italian: & basic knowledge \\
Bulgarian: & basic knowledge
\end{tabular}

\section{Computer Skills}

Microsoft Office, Adobe Photoshop, Adobe Illustrator, Google Docs, ImageJ/Fiji

\section{Publications}

- Saal K.A., Richter F., Rehling P., Rizzoli S.O. Combined Use of Unnatural Amino Acids Enables Dual Color Super-Resolution Imaging of Proteins via Click Chemistry. submitted

- Richter F., Dennerlein S., Nikolov M., Jans D.C., Naumenko N. et al. ROMO1 is a constituent of the human presequence translocase required for YME1L import. in Revision

- Richter K.N., Revelo N.H., Seitz K.J., ..., Richter F., et al. Glyoxal as an alternative to PFA in immunostaining and nanoscopy, The EMBO Journal (2018) 37: 139-159, featured on cover 
- Denkert N., Schendzielorz A.B., Barbot M., Versemann L., Richter F., et al. Cation selectivity of the presequence translocase channel Tim23 is crucial for efficient protein import, eLife, 6(2017), p. e28324

- Callegari S., Richter F., Chojnacka K., Jans D.C., Lorenzi I., et al. TIM29 is a subunit of the human carrier translocase required for protein transport, FEBS Lett., 590 (2016), pp. 4147-4158, featured on cover

\section{Conferences}

- 06/2018: 68 ${ }^{\text {th }}$ Lindau Nobel Laureate Meeting, Lindau, Germany

- 03/2018: Gordon Research Seminar and Conference, Galveston, USA

- 03/2017: 68 ${ }^{\text {th }}$ Mosbacher Kolloquium, Mosbach, Germany

- 09/2016: Science Day at the Weizmann Institute of Science, Rehovot, Israel

- 03/2015: EMBO Conference, Dubrovnik, Croatia

- 09/2011: Symposium of Amgen Scholars Program 2011, Cambridge, UK 